\title{
Making rivers modular Emerging river science 1980-2005
}

Mieke van Hemert 


\section{Making rivers modular}

Emerging river science 1980-2005 


\section{Examination committee:}

Prof. Dr. P.A.A. van den Besselaar, University of Amsterdam

Prof. Dr. S. Kuhlmann, University of Twente

Dr. C.L. Kwa, University of Amsterdam

Prof. Dr. N.G. Schulte Nordholt, University of Twente

Prof. Dr. Ir. H.J. de Vriend, University of Delft

Cover design: Hanne Schaap (hanneschaap@live.nl)

Artwork cover: Gerrit van Meurs (www.bleuetvert.com), water, mozaic 18,5 x $130 \mathrm{~cm}$

(C) Mieke van Hemert 2008

ISBN 978-90-365-2736-1

Printed by: Printpartners Ipskamp B.V.

This thesis was printed with financial support from the Graduate School Science, Technology and Modern Culture (WTMC) and the Department of Science, Technology, Health and Policy Studies (STeHPS) of the University of Twente. 


\title{
MAKING RIVERS MODULAR EMERGING RIVER SCIENCE 1980-2005
}

\author{
PROEFSCHRIFT \\ ter verkrijging van \\ de graad van doctor aan de Universiteit Twente, \\ op gezag van de rector magnificus, \\ prof. dr. W.H.M. Zijm, \\ volgens besluit van het College van Promoties \\ in het openbaar te verdedigen \\ op woensdag 10 december 2008 om 16.45 uur
}

door

Annemieke Jacqueline van Hemert

geboren op 14 april 1965

te Eindhoven 
Dit proefschrift is goedgekeurd door de promotor

Prof. Dr. A. Rip

en de assistent-promotor

Dr. B.J.R. van der Meulen 
Voor mijn zussen

Marijke en Madeleine 


\section{Table of contents}

$\begin{array}{ll}\text { Acknowledgements } & 8\end{array}$

Chapter 1 Introduction 9

1.1 River science as an object of study 9

1.2 Structure of the thesis 11

Chapter 2 Conceptual tools, research questions and design 13

2.1 Conceptual tools 13

2.1.1 Science as practice, co-production, contextual history 13

2.1.2 From practice to configuration 16

2.1.3 Local research configurations 17

2.1.4 Institutional contexts 21

2.2 Research questions 24

2.2.1 Diagnoses of recent science 25

2.2.2 Aspects and questions 28

2.3 Research design 29

Chapter 3 Emerging river science as a cosmopolitan field 35

3.1 Regulated rivers on the research agenda 35

3.2 Interdisciplinary river research around 1980

3.3 The shift to spatial complexity 41

3.4 Spatial technologies and issues of scale $\quad 44$

3.5 Institutionalising interdisciplinarity 46

3.6 Conclusions 52

Chapter 4 Dutch science policies and evolving river science specialties 55

4.1 Inter-institutional and interdisciplinary research cooperation:
group leaders' strategies

4.2 Dutch science policies $\quad 61$

4.3 Landscape ecology $\quad 65$

4.4 Freshwater ecology 69

4.5 Geomorphology $\quad 72$

4.6 Hydrology

4.7 Hydraulics 80

4.8 Commonalities and contrasts 83

4.9 Conclusions $\quad 84$

Chapter 5 Emerging river science in the Netherlands $\quad 87$

5.1 An ecological-spatial turn in river management $\quad 87$

5.2 Emerging interdisciplinary river science $\quad 92$

5.3 The shaping of a local research configuration $\quad 97$

5.4 Conclusions 105

Chapter 6 Conclusions $\quad 109$

6.1 Research findings 109

6.2 Contribution to current debates 113

6.3 Rivers and pluralism: a debate on nature development 120

Bibliography 125

Appendix 1: interviews 133

Nederlandse samenvatting 133

$\begin{array}{ll}\text { Curriculum Vitae } & 140\end{array}$ 


\section{Acknowledgements}

During the six years that this PhD study took, I experienced the support of many people. I would like to thank them all. A number of people have accompanied me more closely in my meandering moves. I thank Arie for his critical and trusting guidance, an exceptional readiness to comment texts and for his hospitality, Barend for his encouraging guidance and stimulating suggestions, and both for their contributions to this study.

The STeHPS department provided an intellectually stimulating and welcoming environment to do research and I highly enjoyed assisting Adri Albert de la Bruhèze and Nil Disco in their history of civil engineering course.

Annemiek Nelis and Paul Wouters offered inspiring, exciting WTMC-workshops and summer schools in a great ambiance. Sally Wyatt and commentators made dissertation days a crucial event in the long process from texts to thesis.

Loet Leydesdorff kindly gave me access to his computer program and produced the journal environment figure.

The interviews that I had with a number of people have been crucially important for my understanding of river research and its contexts. I am indebted to the interviewees for their contribution.

I gratefully acknowledge a PhD circulation grant from the European PRIME network of excellence for a 6-months stay at the Laboratoire Techniques, Territoires et Sociétés (LATTS) in France. Catherine Paradeise generously agreed to be my supervisor, introduced me to the Paris STS community and invited me to take part in a PhD exchange with Bielefeld. This period has been an invaluable breeding time.

Hanne Schaap designed the cover of this book, using a picture of an art work made by Gerrit van Meurs. I thank them both for their beautiful contribution.

For moral support and encouragement, commenting of texts, stimulating conversations, shared meals, music nights, movie nights, reading club sessions, curious and critical questions, walks, talks, relaxing tasks, relativising remarks, warm advice, or a combination of these, my thanks go to:

Marlous Blankesteijn, Gerrie Bres and Piet-Hein Spieringhs, Caro de Bruijn, Lynsey Dubbeld, Rogier Fokke, Jurgen Ganzevles, Lilian van Honk, Elbert Kaan and Henriëtte Reerink, Tembile Kulati, Chunglin Kwa, Femke Merkx, Alexander Mispelblom Beyer, Frank van der Most, Ernest Müter and Ans de Vree, Suman Natarajan, Elly Oenema and Madhu Ramnath, Tilo Propp, Joke Stephan, Jan Stevens, Swen Stoop, Rieks van der Straaten, Rita Struhkamp, Lara Tauritz Bakker, Stefan Verhaegh, Maria de Vogel, Anne Wesselink, Martijn Wit, and for last-minute editing work, to Jeroen Warner.

I am grateful to my brother-in-law John, who died almost two years ago, for friendship, the sharing of existential quests, and English translations. My sisters Marijke and Madeleine have been insisting that I take myself seriously, and enjoy life beyond intellectual efforts. I thank them for that, and for sistership. And well, yes, they are there, my cats, calmy contemplating unfathomable thoughts, like cows, and being great company. 


\section{Chapter 1 Introduction}

Conceptions of nature and landscape, including of rivers, vary over time, place, and cultural practices. This study discusses conceptions of rivers in contemporary scientific practices. It shows how new views of rivers emerge in particular technological and institutional contexts.

Making rivers modular? The hundred-odd pages that follow are to elucidate this curious combination of terms. The 'making' in the title refers to the practice of science, of river science in this case. River scientists make rivers into an object of study, they make divisions of labour between specialties, they make interdisciplinary models of rivers and they make rivers into sites of experimentation, designing river landscapes by using model results. 'Modular' derives from 'module' in the sense of 'a self-contained component of a system, often interchangeable, which has a well-defined interface to the other components' 1 . 'Modular' then is an approach using 'a set of modules that allow flexibility in the way they are combined'2. 'Modular' is associated with interchangeability and recombinability of standardised units, nested complexity, and systems thinking. In this study it will be shown how in the practicing of river science, rivers have been made modular.

\subsection{River science as an object of study}

In the course of the twentieth century, ongoing specialisation within biology, earth science and engineering made rivers into objects of study and control for such disparate research areas as stream ecology, fluvial geomorphology, surface hydrology and fluvial hydraulics. Stream ecologists have studied the river as an ecosystem, with its characteristic plant and animal communities, fluvial geomorphologists have been interested in the processes that shape the river as an abiotic landscape element, surface hydrologists have concentrated on how rainwater collects into streams and rivers, while fluvial hydraulic engineers have been using their knowledge of water flow in attempting to control rivers and make them navigable. Over the last few decades, practitioners of these biological, earth scientific and engineering fields have aimed at integrating their specialised approaches to studying and managing rivers. These attempts at integration, which started to take shape around 1980, have given rise to 'river science'.

In recent years, river science practitioners have promoted river science as an invitingly inclusive, highly heterogeneous configuration of practices of studying and managing rivers. In characterizing their newly established scientific society, the founding members of the International Society for River Science (ISRS), established in 2006, state that:

The society seeks to promote a basic understanding of the structure (biological, chemical and physical) and functioning of lotic [running water] ecosystems, particularly rivers, through disciplines contributing to the emerging, integrative field of river science. These include, but are not limited to, aquatic and floodplain ecology, civil and environmental engineering, environmental chemistry, environmental policy, fisheries, geographic information systems analysis, geomorphology, hydrology, landscape ecology, mathematical modelling, river conservation and rehabilitation, social sciences and economics, technology applied to river management and water quality studies. ${ }^{3}$

\footnotetext{
1 http://en.wiktionary.org/wiki/module accessed 14 August 2008

2 http://en.wiktionary.org/wiki/modular accessed 14 August 2008

3 James A. Thorp, Jack A. Stanford, Martin C. Thoms, Geoffrey E. Petts 'Global partnerships and the new international society for river science (ISRS)' in: River Research and Applications, 23/1, 2007, p. 3
} 
The listing of fields is a programmatic statement rather than indicating fields that have engaged in interactions most strongly to give shape to interdisciplinary river science over the last three decades. In 2004 Geoffrey Petts, editor-in-chief of the international journal River Research and Applications, river science's core journal, noted that 'most papers focus on the interface of hydrology, geomorphology and ecology's. This specific configuration of fields forms the focus of this study, a configuration that has come to interact in various ways with the practices listed by the founders of the ISRS.

River science has emerged in a period that has been diagnosed as seeing important transformations in science and the societal contexts in which new knowledge emerges. It may thus be expected that river science reflects these transformations in some respects. How does river science fit in the diagnosis of an emerging 'transdisciplinary' mode of knowledge production, which entails a dissolution of disciplinary boundaries among others? How has a concern for societal relevance, and relevance to specific institutions and policy sectors shaped river science? How have fast developing technologies contributed to giving shape to interdisciplinarity in river science? How have science policies contributed to these developments? These are the questions this study of river science deals with. To address these questions, this study builds on insights and approaches from the field of science and technology studies and employs a specific conception of science and how it evolves. Both the diagnoses of recent science that have elicited research questions and the conceptual tools will be discussed in chapter 2 . Here, I will briefly introduce my approach to studying science, the central research question, and the structure of the thesis.

In science and technology studies, scientific practices are considered cultural practices. Approaching science as cultural practice has brought with it a recognition of its discursive, material and social dimensions. Scientists produce texts and things, use instruments and work in specific settings, form communities, adopt routines and coping strategies, and try to perform in ways accepted by colleagues and others. Science and technology studies include ethnographical, historical, sociological and philosophical approaches. This study offers historical accounts of river science and adopts a so called 'co-production' approach to studying scientific practice configurations. As an approach, co-production foregrounds relations and interdependencies in the shaping and working of knowledge in society. As will be discussed in more detail in chapter 2, this study focuses on conceptual, instrumentational and institutional dimensions of river science's practice configurations.

The central research question that has guided my study of river science is:

How have conceptual, instrumentational and institutional dimensions of river science evolved interdependently between 1980 and 2005?

\footnotetext{
${ }^{4}$ Geoffrey E. Petts 'Editorial' in: River Research and Applications, 20, 2004, p.1. Like 'river science', each of the three specialty names can still refer to different practices. Petts here clarifies: 'About one third of the papers start from physical perspectives (flow variability, flow regimes, extreme flows, hydraulics, sediment transport, and channel and floodplain dynamics); one half present biological perspectives (plants, invertebrates, fish; and occasional papers on birds and other animals); and about one-fifth focus on management issues and the development of management tools.'
} 
As river science is an emerging interdisciplinary field, studying its concepts enables me to address the question of how the different conceptions of rivers that have guided ecologists, geomorphologists and hydrologists in their research practices, have been treated as either commensurable or incommensurable and in what ways. Has river science come to be guided by a conceptual framework that is considered unified, complementary, integrated or fragmented by its practitioners? What has been the conceptual common ground, besides an everyday notion of rivers, on the basis of which ecologists, geomorphologists and hydrologists have come to cooperate and how has this conceptual common ground evolved? How has the relevance of river science to river management contributed to shaping its guiding concepts?

A perspective on science as practice brings with it an acknowledgement of instruments as part of the material setting of research practices. There is, however, an additional reason to bring to the fore instrumentation as a dimension of the practice of river science, which concerns the time and conditions of its emergence. River science has been emerging in the era of technoscience, which raises the expectation that shared technologies rather than conceptual common ground may have enabled cooperation between the different fields. Studying the instrumentational or technological dimension of river science enables me to compare the role that instrumentation has played in creating a common ground for ecology, geomorphology and hydrology with that of concepts.

The institutional dimensions of river science are a third element. In this study institutional refers to informal and formal organisational and inter-organisational arrangements, including cosmopolitan fields, national level specialty institutions, their combinations in research programmes and centres, and institutions which provide funding and ask for practical problems to be solved or innovations to deliver. River science has been emerging at a time of important institutional change in the landscape of science, and is itself a case of institutional innovation. Whereas a disciplinary framework provided the primary orientation for and organisational set-up of academic science around 1980, the proliferation of interdisciplinary, inter-organisational arrangements alongside existing arrangements has resulted in increased institutional heterogeneity as compared to the disciplinary organisational logic. Yet, the new institutional arrangements develop their own structure, divisions of labour and mutual positionings. What appears to be heterogeneous in certain dimensions, may be more structured in other dimensions.

\subsection{Structure of the thesis}

Chapter 2 articulates conceptual tools, distills further research questions from general diagnoses of recent science and presents the research design. Chapters 3, 4 and 5 discuss emerging river science in three different 'cross-sections', yielding three historical accounts of how river science evolved between 1980 and 2005. Together, the three accounts provide an interpretation of how institutional and technological contexts contribute to shaping a local river research configuration, a conceptual approach that will be discussed in more detail in chapter 2 .

Chapter 3 is an account of the emergence and development of river science as a cosmopolitan scientific field. A series of international meetings devoted to river degradation and restoration which started in 1979, the establishment of an international scientific journal in 1987 and the establishment of a river science society in $\mathbf{2 0 0 6}$ are indicative of the gradual institutionalisation of river science as a separate field. The historical account shows how interdisciplinary divisions of labour in river science institutionalise in interaction with conceptual and instrumentational developments. 
Chapter 4 discusses developments in five specialties (hydraulics, hydrology, geomorphology, landscape ecology and freshwater ecology) that contribute to interdisciplinary river science as practised in the Netherlands. An account of the shifts and continuities in national science policies in the same period sheds light on the question of how science policies may have contributed to conceptual, instrumentational and institutional developments in these five specialties in the Netherlands.

Chapter 5 provides an account of emerging river science in the Netherlands and discusses the structure of a local river research configuration. The emergence of river science as a cosmopolitan field and national science policies inducing institutional change, accounts of which have been given in chapters 3 and 4, appear as important contexts contributing to the emergence of river science in the Netherlands. An account of shifts and continuities in river management policies and practices notes yet another context of importance for the emergence of river science in the Netherlands. The second part of the chapter provides an analysis of the structure of a local river research configuration as shaped in part by national river management policies and practices.

Chapter 6 summarises research findings and presents conclusions, exploring how the study contributes to discussions concerning transformations in scientific practices and ways of conceiving of and intervening in rivers. 


\section{Chapter 2 Conceptual tools, research questions and design}

This study of the emerging field of river science employs concepts and approaches from science and technology studies. The question how river science's conceptual, instrumentational and institutional dimensions evolve interdependently guides the overall analysis. Such a perspective on science's dynamics allows me to assess the value of some general diagnoses of recent science for understanding what is happening in particular scientific practices, river science in this case. The first part of this chapter presents conceptual tools, the second part briefly discusses three general diagnoses of recent science from which I distill further questions for my study of river science, and the third part presents the research design.

In science studies, science is conceptualised as a wide array of cultural practices, each practice with its own particularities. Yet, diverse as scientific practices may be, science may be approached analytically as characterised by particular dimensions. In this study, scientific practice configurations are conceived of as having conceptual, instrumentational and institutional dimensions.

The perspective on scientific change adopted in this study combines two approaches to science as practice. The first is best known as the co-production perspective, the second as contextual history of science. The particular co-production perspective adopted in this study interprets scientific change as an ongoing mutual adjustment between conceptual, instrumentational and institutional dimensions of scientific practices. Contextual history of science foregrounds how changing concepts, instruments and institutions emerge through the strategising of actors in contexts. I will only briefly introduce these interpretive strategies since they are mainstream science studies approaches which I do not question in this study. The innovative aspect of this study is its unfolding, cross-sectional approach to studying an emerging scientific field and its local configurations.

\subsection{Conceptual tools}

\subsubsection{Science as practice, co-production, contextual history}

Approaching science as practice has been a way to foreground the interdependency between knowledge as concepts, ideas, representations, and the social and material orderings that scientists produce and are part of. The traditional view of science holds that scientific activity, by virtue of specific methodology, yields theories and statements which, in a cumulative way, represent the world ever more faithfully. This view has been undermined persistently within the field of science and technology studies, and has given way to a view of science as a very wide array of cultural practices that evolve in historically contingent ways. Conceptions of science as cultural practice acknowledge that scientists represent the world, in theories, concepts, statements, images, diagrams and models, as much as they reshape it, both through representations and materially. In producing new forms of life, materials, numbers, images, texts, scientists, etc. no aspect of scientific practice takes precedence.

The perspective of co-production is introduced in this study to discuss relations and interdependencies between aspects of particular scientific practices, and between scientific and other practices. It conceives of scientific practices as normative and goal oriented, like other practices. I will briefly discuss versions of co-production which have informed my analysis of river science. 
lan Hacking speaks of co-production as a mutual adjustment or tailoring of the various elements of laboratory practice ${ }^{5}$. In his conception of science as practice, theories do not represent an independent reality. Instead, theory, instrumentation and data analysis evolve in conjunction with one another, thus stabilising phenomena. Hacking calls this the 'self-vindication' of the laboratory sciences: they produce relatively stable constructs of conceptual and material elements in a laboratory setting. While Hacking insists that laboratory sciences are different from observational, e.g. field sciences, I would like to extend his idea of tailoring to my object of study, river science. Firstly, Hacking insists on the difference only to explain the stability of the laboratory sciences, not denying that mutual adjustment occurs in any scientific practice. Secondly, the difference between laboratory and field sciences is one of degree only. Hacking agrees with Latour that fields may be made into laboratories, he draws a line only between uninterfering observation and controlling intervention. But this analytical line may be crossed, and this is what happens in river science, in how it interacts with its object of study. I would contend that hydraulics, which has concentrated on studying water flow in straight canals, and on the basis of that knowledge straightened rivers to make them behave in controllable ways, does cross the line between lab and field. In river science, the river is also part of the experimental set-up, which mixes observation with intervention. In these field experiments, phenomena may not be stabilised to a high degree, but mutual adjustment may be at work nevertheless. Yet, this sort of coproduction in experimental set-ups is only a side issue in this study of river science. The more general point is that in scientific practice, its elements are mutually adjusted, and that this is an ongoing process.

A related conception of co-production has emerged from the work of Michel Foucault. In his later work, Foucault conceived of knowledge as a dynamic interplay between discursive and nondiscursive dimensions of practice ${ }^{6}$. This dynamic interplay embodies relations of power that are productive and that meet with resistance. In this conception, neither subjects nor objects of knowledge are given, they emerge together. This conception of co-production brackets phenomena and their (in)stability and focuses on mutual adjustments between subjects and objects of knowledge and the various elements, discursive, material, bodily etc. of knowledge practices. Like Hacking's idea of tailoring, this conception of co-production inspired on Foucault's work has informed my analysis of how conceptual, instrumentational and institutional dimensions of knowledge practices undergo mutual adjustment.

Sheila Jasanoff conceives of co-production as the interdependent production of natural and social orders, while at the same time questioning these categories ${ }^{7}$. She draws a variety of strands of co-production together, emphasising relations and interdependencies between institutions, ideas, representations, things, bodies, identities, organisations, technologies, in short everything that undergoes ordering and contributes to ordering. In this conception of coproduction the world is shaped in part by how we represent it. The co-production outlook is interpretive and relational, while the choice of relations and interdependencies discussed depends on the issue of concern. Co-production is reflexive about how representations -

\footnotetext{
5 lan Hacking 'The Self-Vindication of the Laboratory Sciences' in: Andrew Pickering (ed.) Science as practice and culture Chicago: The University of Chicago Press, 1992, pp. 29-64

6 Hubert L. Dreyfus and Paul Rabinow Michel Foucault. Beyond Structuralism and Hermeneutics Chicago:

The University of Chicago Press, 1983

${ }^{7}$ Sheila Jasanoff 'The idiom of co-production' in: Sheila Jasanoff (ed.) States of knowledge: the coproduction of science and social order London: Routledge, 2000, pp. 1-12 and Sheila Jasanoff 'Ordering knowledge, ordering society' in the same volume, pp. 13-45
} 
including one's own - contribute to shaping reality, while acknowledging that one cannot control how they will8.

Contextual history of science as the contextual understanding of how scientific practices evolve foregrounds the agency of scientists and other actors in bringing about change. This provides me with a perspective to understanding evolving concepts, instrumentation and institutions that adds to an understanding of developments as 'anonymous' mutual adjustments between the various dimensions of scientific practices. Scientists strategise and act with regard to a wide variety of contexts. Getting access to research funding, obtaining research tools, maintaining an institutional basis, formulating do-able research projects, getting articles published, building up credibility with regard to a variety of audiences, keeping abreast of promising approaches etc. are some of the main concerns that scientists have to deal with in productive ways.

In articulating contextual history of science from a science as practice perspective, Dominique Pestre draws the attention to dynamics of change 9 . Dynamics of change are somewhat underplayed in the above conceptions of co-production, which focus more on stabilisation and ordering. By arguing that in scientific practice each dimension - whether conceptual, material, instrumental, technical or political - continuously reshapes the other dimensions, Pestre presents a dynamic conception of co-production. This outlook foregrounds the open and ongoing character of mutual adjustment. Mutual adjustment may result in relative stabilisation but events and interfering processes, phenomena, may also bring gradual or abrupt change. In this study of river science, I try to capture both longer term change and continuity as well as significant events (in the common sense meanings of these terms).

Co-production in this study

The co-production approach to scientific practices aims to discuss all sorts of relations and interdependencies. Which relations and interdependencies to focus on depends on the sort of contribution one wants to make to particular debates on how knowledge is shaped by and shapes society, technology, culture, nature etc. A sensibility to what categorisations may do, and an acknowledgement that social and natural kinds as categorisations are not given but made is also part of the co-production outlook as sketched above. Analytical distinctions made in this study between concepts, instrumentation and institutions should not be seen as mutually exclusive and complementary, but as different dimensions. As an example, institutions may be conceived as entailing discursive, conceptual, technological, instrumentational, social and other dimensions. The analytical distinctions serve to discuss the dimensions separately and their interrelations.

In the analysis of river science as a case of contemporary science, I focus on three sorts of interrelations. Firstly, the mutual adjustment of the different dimensions of scientific practices is open, ongoing, and represents scientific change - change of scientific practices - as episodes of relative stabilisation and gradual or more sudden reconfiguration. These interrelations are discussed most explicitly in chapter 3. Secondly, there are search strategies as well as institutional survival strategies. Search strategies are conceptual and instrumentational approaches. I call the strategies that scientists and research groups adopt vis-à-vis science policy requirements and opportunities for interdisciplinary and inter-institutional research cooperation institutional survival strategies. This allows for studying interdependencies between institutional

\footnotetext{
8 Sheila Jasanoff 'Beyond Epistemology: Relativism and Engagement in the Politics of Science' in: Social Studies of Science vol. 26, no. 2, 1996, pp. 393-418

9 Dominique Pestre 'Pour une histoire sociale et culturelle des sciences. Nouvelles définitions, nouveaux objets, nouvelles pratiques' in: Annales. Histoire, Sciences Sociales, 50/3, 1995, pp. 487-522
} 
change as induced by science policies on the one hand and conceptual and instrumentational change on the other. These interdependencies are discussed in chapter 4.

Then, there are contexts relevant to the practising of river science. Here I combine an exploration of which particular contexts are of importance in particular situations with a selective approach to articulating the ways in which some institutional and technological contexts leave noticeable traces in cosmopolitan and local configurations, thus how these are co-produced with these contexts ${ }^{10}$. In order to arrive at a focused account, I concentrate on the practices and configurations of river science, treat 'river science' as a unit of analysis, and aim at keeping the accounts within reasonable bounds. Thus, while science policies are certainly influenced in part by scientific practices, I do not discuss this interdependency and treat science policies as a context for scientific practices.

Co-production as the shaping and working of knowledge in society figures most visibly in my third account of interdependencies in chapter 5. In analysing the shaping of a local research configuration, I discuss how river science in the Netherlands has been shaped by the policies and practices of river management, but my interest is also in how river science contributes to shaping the river landscape.

\subsubsection{From practice to configuration}

Following Joseph Rouse, I take scientific practices to be 'practical configurations of the world' 11 . Theoretical practices are part of these configurations, involving 'modeling particular situations or domains; articulating, extending, and reconciling these models and their constituent concepts and techniques; and connecting theoretical models to experimental systems'. Rouse argues that historiography in terms of methods, concepts, and standards of scientific practices, in terms of regularities, underplays temporality and openness of practices. While this latter argument might be taken as denying the value of historical accounts of scientific practices in terms of such categories as concepts, instruments and institutions, I do not take it as such. Rouse suggests that these historical accounts are to be dynamic, that it should be acknowledged that elements of practice configurations evolve interdependently, which seems to be in line with a dynamic coproduction perspective.

An object may emerge through the interplay between concepts and instrumentation without a theory being articulated. Instrumentation, in my usage of the term, includes anything that mediates between a (collective) subject of knowledge and its object, thus contributing to the constitution of both. Concretely, instrumentation may include computers and computer programmes, techniques of producing and manipulating data, experimental set-ups, internet, etc. I acknowledge that a distinction between concepts and instrumentation may not always make sense. Other than being mental constructs, concepts are part of discourses and emerge from texts, drawings, diagrams, computer models. For certain questions, however, it does make sense

\footnotetext{
10 The distinction between local and cosmopolitan made here derives from sociology of organisations and professions. Cosmopolitan refers to aggregation of elements of local knowledge practices through the sharing of standards, models and other elements that are being decontextualised, through abstraction and circulation. Cosmopolitanisation of technological and scientific practices is a historical process, largely occurring within nation states first, internationalisation becoming pervasive in the $20^{\text {th }}$ century. International journal publishing has been a conspicuous cosmopolitanisation activity leading to the emergence of scientific fields. See also J.J. Deuten Cosmopolitanising technologies. A study of four emerging technological regimes Doctoral dissertation University of Twente, 2003.

11 Joseph Rouse 'Understanding Scientific Practices. Cultural Studies of Science as a Philosophical Program' in: M. Biagioli The Science Studies Reader New York: Routledge, 1999, pp. 442-456
} 
to make a distinction between concepts and instruments. In this study, the distinction serves to discuss how concepts and instruments are mutually adjusted and whether a primacy of one or the other may be at work. In this study of river science, I limit the articulation of concepts and instruments to what is relevant in the context of a particular account. Thus, I do not discuss laboratory and field techniques where the main thrust in interdisciplinary river science appears to be in computer modeling and remote sensing techniques.

The choice of institutions as a third dimension of scientific practice configurations relates to what is undergoing important change according to diagnoses of contemporary science. Under institutions I rubricate cosmopolitan scientific fields, organisations oriented to specific scientific fields at national or other levels, governmental organisations and inter-organisational arrangements, inter-organisational arrangements (including centres and programmes) of universities, research groups, NGOs, firms, etc. - the list is open to potentially any sort of organisation or arrangements between them which has institutional features, that is, which has some programs, policies, rules, practices that guide towards collective goals. I prefer to call this an institutional dimension rather than an organisational one as institution is a broader category, which includes collective ways of going about that are not explicitly organised. The terms institution, institutional dimension and inter-institutional arrangement become meaningful in the context of a particular account. Like with the pair of concepts and instrumentation, I do not intend to fixate these terms but use them in contextually relevant ways.

Distinguishing between concepts, instruments and institutions thus allows for studying their interrelated development. In this way, relations between intellectual and institutional change - a relatively unexplored interdependency 12 - can be discussed.

Making the threefold distinction of concepts, instrumentation and institutions is also a way of linking up with practitioners of river science, to whom these distinctions matter. By using generally recognised dimensions of science and offering an alternative interpretation of how they develop together, I hope my study of river science will be of interest to river science practitioners.

\subsubsection{Local research configurations}

\section{Local knowledge}

In analysing how a variety of contexts may contribute to river science's concepts, instruments and institutions, I distinguish between a local research configuration and relevant contexts. In doing this, I build on conceptions of science that foreground the localness of knowledge. As the notion of local knowledge and relations between local knowledge and cosmopolitan scientific fields are subject to varied interpretations, I will briefly discuss the conceptions that inform this study.

Joseph Rouse conceives of science as locally situated practice configurations which generate concrete, local achievements ${ }^{13}$. Both what constitutes a research opportunity and how it is dealt with are locally situated. A local configuration refers to researchers and their skills, equipment, theories as tools, concerns, resources and needs, etc. This local configuration is also localised, at a site of investigation: a laboratory, clinic or field site. Traffic between the local configuration and scientific fields is in two directions. Firstly, formulating a research problem including the ways to deal with it, involves applying a paradigm. Application of a paradigm involves skillful interpretation of what guides a community of practitioners, in terms of activities and achievements, not just

\footnotetext{
12 Helen E. Longino The fate of knowledge Princeton: Princeton University Press, 2002, p. 212

13 Joseph Rouse Knowledge and power: Toward a Political Philosophy of Science Ithaca: Cornell University Press, 1987
} 
theories ${ }^{14}$. Theories are among the tools that may be used to formulate and deal with a problem, and they are not simply applied but serve as models. Secondly, to allow the local achievement to be built upon, to be extended, it is adapted to contribute to new local configurations. This process of adaptation involves the generation of practical standards at the level of the field, the scientific community. Furthermore, science, while not being universal but aggregated local knowledge, may have global, strategic effects.

In Rouse's view local configurations and practices are shaped by a variety of concerns. A scientist may choose a certain approach when it reconciles a range of concerns relevant to the local situation ${ }^{15}$. Thus, the scientific field, and its paradigm(s), contribute to the shaping of the local configuration alongside other relevant contexts.

Helen Verran and David Turnbull have characterised scientific knowledge as indigeneous knowledge, and adopted the term assemblage to discuss how in all knowledge practices heterogeneous elements are rendered equivalent ${ }^{16}$. In their conception, local knowledge practices and global knowledge systems are in dialectic opposition, these dialectics embodying dynamic relations of power17. Turnbull also proposed to conceive of assemblages of local knowledge as extending knowledge spaces ${ }^{18}$. Local knowledge is situated, located, while an assemblage links up local sites, people and activities. In a local situation, social strategies and technical devices (which may include theory as a tool) constitute knowledge as practice. The creation of equivalences and connections between local knowledges gives rise to a knowledge space, an assemblage. Scientific fields are examples of assemblages, as are other knowledge systems. The notion of assemblage thus serves to deal with science and other sorts of knowledge in equal terms. In any knowledge system heterogeneous elements are rendered equivalent. The creation of equivalences and connections makes it possible to move knowledge from one place to another. Standardisation and homogenisation are among the strategies to accumulate, aggregate knowledge and to transmit it to another place. Strategies of standardisation and homogenisation are powerful ways of extending knowledge spaces. In Turnbull's examples of scientific knowledge spaces, scientific fields figure as important contexts. Paradigms may provide practical guidance to research activities.

Helen Longino conceives of science as a social activity, undertaken within communities employing local epistemologies ${ }^{19}$. A local epistemology is made up of substantive and methodological commitments and goals. Local knowledge involves the practicing of a local epistemology in a particular situation of inquiry. A situation of inquiry brings with it an approach,

\footnotetext{
${ }^{14}$ Rouse interprets Kuhn's conception of science as a practice-oriented view, including the paradigm notion, pointing out that Kuhn's conception has often been interpreted as theory centred.

15 Joseph Rouse 'Foucault and the natural sciences' in: J. Caputo and M. Yount Foucault and the critique of institutions University Park: The Pennsylvania State University Press, 1993, p. 155

16 Helen Watson-Verran and David Turnbull 'Science and Other Indigeneous Knowledge Systems' in: S. Jasanoff (ed.) Handbook of science and technology studies Thousand Oaks, CA.: Sage 1995, pp. 115-139. Verran and Turnbull adopt the notion of assemblage from Deleuze and Guattari, in the sense of 'an episteme with technologies added that connotes the ad hoc contingency of a collage in its capacity to embrace a wide variety of incompatbile components' (p. 117)

17 The notion of global does not mean that the systems are spatially extended at a global scale. Global is like cosmopolitan an alternative for 'universal': the extendedness and power of knowledge practices are not given but made. Verran and Turnbull note that science is a global knowledge system using texts, standardised measurement, the notion of law, theory etc. They discuss a variety of other systems, including Gothic catedral building, Anasazi and Inca architecture and infrastructure, Pacific navigation and Yolngu kinship-land relations.

18 David Turnbull Masons, Tricksters and Cartographers. Comparative Studies in the Sociology of Scientific and Indigenous Knowledge London: Routledge, 2000

19 Helen E. Longino The fate of knowledge
} 
an application of a local epistemology to a particular domain or phenomenon. Concretely, an approach entails research questions, models, tools and strategies. Thus, in a situation of inquiry researchers who are part of a larger community employ intellectual and social strategies vis-à-vis a domain or phenomenon. As Longino's concern is acceptance of pluralism as opposed to theoretical unification, her notion of local knowledge entails that it is partial. A local epistemology is a selection of epistemological strategies, and all such selections are partial. A plurality of local epistemologies may be practised within a field, without there being a necessity of these epistemologies being compatible.

My perspective on how a local research configuration is shaped by a variety of contexts combines elements of the above conceptions of local knowledge. A local research configuration revolves around research problems, and has conceptual, instrumentational and institutional dimensions. Scientific fields may be among the relevant contexts shaping the local research configuration but do not simply yield research problems. Local research configurations emerge within localised settings, which contribute to their shaping, and thus the shaping of research problems.

Since my focus is on scientific practices, not other sorts of knowledge, I call the knowledge configuration a research configuration, but I do want to show how scientific knowledge is assembled like other sorts of knowledge. This I do by analysing how a local research configuration is shaped by a variety of contexts. I prefer not to use the notion of assemblage as it does not easily allow for distinguishing between a local configuration and the extended knowledge space of the scientific field. For my discussion of cosmopolitan fields and local configurations, this distinction matters. I also want to distinguish between the different scientific fields that may contribute to the shaping of a local research configuration. In this study then, a local research configuration is conceived of assembled research problems, in which field specific research problems may be combined. I will come back to the problem of how multiple institutional contexts contribute when discussing the local research configuration in more detail.

\section{Contexts as an alternative for levels}

The distinction between a local research configuration and relevant contexts makes it possible to conceive of the local as being shaped by a variety of contexts, which need not be ordered as levels, or have the properties of a system. Joan Fujimura alludes to a multi-level conception of research in her analysis of how scientists construct do-able research problems in an experimental laboratory setting. She distinguishes between three levels of work organisation, the experiment, the laboratory and the social world, and argues that alignment of these three levels results in a do-able research problem ${ }^{20}$. While her analysis of constructing do-able research problems is illuminating, I would prefer to speak of multiple contexts rather than levels. There are two aspects of Fujimura's conception which suggest that context would be a more appropriate term than level. Firstly, in her analysis, the social world level turns out to be a level of worlds in the plural: articulation is required with 'worlds outside the laboratory'21. Secondly, Fujimura emphasises that the levels of experiment, laboratory and social world(s) are not to be conceived as a hierarchy 22 . The multiple worlds outside the lab and the two within the lab thus stand in no particular order a priori, and alignment is a matter of accommodating experimental practice to a variety of contexts, both within the lab and outside it.

\footnotetext{
20 Joan H. Fujimura 'Constructing 'Do-Able' Problems in Cancer Research: Articulating Alignment' in: Social Studies of Science, 17/2, 1987, p. 261

21 idem, p. 268

22 idem, fn 14 p. 262
} 
While I thus prefer to use contexts as an alternative for levels, I do use terms like national, European and cosmopolitan level in a common sense.

Structure of local research configurations

Local research configurations revolve around temporarily stabilised ways of articulating research problems. In this conception, a research problem, and the conceptual, instrumentational and institutional ways of dealing with it constitute local knowledge. Local research configurations may be analysed with respect to their structure, and their heterogeneity. In conceiving of local research configurations this way, I build on Joan Fujimura's conception of productive research practices as revolving around do-able research problems - as briefly introduced above - and standardised packages as efficient ways to stabilise research outcomes. Central to this conception, in turn, is Susan Leigh Star and James Griesemer's notion of boundary objects ${ }^{23}$.

Star and Griesemer introduced the notion of boundary object to explain how, in the absence of consensus, cooperation between different social worlds may yield scientific knowledge. A boundary object, which may be abstract or concrete, satisfies the needs of different social worlds while maintaining coherence, a common identity, across these worlds. It derives this dual capacity from being 'weakly structured in common use, and becom[ing] strongly structured in individualsite use'. Put differently, a boundary object is ambiguous, flexibly interpreted, when used across worlds, but has a restricted meaning and use in each of these worlds separately. It allows for both autonomy and mutual understanding and cooperation. Star and Griesemer mention methods standardisation as another way of enabling cooperation and creating coherence across worlds in the production of scientific knowledge. Standardization of methods creates common ground in a different way, restricting autonomy more than boundary objects do. Rather than coordinating differentially across and within worlds, standards extend across worlds.

Joan Fujimura has introduced the notion of the standardised package to account for the stabilization of facts in heterogeneous research configurations. A standardized package combines boundary objects with standardized methods. Like a boundary object, a standardised package is an interface between multiple social worlds. The difference between a boundary object and a standardised package is in its degree of structure:

A package differs from boundary objects in that it is used by researchers to define a conceptual and technical work space which is less abstract, less ill-structured, less ambiguous and less amorphous. ${ }^{24}$

A standardised package may be more strongly structured, it still allows different worlds to articulate their own research problems, even if they share theory and methods, as in Fujimura's example of a theory-method standardized package. A shared theory also does not exclude commitment to field-specific theories that are compatible with the shared theory. In Fujimura's case oncogene theory provided researchers with new tools to continue existing lines of work, while at the same time contributing to the new, shared theory.

\footnotetext{
${ }^{23}$ Susan L. Star and James R. Griesemer 'Institutional ecology, "Translations", and Boundary Objects: Amateurs and Professionals in Berkeley's Museum of Vertebrate Zoology, 1907-39' in: Social Studies of Science 19, 1989, pp. 387-420

24 Joan H. Fujimura 'Crafting Science: Standardized Packages, Boundary Objects, and “Translation"' in: Andrew Pickering (ed.) Science as practice and culture Chicago: The University of Chicago Press, 1992, p. 168
} 
In the proposed conception of a local research configuration, what the different parties involved minimally share is a research problem. The shared research problem may allow the different parties to formulate their own research problems and to practise their own research lines while simultaneously dealing with the shared research problem through cooperation. There may be few or many boundary objects involved, and boundary objects may be accompanied by standardisation of concepts or instruments. Local research configurations may thus exhibit structure to a varying degree.

Yet, there is more to the structure of local research configurations than heterogeneity and flexibility. Neither Star and Griesemer, nor Fujimura pay attention to the question of primacies, or more generally relations of power within research configurations characterised by heterogeneity and cooperation. Yet, the common ground made up of boundary objects and standardised packages may embody power relations in various ways. The common ground may be conceptual or instrumentational, or of a combined character, and one may have primacy over the other. The concepts and instruments of the various scientific fields involved may also contribute to shaping the common ground to a different degree. Put differently, the concepts and/or instruments of one scientific field may have primacy over others. The question how local research configurations have attained structural features in terms of primacies may be approached from a variety of angles. A sociological analysis of relations between scientific fields may contribute to an understanding of the primacies at work in local research configurations. Differences in status between fields may play a role in interdisciplinary struggles, as Norbert Elias pointed out at a time physics was generally still regarded the queen of the sciences and the category of basic science was enjoying the highest prestige:

As a rule, higher ranking and more powerful disciplines can impose upon those who rank lower their own method and categories of thinking as a model to be imitated. ... The more "basic" a discipline can effectively claim to be in relation to others, the higher is usually its prestige, and the greater its relative power. ${ }^{25}$

How differences in status have evolved over the last few decades and whether status plays a role in structuring interdisciplinary configurations are empirical questions. Status is also only one among many possible explanations of primacies in interdisciplinary configurations. In this study, emerging primacies and hierarchies will be traced empirically, rather than that claims will be made about their role in general.

\subsubsection{Institutional contexts}

Scientific fields

Scientific fields may be conceived of as institutional contexts alongside other contexts like science policies or sectoral policies and the institutional arrangements they give rise to. Local research configurations may be conceived of as shaped by these various contexts in different ways. Scientific fields are 'systems of work organisation and control' or 'reputational organisations' in Richard Whitley's terms and provide a major context for articulating research problems in academic science:

\footnotetext{
${ }^{25}$ Norbert Elias 'Scientific establishments' in: Norbert Elias, Herminio Martins and Richard Whitley (eds.) Scientific Establishments and Hierarchies, Sociology of the Sciences Yearbook, volume VI, Dordrecht: Reidel, 1982, p. 23
} 
Intellectual fields are here seen as the major forms of social organizations which structure the framework in which day to day decisions, actions, and interpretations are carried out by groups of scientists primarily oriented to public intellectual goals. ${ }^{26}$

As Whitley has pointed out, scientific fields differ in intellectual and social structure (for historically contingent reasons) and thus provide for different sorts of coordination. One aspect of coordination is what Cornelis Disco and colleagues call divisions of cosmopolitan (design) labour ${ }^{27}$. Articulating a research problem is, in a certain sense, doing a task within the context of larger projects undertaken within a field. How narrowly circumscribed or open the range of possible tasks is varies between fields. Other structural features of fields have to do with degrees of adherence to common standards, and mutual positioning resulting in distributed or concentrated reputations.

Since local research configurations may be oriented to more than one scientific field, and to other sorts of institutional contexts as well, articulating a research problem can not simply be considered a task performed within the division of labour of a scientific field. Scientific fields rather figure among a variety of contexts relevant to the articulation of a research problem. Acknowledging a variety of relevant contexts makes it possible to analyse their specific contributions to the shaping of the local research configuration and the research problem around which it revolves.

\section{Science policies}

Science policies are among the more distant contexts shaping contemporary scientific practices. Studying the ways in which science policies may contribute to shaping scientific practices asks for a combination of insights from science policy analysis and science studies. These are, however, fields that until recently built on very different conceptions of science and the ways in which science policies may impact on scientific practices ${ }^{28}$. Science policy analysis mostly black-boxes scientific practices and focuses on the conditions that science policies create for scientists to obtain resources and to account for the use of these. The black-boxing of the scientific practices is related to a prevailing conception of science's content as developing independently from the conditions that allow for its practice. The so-called 'internal development of science' is seen as only enabled or constrained by specific fields, and provided with direction, not as shaped by science policies, in the concepts and the novel entities it produces as much as in its resource structure and orientation. Science policy analysis also tends to approach science generically, thus ignoring the differential impact of science policies on specific scientific practices.

In science studies, on the other hand, there has been an emphasis on studying scientific practices as being shaped by heterogeneous concerns, among which science policies have hardly appeared as specifically interesting and important. Yet, it may be argued that science policies are of specific interest and importance as its discourse reflects how governments perceive relations

\footnotetext{
${ }^{26}$ Richard Whitley The intellectual and social organization of the sciences Oxford: Clarendon Press, 1984, p. 8

${ }^{27}$ Cornelis Disco, Arie Rip and Barend van der Meulen 'Technical innovation and the universities: divisions of labour in cosmopolitan technical regimes' in: Social Science Information, 31/3, 1992, pp. 147-162 28 Martin Lengwiler and Dagmar Simon note a rapprochement between science policy studies and science \& technology studies, as some science policy studies adopt a constructivist stance, while STS has come to devote more attention to political institutions and macro-level analyses. Martin Lengwiler \& Dagmar Simon (eds.) New Governance Arrangements in Science Policy, Social Science Research Center Berlin, August 2005, p. 8.
} 
between science and society, and as its arrangements are geared to coordinating science, hierarchically or in a networking mode 29 .

Science policies mostly refrain from formulating policy aims in terms of specific concepts and technologies to be employed by scientists: these are deemed 'internal to science' 30 . The aims of science policies are rather set in terms of notions such as excellence, relevance, competitiveness and interdisciplinarity and the selection of priority areas of research. The ways and means to realise these aims are formulated in terms of institutional arrangements, including funding programs. Science policy discourse may thus be analysed in terms of its guiding notions and the institutional arrangements that are being proposed. Institutional arrangements, in turn, are geared to specific policy aims. Foresight exercises, advisory councils, research quality assessments and research funding arrangements serve specific aims. They are, in Aant Elzinga's words 'forms of orchestration that are employed to encourage scientists to orient their efforts in accord with particular priorities'31. There is, however, a continuum between agenda building as induced by science policy arrangements, and agenda building as 'aggregation' through selforganising processes, as Arie Rip and Barend van der Meulen point out ${ }^{32}$. Thus, coordination may range from steering to orchestration to aggregation, depending on how strongly science policy arrangements contribute to agenda building processes, in other words, depending on the extent to which government emerges as a central actor. In the Netherlands, coordination by steering is low as compared to coordination through aggregation 33 .

The multifarious ways in which scientists respond to science policy arrangements may be framed in terms of what Norma Morris and Arie Rip call coping strategies ${ }^{34}$. Response is actually too passive a term, since scientists attempt to influence arrangements and priorities. For the purpose of my analysis, however, it suffices to look whether and in what way science policies have contributed to shaping scientific practices. In terms of governance as processes of social coordination, science policy discourse and proposed arrangements represent the dimension of steering, while the institutional strategies of scientists, and the conceptual and instrumentational strategies that are being co-produced, contribute to agenda building from the bottom-up, the dimension of aggregation. Both dimensions contribute to outcomes of processes of coordination. This occurs at the intermediary level, e.g. in research arrangements that have been proposed by government or an intermediary organisation like the research council, and are given institutional form by scientists. In this study, governance of science is being analysed the intermediary level of national research programmes and centres, and national specialty institutions.

\footnotetext{
29 Heide Hackmann differentiates between hierarchical governance, in which government assumes a central role, and networking, in which processes of social coordination are distributed over a range of societal actors, among which government. Heide Hackmann National Priority-setting and the Governance of Science Doctoral Dissertation University of Twente, 2003, pp. 8-10. Her focus is on processes of policy formulation, not outcomes, but the distinction between hierarchical and networking modes of governance is a more general one.

30 Technology-oriented programmes do aim at technology development, but not specifically at the adoption of technologies as instrumentation in scientific practices. This adoption, if it can be attributed to the programmes, may be conceived as an unintended side effect.

${ }^{31}$ Aant Elzinga 'The science-society contract in historical transformation: with special reference to "epistemic drift" in: Social Science Information, 1997, p. 423-424

32 Arie Rip and Barend J.R. van der Meulen 'The post-modern research system' in: Science and Public Policy, 23/6, 1996, pp. 343-352

33 idem, p. 348

34 Norma Morris and Arie Rip 'Proactive adaptation. Scientists' coping strategies in an evolving research system: the case of life scientists in the UK' in: Science and Public Policy 33/4, 2006, pp. 253-263
} 


\section{Sectoral policies}

Sectoral policies may be among the contexts that contribute to shaping local research configurations. In analysing global climate change research, Simon Shackley and Brian Wynne propose the term mutual construction to avoid a priori categorisation of science-policy interactions ${ }^{35}$. Categories such as applied science, regulatory science, policy relevant science or mandated science say little about the relations and mutual dependencies between specific scientific practices and sectoral policy arrangements, and obscure the fact that what is called pure or fundamental research may also be shaped by sectoral policies in subtle ways. Accounts of mutual construction - a notion closely related to that of co-production - foreground how scientific practices, and scientific fields in turn, may be shaped in part by sectoral policies and vice versa. For global climate change research, Shackley and Wynne found that:

... policy agendas play a role in influencing choices concerning even quite detailed issues of scientific methodology and may come to shape the developmental trajectory of the particular scientific field in question ${ }^{36}$.

Sectoral policies may thus contribute to shaping the research problem of a local research configuration as well as its conceptual, instrumentational and institutional dimensions. How they contribute is an empirical question.

\subsection{Research questions}

In science studies, there is widespread agreement that scientific practices have been undergoing thorough transformation since roughly 1980. Technoscience, post-modern science, mode 2 science and strategic science are some of the labels used to indicate widespread, qualitative change. The different diagnoses of change vary greatly, however, as to which dimensions of science are foregrounded and what the transformation entails.

As river science emerged over the last three decades, it is an interesting case to evaluate some of the claims about transforming scientific practices. As it emerged under the conditions that are said to have transformed science, it will embody the changes to a greater extent than older fields. I treat it as a case not to make tentative generalisations about transformations in scientific practices - which is problematic anyway from a perspective of science as diverse cultural practices - but to articulate some of the most prominent claims made in the diagnoses a little further. This articulation then serves to evaluate the claims by using the conceptual tools presented above, and to enrich the analysis of the practices of river science.

Diagnoses of recent science have an object in common, namely "contemporary scientific practices' but that is about all they have in common conceptually. Conceptions of scientific practices and of scientific change differ, some of these conceptions are more articulated than others, interrelations with other fields of practices are more or less articulated etc. I am not going to compare and evaluate diagnoses in these respects ${ }^{37}$. In what follows, I will articulate claims

\footnotetext{
35 Simon Shackley and Brian Wynne 'Global climate change: the mutual construction of an emergent science-policy domain' in: Science and Public Policy, 1995, pp. 218-230

36 idem, p. 226

37 There are numerous articles dealing with conceptual and empirical shortcomings of diagnoses of recent science. A number of these diagnoses and their reception are reviewed in Laurens K. Hessels, Harro van Lente 'Re-thinking new knowledge production: A literature review and a research agenda' in: Research Policy 37, 2008, pp. 740-760. They point to a need for more empirical evidence for specific aspects of change and transformation, to which this study aims to contribute.
} 
made in a number of diagnoses concerning aspects of scientific practice that figure in this study. I articulate the claims in terms of further research questions, which will be evaluated in the conclusions of the study as a whole. To distill aspects and questions, I will first briefly discuss the relevant diagnoses 38 .

\title{
2.2.1 Diagnoses of recent science
}

\section{Mode 2 science}

The thesis of a shift to another mode of knowledge production, mode 2, is a widely known and highly contested diagnosis of recent science. In The new production of knowledge Michael Gibbons and colleagues discuss what they consider the traditional and the emerging mode of knowledge production in terms of oppositions ${ }^{39}$. The new mode of knowledge production is said to emerge alongside mode 1 , the traditional mode of knowledge production. A first opposition between the two is in the context that contributes most importantly to the formulation of research problems and solutions. In mode 1, research problems are formulated and solved within academic, disciplinary contexts while in mode 2 , knowledge is being produced in a context of application. This context of application is intellectually and socially more complex than that which has characterised applied sciences like engineering. A related opposition is in the extent to which disciplines are the primary context for recognition. The term transdisciplinarity is presented as more or less synonymous with mode 2 . Transdisciplinarity is characterised as knowledge producing practices in which the intellectual agenda is not set within a discipline, but in terms of a practical problem. The practical problem is translated in heuristic guidelines for integration of contributing knowledge practices. Integration of disciplinary and other contributions thus happens with an eye on solving the practical problem as it emerges. Gibbons and colleagues state that:

\begin{abstract}
The transdisciplinary mode of knowledge production described by us does not necessarily aim to establish itself as a new, transdisciplinary discipline, nor is it inspired by restoring cognitive unity. To the contrary, it is essentially a temporary configuration and thus highly mutable. It takes particular shape and generates the content of its theoretical and methodological core in response to problem-formulations that occur in highly specific and local contexts of application 40 .
\end{abstract}

Thus, whether integration proceeds by the sharing and confrontation of epistemologies, theories, models, technologies, data or else, is an open question. Information technologies are, however, identified as playing an important role and as creating new linkages. Preferences in theory building are said to be shifting. In mode 2 the interest is less in the search for unifying first principles than in the concrete and the particular. Increasingly sophisticated instrumentation for data collection, diffusion of techniques from one discipline to another and the importance of computational models of simulation and dynamic imaging contribute to 'a pluralism of approaches which combine data, methods and techniques to meet the requirements of specific contexts'41.

\footnotetext{
38 I restrict my discussion to the original formulation of the diagnoses, all made around the mid-nineties. Later reformulations of the aspects dealt with in this study are largely in line with the original diagnoses. 39 Michael Gibbons, Camille Limoges, Helga Nowotny, Simon Schwartzman, Peter Scott, Martin Trow The New Production of Knowledge: the Dynamics of Science and Research in Contemporary Societies London, Sage, 1994

40 Idem., p. 29-30

41 idem, p. 44
} 
Organisationally and institutionally, the opposition between mode 1 and mode 2 is captured by the terms homogeneity, hierarchy and institutionalisation vs. heterogeneity, heterarchy and transience. The traditional academic discipline oriented research groups were relatively homogeneous, hierarchically organised and institutionally stable. In mode 2 research teams, practitioners from a variety of disciplinary and institutional backgrounds cooperate with an eye to solving societal problems:

Social scientists work alongside natural scientists, engineers, lawyers and businesspeople because the nature of the problems requires it. ${ }^{42}$

The mode 2 thesis exhibits ambiguity as to the extent to which the new heterogeneous configurations tend to institutionalise (apart from what the aims may be). On the one hand, mode 2 research teams are said to be transient, operating without a pressure to institutionalise ${ }^{43}$. On the other hand, the possibility of institutionalisation of transdisciplinary fields into disciplines ${ }^{44}$ and the emergence of a host of new institutional arrangements, linking government, industry, universities, and private consultancy groups ...'45 refer to new stabilisations.

\section{Strategic science}

In his diagnosis of an emerging regime of strategic science, Arie Rip emphasises a particular dimension of scientific change ${ }^{46}$. The diagnosis entails that internalisation of relevance is becoming characteristic of science in general and resulting in transformations of both local search practices and scientific fields. Relevance has been promoted by science policies, but scientists have also actively pursued it, which makes internalisation of relevance an outcome of interactions between science policies and scientists. Rip argues that relevance of scientific practices to specific concerns of societal actors is not a new phenomenon as such, and relevance has been built in in certain fields since the time of their emergence. Hydraulics is a case in point. Yet the ideology of pure science, and purification work, gave rise to a distinction between pure and applied science, the former having the highest status. Pure science was considered to be an autonomous realm, not to be interfered with. The metaphor of science as an endless frontier, introduced by Vannevar Bush in 1945, continued the view of science as having its own internal logic, an infinitely unfolding realm that would automatically contribute to progress. Since the seventies, however, science policies have pressurised scientists to legitimise their research in terms of societal relevance and scientists have colluded in the search for relevance. Relevance thus became an explicit concern among scientists, which has contributed to shaping research practices. Concerns of relevance have been combined with concerns of excellence, the latter entailing an orientation to scientific fields in the production of novelty. The sustained attempts of scientists to combine concerns of excellence and relevance has, according to Rip, resulted in socio-cognitive change in scientific fields. Put differently, what guides scientists in pursuing excellence has been shaped, over the past few decades, by concerns for relevance and fields may thus be said to have relevance inbuilt.

\footnotetext{
42 idem, p. 7

43 idem, p. 17

44 idem, p. 29

45 idem, p. 76

46 Arie Rip 'A cognitive approach to relevance of science' in: Social Science Information 36/4, 1997, pp. $615-640$
} 
In science policy circles, strategic research has been identified as a new category in the eighties. The two-fold distinction between pure (or basic, fundamental) and applied science gave way to a three-fold distinction with strategic research as a new category. A much quoted definition is the one that science policy analysts Irvine and Martin introduced in 1984:

Strategic research: Basic research carried out with the expectation that it will produce a broad base of knowledge likely to form the background to the solution of recognized current or future practical problems.

It is Rip's thesis that strategic research, as defined above, has become the dominant way of combining excellence and relevance, thus giving rise to a regime of strategic science.

\section{Post-modern science}

Paul Forman notes three main characteristics of recent science, as it is undergoing transformation under post-modern conditions ${ }^{47}$. First, an ongoing acceleration of knowledge production, experienced as overproduction and manifest as steeply rising publication, second, an instrumental orientation, combined with novelty being generated by technological tools rather than concepts and thirdly, an acceptance of proprietary, interested knowledges, which reorients science towards the market and toward particular problems, while dissolving disciplines. Only the latter two characteristics appear as relevant given the conception of scientific practices adopted here, and I will thus focus on these.

According to Forman, contemporary science is instrumental in two senses: scientific practice is dominated by instruments, and an instrumental attitude is prevalent. As the second sense, which involves a prevailing attitude or rationality is again beyond my study of scientific practice configurations, I will only discuss the diagnosis of instrumentality as a primacy of instruments in the production of novelty. The production of novelty by technological means is not new, argues Forman, but has been greatly intensified after WW II and has brought about qualitative transformation. In current technoscientific practices technologies rather than concepts have primacy in the production of novelty. This shift, or even reversal, is partly due to a reappraisal of the status of technology and theory in postmodernity. The status of abstract theory has waned, and producing novelty by means of instruments has gained in status. A further consequence of the primacy of instruments is what Forman calls 'tool-constituted "incommensurability"': the sharing of instruments makes a technoscientific community cohere and makes its practices "incommensurable" with those of other communities using their own set of instruments ${ }^{48}$.

A similar interplay between changing practices and reappraisal of practices is at work with respect to the binding of knowledge production to particular interests. The binding of knowledge production to particular institutions, such as universities and research institutes, and interests such as welfare, military and commercial, has a long and varied history. But it is the postmodern acceptance of proprietary, interested knowledge as opposed to the modernist ideology of science as uninterested and free, which reinforces science's orientation to the market and other powerful interests, argues Forman:

\footnotetext{
47 Paul Forman 'Recent Science. Late modern and post-modern' published in 1997, reprinted in: Philip Mirowski and Esther-Mirjam Sent (eds.) Science bought and sold. Essays in the Economics of Science Chicago: The University of Chicago Press, 2002, pp. 109-148

48 Hacking calls this literal incommensurability, as there is 'no body of instruments to make common measurements'. Ian Hacking 'The self-vindication of the laboratory sciences', p. 31
} 
... the long-term historical process of binding knowledge production to the interests of powerful institutions, which under the conditions of modernity operated under significant ideological constraints, has now, under those of post-modernity, advanced unhindered and extended in every possible direction. ${ }^{49}$

The proliferation of interested knowledges fragments knowledge production in a different way than ongoing specialisation within disciplines did. The image that emerges from Forman's diagnosis is one of proliferating technoscientific cultures producing novelty instrumentally, that is by means of technological tools, and with an eye to specific interests.

\subsubsection{Aspects and questions}

What sort of questions may be distilled from the above diagnosis? Which aspects of scientific practices are diagnosed as undergoing important transformation? I will briefly review the most salient aspects to distill further questions for my study of river science.

Primacy of technology

Two of the diagnoses claim a prominent role of technology in the production of knowledge, and a backgrounding of unifying theory. Forman claims that new knowledge is being produced instrumentally rather than by articulating theories, and that technoscientific cultures cohere around these technological tools. Thus, Forman claims a primacy of instrumentation over theory in scientific practices. Gibbons and colleagues also note a growing role of technological tools and a waning of interest in unifying principles, but do not suggest a primacy of technology. The diagnoses thus raise the question what role technology in terms of instrumentation plays in river science, and whether or not to speak of a primacy of technology.

Disciplines, interdisciplinarity and transdisciplinarity

Two of the diagnoses see disciplines dissolving. Forman claims that proliferating technoscientific cultures rather than disciplines now provide scientists with an orientation. Gibbons and colleagues claim that transdisciplinary configurations emerge, with integration proceeding with a practical problem in view, through the sharing of theory, epistemology, and/or technological tools. These transdisciplinary configurations may institutionalise as new fields. The diagnoses thus raise the question what is being shared across the fields that contribute to river science, what provides for a common ground, and whether disciplinary frameworks are still relevant in any way.

Institutional heterogeneity

The mode 2 diagnosis claims that knowledge is currently being produced in institutionally heterogeneous configurations. In the diagnosis, institutional heterogeneity is related to the dissolution of disciplines as guiding institutions and a prevailing orientation towards practical problems. Universities, research institutes, governments, firms, NGOs, and other societal actors and institutions now jointly produce new knowledge. The diagnosis also suggests that relations in these knowledge producing practices are heterarchical rather than hierarchical. This raises the question which institutions participate in local river research configurations and how these configurations are structured.

\footnotetext{
49 Forman 'Recent Science' p. 125
} 
Relevance, practical problems and binding

Whether framed in terms of local search practices shaped by their relevance for concrete sponsors, the binding of knowledge to specific institutions and interests, or knowledge production in a context of application, the diagnoses point to a growing influence of sponsoring or otherwise directly interested actors and institutions, and an orientation towards practical problems. The mode 2 diagnosis claims that an orientation to practical problems shapes the integration of contributions from different fields and institutions, while the diagnosis of strategic science suggests that relevance is largely shaped through expectations about the potential solving of practical problems that are yet to emerge. This raises the question whether and how river science's local configurations are being shaped in interaction with specifically interested actors and institutions, and how practical problems are co-produced with research problems.

\section{Governance of science}

While Forman considers the condition of post-modernity responsible for the binding of knowledge to specific institutions and interests, the dissolution of disciplines and the proliferation of technoscientific cultures, Rip suggests that interactions within the research system, between science policies and scientists, have played an important role in the rise of strategic science. Gibbons and colleagues mention globalisation and an increasing complexity of societal problems. This raises the question how science policies may have contributed to the emergence and institutionalisation of river science and asks for an interpretation of relevant societal conditions beyond science policies.

\subsection{Research design}

Mainstream as the conceptual tools used in this study may be, the research design and presentation of research findings are more innovative. Studies of scientific practices mostly either focus on the level of scientific fields, or provide rich accounts of practices in localised settings. The former kind of studies generally do not provide much information on how particular models, concepts or instruments emerge. Studies that focus on local scientific practices on the other hand tend to articulate only the contexts that appear to be immediately relevant from the perspective of the localised setting. Then there are studies that do articulate both structural and local aspects of science and technology by adopting a system's conception, assuming multi-level interaction. This study aims to explore an alternative to multi-level conceptions of science and technology. While a well articulated alternative is available: actor-networks, it has its limitations. An actor-network may be conceived of as extended and interlinked in multiple dimensions. Yet, actor-network analyses do not employ distinctions such as between concepts, instruments and institutions to discuss interrelations. This study, then, explores an alternative by neither adopting a multi-level systems perspective nor an actor-network approach, but by presenting different 'cross-sections', unfolding river science in cosmopolitan, national and local configurations. The study zooms in, in subsequent chapters, from river science as a cosmopolitan scientific field, via specialties contributing to river science institutionalised at a national level and river science emerging at this same national level (the Netherlands), to the emergence of a local research configuration, in the national setting. The term 'cross-sections' applies not in the sense that there is first river science as a coherent whole from which then slices are made and presented. It refers to the different accounts that are interlinked but have a distinct character. The accounts cover the same period of roughly twenty-five years, from 1980 to 2005, presenting different but related 
river science configurations. Thus, they are mutually informative: interpretation of sources to construct accounts of the separate cross-sections benefits from the other accounts. This results in a relatively robust composite picture of river science as it has been emerging between 1980 and 2005.

The first account treats river science as a cosmopolitan scientific field as its unit of analysis. The account is based on an iterative interpretation of a variety of written sources: research articles and papers, reports, books and websites. The starting point of the iteration was the question whether something of an interdisciplinary river science configuration had emerged at the cosmopolitan level at all. From the perspective of river research as practised in the Netherlands, interdisciplinary river science initially seemed only a loosely structured collection of specialty combinations, and at the cosmopolitan level only one journal specifically dealt with interdisciplinary river research. The starting point proved fruitful, since gradually it appeared that interdisciplinary river science has a life of its own and has become more than ad hoc combinations of specialties.

The second account focuses on the national level and has specialties contributing to river science as its unit of analysis. This provides the possibility to study science policies as a context for institutional strategizing within specialties and some of the consequences of this strategizing at the national level. The national level seemed most appropriate to study science policies' impacts, since at the beginning of the period under consideration governance of science was a predominantly national affair. For a similar reason, specialties are an appropriate unit of analysis since in 1980, Dutch scientists were organised at the national level in specialty specific working communities mostly oriented to a single discipline. The main reason to select five specialties, landscape ecology, freshwater ecology, geomorphology, hydrology and hydraulics is that most cross-disciplinary (or actually cross-specialty) cooperation in Dutch river research appears to take place among these specialties. This set of specialties is a national level, and more specifically Dutch version, of the cosmopolitan configuration of ecology, hydrology and geomorphology. Selecting these five specialties inevitably results in a reduction of the manifold complexity of river science as interlinked scientific and other practices, but is based on patterned interactions and labellings. Yet, contingencies are visible in the accounts as well. Where one specialty label is used in a particular occasion by particular actors, another may be used in a different occasion. To give some examples: what may be rubricated under fluvial geomorphology in one occasion, may be labeled sedimentology or physical sedimentology in another, or again fluvial hydraulic engineering. These distinctions are sometimes made on the basis of the particular approach to studying sediment transport and deposition: geomorphology and sedimentology include historical reconstructions and taxonomies, while physical sedimentology and fluvial hydraulic engineering are physics-mathematics oriented, and in all specialties statistics are used as well. As a second example, hydrology sometimes includes hydraulics, but on other occasions practitioners insist on making a distinction. And should not biogeochemistry be included as a specialty contributing to river science? For the US Geological Survey, biogeochemistry is a fourth specialty contributing to river science alongside hydrology, geomorphology and ecology 50 and in the Netherlands too, there is such a contribution. My approach to this kind of complexity has been to be selective in choosing units of analysis but to be more open to overflowing categories in the historical accounts, if contextually relevant. As an example, scientists may have several specialty affiliations, but in a particular account only one such affiliation may matter. The unit of analysis

50 Committee on River Science at the US Geological Survey River Science at the US Geological Survey Washington: The National Academies Press, 2007, p. 20 
selection has thus been based on what emerged, from a variety of sources, as the most relevant set of specialties, in the light of preliminary analyses of cosmopolitan and local research configurations. From a preliminary analysis of specialties as sets of journals, it appeared that hydraulics, hydrology, and geomorphology may be considered distinct specialties (at least until 2003) even if some convergence is visible between the latter two specialties. In ecology, many more specialties than freshwater ecology and landscape ecology are distinguishable. Figure 1 gives an impression of the specialties as sets of journals environment of river science's core journal River Research and Applications ${ }^{51}$.

To discuss science policies as a context for institutional strategising, the focus is on science policy discourse as it evolved between 1980 and 2005. The account of science policy discourse is largely based on science policy documents and secondary sources. This may seem a very limited approach to investigating opportunities and requirements that scientists have to deal with. Science policy discourse says little about the attempts at hierarchical coordination of network governance the central government actually undertakes and what sorts of practices the densely populated level of intermediary organisations engages in. Yet, since I also provide sketches of specialty developments and offer a glimpse of group leaders' strategies, the different accounts together allow me to assess how science policies appear to have worked out. That is, how they have contributed to conceptual, instrumentational and institutional change of the specialties at the national level. It would be worthwile to articulate science policy practices in much more detail and also pay attention to the ways in which scientists contribute to shaping science policies, but a one-way, meso-level approach is appropriate in the context of the account as a whole, because the question is how the adoption of institutional, conceptual and instrumentational strategies by scientists is to be understood as conditioned by science policies. Interactions between scientists and science policy officials have received attention ${ }^{52}$, but it is the patterning in institutions and time frames surpassing research programmes that this study focuses on.

To find out about strategies as how scientists deal with opportunities and requirements as perceived by them, I conducted interviews with a number of group leaders. A major topic was how they dealt with opportunities for interdisciplinary and inter-institutional research cooperation, but the interviews were generally about a range of issues pertaining to trends in river research, science policies, funding opportunities and whatever came up as relevant. I acknowledge the situated character of the interviews: they are informative events rather than structured ways of extracting information. It is fair to assume that the respondents have wanted to provide a strategically sensible image of their strategies and successes. The occasional 'this is not for the record' instruction or the reluctance to say something about a conflict of the past says so much. But that doesn't make the interview material less valuable. It may be worthwile to know what happens behind all sorts of scenes in the context of other research questions. Thanks to the

\footnotetext{
51 The identification of specialties as sets of journals proceeds by a method and tool developed by Leydesdorff and Cozzens. L. Leydesdorff and Susan E. Cozzens 'The delineation of specialties in terms of journals using the dynamic journal set of the SCl' in: Scientometrics vol. 26, no. 1, 1993, pp. 135-156. The same tool was also used to get an impression of the journals cited in the journal River Research and Applications, and its specialty environment. This journal is not a core journal by scientometric standards: in the factor analyses it appeared to be mostly part of a set of aquatic ecology journals. It is, however, a core journal of river science as it emerged from the series of symposia on regulated rivers, the focus of this study.

52 Examples of studies of interactions between scientists and science policy officials in research programmes are Elisabeth Shove 'Principals, agents and research programmes' in: Science and Public Policy 30/5, 2003, pp. 371-381 and Chunglin Kwa 'Speaking to science. The programming of interdisciplinary research through informal science-policy interactions' in: Science and Public Policy 33/6, 2006, pp. 457-467.
} 
ethnographical approach to studying science detailed accounts are available on how the public image of scientists doesn't quite match with the messiness of workfloor practices, and how frontstage and back-stage stories are different also as a professional strategy. But for the purpose of discussing scientists' strategising vis-à-vis science policies and other contexts in terms of collective patternings, a public discourse oriented interview approach is appropriate. To interpret patternings at collective discursive levels, strategies as uttered in public fora are the most informative ones.

The specialty developments sketched in the national level account are again based on an interpretation of a variety of written sources: inaugural speeches, annual reports, newsletters, research contributions and available specialty histories. They are sketches of broad conceptual, instrumentational and institutional developments rather than thoroughly researched specialty histories. Yet, they do provide enough detail to draw contrasts and commonalities in terms of collective patternings and, informed by the interviews on strategies, to offer an interpretation of how science policies geared to interdisciplinary and inter-institutional research cooperation have contributed to developments.

The third account further articulates developments in the Netherlands, by looking at the shift to a new river management regime and emerging interdisciplinary river science in the Netherlands, and into the details of a local research configuration. In this account, elements of the cosmopolitan and national level are interpreted as contexts. The analysis of the structure of a local river research configuration thus builds upon the former accounts without reducing the local research configuration to either a local instance of a cosmopolitan field or a local instance of a national level specialty combination. The local research configuration has a life of its own, while it bears the traces of a variety of contexts. The account is based on interpretation of a variety of written sources and interviews with informants.

The sorts of accounts that result from my interaction with the research material are both constrained by this material, by my selection and interpretation of it and my choice of how to proceed iteratively. The material led me into avenues that I didn't foresee and I have partly let myself be guided by what seemed worthwile to articulate without fully understanding what I might be after, yet gradually coming to grips with it. My conception and understanding of river science has been co-produced with my (ways of accessing) research material and social and institutional environment, so to speak.

Fig.1 (next page) Journals cited by the journal River Research and Applications in 2003. The lines indicate strength of similarity in the being-cited pattern in the journal's citation environment. 112 journals, 24 specialties (components identified by factor analysis). First 15 components: 1. general ecology, 2. limnology (River Research loading 0.45), 3. fisheries research-1 (River Research loading 0.46), 4. Science, Nature 5. hydrology 6. estuarine ecology 7. geomorphology 8. wildlife management 9. sedimentology 10. geophysics 11. conservation 12. geochemistry 13 . water research 14 . fisheries research-2 15 . hydraulics. Figure produced by Loet Leydesdorff. 


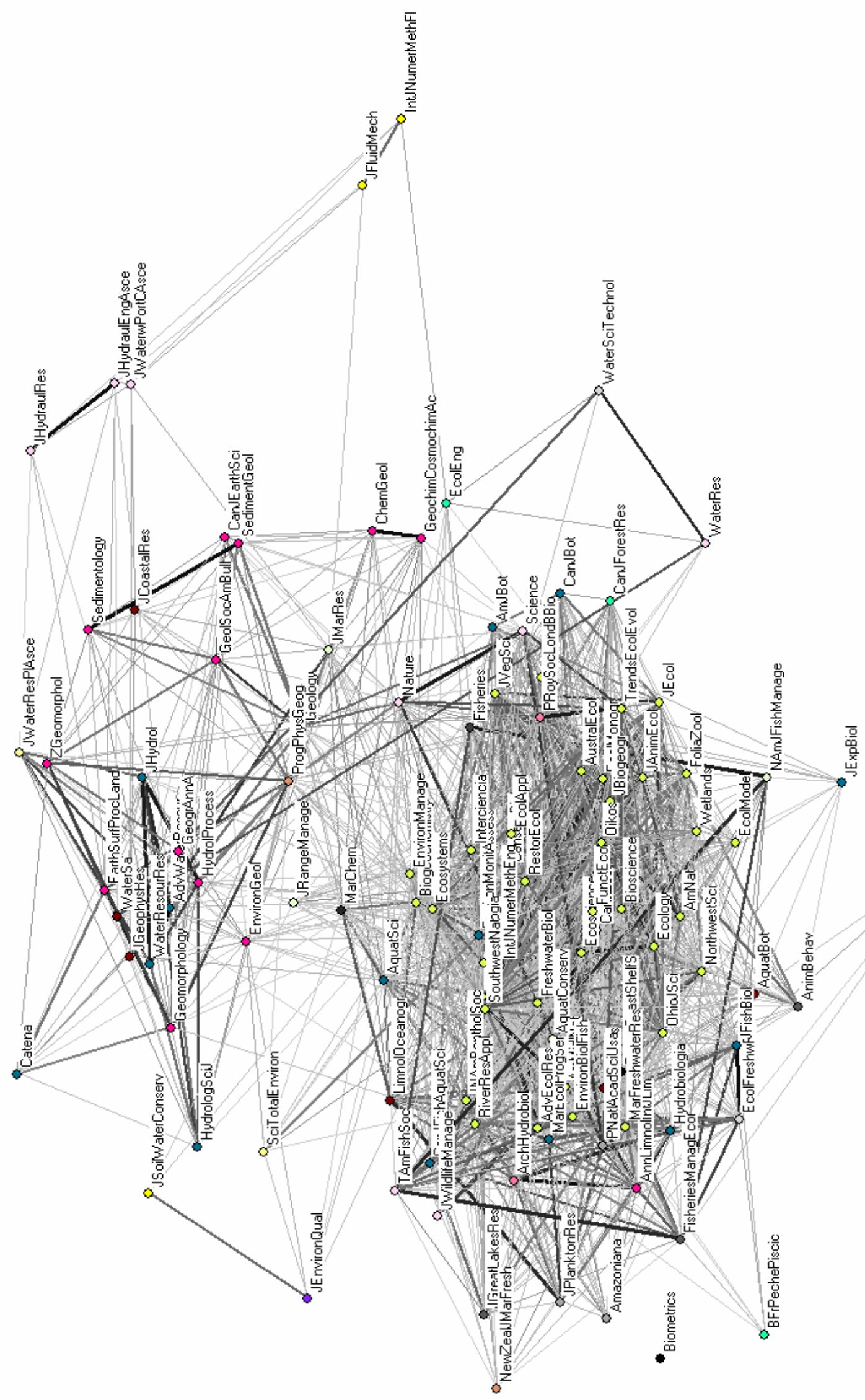




\section{Chapter 3 Emerging river science as a cosmopolitan field}

River science has emerged as an interdisciplinary field combining insights and approaches from ecology, geomorphology and hydrology among others. Three decades ago, practitioners of these fields started to work on interdisciplinary approaches to studying rivers, to help fight river degradation and to advance their own specialty approaches. At the time, theoretical unification was a guiding ideal, albeit a quickly fading one. Complexity thinking came to pervade ecology and the earth sciences, of which river scientists forged their own version. I will give an account of the experimental beginnings and the subsequent institutionalisation of interdisciplinary river science as an interplay between strands of complexity thinking, available remote sensing techniques, computer modelling and guiding notions of interdisciplinarity. I argue that the mutual adjustment of concepts, technologies and interdisciplinary divisions of labour has been guided by a particular discourse. A discourse on modularity, strongly influenced by information technologies, contributes to shaping river science's interdisciplinary practices, including theory building, as much as concrete information and imaging technologies do.

\subsection{Regulated rivers on the research agenda}

River science emerged around an issue 53. An international interdisciplinary river research community started to take shape around 1980 , when river degradation was on the agenda of environmental movements, and governments hired environmental experts to do impact assessments. The issue of river degradation attributed to dams, and the new approach of stream ecologists who started to study rivers as functional wholes, combined to make dammed rivers an object of study within ecology. But how did the issue of dammed, degraded rivers gain such momentum as to give rise to an interdisciplinary scientific field?

In April 1979, on the shore of Lake Erie, more than 500 scientists gathered for the First International Symposium on Regulated Streams (FISORS), organized by freshwater ecologists James Ward and Jack Stanford54. James Ward was associate professor in limnology at Colorado State University at the time, Jack Stanford held the same position at the University of North Texas. They had both studied insects in mountain streams in their doctoral research early seventies, enjoyed collaborating and were concerned about the impact of dams on riverine fauna55. The FISORS symposium was the plenary session of an annual meeting of limnologists, organized by the North American Benthological Society. At another limnology conference in Copenhagen, two years before, Ward and Stanford had agreed that the time was ripe to organize an international meeting on the subject of regulated streams, and mobilised the support of the North American Benthological Society and the National Science Foundation to organize FISORS. Their motivation was twofold: advancing stream ecology as a subdiscipline of freshwater ecology and contributing to the growing body of evidence that building dams meant destroying river ecosystems.

\footnotetext{
53 In the eighties, 'mission-oriented science', science oriented to specific societal problems, would have been the science studies framing. But the notion of issue conveys the political character of problems much better: it refers to dissensus and contestation over problem definitions and solutions. For an innovative view on the role of issues in politics, with examples of issues concerning large dams, see Noortje Marres No Issue, No Public. Democratic Deficits after the Displacement of Politics Doctoral Dissertation University of Amsterdam, 2005.

54 James V. Ward and Jack A. Stanford The ecology of regulated streams New York \& London: Plenum Press, 1979

55 Klement Tockner, Christopher Robinson ‘James Vernon Ward - eine Nachbetrachtung’ in: EAWAG Jahresbericht 2002, p. 3
} 
Stream ecology dealt with entire rivers as functional wholes, which was a new approach compared to the small scale that limnologists were used to study. Freshwater ecologist Noel Hynes had introduced this holistic approach to studying rivers in the early seventies. The ecology of running waters, a volume of more than five hundred pages on stream ecology which appeared in 1970 and a later article titled 'The stream and its valley' in a limnological journal made Hynes the founder of stream ecology. Stream ecologists had, however, focused their attention on relatively pristine rivers. In a contribution titled 'Dammed rivers of the world', Ward and Stanford introduced their research agenda by stating that '[n]o one has yet investigated functional, as well as structural, aspects of tailwater ecosystems from a hypothesis-oriented and experimentally defined approach'56. The research programme that they proposed to the community of aquatic ecologists involved an extension of Hynes' approach to regulated rivers. With FISORS, 'the discipline of regulated river ecology' had been established, as Ward and Stanford retrospectively rated the historical importance of their agenda building effort at Lake Erie. ${ }^{57}$

The damming of rivers for hydropower, irrigation and flood defense gave rise to fierce protests in the US in the late seventies 58 . The post WW II decades were a hey-day of dam building, notably for hydropower. World-wide, more than 8000 large dams had been built between 1945 and 197159. In the US, the building of dams had met with resistance since the rise of the conservation movement in the late $19^{\text {th }}$ century, but the prevailing mentality was that of celebrating technological progress and controlling nature. With the rise of the environmental movement and environmental legislation from the 1960s onwards, the resistance against dam building grew and in some cases led to the halting of dam construction. Ecologists and geomorphologists started to voice their concerns about river degradation in academic and popular scientific fora. In a 1971 issue of Science, geomorphologist Gordon Wolman warned that damming might have more far reaching effects on river ecosystems than pollution 60 . Before, river pollution had received a lot of attention among environmentalists. In her influential book Silent Spring from 1962, Rachel Carson had devoted a chapter to the subject, titled 'Rivers of death'.

The energy crisis of the early seventies brought a new wave of hydropower projects, but calls for river protection also became stronger, backed by environmental studies. Rivers were also increasingly used for recreational purposes, and seen as wilderness areas to be preserved rather than turned into reservoirs. In 1976, as a candidate for president, Jimmy Carter declared that he would 'halt the construction of unneccessary dams by the Army Corps of Engineers' 61 . During his presidency, he directed federal agencies to study rivers for inclusion in the Wild and Scenic Rivers System, a river conservation scheme which dated from 1968, but wasn't very effective. 62 In 1978, the construction of an almost finished dam was temporarily halted by a ruling of the Supreme Court. The presence of the snail darter, an endangered fish species, provided legal arguments to stop the building of the dam ${ }^{63}$.

\footnotetext{
56 Jack A. Stanford and James V. Ward 'Dammed rivers of the world: symposium rationale', in: James V. Ward and Jack A. Stanford The ecology of regulated streams p. 3

57 Jack A. Stanford and J.V. Ward 'Revisiting the serial discontinuity concept' in: Regul. Rivers: Res. Mgmt. 17, 2001, p. 303

58 Tim Palmer Endangered Rivers and the Conservation Movement Berkeley: University of California Press, 1986

59 Geoffrey Petts Impounded rivers. Perspectives for Ecological Management Chichester: John Wiley, 1984, p. 4

60 M. Gordon Wolman ‘The Nation's Rivers’ in: Science 26 November 1971, vol. 174, no. 4012, pp. 905918

${ }^{61}$ Palmer Endangered rivers p. 199

62 idem. p. 154

63 idem, p. 119
} 
Ward and Stanford thus launched their research agenda in a favourable political climate. What is more, they were effectively part of the social movement that fought against the damming of rivers. While noting a tension between advocacy and science, and laying emphasis on their scientific orientation, Ward and Stanford made clear that they shared the agenda of the river conservation movement. The evocation of a dramatic sense of loss mingles with scientific literary style when they illustrate the impact of dams on river ecology:

\begin{abstract}
The Gunnison River in Colorado embodies many of the characteristics of a stream continuum interrupted by impoundments and altered by downstream flow regulation. Pteronarcys californica (Insecta: Plecoptera), the lumbering willow fly, once characterized the River. Enough nymphs for a days fishing could be collected by dislodging a few large rocks on the river bottom; nymphs were abundant in leaf packs, which commonly accumulated on the upstream side of obstructions or in crevices in the substrate.
\end{abstract}

The willow flies, leaf packs, and much of the river are gone today. ${ }^{64}$

Further scientific study was to halt the destruction of river ecosystems like the Gunnison. Ecologists' task was in providing arguments for a more ecologically sound river management. The research agenda that Ward and Stanford proposed revolved around the question how regulation affected river organisms. Cause-effect relationships were to be studied holistically, that is, of the river valley as a whole and in terms of ecosystem nutrient and carbon cycles, community productivity and life histories of species.

FISORS, being part of a limnological conference, was primarily addressed to aquatic ecologists, but also attracted earth scientists, notably geomorphologists and hydrologists, and engineers. Ongoing specialisation in academia had given rise to a variety of specialty approaches to studying rivers, including stream ecology, fluvial geomorphology, surface hydrology and fluvial hydraulics. In the course of the sixties, interdisciplinarity had emerged as an ideal to provide a basis for solving societal problems 65 . As geomorphologist Gordon Wolman put it: 'The rationale for interdisciplinary studies is based on the common observation that problems in the real world are not separable into disciplines' 66 . At the same time, an older ideal, that of theoretical unification, had not yet disappeared as an ambition among ecologists and earth scientists. Research practices of biological, earth scientific and engineering specialties differed in many respects, but there were shared orientations too. By the seventies, systems thinking and computer modelling had come to create a common ground for ecology, earth science and engineering. More specifically, stream ecology's move to the whole river catchment as a unit of analysis brought it closer to fluvial geomorphology and surface hydrology which had been dealing with river catchments as units through the use of aerial photography. Mathematical modelling had also brought small scale oriented freshwater ecology into contact with fluvial hydraulics. At the time FISORS was held, interdisciplinary river research was being experimented with in a variety of ways. I shall discuss three such experiments, which yielded influential conceptual innovations in river science.

\footnotetext{
64 Ward \& Stanford The ecology of regulated streams, p. 3

65 Peter Weingart 'Interdisciplinarity: The Paradoxical Discourse' in: Peter Weingart \& Nico Stehr Practising interdisciplinarity Toronto: University of Toronto Press, 2000, pp. 25-41

66 M. Gordon Wolman 'Interdisciplinary education: a continuing experiment' in: Science New Series, Vol. 198, No. 4319. (Nov. 25, 1977), pp. 800-804.
} 


\subsection{Interdisciplinary river research around 1980}

\section{The River Continuum Concept}

In the 1970s, the Stroud Water Center in Pennsylvania, which had been set up as a field station of the limnology department of the Philadelphia Academy of Natural Sciences, profited from a Rockefeller grant to study the White Clay Creek which ran through its premises ${ }^{67}$. The research agenda of its director, Robin Vannote, linked up with Noel Hynes' conception of stream ecology. In contrast with the limnological approach, which involved 'studying a square metre to death' as Vannote put it, stream ecologists should study an entire stream as a functionally linked system. The White Clay Creek and its catchment of 100 square miles was inventoried and monitored using physical, chemical and biological sampling methods. The work was continued as the River Continuum Project during the latter half of the seventies, funded by the NSF. Vannote had theoretical ambitions too, which he articulated as an analogy between the biological and the physical aspects of a river. He was informed about energy-equilibrium theory elaborated by fluvial geomorphologists Walter Langbein and Luna Leopold (conservationist Aldo Leopold's son) at the US Geological Survey. Geomorphological energy-equilibrium theory entailed that physical aspects of a meandering river, its depth, velocity, and slope, mutually adjust to reach a state of quasiequilibrium or dynamic equilibrium. The quasi-equilibrium was assumed to be the result of two opposing tendencies: an efficient work rate (minimum entropy production) for the river as a whole, and uniform energy expenditure along the length of the river. As a freshwater ecologist, Vannote was familiar with ecosystems as functionally related food-web systems or energy-matter conversion systems tending to equilibrium. As he conceived of the river as a whole ecosystem, he felt that an analogy could be drawn between a river's local physical and biological energy equilibrium states, along its entire length. Vannote called this theoretical contribution to stream ecology the River Continuum Concept ${ }^{68}$. In biological terms it meant that the composition and functioning of communities in a particular section of a river are adjusted to the physical conditions there and that communities too reach a dynamic equilibrium as a result of two opposing tendencies: efficient energy expenditure on the one hand and uniform energy expenditure (both through the year and along the river) on the other.

The River Continuum Concept involved the drawing of an analogy between earth scientific and ecological theory and was an attempt at unification. It turned out to be a last attempt at theoretical unification, as we will see.

\section{Fluvial Hydrosystems}

In 1975 a team of CNRS researchers from the Universities of Lyon and Grenoble, led by freshwater ecologist Albert Roux received funding from the Ministry of the Environment and the Ministry of Research and Technology to start an interdisciplinary research programme. PIRENRhône, a long term study of the upper part of the Rhône river in France was to contribute to ecologically sound management of rivers. The aim was to study the Upper Rhône in a holistic way, with contributions from freshwater ecology, plant sociology, hydrology, geomorphology, history, economics and law. Researchers working within these fields conducted their studies separately,

\footnotetext{
67 http://www.stroudcenter.org/portrait/index.htm accessed 13 November 2007

68 Vannote, R.L. G.W. Minshall, K.W. Cummins, J.R. Sedell and C.E. Cushing 'The River Continuum Concept' in: Canadian Journal of Fisheries and Aquatic Sciences, 37, pp. 130-137, 1980
} 


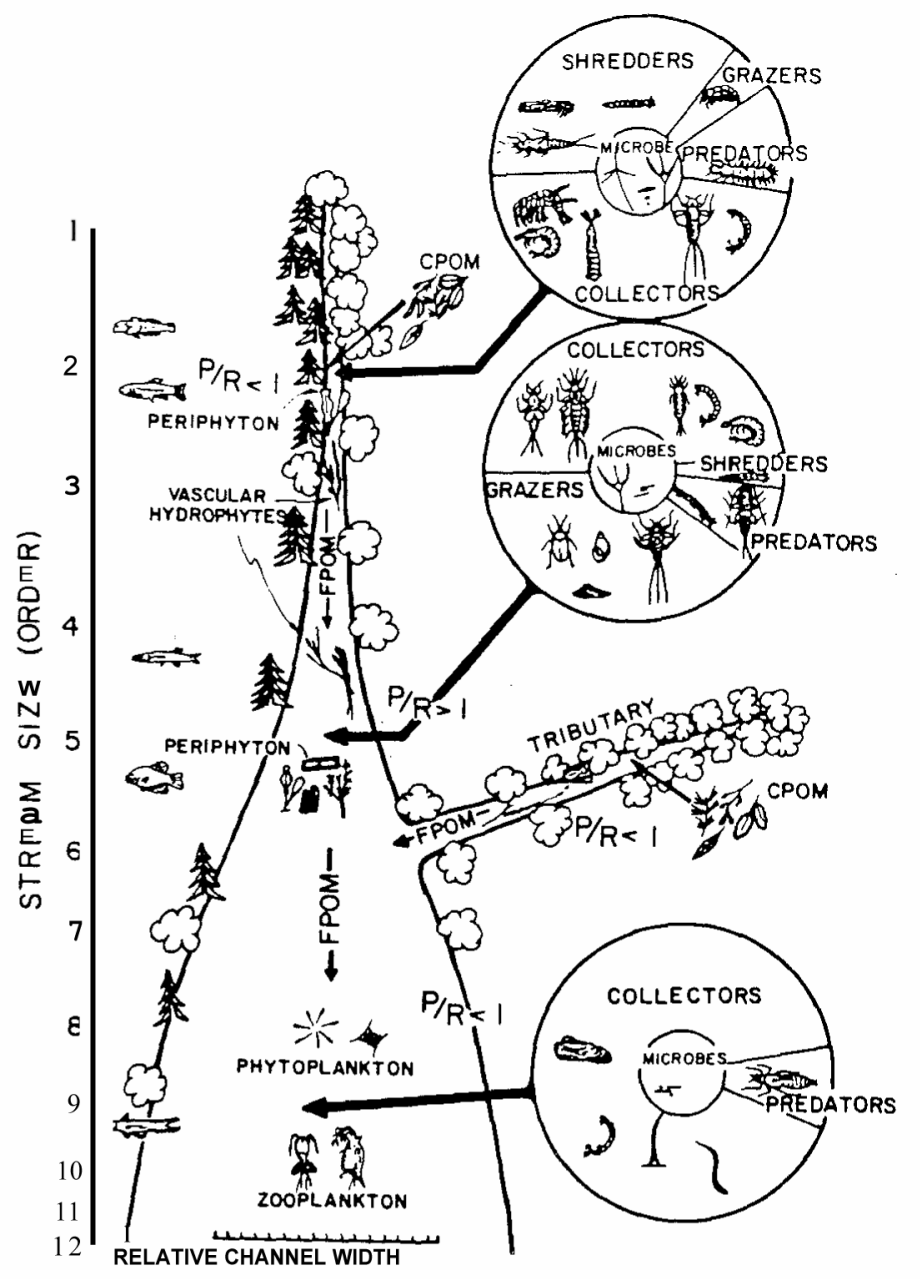

Fig. 2 A diagram of the River Continuum Concept in: R.L. Vannote et al. 'The River Continuum Concept' p. 132

the results of which were to be synthesized subsequently. One such synthesis was a polythematic map, based on freshwater ecological, plant sociological, hydrological and geomorphological studies. ${ }^{69}$ Freshwater ecologist Claude Amoros proposed the term fluvial hydrosystem as a concept unifying biological and physical dimensions of a river. The fluvial hydrosystem was a conception of the river ecosystem in terms of a spatial hierarchy and temporal dynamics. ${ }^{70}$ The Rhône catchment contained the Upper Rhône from Lake Geneva to Lyon as a fluvial hydrosystem, which contained a fifteen square kilometres wide braiding river plain as a 'functional sector', of which an abandoned river meander formed a 'functional set'. The smallest spatial unit was what

69 C. Amoros, M. Richardot-Coulet, J.-L. Reygrobellet Cartographie polythématique appliquée à la gestion écologique des eaux. Publication PIREN, 1982 .Freshwater ecologist Monique Coulet combined being researcher and activist. As a CNRS researcher, she participated in PIREN-Rhône from 1975 onwards, after having completed a hydrobiological PhD study on a small mollusc. As an environmental activist, she protested against plans for dams in the Rhône river and initiated the 'Loire vivante' campaign in 1986. Source: excerpts from an article in Terre Sauvage no. 176, http://www.ramsar.org/award/key awards2002 interview coulet e.htm accessed 20 June 2006. 70 C. Amoros, A.L. Roux, J.L. Reygrobellet, J.P. Bravard and G. Pautou 'A method for applied ecological studies of fluvial hydrosystems' in: Regulated Rivers 1, 1987, pp. 17-36 
geomorphologists called an elementary landform, a gravel bar in a river for instance. This elementary landform was considered to be a functional ecological unit at the same time, as it provided the habitat for a specific association of pioneer plants. Thus, apparently, botanists and geomorphologists reached agreement that associations and landforms mapped onto each other and could be called 'functional units'. The associations were regarded statistical units ${ }^{71}$. The process of reaching agreement on intermediate map units appears to have been aided by aerial photography. ${ }^{72}$

The PIREN-Rhône research may thus be characterized as a form of interdisciplinarity based on a shared classification. The Fluvial Hydrosystem as a spatio-temporal conceptualization of the river ecosystem and a mapping exercise which was to synthesise field data gathered by freshwater ecologists, plant sociologists, hydrologists and geomorphologists, yielded a shared spatial classification. Declaring physical landforms and biological associations as belonging to one and the same spatial unit was the main synthesizing act within the Fluvial Hydrosystems framework, which was itself a concept unifying ecology, geomorphology and hydrology in spatial terms.

\section{Physical Habitat Simulation (PHABSIM)}

In the late 1970s, concern about the effects of river regulation on fish populations led the Environmental Protection Agency to fund a project at the Office of Biological Services of the US Fish and Wildlife Service ${ }^{73}$. The Cooperative Instream Flow Service Group, led by ecologist Clair Stalnaker, was given the task to quantify effects of stream regulation on specific fish species, like the salmon. Downstream a reservoir, flow levels were largely determined by the operation of the hydropower unit, but could be adjusted in such a way that fish populations would have a better chance of survival. Minimum flow levels, below which fish survival was severely threatened had already been identified. A new approach was to rate a stream as more or less suitable for specific fish species at particular life stages, for instance the spawning of salmon, given water depths and velocities at different sections of the stream. Observations and measurements had yielded particular ranges of stream velocities and depths at which salmonids spawned. The suitability of a stream for the spawning of salmon could thus be rated for particular discharges, since stream depths and velocities vary with discharge, the total amount of water that passes through the river bed per unit of time. Stream sections displaying depths and velocities at which salmonids could spawn were considered suitable 'physical habitat'.

Measuring depths and velocities in particular streams was a time consuming and expensive affair, for which hydraulic simulation models provided a relatively cheap alternative. At the time, hydraulic simulation models comprised a set of equations solved iteratively. The Colorado State University CYBER 172 mainframe computer calculated velocities and water levels from a given discharge in five to ten seconds ${ }^{74}$. The output of the hydraulic simulation model formed input for a habitat simulation system, which then yielded a curve displaying suitable habitat area (for a fish species at a particular life stage) per unit length of stream as related to discharge.

The Physical Habitat Simulation (PHABSIM) system as it was called, thus brought together hydraulics and freshwater ecology. It connected these fields by assuming a causal link between

\footnotetext{
${ }^{71}$ C. Amoros et al. Cartographie polythématique, p. 39

72 J.P. Bravard, C. Amoros, G. Pautou 'Impact of civil engineering works on the successions of communities in a fluvial system' in: OIKOS 47, 1986, p. 93

${ }^{73}$ http://www.fort.usgs.gov/products/Publications/15000/preface.html accessed 19 November 2007

${ }^{74}$ Robert T. Milhous ‘The PHABSIM system for Instream Flow Studies' in: Proceedings for the 1979

Summer Computer Simulation Conference pp. 440-446, 1979
} 
physical conditions and biological organisms. The common ground on the basis of which hydraulic, simulated data could be made relevant for freshwater ecology were stream sections for which velocity and depth could be converted into habitat suitability. The theoretical orientations of hydraulics and freshwater ecology were left implicit, contained within the subsystems which comprised PHABSIM.

\subsection{The shift to spatial complexity}

Three aspects of theorising in interdisciplinary river research were to shift substantively in the decade that followed the First International Symposium on Regulated Streams. Firstly, river researchers abandoned energy equilibrium theory and embraced various strands of chaos theory. Secondly, complexity thinking came in the place of unified theory. Thirdly, the emerging field of landscape ecology with its spatial orientation came to replace aquatic ecology as a guiding ecological field in river science. I will first note more general developments in ecology and the rise of landscape ecology and then discuss how river researchers responded and contributed to these shifts.

In the course of the seventies, ecologists joined in a wave of interest in the modelling of nonlinear, dynamical systems ${ }^{75}$. An influential proponent of the view that ecosystems could exhibit multiple rather than just one stable state was Robert May. llya Prigogine's conception of natural systems as dissipative systems far from thermodynamic equilibrium also came to be embraced widely among ecologists. An overall effect was the demise of equilibrium theory and a growing emphasis on variability in its spatio-temporal manifestations. Temporal fluctuations and spatial heterogeneity became the focus of mainstream ecological research.

At around the same time, landscape ecology was emerging as a new, holistic approach to the landscape. Aerial photography had been constitutive of landscape ecology as it had been introduced by the German biologist-geographer Carl Troll in the 1950s and taken up by geographers and ecologists in continental Europe. An international meeting of landscape ecologists in the Netherlands in 1981, attended by American ecologist Richard Forman, marked the integration of landscape ecology in mainstream ecology ${ }^{76}$. Forman had proposed a different conception of landscapes. His primary concept was that of 'patches' making up a forest landscape as a heterogeneous 'mosaic'. In the course of the eighties the concept of patch came to be widely accepted as an alternative to continental European landscape ecology with its concept of 'ecotope'. The concept of patches was introduced by Forman and his French colleague Michel Godron in 198177. The publication of two landscape ecological textbooks, Landscape ecology. Theory and Application (1984) by Zev Naveh and Arthur Lieberman and Landscape ecology (1986) by Forman and Godron contributed importantly to making landscape ecology a widely followed approach to studying landscapes. The first book devoted a chapter to remote sensing as a tool for landscape ecological studies, discussing the recent extension of remote sensing from aerial photography to satellite multispectral scanning systems. The connection between the spatial, landscape ecological conception of landscapes and available remote

\footnotetext{
75 David Aubin and Amy Dahan Dalmedico 'Writing the History of Dynamical Systems and Chaos: Longue Durée and Revolution, Disciplines and Cultures' in: Historia Mathematica 29, 2002, pp. 1-67

76 Richard T.T. Forman 'The beginnings of landscape ecology in America' in: I.S. Zonneveld and R.T.T. Forman Changing landscapes. An ecological perspective New York: Springer-Verlag, 1990 pp. 35-41

77 R.T. Forman and M. Godron 'Patches and structural components for a landscape ecology' in: BioScience 31/10, 1981, pp. 733-740
} 
sensing imagery, was beginning to play a crucial role in ecology and the earth sciences. I will come back to this connection in the next section.

In river research, the abandonment of equilibrium thinking and the adoption of chaos theory and complexity thinking are noticeable from the mid-eighties onwards. In a review article on developments in stream ecology, the ecologists who had introduced the River Continuum Concept five years before, called the RCC a paradigm which 'has served to focus attention on rivers as integrated systems and to stimulate the formulation and testing of systems-level hypotheses which have helped to move lotic ecology from a descriptive to a predictive mode'78. Notably absent, however, in the updated version of the RCC that the group presented in 1985 was energy equilibrium theory. Rather, the article served in accommodating the RCC to the shifting views on temporal and spatial variability and proposed links between ecology and geomorphology at the habitat level, not the level of the whole river catchment. The authors no longer regarded equilibrium an overall condition which determines ecosystem structure and function, yet '[t]here seem to be certain periods during the year when equilibrium (hence deterministic or density dependent) conditions may prevail'79. By the mid-eighties, energy equilibrium theory had left the stage as a unifying deductive framework to predict river morphology and ecology.

PIREN-Rhône researchers, on the other hand, were accommodating the new chaos theoretical insights to their concept of Fluvial Hydrosystem by explicitly linking up with Prigogine's theory of dissipative systems. They adopted the view that 'an ecosystem [is] a dissipative structure that obeys nonequilibrium thermodynamic laws' 80 . Amoros and colleagues, however, did not consider the theory of dissipative systems which unified biology and physics a theory that allowed for deductions. For them, river ecology and geomorphology were not to be deduced from the theory of dissipative systems. In contrast with energy equilibrium theory, neither deduction nor deterministic prediction played a role. Within the Fluvial Hydrosystems framework, an ecosystem was a 'landform plus biocoenose', the primary spatial unit as identified in the PIREN-Rhône mapping exercise. This spatial conception of the river ecosystem allowed them to link up explicitly with the emerging field of landscape ecology. Thus, they confidently stated: "[o]ur approach addresses the objectives of landscape ecology'81. Landscape ecology had been focusing on terrestrial ecosystems, but was being extended to riverine ecosystems. In 1985, the first landscape ecological symposium held at the annual meeting of the Ecological Society of America focused on 'relations between vegetation and geomorphology in terrestrial and riverine ecosystems'82. Ecologist Henri Décamps, who contributed to the PIREN-Rhône research, advocated a landscape ecological approach to rivers based on the patches concept introduced by Forman and Godron 83 .

Hierarchy theory as introduced by Timothy Allen and Thomas Starr provided stream ecologist Christopher Frissell and his colleagues at the Oak Creek Laboratory of Biology at Oregon State University with a theoretical background for their conception of rivers as spatially nested hierarchies. Frissell and his colleagues presented their conceptual framework as an 'integrative,

\footnotetext{
78 Minshall, G.W., K.W. Cummins, R.C. Petersen, C.E. Cushing, D.A. Bruns, J.R. Sedell, and R.L. Vannote 'Developments in Stream Ecosystem Theory' in: Can. J. Fish. Aquat. Sci. Vol 42, 1985, p. 1046

79 idem, p. 1047

80 Claude Amoros, Jean-Claude Rostan, Guy Pautou, Jean-Paul Bravard 'The Reversible Process Concept Applied to the Environmental Management of Large River Systems' in: Environmental management vol. 11, no. 5,1987 , p. 613

81 idem p. 615

82 Forman 'The beginnings' p. 37

83 Henri Décamps ‘Towards a landscape ecology of river valleys' in: T.H. Cooley and F.B. Golley (eds.) Trends in ecological research for the 1980s New York: Plenum Press, 1984, pp. 163-178
} 
systematic approach for understanding the considerable natural variability within and among streams and stream communities' 84 . In concrete terms, the stream system was supposed to contain successively smaller subsystems: segments, reaches, pool-riffle systems and finally microhabitat systems. The spatial scales of these systems varied from $10^{3} \mathrm{~m}$ for the stream system as a whole, to $10^{-1} \mathrm{~m}$ for the microhabitat system (see fig. 3).

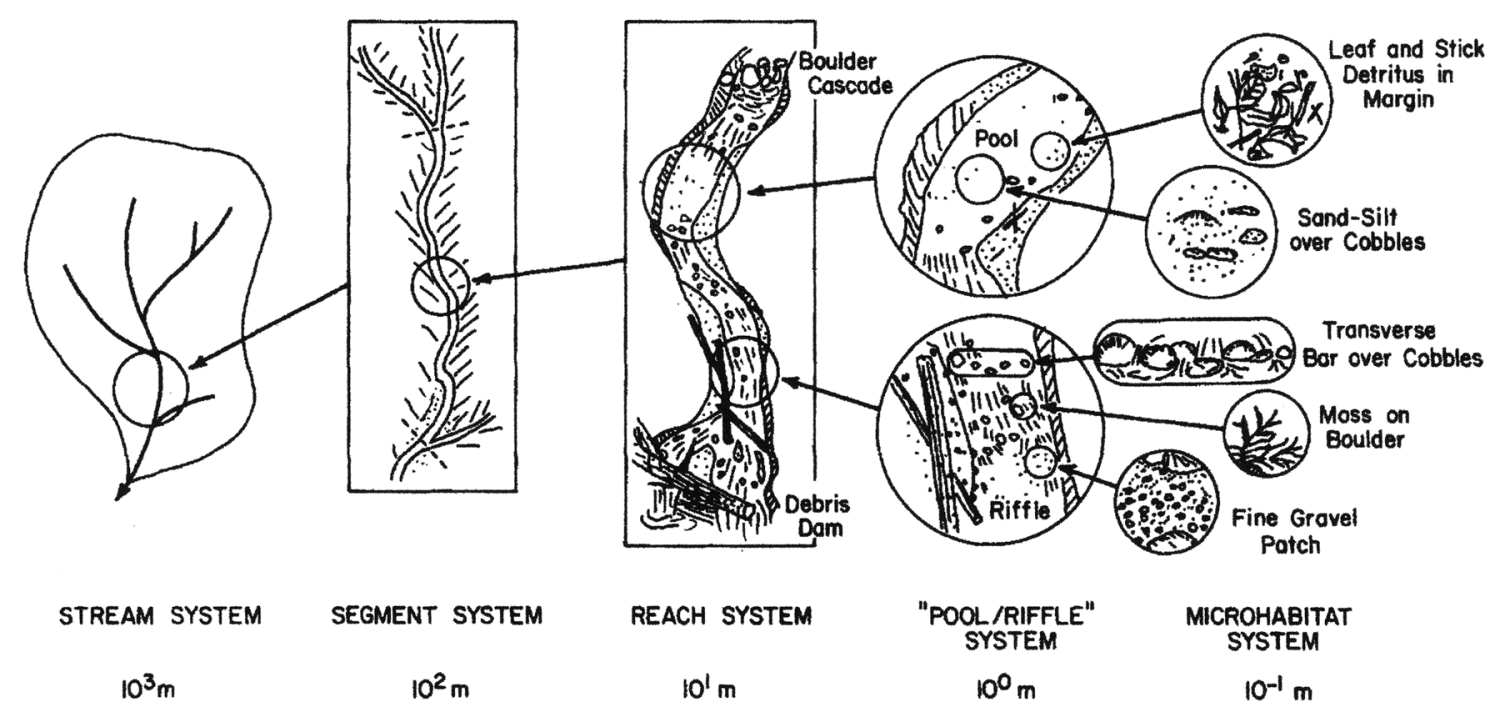

Fig. 3 The river as a spatially nested hierarchy in Christopher A. Frissell et al. 'A hierarchical framework' p. 202

Besides referring to hierarchy theory, which did not entail a spatial conception of ecosystems, Frissell and colleagues built on conceptions of landscapes as spatial hierarchies. Robert Bailey seems to have been their primary source of inspiration in this respect. In 1985, Bailey had introduced a conception of terrestrial ecosystems as spatial hierarchies. He stated that '[s]ince ecosystems are spatial systems, they are consistently inserted, or nested, into each other. Each level subsumes the environment of the system at the level below it, and therefore conditions or controls the behavior of the system below it'85. Unlike Frissell, Bailey made no reference to hierarchy theory, but built on landscape ecological notions. Bailey's main message was that ecosystem management should be based on classification and mapping of ecosystems at various spatial scales, ranging from 1: 10.000 to $1: 3.000 .000$, as each scale is organised differently.

Compared to the River Continuum Concept, the hierarchical framework was presented as an aid rather than an encompassing theory, since no complete representation of the complexity of the river system was deemed possible - an epistemological attitude characteristic of ecology as it evolved during the 1980s. One of the benefits of the hierarchical framework that the authors listed is that 'it provides for integration of data from diverse sources and of different levels of resolution'86. The hierarchical framework asked for such an integration, while diversifying remote sensing imagery was becoming an interesting source of data, as will become clear in the next

\footnotetext{
${ }^{84}$ Christopher A. Frissell, William J. Liss, Charles E. Warren, Michael D. Hurley 'A hierarchical framework for stream habitat classification: viewing streams in a watershed context' in: Environmental Management vol. 10, no. 2, 1986, p. 199

${ }^{85}$ Robert G. Bailey 'The factor of scale in ecosystem mapping' in: Environmental Management, vol. 9, no. 4, 1985, p. 272

86 idem, p. 200
} 
section. Part of complex systems theory is that the system as a whole may maintain its integrity, but its subsystems are only partly determined by what happens at higher levels. Subsystems have their own integrity, which is determined by their specific 'potential capacity' and their environment, which is the next higher level system. A consequence of complex systems theory appears to be that each level of a system, each spatial scale in the case of the river hierarchy, asks for its own explanation or 'model' of system structure and organisation, which cannot be deduced from a theory relevant to the highest level of the hierarchy. Another requirement of the hierarchical framework is that these level specific models can be accommodated to form an integrated whole 87 .

While a hierarchical conception of the river system may be said to have been implicitly present in earlier conceptual frameworks like Fluvial Hydrosystems, Frissell's move to accommodate it to complex systems theory seems to have been decisive for the widespread adoption of the view that 'the river is a spatially nested hierarchy', given the ubiquitous referencing of the article in interdisciplinary river research.

The importance of information technology for the emergence of complex systems theory has been acknowledged by the proponents of hierarchy theory88. The conception of the river as a spatially nested hierarchy, as it builds on complex systems theory, has been influenced by information technologies as well. I will come back to this when discussing how river researchers have come to conceive of interdisciplinary cooperation. But there is another technology without which the conception of the river as a spatially nested hierarchy would not have become a widely adopted view in interdisciplinary river research. The sophistication and diversification of spatial technologies, notably Geographical Information Systems (GIS) and remote sensing imagery, has contributed importantly to shaping the emerging conception of rivers as complex systems. The next section takes a look at the development of remote sensing during the period in which interdisciplinary river research took shape and came to embrace the conception of rivers as spatial hierarchies.

\subsection{Spatial technologies and issues of scale}

NASA launched its first Earth Resources Technology Satellite (ERTS), later renamed Landsat-1, in 1972. A decade before, the First Symposium on Remote Sensing of Environment had brought together interested scientists to discuss civilian use of space-born remote sensing technologies, which NASA resisted. A strong lobby for the Earth Resources Observation Satellites (EROS) programme by the United States Geological Survey (USGS) eventually resulted in NASA's cooperation, and the programme took off in 1966.89 Landsat-1 produced images covering 180 square kilometres with a resolution of $80 \mathrm{~m}$, in green, red, and two infrared bands. The Landsat images provided earth scientists interested in large scale phenomena with exciting new, relatively detailed views of the earth surface. Weather satellites which had been launched in the sixties, had produced radar images with a resolution of more than $1 \mathrm{~km}$.

\footnotetext{
87 Katherine Hayles discusses how, by connecting levels, complexity thinking has its own globalising strategies, although it appears to make a case for the localness of knowledge if contrasted with unifying theory. She notes that self-similarity is the property that makes integration across scales possible. Thus, whole and parts are self-similar. N. Katherine Hayles Chaos Bound. Orderly disorder in contemporary literature and science Ithaca: Cornell University Press, 1990, pp. 211-218

88 T.F.H. Allen and Thomas B. Starr Hierarchy. Perspectives for Ecological Complexity Chicago, The University of Chicago Press, 1982

89 Stephen S. Hall 'Ground truth: Landsat Maps and the Remote Sensing revolution' in: Stephen S. Hall Mapping the next millennium, the discovery of new geographies New York: Random House, 1992
} 
In the study of rivers, the Landsat images were used to monitor water turbidity and water quality parameters and to detect inundated areas, among others ${ }^{90}$. For the detailed mapping of river stretches black-and-white air-photos continued to provide the basic material for the time being, alongside field observations.

NASA launched Landsat-2 in 1975, and Landsat-3 in 1978, the latter producing multispectral images with a ground resolution of $30 \mathrm{~m}$. Another satellite launched in 1978 was the Seasat, which produced radar images of $25 \mathrm{~m}$ resolution using synthetic aperture radar (SAR) technology. A development at least as crucial for landscape research was the declassification of airborne remote sensing techniques parallel to the application of space-born remote sensing for civilian purposes. Around 1980, remote sensing techniques that could be operated from aircrafts ranged from gamma-ray, ultra-violet to infra-red, to radar spectrometry ${ }^{91}$.

In the eighties, satellite remote sensing further diversified with the launch of the Landsat Thematic Mapper (TM) in 1982, and the French competitor, Système Probatoire pour l'Observation de la Terre (SPOT) in 1986. The Landsat TM had a resolution of $30 \mathrm{~m}$, ranging from visible to thermal infra-red wavelengths, the SPOT a resolution of $20 \mathrm{~m}$, in visible to near infra-red. The high resolution meant that maps of scale 25.000, which had been based on air-photos, could now also be produced with satellite imagery. To allow for validation of maps produced by the Landsat TM, NASA commissioned the development of an airborne thematic mapper covering the same spectral bands as the Landsat TM92.

Thus, by the time Christopher Frissell introduced his spatial version of hierarchy theory for rivers, remote sensing imagery - both airborne and satellite - had come to cover a large spectrum of spatial scales. As noted above, spatial conceptions of ecosystems had been introduced by landscape ecologists, and were quickly gaining ground in the eighties.

In the mid-eighties, the use of satellite remote sensing imagery from Landsat MSS, TM and SPOT by river researchers was still in an experimental stage, but developments were considered promising. Digital image processing and integration of remote sensing data in Geographical Information Systems and dynamic models underwent rapid sophistication with the steep rise of computer capacity. By the early nineties, remote sensing imagery had come to be regarded an indispensable source of data for the study of rivers as spatial hierarchies. In reviewing the use of remote sensing imagery from Landsat MSS, TM and SPOT for river studies, Etienne Müller and colleagues from the Centre d'Ecologie des Ressources Renouvelables in Toulouse concluded that space-born remote sensing was a crucial source of data in providing the conception of rivers as spatial hierarchies with empirical content:

There is a need for ecological models that can link complex interactions at several scales (Frissell et al. 1986). One scale is probably not sufficient to explain, detect, and monitor a given process or resource, so it is important to collect at sufficient time intervals, synoptic quantitative data over entire river systems. Only space remote-sensing systems can currently provide such data or can provide areal extrapolation of in-situ samples ${ }^{93}$

\footnotetext{
90 Etienne Muller, Henri Décamps and Michael K. Dobson 'Contribution of space remote sensing to river studies' in: Freshwater Biology, 1993, 29, p. 302

91 Gerald K. Moore 'What is a picture worth? A history of remote sensing' in: Hydrological Sciences Bulletin $24,4,12,1979$

92 J.J. Haggerty Spinoff 1983, NASA Office of external relations, 1983, p. 122

93 E. Muller et al. 'Contribution of space remote sensing', p. 308
} 
The conception of rivers as spatial hierarchies which had emerged in a context of developing spatial technologies, notably remote sensing and geographical information systems, came to be articulated further through, and in interaction with, these same spatial technologies. By the late nineties, this had become a widely followed combination of concepts and instruments in river research. In reviewing the use of spatial technologies in river research, discussed during a European workshop in 1998, ecologist Rob Leuven and colleagues from various European universities noted that 'river scientists have now largely adopted a multiscale approach to river studies, from riverine habitat to landscape'94, and that '[c]urrently, almost all organisations involved in river management (e.g. river scientists, authorities, spatial planners and nature conservation groups) use remotely sensed and spatially analysed data.'95 During the nineties, remote sensing imagery had further diversified and had become more affordable. Laser altimetry from aircraft platforms was considered a promising technique, which could be used to measure the height of vegetation. The Compact Airborne Spectral Imager (CASI) had added hyperspectral imagery to the range of spectral bands, and the first commercial satellite IKONOS, launched in 1999, produced high resolution satellite imagery. Its panchromatic images had a resolution of 1 $\mathrm{m}$ and its multispectral images a resolution of $4 \mathrm{~m}$. In 2001, the commercial Quickbird satellite surpassed this level of detail again.

Within a decade, remote sensing imagery had shifted from an additional source of data into an indispensable source of data to study riverine landscapes. Contributors to the European workshop put it this way: 'actually, the use of remote sensing and geographical information systems is inevitable.' 96

\subsection{Institutionalising interdisciplinarity}

\section{From FISORS to ISRS}

After the First International Symposium on Regulated Streams, international meetings on regulated rivers were being held every three to four years. Worldwide, the building of dams was continuing at a somewhat lower pace during the eighties ${ }^{97}$. In the same period, the traditional engineering paradigm of river management started to crumble. The building of new dams often met with fierce resistance, while local authorities and conservationists started to experiment with stream restoration ${ }^{98}$. Besides ecological degradation, the impact of dam building on the livelihood of river valley inhabitants was gaining more widespread attention. An international social movement which protested against the building of large dams took shape from the mid-eighties

\footnotetext{
94 R.S.E.W Leuven, I. Poudevigne \& R.M. Teeuw 'Remote sensing and Geographic Information Systems as emerging tools for riverine habitat and landscape evaluation: from concepts to models' in: R.S.E.W. Leuven, I. Poudevigne \& R.M. Teeuw (eds.) Application of Geographic Information Systems and Remote Sensing in River Studies Leiden: Backhuys Publishers, 2002, p. 218

95 idem, p. 234

${ }^{96}$ A. Bourcier, I. Poudevigne, R.M. Teeuw 'The use of SPOT imagery as a tool for ecological analysis of river floodplains: a case study in the Seine valley', p. 64 in: R.S.E.W. Leuven et al. Application of Geographic Information Systems and Remote Sensing in River Studies Leiden: Backhuys Publishers, 2002

97 According to the NGO International Rivers there are now 40.000 large dams (higher than $15 \mathrm{~m}$ ) worldwide. From the 1950s until the mid-1970s, large dams were built at a rate of around 1000/year, the rate has declined to around $260 /$ year in the early 1990s. Source:

http://www.internationalrivers.org/en/node/570, accessed 1 August 2008

98 J.A. Gore (ed.) The restoration of streams and rivers. Theories and experience Butterworth: Ann Arbor, 1985; Stefan Kuks 'The Sustainability Performance of National Resource Regimes', p. 44 in: Ingrid KisslingNäf and Stefan Kuks The Evolution of National Water Regimes in Europe Dordrecht: Kluwer Academic Publishers, 2004
} 
onwards. In 1985, an International Dams Newsletter was established as a forum for the anti-dam movement, which became organised as the International Rivers Network in 198799.

As an object of academic study, regulated rivers brought together ecologists, earth scientists and engineers. While FISORS had been a meeting of freshwater ecologists predominantly, subsequent meetings received contributions from landscape ecologists, fluvial geomorphologists, hydrologists and hydraulic engineers as well. Like James Ward and Jack Stanford, there were scientists from other fields whose focus of research was river degradation caused by damming. Physical geographer Geoffrey Petts was one of them, and he soon joined Ward and Stanford's project. From the Second International Symposium on Regulated Streams (SISORS) onwards Petts appears to have made efforts to building an international interdisciplinary river science community. He had completed his PhD on the impact of dams on rivers at the University of Southhampton in 1978. Aged 26, he was appointed lecturer at the University of Loughborough, where he continued to study the impact of river regulation. His first book, Impounded rivers, published in 1984, gained widespread attention among ecologists, earth scientists and engineers who attended the regulated rivers meetings. In Europe, Petts had become aquainted with the PIREN-Rhône researchers, with whom he established a Large European Rivers Network in 1986. Within the framework of the European ERASMUS programme, river researchers from the University of Loughborough and the University of Lyon started to exchange ideas and practices. The Fluvial Hydrosystems concept which had been introduced by Claude Amoros became a common reference within the river research community of geomorphologists, hydrologists and ecologists of Loughborough and Lyon 100.

By 1986, at the Third International Symposium of Regulated Streams (TISORS), the time was considered ripe to launch a scientific journal on regulated rivers. The engineering approach to river management was giving way to integrated river management in many countries. According to Hugh Fish, chairman of the Natural Environment Research Council in the UK and guest editor of the first issue of Regulated Rivers. Research \& Management, the journal was to serve 'the need for effective science-based river management worldwide'101. As editor-in-chief of the journal, Petts was in a good position to continue his project of building an international, interdisciplinary community dedicated to ecologically sound river management. During the late eighties and early nineties, he co-edited volumes on river science and management with aquatic ecologists from the US, UK and France. Petts aimed at addressing both river management practitioners and scientists, the mixed audience which Regulated Rivers also targeted. Alternatives in regulated river management reviewed experiences with small scale river restoration, which had become a widespread practice by the late eighties. Fluvial Hydrosystems, which had first appeared in French, compiled the work done by the community of river researchers from the Universities of Loughborough and Lyon. The Rivers Handbook, consisting of three edited volumes, served to provide a state of the art overview to guide both river scientists and managers.

During the nineties river management practices, including river restoration, continued to meet opposition. Also, the notion of integration had been approached from a predominantly natural scientific perspective, which was no longer regarded tenable. River researchers came to consider social scientific contributions as indispensable to interdisciplinary river science and management. In a programmatic statement made by river researchers from the US, Australia and South Africa in

99 Patrick McCully Silenced rivers: the ecology and politics of large dams London: Zed, 1996, p. 281 and p. 306-307

100 G.E. Petts, H. Moller and A.L. Roux (eds.) Historical change of large alluvial rivers: Western Europe Chichester: John Wiley, 1989

101 Hugh Fish 'Guest editorial' in: Regulated Rivers vol. 1, 1, 1987 
2003, social scientific perspectives were presented as part of a 'new paradigm', which is to 'forge partnerships between scientists and other stakeholders'. The paradigm entailed integration between the fields that have predominantly made up interdisciplinary river science since the early eighties and social scientific perspectives:

Not only must biologists of various subdisciplines interact with physical scientists such as hydrologists and geomorphologists, but social science knowledge about human values, perceptions, behaviors, and institutional culture also need to be integrated into the science that guides river management ... With such integration, science can better inform the decision-making process, despite the complexity of coupled human-natural systems. ${ }^{102}$

Inclusion of social science has also been advocated by the International Society for River Science (ISRS) as presented by its founders (see the quote in chapter 1), yet seems an add-on after integration of ecological, earth scientific and engineering practices ${ }^{103}$. In fact, the integration of ecological, earth scientific and engineering practices is already seen as a challenge. In the summary statement of an international workshop on river basin management organised in 2003 and sponsored by the US Army Corps of Engineers it was noted that integration of these natural scientific approaches has proven difficult104. It is suggested that integration of ecological and earth scientific approaches with engineering ones has been hindered by 'conflicting traditions'. The two traditions distinguished are synthetic and engineering:

\begin{abstract}
In the synthetic approach, scientists have attempted to understand the ecology of rivers at a holistic level and to describe how important riverine processes vary over time and space. ... In the engineering approach, researchers have tried to develop suites of tools that could be used to predict river stage, velocity fields, and bedform as a function of discharge, and to predict velocity and shear stress at multiple points within the river channel. ${ }^{105}$
\end{abstract}

The synthetic and engineering traditions are then evaluated with respect to their usefulness in river basin management. The synthetic approach is judged insufficiently quantitative for river management but can provide guidelines for river restoration. The engineering approach which works with governing equations and grids is considered useful for simulating water flow and water quality but does not work well for biological processes like habitat selection. To be useful for river basin management, quantification is apparently considered to be a basic requirement. To reconcile the different traditions 'the development of approaches that will allow the tools of synthesists and engineers to be coupled together' is suggested. This 'coupling' is a coupling of models which fits the conception of the river as a spatially nested hierarchy: 'the approaches

\footnotetext{
102 N. LeRoy Poff, J. David Allan, Margaret A. Palmer, David D. Hart, Brian D. Richter, Angela H. Arthington, Kevin H. Rogers, Judy L. Meyer, and Jack A. Stanford 'River flows and water wars: emerging science for environmental decision making' in: Front. Ecol. Environ. 1, 6, 2003, pp. 298-306

103 This seems a widely held perspective in interdisciplinary river science. See for example a plea for inclusion of landscape design and cultural anthropology in 'research at the interface of social science and the disciplines of hydrology, geomorphology, ecology, and engineering' that comes with the statement that 'hydroecology will be the central science'. Margaret A. Palmer and Emily S. Bernhardt 'Hydroecology and river restoration: ripe for research and synthesis' in: Water Resources Research, vol. 42, 2006, pp. W03S07

104 Geoff Petts and Robert Kennedy (eds.) Emerging Concepts for Integrating Human and Environmental Water Needs in River Basin Management, US Army Corps of Engineers. Engineer Research and Development Center, September 2005, p. 86 105 idem, p. 85
} 
used by synthesists and engineers must be coupled to simulate the hierarchy of scales typical of systems such as large rivers'. ${ }^{106}$

Interdisciplinarity as modular integration

The last quote about 'coupling' suggesting how various river research practices are to be integrated is illustrative of a broader discourse on interdisciplinary cooperation as it emerged in recent years. Coupling has become part of a modular approach to interdisciplinarity that has come to dominate the sciences that study the earth as a system ${ }^{107}$.

The modular approach is visible in claims about the emergence of new interdisciplinary fields and approaches (itself a widespread strategy in the competition for attention from peers, funders and other audiences): ecohydraulics ${ }^{108}$, eco-hydrology or hydro-ecology ${ }^{109}$, biogeomorphology110, ecohydromorphology ${ }^{111}$ and fluvial landscape ecology ${ }^{112}$ are among the names of fields or approaches that are, according to its advocates, emerging from ecology, geomorphology, hydrology and hydraulics. To characterise a newly emerging field as it relates to constituent fields, the term 'interface' has gained wide currency. Thus, hydrology and ecology are viewed as having an interface:

The terms 'hydroecology' and 'ecohydrology' (including the subdiscipline of ecohydraulics) both imply research at the interface between the hydrological and biological (ecological) sciences ${ }^{113}$

The same counts for ecology and geomorphology:

... there is no real agreement over what makes a biogeomorphological study apart from some focus on the interface between ecology and geomorphology 114

The terms 'coupling' and 'interface' are a first indication of a discourse on interdisciplinarity as modular integration. Separate fields are then viewed as self-contained modules within a larger whole. A more substantive indication is how in recent years river scientists have proposed ways of doing interdisciplinary river science that are adjusted to the widely embraced conception of rivers

\footnotetext{
106 idem. p. 87

107 Amy Dahan speaks of a 'science of couplings' in her analysis of climate change models. Amy Dahan 'Models, anti-reductionnism and complexity in Climate Change' in: P. Cerrai (ed.) The Science of Complexity: Chimera or Reality, Proceedings of Arcidosso International Workshop September 2003, Esculapio Editions, coll. Miriam p. 115-131

108 e.g. Klaus Jorde 'River restoration - Potential, Constraints, and the Role of Ecohydraulics', in Proc. $4^{\text {th }}$ Ecohydraulics Conference, March 4-8, 2002, Cape Town, South Africa

109 e.g. Zbigniew W. Kundzewicz 'Special Section on Ecohydrology-Editorial' in: Hydrological Sciences, 47, 5, 2002, pp. 797-798, David M. Hannah, Paul J. Wood and Jonathan P. Sadler 'Ecohydrology and hydroecology: a 'new paradigm'?' in: Hydrological Processes, 18, 2004, pp. 3439-3445

110 e.g. L.A. Naylor, H.A. Viles, N.E.A Carter 'Biogeomorphology revisited: looking towards the future' in: Geomorphology 47, 2002, pp. 3-14

111 e.g. Stewart J. Clarke, Lydia Bruce-Burgess and Geraldene Wharton 'Linking form and function: towards an eco-hydromorphic approach to sustainable river restoration' in: Aquatic Conserv: Mar. Freshw. Ecosyst. 13, 2003, pp. 439-450

112 e.g. Geoffrey C. Poole 'Fluvial landscape ecology: addressing uniqueness within the river discontinuum' in: Freshwater Biology, 47, 2002, pp. 641-660

113 David M. Hannah, Paul J. Wood and Jonathan P. Sadler 'Ecohydrology and hydroecology: A 'new paradigm'?' in: Hydrological Processes 18, 2004, p. 3439

114 L.A. Naylor, H.A. Viles, N.E.A. Carter 'Biogeomorphology revisited: looking towards the future' in: Geomorphology 47, 2002, p. 4
} 
as spatially nested hierarchies. I will discuss three such proposals to show how these adjustments are part of a discourse on modular integration.

Martin Thoms and Melissa Parsons from the University of Canberra in Australia have proposed to study rivers by combining river ecology, hydrology and fluvial geomorphology into "ecogeomorphology'115. They conceptualise eco-geomorphology as a systemic integration of the three specialties which takes into account the different scales and hierarchies distinguished by practitioners. The conception of the river as a spatially nested hierarchy provides a common ground:

Hierarchy is the common thread running through hydrology, fluvial geomorphology and freshwater ecology and is therefore a fundamental tenet of eco-geomorphology ${ }^{116}$.

To match the different hierarchies distinguished within the three specialties, it is suggested that they fit the same spatial levels of scale and spatial units distinguished within the river hierarchy. Thus, integration between elements and levels results, one specialty specific process influencing another as a conditioning factor, on the same and on a lower level of scale (see figure 4).

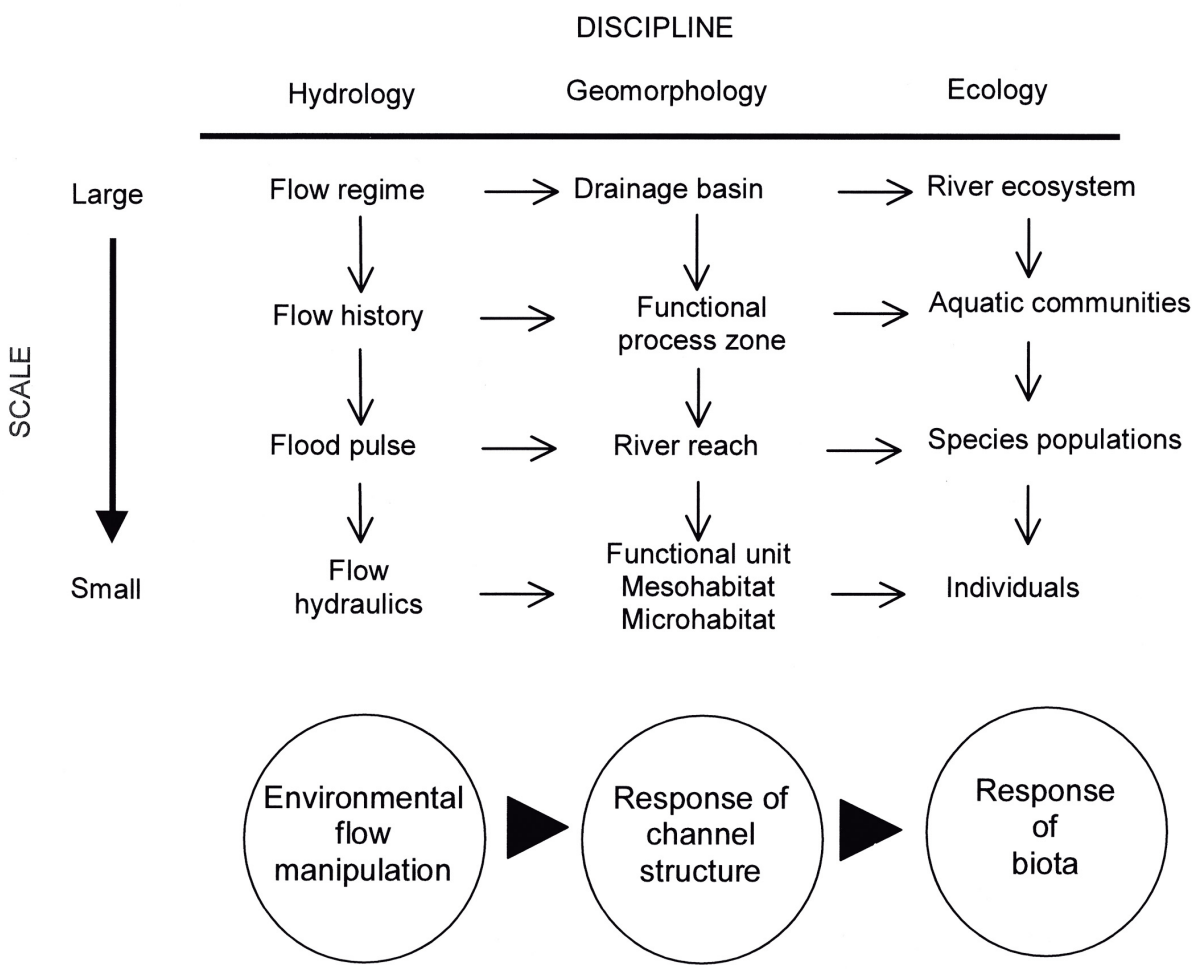

Fig. 4 The matching of hydrological, geomorphological and ecological river hierarchies in: Martin C. Thoms \& Melissa Parsons ‘Eco-geomorphology: an interdisciplinary approach to river science' p. 117

Another approach to interdisciplinary river science that equally takes a hierarchical conception of rivers as a point of departure for assigning tasks to specialties has been proposed by Geoffrey

115 Martin C. Thoms \& Melissa Parsons 'Eco-geomorphology: an interdisciplinary approach to river science' in: Fiona J. Dyer, Martin C. Thoms \& John M. Olley (eds.) The Structure, Function and Management Implications of Fluvial Sedimentary Systems IAHS Publication no. 276, Wallingford, IAHS Press, 2002, pp. 113-119

116 idem, p. 115 
Poole from the University of Georgia in the US ${ }^{117}$. Poole promotes 'fluvial landscape ecology' as a field that integrates hydrology, fluvial geomorphology and stream ecology. In line with recent accommodations of hierarchy theory to landscape ecological notions, he calls the spatially nested units of the river hierarchy 'patches':

Along with the application of landscape ecology principles to fluvial ecosystems has come a widely held view of fluvial landscapes as multiscaled nested hierarchies of interactive terrestrial and aquatic elements (Frissell et al. 1986, Townsend 1996), where elements are defined as the basic, relatively homogeneous units (patches) observable within a landscape at a given spatial scale ${ }^{118}$.

Poole then suggests that processes in a river hierarchy work both bottom-up, giving structure to a patch, and top-down, as context for patches. The river hierarchy as a whole is viewed as a multilevel system with feedback loops across the spatial scales. In this systems architecture, specialties are associated with sets of problems, relating to processes or structural features at a variety of scales in the river hierarchy (see fig. 5).

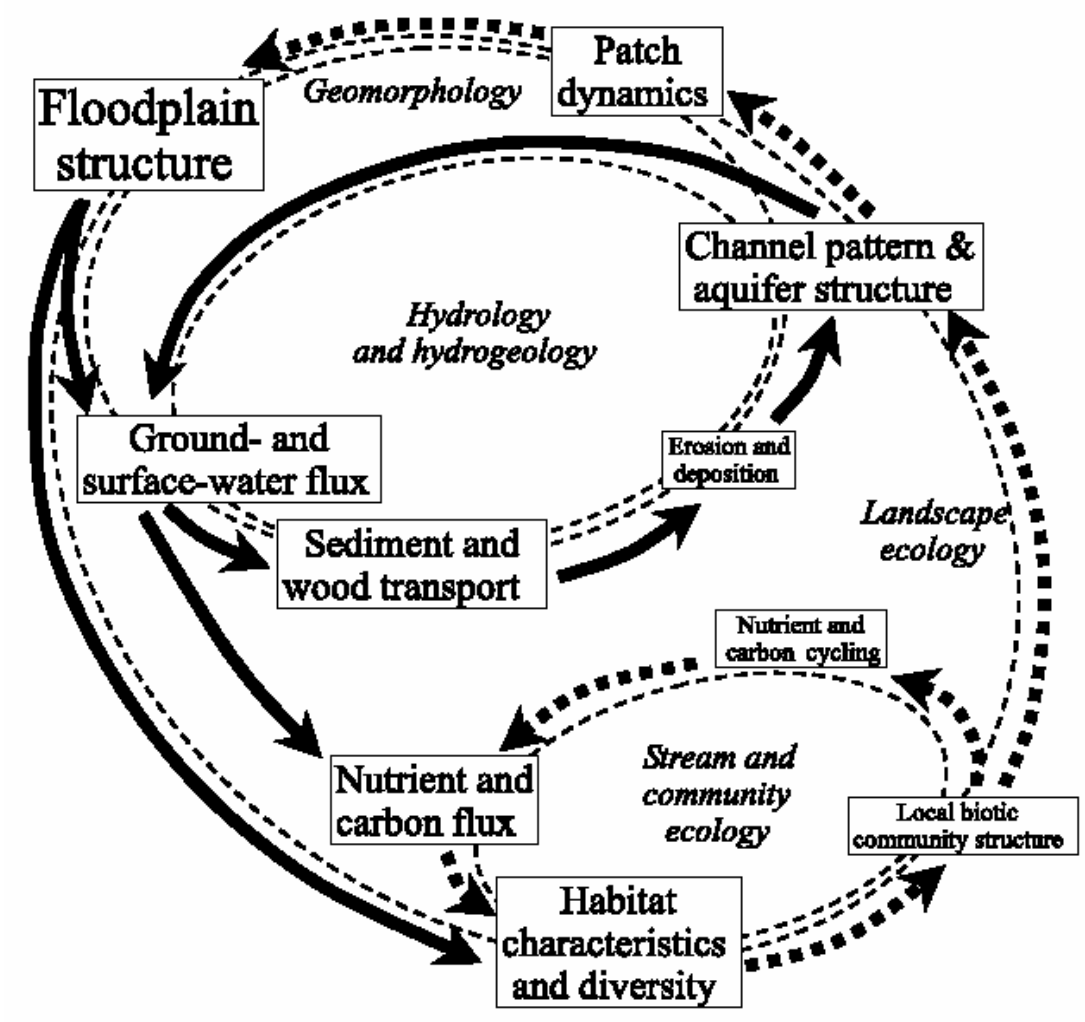

iology, 47, 641- 660

Fig 5 River science specialties related to river processes and structures at various scales in: Geoffrey C. Poole 'Fluvial landscape ecology' p. 645

A team of river researchers from the University of the Witwatersrand in South Africa and the University of Canberra in Australia have extended Thoms and Parsons' earlier proposal for a

\footnotetext{
117 Geoffrey C. Poole ‘Fluvial landscape ecology: addressing uniqueness within the river discontinuum' in: Freshwater Biology, 47, 2002, pp. 641-660

118 idem, p. 642
} 
conceptual framework for interdisciplinary river science ${ }^{119}$. They suggest that interdisciplinary river science cannot do without such conceptual frameworks:

\begin{abstract}
Successful interdisciplinary science requires that the separate disciplines gain a common understanding of the nature of the problem at hand, identify the scales of relevant subsystem components, the underlying processes or phenomena, and the important variables involved. Successful interdisciplinary science requires joining of many areas of understanding into a single conceptual-empirical structure (Pickett et al. 1994) ${ }^{120}$.
\end{abstract}

Like in the earlier proposal, the different hierarchies distinguished within the specialties of geomorphology, hydrology and ecology are a starting point, and process interactions connect the hierarchies. More explicitly than in the earlier proposal, a systems architecture is suggested. The different specialty domains are represented as subsystems at each level of the hierarchy. The subsystems are connected in a flow-chain model in which a process changes a material subsystem, which in turn leads to a biological response. For example, sediment may be moved by water which results in a change of the physical habitat to which plants or animals respond.

The above discussion of proposals of how to do interdisciplinary river science suggests that a discourse on modular integration is at work, which in recent years has brought with it an apparent adjustment between divisions of labour between specialties and the predominant conception of the river as a spatially nested hierarchy 121 .

\title{
3.6 Conclusions
}

While the emergence of interdisciplinary river science as a cosmopolitan field can be attributed to creative and strategic efforts of ecologists, geomorphologists and hydrologists striving for an ecologically sound alternative to the engineering paradigm of river management, river science has evolved in ways beyond the aims and intentional strategies of these actors. Their efforts materialised in a context of rapidly developing information technologies, diversifying remote sensing imagery and the widespread adoption of complexity thinking. Technologies are playing an important role in how interdisciplinary river science institutionalises. The coupling of specialty modules to build integrated models that simulate riverine processes is an information technological practice, remote sensing is regarded an indispensable source of data and the discourse on modularity bears strong information technological connotations ${ }^{122}$.

What can be concluded about the various mutual adjustments at work between conceptual, instrumentational and institutional dimensions of river science? It appeared that the River Continuum Concept, which took the river catchment as its unit of analysis was a last attempt at unifying river ecology and geomorphology through a shared deductive theory. The rise of complexity thinking, notably hierarchy theory, in a context of diversifying remote sensing imagery

119 E.S.J. Dollar, C.S. James, K.S. Rogers and M.C. Thoms 'A framework for interdisciplinary understanding of rivers as ecosystems' in: Geomorphology 89/1-2, 2007, pp. 147-162

120 idem, p. 147

121 I suggest that the discourse on modularity is a Foucauldian discourse, which actors do not use intentionally, but which works as a 'condition of possibility' for the emergence of subjects and objects. 122 In Donna Haraway's 'Cyborg Manifesto', ‘modular construction' appears in opposition to 'functional specialization' in a two-column list of terms indicating transformations. The transformations are indicative of an 'informatics of domination', a diagnosis of restructuring power relations in post-industrial society as conditioned by science and technology. Donna Haraway Simians, Cyborgs and Women: The Reinvention of Nature New York, Routledge, 1991, pp. 149-181 
then made river researchers adopt a conception of the river as a spatially nested hierarchy. Mutual adjustment is apparent between the adoption of remote sensing imagery of various resolutions, as instrumentation, and the articulation of a view of rivers as spatially nested hierarchies, as concept. In parallel to the widespread adoption of a hierarchical conception of rivers and the use of remote sensing imagery as a main source of data, river researchers have begun to reflect more explicitly on how to realise interdisciplinarity, how to assign tasks to specialties and combine these. Here, an adjustment of divisions of labour between specialties, an institutional dimension of river science, to the hierarchical conception of rivers is apparent. These subsequent sorts of adjustments have been at work in a period in which information technology, notably simulation modelling, has come to be taken for granted as a basic constituent of the practicing of river science.

I conclude that the mutual adjustments between conceptual, instrumentational and institutional dimensions of river science are part of a particular discourse, which I call a discourse on modularity. The emergence of this discourse is to be understood in the context of information technologies and systems thinking. Systems thinking has been associated with a view of nature as machine-like ${ }^{123}$. Modular integration is associated with systems thinking, and returns explicitly in the machine emblematic of the information age, the computer. This is not to say that modular river science resembles the architecture of a computer. It is to point out that the discourse on modularity is pervasive, while the particular form it takes differs in different domains.

${ }^{123}$ Chunglin Kwa has analysed how the metaphor of nature as a cybernetic, self-regulating machine has mediated between ecology and science policy at the time of the International Biological Programme, in the 1960s. Chunglin Kwa 'Representations of Nature Mediating between Ecology and Science Policy: the Case of the International Biological Programme' in: Social Studies of Science 17, 1987, pp. 413-442 


\section{Chapter 4 Dutch science policies and evolving river science specialties}

The emergence of interdisciplinary river science as a cosmopolitan field has been brought about by the sharing of concerns, ideas, concepts, instruments, techniques, data etc. that are part of river research configurations in particular localised settings. In the localised settings, national science policies are among the relevant contexts shaping research practices and configurations. The national level is also a level at which scientific communities organize, partly in response to science policies. In this chapter, I will investigate the role of national science policies in the shaping of institutional, conceptual and instrumentational dimensions of specialties that contribute to interdisciplinary river research in the Netherlands. I will first give an impression of how group leaders whose research groups are oriented to landscape ecology, freshwater ecology, geomorphology, hydrology or hydraulics have responded to requirements and opportunities for inter-institutional and interdisciplinary research cooperation. I call the strategies that research groups adopt vis-à-vis these requirements and opportunities 'institutional survival strategies'. The responses of group leaders provide some clues as to how conceptual and instrumentational approaches, which I call 'search strategies', and institutional survival strategies go together. This leads me to study in more detail relations between national science policies on the one hand and conceptual, instrumentational and institutional strategies adopted within the five specialties on the other. The conclusion discusses ways in which national science policies, by inducing institutional change, seem to have contributed to the widespread adoption of specific search strategies.

\subsection{Inter-institutional and interdisciplinary research cooperation: group leaders' strategies}

As a full professor of environmental sciences at the University of Nijmegen, Piet Nienhuis has been head of the department of Environmental Studies, established in 1991, until his retirement in 2003. Nienhuis had been appointed extraordinary professor of estuarine ecology at the University of Nijmegen in 1988 after having been involved, since 1965, in ecosystem research and monitoring the ecological impact of the Delta Works at the Delta Institute for Freshwater Research (DIHO). When appointed professor of environmental sciences in 1993, Nienhuis saw it as his mission to provide the environmental research group, which had been concentrating on educational tasks, with a clear research focus ${ }^{124}$. By 1995, the group had formulated a research programme with 'river science' as its denominator, which revolved around integrating a variety of lines of environmental research on river basins. ${ }^{125}$ When asked about his strategies, Nienhuis presents a more or less coherent repertoire which he considers basic to the survival of his research group. He puts particular emphasis on research assessments as a primary focus of attention, which may provide guidance in undertaking particular activities. Embarking on interinstitutional research cooperation answers requirements in this context:

The reason why we are participating in the Centre for Wetland Research (CWE) - I've been saying from the beginning that even if we are environmental scientists and we are interested in sustainable development - we shouldn't neglect the link with fundamental ecology. That's where you earn your credits, the fundamentalists so to speak. That's where you earn your

\footnotetext{
124 Interview, Piet Nienhuis, 28 April 2003

125 P.H. Nienhuis ‘Rivierkunde 1995-2000. Onderzoek vakgroep Milieukunde KUN' Verslagen Milieukunde nr. 100, 1995
} 
credits for research quality assessments and the like. Those are the hinges around which organising research revolves ${ }^{126}$.

Nienhuis reasons that research assessments require his group to link up with what he considers to be fundamental ecological research. Yet, embarking on cooperation with research groups oriented to other disciplines appears to be of strategic importance as well. To acquire funding from the Land-Ocean Interactions in the Coastal Zone (LOICZ) programme, which is part of the International Geosphere-Biosphere Programme (IGBP) managed by the national research council NWO, ecologists have to cooperate with earth scientists:

LOICZ is an interactive programme. If an ecologist submits an application, he doesn't score. We have submitted a proposal jointly with Utrecht University, that means geomorphology and ecology. That has been accepted. ... The interaction between bèta disciplines, with a gamma sauce, added - since ultimately it is about sustainable river management, whatever that may be - leads to innovative questions that appeal to the programme committee, which get lifted out, get a score good or excellent ... That's what is being granted funding.

To be successful in obtaining funding in integrated programmes, however, ecologists shouldn't invest too much in cross-disciplinary research cooperation, and stay close to ecology's agenda:

It's still the case that our policy in submitting proposals in an integrated programme is to score foremost with an eye on the discipline.

Besides the importance of resolving the tension between staying close to disciplinary agendas and embarking on interdisciplinary research cooperation, Nienhuis' strategies have an eye on scaling up institutionally. The group participates in a number of inter-institutional research centres and schools, and actively pursues inter-institutional research cooperation to get access to specific sources of funding. European funding, the national ICES-KIS scheme, and NWO research programme funding all require inter-institutional research cooperation. For Nienhuis, staying close to disciplinary agendas while embarking on inter-institutional, interdisciplinary research does require investing energy in, but ultimately pays:

[The Darwin center] is another attempt at tying together various fields. These boundary areas between fields, ... physics, chemistry, geology, physical geography, ecology, that's where research questions are, really. That doesn't mean you've seen enough of the profundity of your own field - disciplinary knowledge remains important - but if you want to make progress in understanding systems, ecosystems, you need these kinds of links. And that's trendy. ... We won't be housing a new centre. This initiative is brought in under the flag of the CWE. [MvH: so there's no tension about which centres to join and which ones not to join?] No, because there's extra money involved here as well. That remains. There always remains, I don't mind to admit, a certain opportunism, more than pragmatism, in the choices you make.

Gerard van der Velde leads the section of Aquatic Animal Ecology, that is part of the department of Ecology at the University of Nijmegen as an associate professor. He joined the aquatic ecology group in Nijmegen in 1974. In 1980, he completed his PhD on riverine lake ecosystems and stayed with the aquatic ecology group to do research on riverine, estuarine, coastal and marine

126 Interview, Piet Nienhuis, 28 April 2003. Interviews were held in Dutch, translations of quotes are my own. 
ecology. Van der Velde has affiliations with the Free University of Brussels, as a visiting professor in marine ecology, and the Natural History Museum Naturalis at Leiden, as a guest collaborator. While having been trained as a biologist and a geologist and being affiliated with several institutes, Van der Velde comes up with a rather critical assessment of interdisciplinary and interinstitutional research cooperation. In his view, interdisciplinary research cooperation requires a mutual interest each other's object of research. Yet, he finds that earth scientists often show a lack of interest in biological organisms and tend to focus exclusively on the abiotic environment. Attempts at sustained cooperation falter:

We view the abiotic environment as something an organism has to count with, or in which it functions. Vice versa, I don't have the impression that sedimentologists care about, say, the mud shrimp, they don't even notice it's there. It may be difficult to quantify. That means that we don't continue. I find it difficult to talk with people who are not interested in biology. ${ }^{127}$

As doing interdisciplinary research provides access to important sources of funding, this presents Van der Velde with a problem. In his view, research on the ecology of aquatic organisms tends to suffer from the current emphasis on interdisciplinary, inter-institutional research cooperation. Within his own field, that of aquatic ecology, Van der Velde finds that there is a tendency towards generalizing from case studies, which he doesn't agree with. He is explicit about the fact that he finds inter-institutional centres and programmes not at all conducive to his research. One of the main problems is that only certain approaches benefit from interdisciplinary, inter-institutional research cooperation to the detriment of less trendy ones:

[Research centres] are a typical Dutch solution I would say. Just make a very large cluster, and almost everything that is unique will be attached as an appendix. ... They rather hinder, they don't yield anything for me. ... That's just one of the problems, the flexibility of research. ... There have been research programmes, IRMA-SPONGE and all that, that's regular research, it concerns what may be modelled. But if you really want to follow what's there in the river, you will have to be there, a model won't do. So it is conducive to some research, but not to mine. I actually try to avoid getting involved in all these organisations. Officially I'm part of it, but if I would work that way, I would not produce anymore.

Hans Middelkoop leads the fluvial research group at the department of Physical Geography, University of Utrecht as an associate professor. He studied physical geography at the same university and completed his $\mathrm{PhD}$ on sedimentation rates in the floodplains of the Rhine river in 1997 within the scheme of the National Research Programme on Climate Change. After having been affiliated to Rijkswaterstaat's freshwater research institute RIZA to study hydrological impacts of climate change, Middelkoop returned to the University of Utrecht. Reconciling the need to stay close to disciplinary agendas while participating in interdisciplinary programmes for Middelkoop is a matter of combining disciplinary parts in an interdisciplinary whole:

We are involved in a LOICZ project, together with the University of Nijmegen. We look at vegetation and roughness: vegetation in the floodplain, which we measure by using laseraltimetry, what does this mean for water flow patterns? Then there is a PhD student who looks at sedimentation, including accumulation of heavy metals, and there is a PhD student at the University of Nijmegen who looks at the impact of heavy metals on ecosystems, food

127 Interview, Gerard van der Velde, 30 May 2005. 
webs. So that's one project. The PhD students work on their specialist theme, but the project as a whole is much more interdisciplinary. ... There will be a post-doc too, in the LOICZ project. It's the post-doc who finally has to tie things together and say something about the whole riverine region. ${ }^{128}$

Concerning the pressure to scale up institutionally, Middelkoop emphasizes that scientists who agree on participating in an inter-institutional centre are in no way forced to cooperate or to adjust their research. Cooperation rather results from identifying mutual interests, the aggregation of which may be stimulated in inter-institutional centres, sometimes with an eye to specific sources of funding:

I am a member of NCR too ... and there's a programme committee - which doesn't programme. The committee indeed shouldn't enforce a programme from above, that won't work. ... The only thing you can do is, of course, when people have ideas, if they may benefit from one another, is to say: go sit together to exchange information. That's what NCR and ICG are both very good for. And what NCR is good for too is to announce that there will be a large European programme, and organising NCR's members participation in it. Now, that's a way of programming too, creating opportunities to join something larger which you can't join as a single group. ICG doesn't do that. Its members inform each other about what they are doing, and if that leads to interesting things, one profits from it of course.

Between 1999 and 2005, Peter Troch has been leading the Hydrology and Quantitative Water Management Group at the University of Wageningen as a full professor. Troch completed his PhD on the modelling of river catchment runoff at the University of Ghent in 1993. He then led a European research project on determining soil moisture content using satellite images and continued doing research on the use of remote sensing in hydrology. When Troch came to the Netherlands to lead the hydrology group at the University of Wageningen, hydrologists considered their field to be in a rather marginal position among the earth sciences. A national research school had faltered, hydrology was considered to be institutionally fragmented. It also suffered from a low status, answering the needs of other fields rather than operating as a fully-fledged scientific field itself. In Troch's view, inter-institutional cooperation and enhancing hydrology's status and visibility go together. The Boussinesq centre, established with the aim of realizing a national level hydrology research programme as formulated in a foresight exercise by the Royal Academy of Science combines these aims. In Troch's view, there is also no contradiction in enhancing hydrology's status and interdisciplinary research cooperation, as long as hydrology has primacy in interdisciplinary research:

We put hydrology center stage, not all sorts of derived products. For the first time, I believe, in the history of Dutch science, hydrology will be central. We let our curiosity of how a catchment works guide our research. And biology, mathematics, meteorology, physics and all the other disciplines which have their place in Dutch research policy, will be supportive ${ }^{129}$.

Inter-institutional cooperation is to enhance the quality of hydrological research, with the research programme as a guiding framework:

128 Interview, Hans Middelkoop, 17 May 2005.

129 Interview, Peter Troch, 24 May 2005 
We have a research programme that we agree on, formulated in the foresight report, which we will concretize by gathering in a virtual centre and by labelling a number of PhD students as Boussinesq PhDs. That means these PhD students will do research that is relevant for the themes identified in the foresight report, and will try to enhance their individual research by getting together. What is more, by facilitating access to labs, by making available data bases and models, so that PhD students don't have to invent the wheel. And that, I believe, will lead to better quality, enhanced visibility and, may be, ultimately, NWO funding.

Since 1997, Huib de Vriend has been leading the River Morphology and Engineering group at the University of Delft as a part-time professor. De Vriend had been affiliated to Delft Hydraulics and the University of Delft, where he studied civil engineering and completed his PhD in 1981. In 1993 he moved to the University of Twente to teach civil engineering and management and to lead research on integrated systems and modelling. In 2002, De Vriend became director of Delft Hydraulics, one of the five so-called Large Technological Institutes in the Netherlands, which operates as an independent research and consultancy institute with the Dutch water sector as an important client. The research programme of his group at the University of Delft is a mixture of hydraulic engineering and geoscience and involves collaboration with ecologists. De Vriend considers interdisciplinary research 'the way to go, since the market increasingly demands it'. At the same time, he finds that opportunities for doing interdisciplinary research are still few. In his experience, committees within the national research council NWO responsible for selecting grant applications tend to assess these on the basis of disciplinary criteria. Funding schemes without peer review selection procedures are more amenable for starting interdisciplinary research lines. The group's efforts in biogeomorphology build on $\mathrm{PhD}$ research funded within the ICES-KIS scheme among other sources of funding. In the biogeomorphology research line, there is coupling of specialty models, which are considered 'tools'. As De Vriend puts it:

We don't ask ecologists: how did you do that?, and they don't ask us. When I'm doing biogeomorphology with this PhD student - he's from the University of Wageningen so he's close to ecology - we use a vegetation development model. We don't elaborate lateral methodological linkages, we borrow tools from ecologists and they borrow from us. ${ }^{130}$

I don't know how ecologists work. For us mechanics is at the top of the ladder. Hydraulic engineers tend to frown when you start talking about entropy.

This coupling of models without probing into the theories and methods of ecologists isn't necessarily De Vriend's preferred way of doing interdisciplinarity. It's rather that somehow interdisciplinary research tends to proceed by building specialty specific models and integrating the result:

We started bringing together biologists and geomorphologists [in Delft Cluster I]. I said that we should invest time to learn to talk together. We haven't succeeded in finding a form for it, so we have just done our projects - that means defining work, doing the work 'at home', and bringing it together. It is still making do, developing a shared language. But [DC I] did lead to interesting new projects. So we do get closer, but at a very slow pace. And, to be honest, we're still at the stage of surprise. Especially with ecologists.

130 Interview, Huib de Vriend, 4 May 2005 
De Vriend considers inter-institutional research centres and programmes combining different disciplines conducive to answering the societal/market demand for interdisciplinary research and is well aware of policy arrangements and incentives to establish such centres and programmes. Having been involved in both the establishment of the Netherlands Centre for Coastal Research in 1992 and the Netherlands Centre for River Studies in 1998, he finds it a deception that neither of the centres has been granted some form of recognition and funding from NWO or the Royal Academy of Sciences. In 2000, the existing Research School for Hydraulic and Geo-technical Engineering had been discontinued as NCK and NCR functioned as platforms for exchange and $\mathrm{PhD}$ education, covering the major part of hydraulic research in the Netherlands. An effort to have biogeomorphology included in the Darwin Center for Biogeology faltered. On the other hand, De Vriend's research groups at Delft University and Delft Hydraulics do profit from funds at the European and national level which require inter-institutional cooperation in research programmes, by embarking on such cooperation with the Netherlands Institute for Ecological Research (NIOO) and the nature management research institute Alterra among others. Being responsible for $R \& D$ in a commercially operating lab, De Vriend foregrounds 'market demand' as a source of pressure for interdisciplinary research, rather than science policies:

One observes that the demand is towards interdisciplinarity. You have to link up with this trend. If you don't do this within your own institute, you will have to do it by creating alliances with other institutes. In that case you have to enter the market together. And you have to do research together, because if you want to sell that kind of products in the market, you will have to develop them.

What do the above responses of group leaders tell us about their institutional survival strategies as induced by science policies and the way these relate to the search strategies they employ? Firstly, there are striking differences. The five group leaders that I interviewed operate in different contexts. Besides being oriented to different fields, their audiences vary between predominantly academic and governmental, their own position and the positioning of their groups within the university differs and the universities themselves provide different organizational contexts. The group leaders are also in different phases of their career, have taken different career paths and have developed a personal outlook and style. Yet, there are also commonalities and patterns when it comes to dealing with opportunities and requirements for doing inter-institutional and interdisciplinary research. It appears that all of the group leaders find that participating in interinstitutional and interdisciplinary research arrangements is a necessary requirement to get access to research funding. Embarking on interdisciplinary, inter-institutional research cooperation may thus be called an institutional survival strategy - and a practically obligatory one at that. It also turns out that inter-institutional and interdisciplinary research arrangements favour some search strategies over others. Interdisciplinary research cooperation involves accommodating research lines that are considered promising within the context of a particular field, with those of other fields. It appears that at present the most viable way to do this is to integrate field specific models without probing into the content of the models that are not in one's own field.

The above assessment of group leaders' responses to requirements and opportunities for inter-institutional and interdisciplinary research cooperation raises questions about structural impacts of science policies. A structural effect of policies which make scientists favour certain search strategies over others as these fit emerging institutional configurations, may be that the favoured search strategies become widely adopted. Of course, other contexts may be relevant for 
the shaping of these search strategies as well. The influence may also go in the other direction: institutional configurations may also be molded to accommodate search strategies that are considered promising.

To further investigate relationships between science policies concerning inter-institutional and interdisciplinary cooperation on the one hand and the adoption of specific search strategies on the other, I will first sketch how inter-institutional and interdisciplinary cooperation has been advocated in national science policies between roughly 1980 and 2005. Next, I will provide sketches of developments in five specialties, as they organized at the national level during the same period.

\subsection{Dutch science policies}

Science policy analysts have identified the early eighties as a period of transition to a new science policy regime, in which attempts to coordinate science intensified and in which science came to be closely associated with innovation ${ }^{131}$. The Netherlands were no exception in this regard. The late seventies were a period of economic recession, and the belief that society and the economy would automatically benefit from science if scientists were provided with adequate resources had eroded132. The Science Policy Memorandum of 1975 marked the onset of explicit attempts at steering through coordinated policy making. ${ }^{133}$ In 1979, the Ministry of Education and Sciences came with an Innovation Policy memorandum. Within a few years, science and technology came to be seen as an integrated policy domain with fast emerging technologies like micro-electronics, information technology and biotechnology deserving special attention ${ }^{134}$.

A central notion in the science policy discourse of the early to mid-eighties was that of efficiency ${ }^{135}$. The Science Budget of 1979 had drawn attention to the importance of good research management and the benefits of 'management information systems'. ${ }^{136}$ The general outlook was that within science, money was to be spent more efficiently. Besides more explicit coordination through 'management', enhancing efficiency required coordination of research efforts within disciplines, at the national level. An efficient research system was to be realised by concentrating research efforts and decreasing fragmentation, which required enhanced cooperation between individual researchers and research groups and a clearer division of tasks at the level of disciplines ${ }^{137}$. From the early eighties onwards, the Ministry of Education and Sciences confronted universities and research institutes with policy directives geared to enhance efficiency along these lines. At the universities the so-called 'Operation Division of Tasks and

\footnotetext{
131 David Guston gives an overview of periods as distinguished by science policy analysts. David Guston Between Politics and Science: assuring the integrity and productivity of research Cambridge: Cambridge University Press, 2000 p. 141

132 Stuart Blume 'The development of Dutch science policy in international perspective 1965-1985. A report to the Raad van Advies voor het Wetenschapsbeleid' Zoetermeer: Ministerie van Onderwijs en Wetenschappen, 1985. In 1989, the Ministry of Education \& Sciences itself reflected on a turn, late seventies, early eighties in science policy. It noted 'forceful intensification of science policy' Ministerie van Onderwijs en Wetenschappen Wetenschapsbeleid in de jaren tachtig. Uitwerking van het model van gezamenlijke actie, Zotermeer: Ministerie van Onderwijs en Weetenschappen, 1989

133 Anouschka Versleijen (ed.) Dertig jaar publieke onderzoeksfinanciering in Nederland 1975-2005. Historische trends, actuele discusses Den Haag: Rathenau Instituut, 2007 p. 8

134 Ministerie van Onderwijs en Wetenschappen Wetenschapsbudget 1982 Den Haag: SDU, 1981

135 The Dutch notion of 'doelmatigheid' could also be translated as effectivity. The translations of quotes from Dutch policy documents are my own.

136 Ministerie van Onderwijs en Wetenschappen Wetenschapsbudget 1979, Den Haag: SDU, 1978, p. 29

137 idem, p. 109
} 
Concentration' entailed a series of entrenchments from 1982 onwards. A new system of research financing called 'Conditional Funding' had been elaborated since 1979, and came into operation in 1983. Part of the research funding that universities received from the Ministry of Education and Sciences was allocated on the condition of ex-ante quality assessment. Until then, university research funding came as block grants based on the number of students. For the first time, research groups at universities had to formulate five-year research programmes. These research programmes were then assessed by disciplinary peer-review committees. Research programming was also introduced at research institutes. An 'Operation for Efficiency Enhancement' which started in 1983 introduced research programming at research institutes. Emerging 'new public management' ideals found their expression in these operations ${ }^{138}$.

Throughout the eighties, the general thrust of science policies was towards increased cooperation and coordination. Enhancing cooperation continued to be a central concern in 1988, when a memorandum on science policies for the next decade appeared: 'Research institutes, firms and departments will have to cooperate yet more intensively and find new ways of organizing research and new ways of dealing with and making use of knowledge. Science policy can create conditions for this and fulfill a stimulating role'139. Yet, while cooperation and coordination within disciplines had been aimed at during most of the decade, interdisciplinary cooperation and coordination between disciplines now started to become an important concern as well. Increased interaction and growing interdependencies were observed between all sorts of societal sectors which were previously operating relatively autonomously: 'Different disciplines exhibit all sorts of until recently unsuspected interfaces and increasingly interact. What is more, changes in science and in society influence each other ever more strongly.' ${ }^{140}$ The overall message was that faster changes and increased interaction and interdependencies required yet more efforts at coordination: 'Now that both in science and society the pace and complexity of processes of change increase, good coordination is required more than ever.' ${ }^{141}$ Besides coordination of research efforts, and between science and society at the national level, international research cooperation and coordination was again another area of concern. Firstly, Europe was becoming increasingly relevant as a level of governance. Secondly, global economic, geopolitical and environmental interdependencies were generally experienced as undergoing dramatic shifts. Economic globalization, the end of the cold war and global sustainable development were primary societal concerns in the late eighties. A more efficient division of tasks, which during the eighties had entailed coordination and coordination of research at the national institutional level of disciplinary working communities, now came to be associated with national scientific and technological competitiveness in a Europeanizing and globalizing economy. A future division of tasks, both efficient and viable in terms of competitiveness, was foreseen at transnational levels: 'Due to scaling up, research institutes will increasingly have to cooperate internationally. This serves to promote a European, or in the long term even a global division of tasks. ${ }^{142}$ Thus, by the late eighties, coordinating research efforts within and between disciplines, between science and society, and internationally had become a more or less coherent set of

\footnotetext{
138 In a 1989 review document these ideals are formulated as 'intensified management combined with greater autonomy' (Ministerie van Onderwijs en Wetenschappen Wetenschapsbeleid in de jaren tachtig. Uitwerking van het model van gezamenlijke actie, 1989).

139 Ministerie van Onderwijs en Wetenschappen Naar een wetenschapsbeleid voor de jaren negentig.

Discussienota Den Haag: DOP, 1988, p. 7

140 Min. O\&W Naar een wetenschapsbeleid voor de jaren negentig 1988, p. 5

141 idem, p. 11

142 idem, p. 15
} 
policy aims. The scaling up of research, that is, organizing research within larger institutional arrangements, was thereby seen as self-evident, an economic logic which also applied to science.

The growing interest in interdisciplinary research and institutional upscaling was also noticeable at the national research council. Until 1988, the national research council ZWO, the Organization for Pure Scientific Research, had distributed research grants through peer-review selection within national specialty oriented 'working communities'. These working communities formed part of national disciplinary 'foundations' but operated relatively autonomously. In 1988, the prefix 'pure' was omitted from the name of the national research council, which indicated a shift in the distribution of grants to include types of research considered strategic, interdisciplinary or otherwise societally relevant. The governance structure of the council, renamed the Netherlands Organization of Scientific Research (NWO) also underwent change. In 1989, it was decided that the foundations for biological research, BION, and earth scientific research, AWON, were to merge. The working communities lost part of their discretion to the newly created board for biology, oceanography and the earth sciences, BOA. Like the ministry of Education and Sciences, the national research council emphasized institutional upscaling as a necessary development to sustain national competitiveness ${ }^{143}$. Research programmes along thematic lines were to contribute to the required 'concentration' and 'bundling' of research efforts.

In the nineties, institutional upscaling and systematic programming continued to be of central importance to concentration of research efforts and enhancing coherence in the research system as a whole. Foresight exercises, as elaborated by policy analysts Irvine and Martin, came to be considered instrumental in the formulation of priorities within disciplines. The governing power of universities was to be enhanced through strategic planning and a more prominent role of faculty boards in research management, including the selection of research themes. The Ministry furthermore urged universities to establish inter-faculty research institutes ${ }^{144}$. In 1991, the minister of Education and Sciences issued a directive to establish graduate research schools. It was left to the universities to either cooperate with other universities or establish schools individually. The primary function of the research schools was to enhance the quality of graduate training. Yet, the research schools also fitted the aim of institutional scaling up: 'Research schools are an important and logical step in the development towards scaling up in research.' 145

In the mid-nineties, the 'knowledge economy' emerged as a new notion to guide the integration of science and technology policies. In a memorandum titled 'Moving Knowledge' the Ministry of Economic Affairs formulated policies to enhance the national innovative capacity which required the creation of a coherent and efficient 'knowledge infrastructure'. ${ }^{146}$ To realize these aims, stimulating cooperation between public research institutions and R\&D departments of firms on the basis of a supply-and-demand logic was considered to be of vital importance. What is more, the Minister of Economic Affairs was to have a say in the formulation of priorities in public research funding. In 1992, a scheme of research funding from national gas revenues had been introduced to strengthen the knowledge infrastructure. The term knowledge infrastructure

143 NWO Meerjarenplan 1991-1994, Nederlandse Organisatie voor Wetenschappelijk Onderzoek, Den Haag, 1990

144 Ministerie van Onderwijs en Wetenschappen Wetenschapsbudget 1990 Den Haag: SDU Uitgeverij, 1989

145 Ministerie van Onderwijs en Wetenschappen Wetenschapsbudget 1993 Den Haag: SDU Uitgeverij, 1992, p. 90

146 Ministerie van Economische Zaken Kennis in Beweging: over kennis en kunde in de Nederlandse economie Den Haag:Ministerie van Economische Zaken, 1995 
had been coined as an analogy to the physical infrastructure which was being funded from the same gas revenues. Subsequent rounds of the so-called ICES-KIS scheme (1992-1996 1997 2002, 2004-2009), renamed Bsik in 2003, grew in importance as a source of research funding. To get access to these funds, academic research groups were required to form consortia, and reach agreement on research programmes with government agencies and firms identified as 'users' of research. A scheme of Technological Top Institutes, introduced by the ministry of Economic Affairs in 1995, was also meant to stimulate institutional scaling up of research, to enhance scientific competitiveness, or 'excellence' in specific research areas.

After the mid-nineties, calls for concentration of efforts, cooperation, coordination and institutional scaling up continued unabatedly. Processes of institutional scaling up have been considered instrumental in enhancing the quality of research. Subsidies for 'top research schools' and 'technological top institutes' in the late nineties fitted this line of thinking, but the national research council too was urged to continue the policy of scaling up: 'It is important that NWO continues its policy of concentration forcefully: research money is to be allocated more often in the form of 'large lumps'. ${ }^{147}$

The importance of cooperation across disciplines also continued to be emphasized, but the connotations of interdisciplinarity shifted. Interdisciplinarity had mostly been associated with solving societal, 'real world' problems since the notion had emerged in the 1960s. During the nineties, interdisciplinarity came to be associated with scientific breakthroughs as much as solving societal problems. In the Science Budget of 2000 the 'frontiers of science' aspect of interdisciplinarity is explicit: 'Scientific breakthroughs mostly take place at the boundaries of disciplines. Societal questions are, moreover, commonly of a multidisciplinary character. That is why cooperation across the boundaries of disciplines and with external partners is necessary.'148

In recent years, institutional scaling up has been associated with a European division of tasks. National scientific and technological efforts are to be coordinated so that Europe can compete at the global level. A realization of a European Research Area (ERA) is regarded instrumental in guaranteeing European competitiveness: 'The aim [of the European research area] is that Europe can compete with the U.S., by concentration in larger centres, specialisation in the fields in which a country excells, and unlimited mobility of researchers. ${ }^{149}$

The above sketch discusses both continuities and shifts in Dutch science policies between 1980 and 2005. The general thrust of science policies was towards increased cooperation and coordination, between research groups and societal actors, between research groups nationally, between research groups internationally, and, increasingly, between disciplines. Calls to cooperate, coordinate and programme at the national, disciplinary level were characteristic of the eighties, motivated by a striving for efficiency. Interdisciplinarity was associated with the solving of societal problems and with applied science. During the nineties, cooperation, coordination and programming at national and international levels came to be motivated by competitiveness. Calls for interdisciplinary complementarity on the one hand, and disciplinary coordination on the other, existed side by side and in alteration. This added up to a space of opportunities and requirements in which retaining a viable position within a discipline was to be reconciled with participating in

\footnotetext{
147 Ministerie van Onderwijs, Cultuur en Wetenschappen Wetenschapsbudget 1997 (summary) Den Haag: SDU Uitgeverij, 1996 p. 15

148 Ministerie van Onderwijs, Cultuur en Wetenschappen Wetenschapsbudget 2000, Den Haag: Sdu Servicecentrum, 1999, p. 9-10

149 Ministerie van Onderwijs, Cultuur en Wetenschappen Wetenschapsbudget 2004, Den Haag: Sdu Servicecentrum, 2004, p. 3
} 
interdisciplinary research programmes. In addition, interdisciplinary research also came to be appreciated in its production of novelty.

In the next section, I will give a sketch of developments in landscape ecology, freshwater ecology, geomorphology, hydrology and hydraulics in the same period. How have practitioners of these specialties responded to the sustained calls for cooperation, coordination and programming? How have they responded to calls for interdisciplinarity? How have institutional survival strategies and search strategies developed?

\subsection{Landscape ecology}

Landscape ecology as a holistic, interdisciplinary approach to studying landscapes started to take hold in the Netherlands in the late sixties, early seventies ${ }^{150}$. For les Zonneveld, one of the main proponents of landscape ecology in the country, biologist-geographer Carl Troll was a major source of inspiration. Troll had coined the term landscape ecology in 1939, building on geographical and ecological conceptions of landscapes, notably those of Von Humboldt and Tansley. ${ }^{151}$ It entailed studying interrelations between landscape elements (climate, soil, water, plants etc.) as they are spatially ordered. Central to Troll's landscape ecology was the use of aerial photographs to discern basic landscape units called 'ecotopes'. Zonneveld, who had been studying the brackish Biesbosch area for some twenty years, was excited about Troll's idea of landscape ecology as it seemed to cover exactly the kind of studies he had been doing. In the late sixties, Zonneveld introduced integrated surveying at the National Institute for Aerial Survey (ITC) where he was appointed to a chair in 1968. Anton Vink, who held a chair in physical geography at the University of Amsterdam was equally inspired by Troll's conception of landscape ecology, and practised land surveying emphasizing its relevance for land-use planning 152 .

In 1972, a group of people interested in landscape research and planning, among them les Zonneveld and his brother Jan Zonneveld who held a chair in physical geography at the University of Utrecht, established the Working Community Landscape Ecological Research (WLO). The term 'working community' reflected the ambition to make landscape ecology into a fully fledged scientific field: academic research groups oriented to a particular field were organized as national working communities at the time. But landscape ecological research was much more embedded in policy oriented research institutes than in academia. What is more, an orientation towards application was also explicitly aimed at ${ }^{153}$. To realize this dual ambition, and to get better access to research funding from the national research council, the board of WLO advocated the strengthening of landscape ecology's theoretical underpinnings:

An important point of departure for stimulating research by WLO is the development of landscape ecology as an autonomous, fundamental branch of science, that can serve as a basis for applied research. This means, first of all, devoting ample attention to landscape ecological theory building ${ }^{154}$.

\footnotetext{
150 Jacqueline Cramer Mission-orientation in ecology: the case of Dutch fresh-water ecology Doctoral dissertation University of Amsterdam, 1987

${ }^{151}$ Isaak Zonneveld 'How I became a landscape ecologist' in IALE bulletin vol. 16 no. 16, November 1998

152 J. Cramer, M. Kuiper, J. Vos 'Landschapsecologie: een nieuwe onderzoeksrichting?' in: Landschap

$1984,1 / 3$, pp. 176-183

153 J. Cramer et al. 'Landschapsecologie', p. 178.

154 Het bestuur van de WLO 'De rol van de WLO in het onderzoeksbeleid op het gebied van de landschapsecologie' in WLO Mededelingen 7 (1980) 1, p. 3
} 
Within WLO, a 'working group on theory' had been established to advance landscape ecological theorizing. Landschapstaal (landscape language), which appeared in 1982, was the fruit of nine years of conceptual-foundational discussions and an attempt to come up with a shared conception of landscapes from an ecosystems point of view ${ }^{155}$. The group aimed at formulating unifying concepts, adding up to a coherent framework, while leaving room for different views. In the book, the conceptual outlooks of les Zonneveld, Chris van Leeuwen and Piet Schroevers are recognizable to some extent ${ }^{156}$. For les Zonneveld, Humboldtian holism was a cornerstone of landscape ecology: the unity of landscape form and vegetation was apparent from its 'physiognomy'. In practical terms, landscape ecological research entailed the mapping of spatial units with the aim of discerning relations within and between these units, called topological and chorological relations respectively ${ }^{157}$. Van Leeuwen had elaborated a cybernetic 'relation theory' in which energy transfer was the driving process. Within ecosystems conceived as cybernetic systems, stabilization and (spatial) differentiation was an outcome of selective and regulatory functions. For Schroevers, spontaneous self-organization of biological communities towards a climax, a steady-state, was a central notion which was to guide nature and landscape management. In his view, holistic landscape ecology served as a timely alternative to the prevailing technocratic approaches elaborated along disciplinary lines 158 .

During the eighties landscape ecology underwent rapid institutionalization. In 1981, Dutch landscape ecologists organized the first international landscape ecological congress, which led to the establishment of the International Association for Landscape Ecology (IALE) in 1982. From 1984 onwards, the Landschap journal became the main forum for landscape ecological discussions in the Netherlands. At the time, most landscape ecological research was published as grey literature as it was conducted primarily within policy oriented research institutes. ${ }^{159}$ At universities, landscape ecological research was practised in departments which had biology, physical geography or landscape planning as their primary orientations. In other respects too, landscape ecology was largely invisible as an separate academic orientation. Landscape ecologists realized that institutional survival required coordination and cooperation:

It is important to note that conditional funding offers opportunities for long-term research. In the course of time, striving for the development of a coherent research programme for each field of attention is a must. Coordinating the tasks of different university institutions will be required and cooperation between departments appears to have become indispensable. ${ }^{160}$

Within the conditional funding scheme, a landscape ecological research programme has never materialised. But after the mid-eighties landscape ecology started to become recognized as an academic endeavour, albeit a fragmented one. A project group 'Systems and Landscape Ecology' was established within the biological foundation BION in 1986, and a working community

\footnotetext{
155 P.J. Schroevers (ed.) Landschapstaal. Een stelsel van basisbegrippen voor de landschapsecologie Wageningen: Pudoc, 1982

156 These outlooks are discussed by Mechtild de Jong, who was a member of the WLO working group Theory. Mechtild D.Th.M. de Jong Scheidslijnen in het denken over Natuurbeheer in Nederland Doctoral dissertation University of Amsterdam, 2003

157 I.S. Zonneveld Een eigen weg tot wetenschap Inaugural speech Wageningen University 1982 158 J. Cramer et al. 'Landschapsecologie' p. 179

159 J.M. Cramer \& W. van der Wulp 'De ontwikkeling van de Nederlandse landschapsecologie als interdisciplinair wetenschapsgebied in internationaal verband' in Landschap 6/1, 1989, pp. 47-64 160 R.H.G. Jongman 'En wie betaalt het landschapsecologisch en milieukundig onderzoek?' in: WLO Mededelingen 10 (1983) 4
} 
Landscape Ecological and Environmental Research became part of the foundation for SocialSpatial Research (SRO) in 1988.161

The eighties also saw shifts in concepts and techniques. In 1989, les Zonneveld came with a review of the state of the art of landscape ecological theorizing ${ }^{162}$. In his view, the notions of stability, persistence, diversity/heterogeneity, information, connectivity and dissipative systems had come to make up 'the palette of theoretical concepts' of landscape ecology. In this list several new notions appear, compared to the early eighties. The chaos theoretical concepts of persistence and dissipative systems contrasted with the earlier view of ecosystems tending to stability, a view which the working group theory still appeared to endorse in the mid-eighties ${ }^{163}$. Information had been elaborated as a theoretical notion to come to grips with spatial relations between landscape attributes and variables, a central theme within landscape ecology ${ }^{164}$. The notion of connectivity originated in a strand of theorising that combined biogeographical island theory and metapopulation theory 165 . Employing these theories, landscape ecologists elaborating nature management policies argued that specific animal species could only be expected to survive in sufficient numbers if their fragmented habitats were connected again. The connected habitats comprised an 'ecological infrastructure', a notion that became central in nature management policies in the nineties. In terms of techniques, geographical information systems were gaining in importance. Such systems were based on the reduction of spatial information 'to three fundamental geometrical elements, that is, points, lines and planes'. In a geographical information system, information from a variety of sources, such as field data, aerial photographs and satellite images could be combined. Besides visualised as a map, spatial information could also be used to simulate consequences of landscape planning over time ${ }^{166}$. This kind of spatial simulations were gaining a central role in visualising and promoting the new policies of ecological connectivity.

At the $20^{\text {th }}$ anniversary of WLO in 1992, attending landscape ecologists expressed their concern about landscape ecological research at the universities ${ }^{167}$. In 1989 , les Zonneveld who lectured at both ITC and the University of Wageningen, had retired. At the University of Amsterdam, a part-time chair in applied landscape ecology had been created after Anton Vink, and his successor Pieter Tideman had retired. Looking back at the occasion of his own retirement in 1996, Josef Fanta, who held the part-time chair at the University of Amsterdam, concluded that landscape ecology had hardly survived at the universities. Landscape ecology had been thriving at the research institutes of the Ministry of Agriculture, Nature Management and Fishery, but academic landscape ecology was institutionally weak. To devise strategies to improve the position of landscape ecology, WLO assigned a 'working group universities' the task to come up with an assessment of the situation and a plan for the future. In November 1994, the working group came with an inventory of landscape ecological research taking place at Dutch universities, and

\footnotetext{
161 P.J.M. van der Aart ‘Landschapsecologie binnen NWO' in: Biovisie Magazine 2/Juli 1988

162 I.S. Zonneveld 'Theorieën en concepten: een tussentijdse balans' in: Landschap 1989, no. 1, pp. 65-76

163 Werkgroep 'Theorie' van de WLO 'Methoden en begrippen in de landschapsecologie' in: Landschap 1986, no. 3, pp. 172-181

${ }^{164}$ C. Kwakernaak 'Informatie als begrip in de landschapsecologie' in: Landschap 1986, no. 3, pp. 182 189

165 P.F.M. Opdam 'De metapopulatie: model van een populatie in een versnipperd landschap' in: Landschap 4/4, 1987 Opdam critically discusses the notion of 'ecological infrastructure', arguing that connections are only one among several possible strategies to infer from Levins' metapopulation concept and MacArthur \& Wilson's island theory.

166 P.A. Burrough 'Geografische informatiesystemen: gereedschappen voor landschaps- en milieuanalyse' in: Landschap, 1985, no. 4, p. 269-277

167 J. Fanta Landschapsecologie in de nieuwe tijden Farewell speech, University of Amsterdam, 1996, p. 7
} 
presented its recommendations. It appeared that landscape ecological research was practised at seven universities, and that aspects of landscape ecological research received attention at three national graduate research schools. The three research schools, which had been established in response to a directive issued by the Ministry of Sciences and Education in 1992, had geoecology (ICG), environmental sciences (SENSE) and functional ecology (FE) as their focus. The working group concluded that, in order to strengthen the position of landscape ecology at the universities, the various groups involved in landscape ecological research would need to cooperate on a structural basis:

Given the three themes within landscape ecology, that is: descriptive systems analysis, the study of relations between landscape patterns and processes of matter and energy transport, and the study of metapopulations in a fragmented landscape, in order to realise integration of these themes it is highly desirable to enter into close cooperation. All of the universities mentioned should be involved, together they carry responsibility for the further development of landscape ecology 168 .

The working group also recommended the establishment of a second, complementary chair at the University of Amsterdam and the creation of special chairs on the second and third of the main landscape ecological themes, having in mind the University of Utrecht and Wageningen respectively.

At the $25^{\text {th }}$ anniversary of WLO in 1997 , the situation at universities had not changed much, but landscape ecological research continued to thrive at the Staring Centre (SC-DLO) and the Institute of Forestry and Nature Management (IBN-DLO), the two main research institutes elaborating nature management policies for the Ministry of Agriculture, Nature Management and Fisheries ${ }^{169}$. les Zonneveld concluded that the national policies for nature management, notably the policy to create a National Ecological Network to improve habitat connectivity, were a major achievement of Dutch landscape ecologists. The study of the spatial distribution of habitats and assessing its suitability from the perspective of metapopulations had come to be regarded a specialization within landscape ecology. The same was true for eco-hydrological research, which had developed as a separate theme in the eighties in response to concerns about degradation of wetlands and water systems ${ }^{170}$. Dessication, acidification and eutrophication were major environmental issues then, and the environmental scientists and landscape ecologists who studied these issues, came to see eco-hydrology as a specialist area of expertise ${ }^{171}$. Besides the two specialist themes, in which formalized spatial simulation modelling was becoming a dominant practice, landscape ecology continued to be highly pluralistic in its concepts, research themes and approaches. Land art, history of landscape painting and urban culture figured among the themes of the landscape ecological congress held in 1997. Integration of the various

\footnotetext{
168 WLO werkgroep universiteiten De positie van de landschapsecologie aan de Nederlandse universiteiten November 1994, p. 7

169 Dorschkamp and RIN had merged into IBN-DLO, the Institute of Forestry and Nature Management in 1991.

170 I.S. Zonneveld 'Count your blessings? Twenty-five years of landscape ecology' in: J.A. Klijn \& W. Vos (eds.) From landscape ecology to landscape science. Proceedings of the European congress on landscape ecology Dordrecht: Kluwer, 2000, pp. 30-42

171 Jan Kalkhoven 'Landschapsecologie als zelfstandig vakgebied' in: D. van Dorp et al. (eds)

Landschapsecologie. Natuur en Landschap in een veranderende samenleving Amsterdam: Boom, 1999, p. 43
} 
perspectives, the 'building of bridges' between natural science, social sciences and humanities, also remained a central concern. ${ }^{172}$

In recent years, a number of part-time chairs in landscape ecology have been established, but the position of landscape ecology within academia remains an issue of concern to its practitioners ${ }^{173}$. Compared to the nineties, however, landscape ecology has gained in visibility among the environmental sciences, notably at the universities of Utrecht and Wageningen ${ }^{174}$.

\subsection{Freshwater ecology}

The closure of brackish areas for coastal defense purposes (the Zuiderzee in 1932, and the southwestern estuaries after 1953) had been an important impetus to the institutionalisation of biological freshwater research in the Netherlands, alongside growing concerns about water pollution.175 The distribution and abundance of aquatic organisms were the main focus of research until the 1950s, when physiological and physicochemical lab research came to complement taxonomical field studies. In the course of the 1970s, ecosystems analysis became the dominant framework, in line with international developments. Ecosystems analysis entailed studying both the composition and functioning of aquatic communities, and was considered a synthesis of existing approaches ${ }^{176}$. A major part of aquatic ecological research was taking place at national research institutes, of which the Hydrobiological Institute $(\mathrm{HI})$, the Delta Institute for Hydrobiological Research (DIHO), the National Institute for Wastewater Treatment (RIZA) specifically dealt with freshwater (and brackish) environments. At the time, aquatic ecological research groups existed at the two universities in Amsterdam, and in Nijmegen, Utrecht, Groningen, Wageningen and Delft.

In the late seventies, integration and concentration, both organizationally and in terms of research foci, figured on the agenda of the biological research community. In 1980, sections were formed to integrate the existing working communities within the national foundation for biological research BION. The newly established section of ecology combined the working communities of aquatic ecology, plant ecology and vegetation science, and population ecology ${ }^{177}$. The restructuring of biological research was delegated to the level of working communities, and guided by a hierarchical framework of biological research objects 'from molecules, cells and organisms, via individuals (...), to populations and ecosystems' 178 . Concentration of research had been called for since the mid-seventies and cuts in funding now provided a strong incentive ${ }^{179}$.

\footnotetext{
172 D. van Dorp et al. (eds) 'Landschapsecologie' p. 9

173 Rob Jongman Landscape ecology at the university in Europe Inventory by the IALE, 14-10-2002

174 Chairs with a landscape ecological (including eco-hydrological) orientation have been established at the University of Utrecht in 1998 (Whigham), 2002 (Verhoeven), 2003 (Wassen) and the University of Wageningen in 2000 (Opdam).

175 Wim J. Wolff 'The development of aquatic ecology in the Netherlands' in: Netherlands Journal of Aquatic Ecology 30 (4) 1996, pp. 241-253; E.J.A. Zevenhuizen et al. Een historische schets van de aquatische ecologie in Nederland en Vlaanderen. Publicatie no. 7 van de Nederlandse Vereniging voor Aquatische Ecologie, Amsterdam 1996

176 Jacqueline Cramer Mission orientation in Dutch ecology: the case of Dutch freshwater ecology PhD dissertation University of Amsterdam, 1987, p. 78-79

177 Jaarverslag BION 1980, p. 5

178 Jaarverslag BION 1981, p. 26

179 Jaarverslag BION 1981, p. 1
} 
Notably taxonomical research, low in status compared to the then emerging approaches of molecular biology, population ecology and systems ecology, faced discontinuance ${ }^{180}$.

In 1983, a foresight exercise on biological research in the Netherlands resulted in a report of 463 pages, titled Biologie: van levensbelang (Biology: vitally important). The foresight committee concluded that ecological research could benefit from a further concentration and division of tasks, and a restriction of research objects and research problems ${ }^{181}$. Five years later, ecology is the focus of a research programming effort ${ }^{182}$. A national ecological research programme, formulated by a committee of ecologists is to provide a framework for ecological research at universities and research institutes. While 'concentration' and 'an efficient division of tasks' remained catchwords, coordination of research to international research programmes - the International Geosphere-Biosphere Programme (IGBP) was taking shape - emerged as a new concern ${ }^{183}$. The national research programme had also been accommodated to priorities formulated by advisory councils such as the national council for nature and environment research (RMNO). The accommodation entailed that:

The programme for pure and strategic-fundamental research presented is a synthesis between desired research directions and research priorities set by society' 184 .

The streamlining of ecological research in terms of priority themes was noticeable in the funding scheme of the national research council: three themes were formulated for biology as a whole, the theme of 'genetic variation and fitness' being relevant for the ecosystem level185. In 1989, the foundation for biological research concluded that the national ecological research programme was effective in steering research. ${ }^{186}$ Research foci at the level of working communities showed continuity rather than change. At the time, the working community of aquatic ecological research counted three freshwater oriented working groups, focusing on lakes, macrophytes and rivers. Aquatic ecologists from the universities of Nijmegen and Amsterdam, the Limnological Institute (LI), the National Research Institute for Nature Management (RIN) and the regional Lake IJssel department of the State Water Authority (RDIJ) took part in these working groups. Brackish environments were dealt with by aquatic ecologists at the Delta Institute for Hydrobiological Research (DIHO) ${ }^{187}$.

The early nineties were a time of ongoing restructuring, both at research institutes and universities. The Limnological Institute, the Delta Institute for Hydrobiological Research, both with an aquatic focus, and the terrestrially oriented Institute for Ecological Research merged into the National Institute for Ecology (NIOO). In 1993, the Royal Academy of Sciences, being NIOO's main source of funding, announced budget cuts. NIOO director Wim van Vierssen saw further concentration and an efficient division of tasks as the best strategy of dealing with a smaller budget:

\footnotetext{
180 P.H. Nienhuis Water en waarden. Ecologisch onderzoek als basis voor waterbeheer en natuurbeheer Farewell Speech University of Nijmegen 2003, p. 6

181 K. Verhoeff (ed.) Biologie: van levensbelang Den Haag: Staatsuitgeverij 1983, p. 220

182 P.J.M. van der Aart, J. van Andel, J.W. Woldendorp Programma voor oecologisch onderzoek Den Haag: BION, 1988

183 idem, p. 5

184 idem, p. 12

185 Jaarverslag BION 1988, p. 7

186 Jaarverslag BION 1989, p. 14

187 Jaarverslag BION 1988, p. 353
} 
Our scientific aims are determinant in the first place. It is not yet clear which research will be discontinued, but it will be important to make our activities cohere optimally, as there is still too much overlap now ${ }^{188}$.

In the same period, the Department of Aquatic Ecology at the University of Amsterdam faced discontinuance, as its research was not on the list of 'core tasks' which the faculty had formulated 189 . Aquatic ecologists of the University of Amsterdam had not yet joined one of the research schools that were being established at the time. Yet, the faculty considered participating in a research school a basic condition for obtaining funding, a condition that the aquatic ecology group did not fulfill:

The objection that the committee has not looked into quality is not relevant. What counts is what the Minister is prepared to fund ${ }^{190}$.

Aquatic ecology groups (dealing with freshwater, estuarine and marine environments) at the universities of Groningen, Nijmegen, Amsterdam, Leiden and Utrecht, and the National Institute for Ecology joined the graduate research school Functional Ecology. The broad theme of interaction and feedbacks between individual, population and community was to cover ecological research taking place within the research school Functional Ecology. The two themes of the research school, 'genetic variation and fitness within natural populations' and 'interaction between populations' made up an integrated theoretical framework for ecological research as a whole ${ }^{191}$. The name of the research school furthermore indicated that structural ecological research, the composition of communities, was no longer connected with functional ecological research. 'Structure and functioning of ecosystems' had been a common denominator of ecological research until the eighties. Now, communities figured as a 'level' at which ecosystem ecology and population ecology were to meet192.

In the mid-nineties, biology was subjected to a foresight exercise within a scheme initiated by the Ministry of Sciences and Education and executed by the Royal Academy of Sciences. In its final report, issued in 1998, the committee advocated the bundling of existing biological expertise, and a further division of tasks. The existing trend towards integration of biological research, from the molecular level up to the level of ecosystems and populations, was to be sustained or even enhanced according to the committee ${ }^{193}$. Molecular techniques, information technology and modelling techniques had come to play an important role in biological research. Among the various trends, the committee also noted a growing importance of European funding ${ }^{194}$. At the time, freshwater ecologists from a number of European countries had elaborated a Science Plan Wetland and Aquatic Ecosystem Research. This plan was to provide a coherent framework for European freshwater research, and comprised a contribution to LandOcean Interactions in the Coastal Zone (LOICZ), a core programme of the International Geosphere-Biosphere Programme (IGBP) ${ }^{195}$.

\footnotetext{
188 Lex Linsen 'Banenverlies onvermijdelijk bij NIOO' in: Bionieuws 10, 22 mei 1993

189 Bart Siebelink ‘UvA wil vakgroep schrappen’ in: Bionieuws 10, 22 mei 1993.

190 Idem.

191 Annual Report Functional Ecology 1994, p. 5

192 Annual Report Functional Ecology 1995, p. 87

193 Verkenningcommissie Biologie Biologie: het leven centraal Amsterdam: KNAW, 1998, p. 41

194 idem, p. 51

195 Annual Report Functional Ecology 1996, p. 124
} 
At the occasion of his retirement in 1996, Cornelis den Hartog, who had been professor in aquatic ecology at the University of Nijmegen since 1973, expressed his discontent about the organizational and administrative developments at the university. He called graduate research schools 'administrative monstrosities' and stated that the autonomy of the researcher had eroded with research programming and management ${ }^{196}$. A different appreciation of institutional upscaling and research programming was made in a contribution to a historical sketch of aquatic ecology published on the occasion of the $75^{\text {th }}$ anniversary of the Netherlands Society for Aquatic Ecology (NVAE). Its president Aad Smaal observed that the multidisciplinary, application oriented research in large cooperative arrangements as required within EU funding schemes, provided aquatic ecology with opportunities ${ }^{197}$.

At the University of Nijmegen, Den Hartog was succeeded by Jan van Groenendael, who presented a research agenda revolving around integration ${ }^{198}$. Groenendael aimed at integrating aquatic ecology and terrestrial ecology, and at bringing together the extremes of biological research: the level of the gene and the global level. The establishment, in 2000, of the Centre for Wetland Ecology (CWE), a cooperative arrangement between the University of Nijmegen and the Netherlands Institute for Ecology (NIOO) provided an institutional solution to the question of integration. The universities in Amsterdam and Utrecht later joined the CWE. In its research programme integration is implied by a hierarchical ordering of ecological research objects: from individual, population, community, ecosystem to catchment 199 .

In terms of approaches, freshwater ecologists adopted and elaborated modeling strands and techniques considered promising within the field of ecology as whole. The repertoire of modelling techniques used by freshwater ecologists has come to range from mathematical models to models based on a variety of techniques to order data and discern patterns. These modelling strands and experiments in lab and field are regarded complementary approaches by Martin Scheffer and Ellen van Donk, who were appointed to chairs at the University of Wageningen and Nijmegen respectively200.

\subsection{Geomorphology}

Geomorphology emerged as a separate specialty in the early twentieth century, and remained a central subject within physical geography until the 1970 s $^{201}$. The study of present day processes and landscape ecology then emerged as promising new approaches alongside historical studies of landscape formation, the focus of geomorphological research ${ }^{202}$. At the time, geomorphological research was practised within physical geography departments at the University of Utrecht and

196 C. den Hartog Grootschalige veranderingen in aquatische systemen. (On)voorspelbaarheid en implicaties. Farewell Speech University of Nijmegen 1996

197 Aad Smaal 'Perspectieven voor de aquatische ecologie en de aquatisch ecologen' in: E.J.A. Zevenhuizen et al. Een historische schets van de aquatische ecologie in Nederland en Vlaanderen. Publicatie no. 7 van de Nederlandse Vereniging voor Aquatische Ecologie, Amsterdam 1996, pp. 51-54

198 J.M. van Groenendael Tussen gen en Gaia: oecologie in dilemma Inaugural speech University of Nijmegen 1995

199 CWE 'Research programme Centre for Wetland Ecology. A hierarchical approach to the ecological functioning of wetland ecosystems: the role of vegetation' document at website

www.nioo.nl/cwe/content/cwe.htm accessed 27 September 2004

200 Marten Scheffer Het meer als microkosmos Inaugural speech University of Wageningen 1999; Ellen van Donk Netwerken in het water Inaugural speech University of Nijmegen 2002

201 J.I.S. Zonneveld 'Fysische geografie in Nederland' in: KNAG Geografisch Tijdschrift XI 1977, nr. 3

202 J.H.J. Terwindt Landschap en proces in de fysische geografie Inaugural speech University of Utrecht 1977 
the two universities in Amsterdam. A growing emphasis on quantification, the so-called 'quantitative revolution' in geography, made itself felt in physical geography as well. Quantitative representations - mostly empirical formula - of landscape forming processes gained in status, as they could be used to predict. Historical reconstructions of landscapes were considered too qualitative, and lacking the possibility of prediction 203 .

In the early eighties, enhancing cooperation between universities emerged as an issue, 'at a time of scarcity' as Ward Koster put it at the time ${ }^{204}$. Koster was appointed full professor in physical geography at the University of Amsterdam in 1982, a time of retrenchments. He proposed to establish a working group with the physical geography departments of the two universities in Amsterdam participating. Cooperation would prevent fragmentation of the field, Koster argued, and the desire to cooperate had existed for years. In 1979, the foundation for earth scientific research AWON had been established within the national research council NWO. The working group that Koster aimed at establishing would be part of the working community dealing with soil science, physical geography and quaternary geology which was formed in 1981205. The shift to quantitative representations of landscape forming processes was going on, but apparently too slowly in the eyes of the foresight committee dealing with the earth sciences. The committee urged for a mathematical/physical foundation, and an enhancement of quantitative approaches 206 .

In 1984, Koster called for a rethinking of the strategy of academic physical geography, in the light of the many changes initiated by the Ministry of Education and Sciences. The memorandum on Division of Tasks and Concentration, issued in 1982, had been the start of a 'distressing game of interuniversity chess', with the discontinuance of one the three physical geography departments as a seemingly unavoidable outcome ${ }^{207}$. All three departments had however survived the retrenchments, and the time to cooperate had come, Koster argued:

The need for careful planning of research entails that the three physical geography institutes will have to coordinate their research, to strengthen cooperation, to avoid unnecessary overlap, that is to say, they will need to decide on a national disciplinary plan for physical geography. ${ }^{208}$

The recommendations emerging from the foresight exercise, in which geomorphology had an ambiguous position as it was considered to belong to geography as much as to the earth sciences, were considered relevant for physical geography as well209.

In 1985, six research programmes, two at each university, were granted conditional funding. The study of present day processes (actuo-geomorphology), historical reconstructions of landscapes (paleo-geomorphology) and landscape ecology continued to be the three major research orientations within physical geography, with Geographic Information Systems emerging

203 E.A. Koster and F.J.P.M. Kwaad 'Geomorphology in the Netherlands' in: H.J. Walker and W.E. Grabau (eds.) The Evolution of Geomorphology Chichester: John Wiley \& Sons, 1993, p. 302

204 E.A. Koster Zand erover. Een positiebepaling van de (actuele) paleogeomorfologie Inaugural speech Utrecht University 1982, p. 16

205 Jaarverslag AWON 1981

206 H.J. van Houten Aarde, Wetenschap en Samenleving. Verslag van een Delphi-onderzoek, uitgevoerd in opdracht van de Commissie ad hoc Bestudering positie Aardwetenschappen in Nederland. Zoetermeer: Min. O\&W, 1983

207 E.A. Koster 'Drieëenheid in de fysische geografie?' In: KNAG Geografisch Tijdschrift XVIII Nr. 5, 1984, pp. 324-329

208 idem, p. 327

209 idem, p. 329 
as an important tool 210 . In 1986, research priorities for the earth sciences were introduced, with an eye to 'establishing larger cooperative arrangements'. Geomorphology was to contribute to the theme of 'the earth surface', which had the effects of climate change and measuring and modelling geo-ecosystems listed as focal issues ${ }^{211}$.

In 1989, 'a completely new situation' arose with the merger of the earth scientific and biological research foundations, AWON and BION, under one umbrella, GB-BOA ${ }^{212}$. AWON's board warned that conflicts might arise in the process of jointly formulating multidisciplinary research programmes. While the subdivision of the foundations in working communities remained unchanged, studying the evolution of biosphere-geosphere interactions was listed as a major challenge. For actuo-geomorphology, studying the interaction between hydrosphere, lithosphere, biosphere and pedosphere was to have priority over studying the dynamics of separate spheres. Geomorphological research received ample attention in the process of formulating a national global change research agenda, as Ward Koster was closely involved in programming the Dutch contribution to the International Geosphere-Biosphere Programme. In 1993 he concluded that:

... geomorphological studies are increasingly becoming an integral part of large interdisciplinary research programs founded by national (e.g. Dutch national research programs on environmental pollution and climatic change) and international (e.g. EC programs on natural hazards, man and paleoclimate, and the International GeosphereBiosphere Program) bodies 213 .

The increasingly interdisciplinary embeddedness of geomorphological research was also reflected in more permanent research arrangements. In 1992, Koster (who had moved to the University of Utrecht) and his colleagues from the two universities of Amsterdam jointly established the Netherlands Centre for Geo-ecological Research (ICG) which became the graduate research school for academic research groups oriented to physical geography, geomorphology, quaternary geology, landscape and hydro-ecology, paleobotany and soil science ${ }^{214}$. The research programme of the school saw its research object, geo-ecological systems, as consisting of three subsystems. Geosystems, biosystems and pedosystems, being the respective focus of the fields listed above, together made up geo-ecological systems. Functional and evolutionary conceptions of these systems were regarded complementary. In terms of tools, remote sensing, geographical information systems and a variety of modelling techniques had become widely used, alongside lab experiments and field surveys. The new dating technique of Optically Stimulated Luminescence, had opened up possibilities for dating sediment.

In 1997, the research school presented a revised research programme ${ }^{215}$. Updating the research programme was considered necessary for several reasons, and was motivated in part by research quality assessments which had been made for geography in 1995 and the earth sciences in 1996. Strengthening the cohesion between the research of participating groups, concentrating research on a limited number of research themes, promoting multi-disciplinary

\footnotetext{
210 VSNU, Discipline Overlegorgaan Geografie, Planologie, Pre- en Protohistorie Profielschets Fysische Geografie, Sociale Geografie, Planologie Utrecht: VSNU, 1989

211 Jaarverslag AWON 1986

212 Jaarverslag AWON 1989

213 E.A. Koster and F.J.P.M. Kwaad 'Geomorphology in the Netherlands' in: H.J. Walker and W.E. Grabau (eds.) The Evolution of Geomorphology Chichester: John Wiley \& Sons, 1993, p. 308

214 Eduard A. Koster 'Preface' in: ICG Research at the Netherlands Centre for Geo-ecological Research ICG Publications 3, 1995

215 ICG Research programme of the Netherlands Centre for Geo-ecological Research, October 1997
} 
research groups, coordinating funding and linking up with national and international research programmes figured as the main items on the list of revisions. In the revised programme, the way in which the research themes link up with international research programmes such as the IGBP and EU programmes is a new item. All of the subthemes are said to be either in line with the aims of, or relevant to these international programmes.

A foresight exercise concerning the earth sciences, which issued its final report in 1997, carried a similar message of further concentration and prioritization as ICG's revised research programme 216 . The foresight committee considered the physical geography departments of the two universities in Amsterdam too small. It recommended coordination of research undertaken in the departments, complementarity, and even considering a merger of the two departments. Compared with the foresight exercise held in 1983, the foresight committee now spoke approvingly of the level of quantification that the earth sciences had attained. It also applauded the possibilities for integration of specialty oriented research contributions offered by computer modelling

Partly thanks to the use of strong computers, insight in complex processes is enhanced. The development of numerical models leads to more reliable predictions. Complex interaction between the numerous processes is becoming increasingly apparent. As a consequence, specialist research is increasingly done in the context of 'System Earth'

By 2000, the focus of geo-ecological research as apparent from ICG's research programme had shifted subtly, but noticeably. Geosystems, pedosystems and biosystems were still listed as the subsystems studied by the participating groups, but the focus was now on the interaction of these subsystems, in other words at the interface of the equivalent spheres: atmosphere, biosphere, pedosphere and geosphere'217. The spheres are studied in different disciplines, geomorphology and quaternary geology being oriented to the geosphere. As the geo-ecological system is supposed to exist alongside other nexuses of interfacing spheres, research on the earth surface has given rise to other cooperative arrangements as well. In 1996, the national research council had agreed to fund a cooperative arrangement between five earth scientific research schools, called the Netherlands Environmental Earth System Dynamics Initiative (NEESDI). All sorts of cooperative arrangements then existed with other research schools and institutes as well, ranging in focus from ecology and environmental sciences to civil engineering. Thus, by 2000 , geomorphological research had become embedded in a large number of inter-institutional arrangements, of which ICG remained a central node.

By 2003, research practices revolving around the application and sophistication of remote sensing techniques, dating techniques, computer modelling and Geographical Information Systems had grown to such proportions, that the board of ICG decided to grant it the status of a research theme ${ }^{218}$. The research programme then came to consist of three research themes, one focusing on landscape formation, one on the landscape as a functional ecosystem and one titled 'Innovative Measurement and Modelling'. ICG's list of modelling approaches distinguishes between models that are 'static or dynamic, spatially constant or spatially distributed, stochastic or deterministic, exploratory or confirmatory and quantitative or qualitative in nature'. A

\footnotetext{
216 Overlegcommissie Verkenningen Ruimte voor Aardwetenschappen. Toekomstverkenning aardwetenschappelijk onderzoek OCV, Amsterdam, 1997

217 Ton Dietz \& Frans Kwaad Dutch geography 1996-2000 Utrecht, International Geographical Union, the Netherlands, 2000, p. 4

218 ICG Research Programme 2003 2007, Preface
} 
somewhat different distinction is made by Piet Hoekstra, who was appointed professor at the University of Utrecht in 2004. He distinguishes between data-driven models and physical deterministic models. Physical deterministic models consist of mathematical equations containing parameters that may be based on empirical data. Data-driven models have been developed in response to the growing availability of digital data generated by all sorts of spectral measuring devices. In data-driven models the physical processes that are supposed to generate the patterns in the data are unspecified, they do not require 'prior knowledge of system dynamics' as Hoekstra put it 219 . For predicting coastal dynamics, these models are considered promising, and the two kinds of models may also be combined into 'hybrid models'.

\subsection{Hydrology}

By the 1970s, hydrological research had branched into three specialist subject areas 220 . Agrohydrology concerned itself with water uptake by crops, subsurface hydrology with water flow and storage in soils, while surface hydrology dealt with catchment runoff and water flow. Both for surface and subsurface water flow, physical-mathematical equations had been formulated early twentieth century. The notion of groundwater field potentials had been proposed at around the same time, drawing on an analogy between electrostatics and hydrodynamics.

In the course of the seventies, systems thinking came to serve as a framework for integration. The components of the world-wide water cycle counted as subsystems. In the view of Ben Engelen, who was appointed to a chair in hydrology at the Free University of Amsterdam in 1974, a hydrologist had a task similar to that of an accountant: measuring the components of the water cycle, the inputs and outputs, adding this up to a water balance, and optimizing the balance.221

At the time, hydrological chairs existed within engineering faculties, at the universities of Delft and Wageningen, and earth scientific faculties, at the University of Leiden and the Free University of Amsterdam. The dual disciplinary background of hydrology in engineering and the earth sciences had given it an ambivalent place among the disciplines, which sometimes gave rise to dilemmas. In the early eighties, hydrologists were divided whether to establish a hydrological working community within the Royal Engineering Society (KIVI) or the Foundation for Earth Scientific Research (AWON). The earth scientific connections turned out to be stronger: a hydrological working community became part of AWON in 1981, and was formally accepted in 1983222. The working community counted two working groups: one on surface hydrology and one on groundwater hydrology. Optimizing data gathering, the use of remote sensing imagery and model improvements figured on the list of research topics.

Model improvement was a long-term concern. Since the time hydrodynamic equations had been formulated, hydrologists had been striving for physically based mathematical models. These models were regarded ultimately superior to statistical ones, physics being viewed as the foundation of hydrology. However, since physically based models presupposed ideal, homogenous conditions they were not considered adequate for solving the bulk of hydrological problems which concerned non-ideal, heterogeneous environments. In the course of the seventies, physically based distributed models had been developed to deal with spatial

\footnotetext{
219 Piet Hoekstra 'Recent innovations in coastal research in the Netherlands' in: Ton Dietz, Piet Hoekstra, Frans Thissen (red.) The Netherlands and the North Sea. Dutch Geography 2000-2004 Netherlands Geographical Studies 325 Utrecht: KNAG/IGU, 2004

$220 \mathrm{~J}$. J. de Vries Anderhalve eeuw hydrologisch onderzoek in Nederland Amsterdam: Rodopi, 1982

221 G.B. Engelen Rentmeesters van water. Inaugural speech Free University of Amsterdam, 1974

222 Jaarverslagen AWON 1981, p. 137 and 1983, p. 155
} 
heterogeneity while applying the basic equations. Instead of averaging, or 'lumping' parameters over a watershed, these models solved the basic equations for discrete spatial units. Empirically based statistical models, which dealt with spatial heterogeneity in statistical terms, underwent sophistication at the same time. Geo-statistics and Geographical Information Systems provided new techniques of dealing with spatial heterogeneity. By the eighties then, a range of modelling approaches made up the hydrological toolbox.

While hydrological research groups at the Free University of Amsterdam, and the universities of Delft and Wageningen had survived the retrenchments of the eighties, the institutional position of hydrology and its status as an applied science continued to be an issue of concern. In 1988, the Foundation Hydrological Centre (SHC), an umbrella of institutions involved in water research, came with an assessment of the state of affairs and recommendations for the future development of hydrology 223 . The foundation concluded that the proper answer to the precarious position of academic hydrology was in research programming, coordination, cooperation and a division of tasks. The emerging policy ideal of integrated water management required the integration of groundwater hydrology, surface hydrology, water quality and water quantity while another important policy issue, that of climate change, meant that hydrologists would have to 'shift from micro scale to macro scale thinking'.224

The problem of 'upscaling' was approached in a variety of ways. In the view of Reinder Feddes, who was appointed to a chair in soil physics and agrohydrology at the University of Wageningen in 1990, remote sensing imagery was ideally suited for dealing with problems of scale 225 . Co de Vries, who was appointed to a chair in groundwater hydrology at the Free University of Amsterdam, also in 1990, approached the problem of scale rather differently. He argued that the prevailing reductionist approach needed to give way to a new paradigm based on holism and synthetic thinking. His view entailed that 'the hydrological cycle is governed by a large number of coupled, non-linear subsystems of varying complexity, scale and dynamics'226. Fractal theory was expected to offer a unifying framework for analysing the spatial patterns resulting from the selfregulation of seemingly chaotic but apparently hierarchically ordered systems.

In 1990, the Netherlands Hydrological Society (NHV) was established to create a national platform for exchanges independent of engineering and earth science institutions. In the early nineties steps were also taken to establish a national hydrological research school, in response to the ministerial call for graduate research schools. Research groups at the universities of Delft, Wageningen and Groningen and the Free University of Amsterdam jointly prepared an application for a Research School for Water and Environmental Management. In 1993, Jan van Dam, who was retiring as a professor of hydrology at the University of Delft, spoke approvingly of the initiative. The bundling of academic hydrological forces seemed the right step, as the perspectives of the groups involved were complementary and a national PhD network was already functioning 227 . By the end of 1995, a formal application was ready to be submitted to the Royal Academy of Sciences. The research programme of the school was to reflect the bundling of

223 Stichting Hydrologisch Centrum Onderwijs en onderzoek in de hydrologie en het waterbeheer. Aqua: Quo Vadis, Den Haag: SHC, 1988.

224 Idem.

225 R.A. Feddes Waar blijft het water ... Inaugural speech, University of Wageningen, 1990

226 J.J. de Vries Tussen waterschap en wetenschap Inaugural speech Free University of Amsterdam, 1990 , p. 14

227 J.C. van Dam Hydrologie, grondslag voor water- en milieubeheer Farewell speech University of Delft, 1993 , p. 23 
hydrological research capacity, in order to provide for 'the required critical mass' 228 . The research programme counted three themes. The theme of 'observation, measurement and data-analysis techniques' covered the use of remote sensing imagery and Geographical Information Systems. A second theme focused on 'systems and processes', distinguishing between deterministic, statistical and stochastic methods. A deterministic representation continued to be the ultimate goal:

Ultimately, the research goal is to discover physical, chemical and biological laws that allow for deterministic description of systems and processes. If this deterministic approach is not (yet) possible, research will be oriented towards statistic/stochastic methods to gain insights in systems and processes. ${ }^{229}$

The third theme in the research programme focused on 'model development and application'. Models represented subsystems of the hydrological cycle, or the interaction between them (e.g. between soil, vegetation and atmosphere), and the state of a variable (e.g. soil moisture content) locally, or for a whole catchment.

Notwithstanding its advanced stage of establishment, a graduate research school for hydrologists never materialised. The level of understanding that had made possible the elaboration of a joint research programme no longer held, a conflict arose, and the application was aborted230. This left hydrologists without a national platform to discuss and coordinate research. The Committee Hydrological Research at the Netherlands Institute for Technological Research (CHO-TNO), which had functioned as a national platform for more than four decades, had been discontinued in 1994. The establishment of a research school then seemed a matter of time only. The journal Stromingen (Currents), an initiative of the National Hydrological Society (NHV) served as a forum for discussion from 1995 onwards, but the NHV was not geared to coordinating research. PhD students joined other research schools, such as the national graduate research school for the environmental sciences, SENSE. The situation was considered detrimental to the recognition of hydrology as a fully-fledged scientific field ${ }^{231}$. Institutional fragmentation and the joining of research schools oriented to other fields put hydrology in an unfavourable position vis-à-vis sources of research funding and left the status of hydrology as a subsidiary field among the earth and environmental sciences unchanged.

It took until 2001 before hydrologists embarked on a new attempt to join forces at the national level. The Netherlands Hydrological Platform (NHP) was then established with the aim of getting hydrology recognized as a fully fledged scientific field. The NHP would serve to formulate joint projects, to strengthen contacts between PhD students and to share information ${ }^{232}$. The added value of the NHP was expected to be in 'the search for both coherence and distinction within the field, and in defining priority issues'.233

The research programme of the NHP mostly contained research themes and foci that had been considered important since the early nineties. The problem of upscaling was still on the list,

\footnotetext{
$228 \mathrm{IOH}$ Interinstitutionele Onderzoekschool ‘Hydrologie voor water- en milieubeheer’. Aanvrage KNAWerkenning Delft: Onderzoekschool Hydrologie, 1995

229 Idem, p. 10

230 Overlegcommissie Verkenningen Ruimte voor aardwetenschappen. Toekomstverkenning

aardwetenschappelijk onderzoek. Amsterdam, OCV, 1997, p. 44

231 Roel Dijksma 'Het Nederlands Hydrologisch Platform, een zeer nuttige bundeling van krachten' in:

Stromingen 7, 2, 2001, pp. 47-52

232 idem.

233 Idem., p. 49
} 
as was the further elaboration of integrated models, involving 'the coupling of soil-water-solute substances-vegetation-atmosphere'. By giving priority to these themes, Dutch hydrology aligned itself with research priorities as formulated elsewhere. In a foresight exercise organized in 1997 by the National Research Council of the US, it had been concluded that "[t]he grand challenge of hydrologic science is the coherent coupling of knowledge in all domains - atmosphere, oceans, hydrosphere, and biosphere - across a full range of spatial and temporal scales'234. A new notion appearing in the NHP research programme was 'data-assimilation', a way of estimating the value of a variable by feeding a physical model with values from nearby places. The soil water content of a river catchment for instance could be estimated on the basis of information about only the top layer, obtained from satellite images 235 .

The ambition to have hydrology recognized as a fully-fledged, autonomous scientific field also led hydrologists to lobby for a national foresight exercise to be executed under the auspices of the Royal Academy of Sciences. Reinder Feddes, who had advocated establishing the NHP became a member of the newly established Earth and Climate Council (RAK) of the Academy appears to have convinced the Council about the timeliness of a hydrological foresight exercise. In the foresight committee, the universities of Utrecht, Eindhoven, Nijmegen, Wageningen and the Free University of Amsterdam were represented. The University of Delft, which had played a central role in the aborted attempt at establishing a hydrological research school in 1995, was not represented. All but one of the representatives involved were successors of the key players involved in the research school conflict, which in effect made that conflict something of the past. The foresight exercise resulted in a national research programme for hydrology and a national centre, which was named Boussinesq centre ${ }^{236}$.

The foresight report unequivocally characterized hydrology as an earth science, linking up with, but distinct from other earth sciences ${ }^{237}$. Interactions between the hydrological cycle and four 'systems' were identified as internationally important themes: climate, landforms, ecosystems and society. The foresight committee reformulated these as three priority themes for Dutch hydrology on the basis of scale.

The further sophistication of physically based mathematical models is going on, as physics continues to be regarded the primary foundation of hydrology. One of the advocates of a proper physical foundation is Majid Hassanizadeh, who was appointed to a chair in geohydrology at the University of Utrecht in 2002. He argues for a primacy of physics against the trend of data-driven modelling:

Enormous effort is spent by researchers in various fields of science to find relationships among different physical quantities without looking into the underlying physics. ${ }^{238}$

At the same time he acknowledges that in current geohydrology 'soil heterogeneities, physical and chemical properties, and even biological issues have to be taken into account'. This points to a primacy of physics in hydrology as an interdisciplinary science. Marc Bierkens, who was appointed to a chair in geographical hydrology at the same university in 2003 , sees it as the

${ }^{234}$ Michael R. van der Valk 'Hydrologic Sciences. Taking Stock and Looking Ahead' in: Stromingen, 5/4, 1999, p. 61

235 P.A. Troch Laten we de (water)balans opmaken. Inaugural speech University of Wageningen, 2001, pp. 25-27

236 KNAW Turning the Water Wheel Inside Out. Foresight Study on Hydrological Science in the Netherlands Amsterdam, KNAW, 2005

237 idem, p. 7

238 S. Hassanizadeh Beyond Darcy's law Inaugural speech University of Utrecht, 2002 
ultimate aim of hydrology to build models which do not depend on calibration, a wider category than physically based models alone, since he also counts stochastic models among these. He endorses Hassanizadeh's view that physically based equations are an ultimate ideal239. An entirely different perspective is that of Han Dolman, who was appointed to a chair in ecohydrology at the Free University of Amsterdam in 2003240. Dolman's overall focus is that of 'coupled atmosphere, geosphere, biosphere systems'. One of the research topics within this overall 'integrated perspective' is that of ecohydrological or vegetation patterns, which he sees emerging through self-organization. The self-organization results from a feedback coupling between the various subsystems. Neither physical nor biological processes figure in Dolman's approach. Rather, he advocates long-term monitoring of elementary functions of a system, such as carbon cycling, for which he regards remote sensing an important tool. Self-organization also figures as a central notion in the 'empirical, holist' approach of Huub Savenije who was appointed to a chair in hydrology at the University of Delft in $2005^{241}$.

\subsection{Hydraulics}

Early twentieth century, a new concept, that of the boundary layer, made existing hydrodynamic equations applicable for hydraulic engineering problems ${ }^{242}$. Hydraulics had been based on rules of thumb, but was now provided with a physical-mathematical theory. Hydrodynamic theory has been considered complete in a certain sense, and closed: there are enough equations to establish the values of the variables, and solutions for specific applications exist 243 .

Alongside these mathematical models, other ways of modelling water flow, notably physical scale models and models based on analogies between water currents and electric currents have played an important role in Dutch hydraulic engineering as it developed in the twentieth century. From the 1960s onwards, computerized numerical modelling emerged as a promising avenue, being a more economical and powerful alternative to physical scale models than teams of human calculators had been ${ }^{244}$. In 1969, Michael Abbott, who was affiliated to the International Institute for Hydraulic Engineering (IHE) in Delft, coined the term 'computational hydraulics'245. Ten years later, Cornelis Vreugdenhil, who was appointed to a chair in fluid mechanics at Delft University, devoted his research programme to computational hydraulics, while Abbott published a book on the subject ${ }^{246}$. Reducing the costs of engineering works was a major promise of computational hydraulics, but computer capacity was limited. At the time, Delft Hydraulics disposed of a HP system 1000 mainframe computer, which was used, among others, to compute two-dimensional flow patterns in rivers ${ }^{247}$. In his inaugural address, Vreugdenhil toned down the expectations

\footnotetext{
239 Marc F.P. Bierkens Het Water en de Leer Inaugural speech University of Utrecht 2003

240 A.J. Dolman Blauw en Groen in Broeikas Aarde Inaugural address Free University of Amsterdam, 2003

241 H.H.G. Savenije Het meeste valt ernaast Inaugural speech University of Delft 2005

242 Michael Heidelberger 'Applying models in fluid dynamics' in: International Studies in the Philosophy of Science vol. 20, no. 1, 2006, pp. 49-67

243 Gernot Böhme 'Autonomization and finalization: a comparison of fermentation research and fluid dynamics' in: G. Böhme et al. Finalization in Science, Dordrecht: Reidel, 1983

244 J.C.M. van den Ende The turn of the tide: computerization in Dutch society 1900-1965 Doctoral dissertation University of Delft, 1994

245 http://www.unesco-ihe.org/about/academic_departments/hydroinformatics_and_knowledge_ management/staff information/michael abbott, accessed 19 February 2008

${ }^{246}$ C.B. Vreugdenhil Water, onberekenbaar? Inaugural speech University of Delft, 1979; M.B. Abbott Computational hydraulics London: Pitman, 1979

247 Hydro Delft 1980 nr. 56; Delft Hydraulics Annual Report 1980, p. 15
} 
about computational hydraulics by noting existing limitations. In his view, computers were far from replacing physical scale models:

It seems to me that it is more appropriate to make the sober observation that the 'computational hydrodynamics lab' is still far away, if it will ever appear at all. 248

Besides limited computational capacity, there were conceptual problems, such as the introduction of empirical parameters, simplified geometries and discrete solutions to what were regarded physical continuums, not to mention the mathematically unresolved issue of turbulence.

Delft was the main centre of hydraulic engineering, with groups at the University of Delft, Delft Hydraulics and the International Institute for Hydraulic Engineering (IHE). At the University of Wageningen, hydraulics and surface hydrology were a combined chair, while at the University of Twente a chair in civil engineering management was created in 1987. Herman Wind, who was appointed to the chair, proposed a research programme entailing the modelling of technical, economic and sociological processes to inform decision making in water management ${ }^{249}$. The eighties were a time of shifting prospects for hydraulic engineering. At Delft Hydraulics, a department of Environmental Hydraulics had been established in 1980, which expressed the growing attention devoted to modelling chemical, biological and ecological processes 250 . By the mid-eighties, the most important commissioner of hydraulic research, the State Water Authority (Rijkswaterstaat), had come to embrace the notion of integrated water management, which entailed that ecological considerations were to be taken into account in the design of hydraulic structures. At the time, the Delta Works were near completion, but sea-level rise emerged as a new concern which undermined the idea of coastal defense structures being finished. In 1986, Rijkswaterstaat commissioned a four-year coastal research programme which brought together engineers and earth scientists ${ }^{251}$. The hydraulic and morphological behaviour of the Rhine branches was another concern, which justified the sophistication of computer models for water flow and sediment transport 252 .

By the late eighties, shifts in funding conditions made hydraulic research groups embark on new cooperative arrangements. European funding came to be seen as a potential and much needed additional source of funding for hydraulic research at universities, Rijkswaterstaat's research institutes, and Delft Hydraulics alike. From 1989 onwards, European framework programmes brought together coastal research groups from a number of European countries. Research management was the responsibility of six, later eight hydraulic laboratories. The European partners came to cooperate rather too well for the taste of the EU responsibles, who started to speak of a cartel253. Until the mid-nineties, the further development of numerical models for waves, currents and sand transport, the study of coastal dynamics, was the overall goal of the research cooperation. By then, data-driven modelling had come to be regarded a promising avenue.

Data-driven modelling, which brackets physical processes, had been experimented with at the IHE since the late eighties. Michael Abbott then introduced the notion of 'hydroinformatics', which

\footnotetext{
248 Vreugdenhil Water, onberekenbaar?, p. 7

249 H.G. Wind Civieltechnisch management Inaugural address University of Twente 1988

250 Delft Hydraulics Annual Report 1980, p. 4

251 Mark van Koningsveld Matching Specialist Knowledge with End User Needs Doctoral dissertation University of Twente, 2003, p. 54

252 Delft Hydraulics Annual Report 1986, p. 7 and 26, 1987, p. 20

253 Mark van Koningsveld Matching Specialist Knowledge, p. 64
} 
entailed a hierarchical modular systems view of the aquatic environment. ${ }^{254} \mathrm{~A}$ Hydroinformatics Department was established, the members of which devoted themselves to developing various strands of data-driven modelling255. At Delft Hydraulics, numerical modelling held primacy, undergoing sophistication from $1 \mathrm{D}$ to $2 \mathrm{D}$ and $3 \mathrm{D}$ versions. Remote sensing imagery was being acknowledged as a valuable source of data for monitoring rivers in inaccessible areas ${ }^{256}$. In a few years time, this appreciation of satellite images as an additional source of information would give way to seeing the growing range of remote sensing techniques as a promising source of data for validating numerical models:

Complete 3D-models which compute variables on a 3D grid are in an early stage of development, but will become ubiquitous in the coming years, partly stimulated by the continuous increase in computer capacity and the rise of new synoptic measurement techniques (remote sensing) for waves, currents and even bedforms, which brings detailed model validation within reach 257 .

One of the research programmes in which numerical modelling, remote sensing techniques and Geographical Information Systems received a boost, was Land Water Information technology (LWI). In the programme, which ran from 1993 until 1997, research institutes, universities and engineering firms were supposed to cooperate to strengthen the 'knowledge infrastructure'.

At the time academic research groups were busy establishing research schools, engineering and earth scientific research groups involved in coastal research established a Netherlands Centre for Coastal Research (NCK). Being a cooperative arrangement between Delft Hydraulics, Rijkswaterstaat's research institute for coastal research RIKZ and research groups at the universities of Delft and Utrecht, the centre's composition differed from the academically oriented research schools that were being established. It reflected the trend towards interdisciplinary, inter-institutional cooperative arrangements in which research programmes were formulated in concertation. A research school for hydraulic engineers was established a little later. In 1995, the Netherlands School for Advanced Studies in Hydraulic and Geotechnical Engineering was accredited by the Royal Academy of Sciences. The focus of the research school partly reflected the engineering tradition of designing dikes and waterworks, but also accommodated the geoscientifically oriented branch of riverine and coastal research. The engineering tradition was being continued within research groups at the University of Delft. Han Vrijling, who was appointed to a chair in 1990 focused on probabilistic techniques in the design of dikes and other structures, the strength of these structures, and the risk of their failure258. Kees d'Angremond who was appointed to a chair in the same year concentrated on flexibility in designing waterworks, the strength of structures and their adaptability to changing conditions ${ }^{259}$. The emerging geoscientifically oriented branch of hydraulics, with a focus on natural systems, was reflected in

254 M.B. Abbott Hydroinformatics Aldershot: Ashgate, 1991

255 D.P. Solomatine 'Data-driven modelling: paradigm, methods, experiences' in: Proc. $5^{\text {th }}$ Int. Conf. On

Hydroinformatics, Cardiff, UK, July1-5, 2002

256 Hydro Delft 1990, no. 78

257 L.C. van Rijn Zee en zand in Holland. Over hydrodynamika en morfodynamika. Inaugural speech

University of Utrecht 1995, p. 14

258 J.K. Vrijling Kansen in de waterbouw Inaugural speech University of Delft 1990

259 K. d'Angremond Flexibiliteit in de waterbouwkunde Inaugural speech University of Delft 1990 
new chairs. Marcel Stive was appointed to a chair in coastal morphology at the University of Delft in 1995260, Huib de Vriend to a chair in river morphology at the same university in 1997261.

By 2000, hydraulic research had become embedded in a number of interdisciplinary, interinstitutional centres and programmes. The NCK provided a platform for coastal researchers, from engineering and geoscience groups. A later twin, the Netherlands Centre for River Studies also included ecologists and social scientists (see chapter 5). Delft Cluster, a long-term programme funded from the same gas revenue funds as LWI brought together the Delft based engineering institutes. Five years after its establishment, the research school was considered redundant, NCK and NCR functioning as national platforms for hydraulic engineers 262 .

The emerging focus on natural systems has brought with it the adoption of geoscientific concepts and tools. Huib de Vriend considers remote sensing of great value in combination with mathematical models ${ }^{263}$. Suzanne Hulscher, who was appointed to a chair in water systems at the University of Twente in 2003, speaks of a self-organizing system shaped by physical processes 264 . In hydroinformatics, the combination of data-driven models with numerical physically based models is considered most promising, the former kind of models profiting from the large amounts of digital data available from remote sensing imagery. The basic equations of hydraulics, meanwhile, seem largely but not wholly uncontested. The roughness parameter, for instance, is seen by some as an 'error compensation device' which obscures a lack of insight in physical phenomena265.

\subsection{Commonalities and contrasts}

What are some striking commonalities and contrasts between developments in the five specialties as sketched above? I will briefly review each of the specialties with an eye to these commonalities and contrasts.

Landscape ecology emerged relatively recently compared to the other specialties. Some saw it as a holistic or an anti-scientistic approach rather than a newly arising specialty. But like in other specialities, a striving for recognition in academia brought with it calls for a shared theory, unifying concepts and led to research programming and coordination. A repertoire of modelling strands and remote sensing as an important source of data have come to characterize formalized approaches in landscape ecology, prominent at universities and research institutes. Landscape ecology has retained a pluralistic composition, as apparent from the inclusion of land art, historical and other outlooks on landscapes.

A prominent concern in aquatic ecology as it evolved over the same period was that of 'integration'. Aquatic ecology was well embedded in universities and research institutes, but like other biological specialties was confronted with budget cuts, ongoing calls for efficiency and coordination. The notion of integration legitimized the institutional streamlining of biological research along conceptual lines, as integration was associated with biological hierarchical organization. The institutional streamlining took the form of research programming at the level of

\footnotetext{
260 M.J.F Stive De kust is vrij: pleidooi voor een dynamische omgang met het raakvlak land-zee Inaugural address University of Delft 1995

261 H.J. de Vriend Een kwestie van respect Inaugural speech University of Delft 1997

262 Martine Segers 'Onderzoekscholen sterven langzame dood' in: TUDelta jrg. 32 nr. 36, 2000

263 Huib de Vriend Onzeker? Zeker weten! Farewell speech University of Twente, 2002

264 Suzanne J.M.H. Hulscher Ruwweg natuurlijk waterbeheer? Natuurlijk! Inaugural address University of Twente, 2003

265 Abbott, M. B., Babovic, V. M., and Cunge, J. A. 'Towards the hydraulics of the

hydroinformatics era' Journal of Hydraulic Research, 39 (4), 2001, pp. 339-349
} 
ecology as a whole, nationally and internationally, the identification of priority themes, forced participation in research schools and inter-institutional research cooperation within the framework of integrated research programmes. A variety of modelling strands, lab and field experiments, and the use of remote sensing as a source of data have been adopted in aquatic ecology in recent years.

Being recognized as a distinct field has not been a major concern of geomorphologists in the last couple of decades. Geomorphology has been embedded in both physical geography and earth scientific departments. But a need for increased cooperation, research programming and coordination made itself felt because of retrenchments. Global change and system earth, conceptualized as interacting subsystems, came to serve as frameworks for integration of geomorphology in 'geo-ecological' research arrangements. A variety of modelling strands, dating techniques and remote sensing as a source of data have been adopted in geomorphology in recent years.

A major concern of hydrologists has been to get their specialty recognized as a fully-fledged scientific field, with its own set of theories. Physical deterministic theories have been considered the ultimate ideal, while data-driven modelling has gained in importance over the years. Remote sensing is the main source of data in data-driven modelling. Cooperation, coordination and integration has been called for to improve the position of hydrology in academia. In recent years, hydrologists have come to organize at the national level. A shared research programme is to bring research funding from the national research council closer. Integration is conceptualized in terms of coupled subsystems.

The equations underlying hydraulic modelling are mostly considered complete, but the modelling has been undergoing major shifts in other respects. Numerical hydraulics became widely adopted in the eighties, while institutional configurations remained rather stable. In recent years, data-driven modelling approaches have come to complement numerical modelling. This has brought hydraulics closer to the earth sciences and ecology, which is also visible in institutional configurations. At the national level, centres for coastal and river research incorporate hydraulic research.

Apparent commonalities then, are the way in which specialty practitioners have responded to the calls for efficiency and concomitant retrenchments and subsequent calls for institutional scaling up. In all of the specialties, research programming and the setting of priorities has been introduced in the eighties. In the nineties, research schools and centres have been established at the national level. Some of these centres have a disciplinary orientation (FE: ecology, CWE: ecology, BC: hydrology) others an interdisciplinary (ICG: geo-ecology, NCR: river research, NCK: coastal research). It furthermore appears that all of the specialties speak of self-organizing biogeosystems, have come to use roughly the same repertoire of modelling strands, for which remote sensing is an important source of data. A view of bio-geosystems as interacting, coupled subsystems has gained wide currency.

\subsection{Conclusions}

In this chapter, I have studied institutional survival strategies and emerging search strategies in five specialties in the context of national science policies. I will now draw some conclusions about the relations between institutional survival strategies and dominant search strategies. From the specialty sketches, it appears that some institutional survival strategies have been adopted across the board. Research programming, the setting of priorities, the establishment of inter- 
institutional research schools and centres, and accommodation to international research programmes have multiplied the institutional frameworks in which research groups need to accommodate their research. The specialties also converge in some of the search strategies that they employ, notably the notion of self-organization, a repertoire of modelling strands and remote sensing as a source of data.

The convergence of search strategies reflects what happens internationally, in bio/geoscience and engineering. Scientists adopt search strategies that are considered promising in their fields, and this happens in wider cultural and technological contexts. The above accounts suggest that national science policies can play a role in the widespread adoption of specific search strategies as scientists embark on inter-institutional, interdisciplinary research cooperation and respond to calls for coordination on all sorts of levels. The glimpse offered at the beginning of this chapter on the strategizing of group leaders suggests that these arrangements subtly induce the abandonment of institutionally less viable and the adoption of institutionally more viable search strategies.

The reconciliation of different pressures arising from science policies suggests a further strategic process. As the account shows, science policies have induced scientists to embark on interdisciplinary research cooperation, while having to follow disciplinary agendas as well. A modular solution to cross-specialty cooperation seems an efficient way of reconciling these pressures: by coupling specialty modules, scientists from different specialties do not need to probe into one another's modules and may concentrate on elaborating their own specialty module. As long as the output from one module can serve as data for another, a productive form of interdisciplinary cooperation is realised. This adds to understanding the discourse on modular interdisciplinarity and bio-geosystems noted in chapter 3. There, I related a modular view of interdisciplinary cooperation in river research to the mutual adjustment of concepts, technologies and institutional configurations. Here, I identified a further dynamic at work.

Scientists participating in inter-institutional, interdisciplinary research arrangements are not forced in a top-down way to adopt or abandon specific search strategies. Rather, scientists tend to adopt the more viable institutional, conceptual and instrumentational strategies. As the viability of these strategies depends in part on science policies, these policies contribute to shaping the content of science. 


\section{Chapter 5 Emerging river science in the Netherlands}

Interdisciplinary river research is being practised in localised settings. Sectoral policies may, like science policies, be among the relevant contexts shaping research practices in these settings. In this chapter, I will analyse how river management policies in the Netherlands have contributed to shaping river research practices. First, I will give an account of the emergence of a new river management regime, which entailed an ecological and a spatial turn at the same time. Next, I will discuss how scientists of Dutch universities, by responding to newly arising opportunities for doing policy relevant research, put interdisciplinary river science on the map. Finally, I will analyse how river management policies have contributed to shaping a local research configuration in the Netherlands. Here, the primacy of safety in river management turns out to translate into a primacy of hydraulics in the interdisciplinary configuration. The landscape ecological notion of ecotope provides for a common ground, as do modelling practices and remote sensing as a source of data. I conclude by relating the structure of the local research configuration to relevant institutional contexts.

\subsection{An ecological-spatial turn in river management}

In the early eighties the Dutch State Water Authority (Rijkswaterstaat) maintained large rivers like the Rhine and IJssel as hydraulic structures, conduits. From a civil engineering point of view, the primary function of the Rhine branches was getting rid of water, sediment and ice, in order to prevent flooding of the riverine areas:

[River] management first and foremost serves to guarantee the free discharge of (high) water, ice and sediment for the sake of the safety of the embanked land. This is being realised by maintaining a single, continuous channel. 266

Maintaining the status-quo was the guiding principle. It meant keeping the river channel fixed and either raising or maintaining the dikes at a height that could withstand a flood that was estimated to occur once every 1250 years ${ }^{267}$. This safety norm had been the outcome of expert deliberations in 1977. After the coastal flooding disaster of 1953, the risk of flooding along the branches of the Rhine had been set at once every 3000 years. Yet, the dike raising programme resulting from this safety norm never materialized. In the seventies with its spirit of democratization and environmentalism, dike raising met with growing opposition. The raising and strengthening of dikes came to be seen as unnecessarily destructive of natural, cultural and landscape values. In the public image, Rijkswaterstaat was an authoritarian, technocratic power. In 1977, in response to the growing protests, the government had installed the Becht Committee to reconsider the safety norm of a flood once every 3000 years. The expert committee concluded that a risk of flooding once in 1250 years was safe enough for the riverine region. As a result, the dike raising programme shrunk to smaller proportions. Yet, the protests continued. In 1980, citizens of Brakel fiercely opposed the plans of Rijkswaterstaat, as the dike raising would destroy part of their town.

266 D. de Bruin Rivierbeheer op de Nederlandse Rijntakken Rijkswaterstaat Directie Bovenrivieren Arnhem, 1982, p. 1

267 This so-called design discharge was based on an extrapolation of discharge statistics over a century. The height of the dikes in a section of the river was, and still is, calculated with a hydraulic model fed with a design discharge flood wave. 
Rijkswaterstaat thus saw 'safe discharge' as the primary function of rivers, which could either be compatible with or running counter to other functions or interests. Integrated river management was to ensure that these other interests would be accommodated as much as possible 268 . Keeping the large rivers navigable and monitoring water quality with an eye to the supply of drinking water were regarded important secondary functions. Rijkswaterstaat acknowledged a range of other interests, pertaining to agriculture, recreation, nature and environment, sand and gravel extraction, cultural heritage, infrastructure and industry among others. In the sphere of nature and environmental interests, river pollution was a major concern: the Rhine was nicknamed the sewer of Europe, the water being toxic to many species of fish. Water quality was closely monitored so that intake for drinking water could be halted temporarily in case levels of toxicity exceeded standards for humans. The recreational potential of the river landscape was highly valued, while agricultural overproduction was on the list of problems.

To accommodate concerns about riverine nature, landscape esthetics and cultural heritage, and in the spirit of the widely embraced notion of integrated river management, Rijkswaterstaat started to reconsider the dike raising programme that remained after the safety norm had been lowered in 1977. In 1985, it came with the results of a study into appropriate dike designs, while another study looked into alternatives for dike raising269. Rijkswaterstaat concluded that alternative measures, such as lowering floodplains, would be both insufficient and unfeasible, given the large amounts of clay and sand that would have to be extracted. Extraction of gravel, sand and clay was seen as environmentally destructive and an agreement to halt these extractions was being negotiated 270 .

In 1986, two unrelated events provided the protagonists of a more ecologically sound river management with sources of inspiration and legitimation. On May 13, a prize was awarded to Ooievaar, a landscape design for the riverine region conceived by an engineer, three landscape architects, an art historian and an ecologist 271 . The plan ingeniously combined Rijkswaterstaat's requirement of flood safety with the newly emerging approach of 'nature development' 272 . The floodplains of the Rhine branches would no longer serve agricultural purposes. Riverine habitats would be re-created by removing layers of clay that had been deposited by the river, by digging side channels and by removing summer dikes. The newly created habitats would flood from time to time, develop into softwood forests of willows and poplars and allow the return of fish and other riverine animals and plants. Higher up the river banks, forests of Ash, Oak and Elm would develop, representing the regional climax stage of succession. These one-time restorative measures would bring a self-sustaining ecosystem as it had existed in prehistorical times.

In the civil engineering tradition, forest growth in the floodplains had been regarded a problem: it pushed up the water and thus compromised safety. In Ooievaar, it was suggested that this problem could be solved through compensatory measures. Digging side channels and removing layers of clay and sand that had been deposited by the river would increase the conveyance

\footnotetext{
268 D. de Bruin Rivierbeheer op de Nederlandse Rijntakken p. 70

269 Rijkswaterstaat Maatregelen voor de verlaging van de maatgevende hoogwaterstanden van de Waal Arnhem: RIZA nota 91.022, 1985

270 R.H.G. Jongman 'Voordat de ooievaar komt ...' in: Landschap 1987, nummer 1, p. 45

271 Dick de Bruin et al. Ooievaar. De toekomst van het rivierengebied Arnhem: Stichting Gelderse Milieufederatie, 1987

272 For an account of the shift from nature conservation to nature development see Henny J. van der Windt En dan: wat is natuur nog in dit land?: natuurbescherming in Nederland 1880-1990 Amsterdam: Boom, 1995
} 
capacity of the river, thus compensating for forest growth ${ }^{273}$. What is more, these measures would contribute to restoring the riverine ecosystem and make the much opposed dike raising redundant. Additional advantages were that the extracted clay and sand were economically valuable, the conversion of agricultural land into nature would help shrink butter mountains, and the population would have authentic river nature to explore and admire 274 . In a word, Ooievaar embodied integrated river management.

The second event in 1986 was an ecological disaster. November 1, a fire broke out in a warehouse of the Swiss firm Sandoz in Basel. With the fighting of the fire large amounts of pesticides were released, which in a matter of days killed fish in the river on a massive scale. The Rhine had been toxic to species like the Salmon for decades, and action had been taken to regulate the emission of chemicals, but the Sandoz disaster made politicians and experts call for drastic restorative measures. The crisis led the Ministers of Rhine riparians to congregate and announce a Rhine Action Plan (RAP) a few months later. The plan aimed at the restoration of the Rhine ecosystem, by reducing the discharge of hazardous substances and by making it possible again for fish like the Salmon to migrate upstream and spawn 275 .

Shortly after the Sandoz disaster Minister of Public Works Neelie Smit-Kroes announced that the Rhine was going to be restored along the lines of Ooievaar. A pilot project would be realised in the Guelders Gate, the area where the Rhine river enters the country276. Ooievaar was generally well received among environmentalists and ecologists, but there were critical voices too. Among these was landscape ecologist Rob Jongman who argued that the plan might not be ecologically sound in all respects. Rare river valley plants might be affected by floodplain excavation and the polluted and unquiet character of the riverine area might inhibit the return of certain species. Besides pointing to possibly lacking ecological soundness, Jongman also objected to the way the plan had suddenly been presented by the Minister and Rijkswaterstaat as its new policy. Inhabitants from the area had not been consulted, and farmers were told that they would have to leave the floodplains 277 .

In 1989, side channels were dug and summer dikes were breached in the Duursche Waarden, a floodplain area of the river IJssel owned by the State Forestry Commission. The Ooievaar design thus became reality on a the scale of a single floodplain four years after the plan had been launched. What is more, both the Ministry of Public Works and the Ministry of Agriculture, Nature Management and Fisheries announced large scale interventions in the riverine areas along the lines of Ooievaar. The Third Policy Document on Water Management presented a vision of a 'much more dynamic, a more natural river system', while the Nature Policy Plan announced the

\footnotetext{
273 'Compensation' in a sustainable development context has come to be associated with planting trees to compensate for their destruction, or the production of $\mathrm{CO}_{2}$, elsewhere. Here, it has an entirely different meaning, namely that of compensating for the loss of the discharge capapacity of the river, which may involve the cutting of trees.

${ }^{274}$ At the time, 'butter mountains' was used as an expression to refer to the overproduction of dairy products in the European Community.

275 Koos Wieriks and Anne Schulte-Wülwer-Leidig 'Integrated water management for the Rhine river basin, from pollution prevention to ecosystem improvement' in: Natural Resources Forum, vol. 21, no. 2, 1997, pp. 147-156. Pieter Huisman provides details of how a treaty between the Rhine riparians dating from 1885 was unshelved to provide Minister Neelie Smit-Kroes with ammunition. The Minister simply stated that the treaty, by which it had been agreed that spawning sites of Salmon would be made accessible again, had never been disbanded. Pieter Huisman 'Rijnoeverstaten en Europese Unie ondernemen acties na vergiftingings- en overstromingsrampen' in: Tijdschrift voor Waterstaatsgeschiedenis 16/1, 2007, pp. 46-55

276 R.H.G. Jongman 'Voordat de ooievaar komt ...' in: Landschap 1987, nummer 1, p. 41

277 idem, p. 46
} 
development of 50,000 hectares of nature, part of which was to take place in the floodplains of the large rivers. Agricultural land would be converted into nature on an unprecedented scale.

The early nineties saw the rapid spread of nature development in the floodplains of the Rhine branches. Rijkswaterstaat calculated the lay-out of channels and excavations using state of the art hydraulic and morphological models. Specialized consultancy firms devoted themselves to drawing up plans in cooperation with authorities, fervently supported by nature organizations like the World Wildlife Fund. In 1992, WWF came with its own vision of how the Dutch rivers should be revitalized 278 .

The primacy of flood safety had never been in question whenever nature development projects in the floodplains were being conceived and realized. Rijkswaterstaat had been applying the compensatory principle: forest growth could be compensated by digging side channels and lowering floodplains. In the mid-nineties, however, the safety of the riverine area suddenly came to be seen in a very different light 279 . Two near-flood events in the context of growing concerns about climate change made flood safety an urgent political issue. In two consecutive winters, in December 1993 and in January 1995, flood waves in the Rhine nearly overtopped the dikes in the Dutch riverine area. In 1995, the situation was considered so critical that authorities decided to evacuate people from the land threatened by flooding. The Minister announced a Delta Plan for the Large Rivers, the title of which was to convey a sense of urgency, as it referred to the plan drawn up after the 1953 coastal flooding disaster, in which 1,835 people had died. Measures would be taken to avoid future evacuation, as this was seen as a very undesirable solution. First of all, the dikes were all to be raised to the level that could withstand the design discharge of 15,000 cubic metres per second. This design discharge had been estimated by extrapolating flood statistics from the past. The more dramatic political outcome of the crisis, however, was that the rivers should on the longer term be made climate proof. This introduced anticipatory policy in river management: change was imminent, and figures from the past were no longer considered a good measure. Experts expected that winters would become wetter in the future, and the two near-flood events in themselves raised the figure of the design discharge of 15,000 cubic metres per second. A figure of 18,000 cubic metres per second soon appeared in Rijkswaterstaat's reports as a mid-21st century climate proof design discharge.

Another outcome of the crisis was that water management experts convinced politicians that raising the dikes to ever higher levels was not a sustainable solution to making rivers climate proof. The conveyance capacity of the river could be enlarged by other means, as had been argued for about a decade and practised since 1989. Old solutions that had been abandoned early $20^{\text {th }}$ century, such as floodways, were also to be re-explored. The new policy titled 'room for the rivers' emphasised so-called spatial measures and put the option of dike raising last. The new emphasis on safety and making rivers climate proof was presented as compatible with enhancing river nature. In fact, policy documents presented 'room for rivers' as an inherently river friendly outlook: the rivers would be freed from their narrow corselet of dikes. What is more, 'room for the rivers' would also create room for stakeholders to have a say in planning. Now that spatial measures were prioritized, options like excavating floodplains, digging side channels, removing obstacles, widening the floodplain, in principle allowed for endless combinations. From the civil engineering viewpoint, the degrees of freedom of the hydraulic model could be fully exploited on

\footnotetext{
278 Wereld Natuur Fonds Levende Rivieren Zeist, WNF, 1992

279 This account covering the mid- to late-nineties is largely based on an earlier analysis: Mieke van Hemert 'Ruimte voor de ingenieur. Rivierbeheer in Nederland eind jaren negentig' in: Kennis \& Methode 23/4, 1999, pp. 361-378
} 
the condition that the combination of measures would fulfill the condition of the local design water level.

Both the remaining dike raising programme and the new explorations of how to make rivers climate proof continued to give rise to protests. But it became increasingly accepted that the consequences of climate change for riverine safety should indeed be anticipated, even if numbers like a future discharge of 18,000 cubic metres per second remained contested 280 . Immediately after the near-flood crisis of 1995, advocates of nature development felt that the power had almost entirely shifted back to the engineers of Rijkswaterstaat proclaiming the primacy of safety281. On the other hand, they felt that the policy of 'room for the rivers' still held possibilities for nature development. The main problem was how to reconcile the new safety requirements with nature's requirements.

In recent years, Rijkswaterstaat has introduced the term 'dynamic river management' as an updated version of integrated river management ${ }^{282}$. Dynamic river management is contrasted with the engineering tradition of the past, with its static approach to the river as 'canal and gutter' (kanaal en afvoergoot). In the dynamic approach rivers are to be dealt with as dynamic natural systems, the dynamism being distributed over river managers and rivers, as it turns out. One of the major needs of dynamic river management is close monitoring of the river system. The monitoring is considered necessary for a proper maintenance of the river system. The river is allowed to be more dynamic than a canal, but less dynamic than a freely meandering alluvial river. In maintaining the river's conveyance capacity, however, the river manager is supposed to be able to mimick the natural dynamics that the river lacks. In an extreme flood, an unregulated river may uproot trees and carry large amounts of clay and sand seawards. Dynamic river management suggests that cutting down forests and removing floodplain deposits amounts to the same thing. This approach is also referred to as 'cyclic floodplain rejuvenation', to which I will come back in later sections ${ }^{283}$.

From the above account it appears that river management has been undergoing important shifts between the early eighties and recent years, while there are also continuities. A major continuity is the primacy of safety over other river functions and other considerations. The conception of safety which guides river management has changed in some respects, and shows continuity in other. Like in the early eighties, flood safety is cast in terms of a design flood that is estimated to occur once in 1250 years. The design flood is estimated, and adjusted, on the basis of statistics from the past. But as a response to the near-flood events of the mid-nineties Rijkswaterstaat now counts with a future design discharge which anticipates more frequent flooding as the regional climate changes. A design flood wave determines the conveyance capacity of a river section and a hydraulic model is used to calculate safe designs. The degrees of freedom in the hydraulic model have, however, been reinterpreted to give rise to a whole repertoire of measures to re-design floodplains. This is a major shift in design practice as compared to the early eighties. The guiding principle then was to maintain the status quo, which meant maintaining a single channel and keeping the floodplains largely intact while bringing the dikes to design levels. With the adoption

\footnotetext{
280 Jeroen F. Warner The politics of flood insecurity. Framing contested river management projects Doctoral dissertation University of Wageningen, 2008, pp. 180-183

281 Interview, Eric Marteijn, 19 March 2004

282 N. Douben, H.E.J. Simons en M. ten Harkel Dynamisch rivierbeheer. Inventarisatie informatiebehoefte, resultaten eerste fase. RIZA rapport 2002.004, Arnhem, RIZA, 2002

283 Koen Moons 'Dynamiek buiten oevers. Ingrijpen in riviernatuur mag weer' in: Boomblad nr. 3, 2006, pp. $12-15$
} 
of Ooievaar as a guiding vision in the restoration of the large rivers, the principle of maintaining the status quo was abandoned. Floodplain forests were to replace grasslands, and side channels were to complement the main channel. River management became more of a spatial planning affair, with hydraulic models as ultimate checks for floodplain design ${ }^{284}$. Around 1990, measures along the lines of Ooievaar were considered one-time restorative measures from an ecological point of view, the idea being that once restored, riverine ecosystems would maintain themselves as complete ecosystems. From an hydraulic engineering point of view, however, the growth of riverine forests was a problem unless completely compensated by the lowering of floodplains in the initial floodplain design. The near-flood events of the mid-nineties put this problem prominently on the agenda. Safety and ecology were debated as antagonistic aims, while the primacy of safety remained uncontested among river management authorities and in the law. In the late nineties, the antagonism died down again as ecologists and engineers came to elaborate solutions answering both hydraulic and landscape ecological requirements. Dynamic river management as has been elaborated in recent years, entails a further shift in how ecological considerations are made compatible with hydraulic requirements. Ecological measures are no longer considered one-time restorative measures. Instead, regular maintenance is to mimick the dynamism of unregulated rivers.

\subsection{Emerging interdisciplinary river science}

In the early eighties, small lakes in the floodplains of the Rhine were an object of ecological study. The lakes, abundant with water lilies, were being studied as 'nymphaeid dominated ecosystems' by the Nijmegen Laboratory of Aquatic Ecology285. At the University of Wageningen, landscape architects and landscape ecologists elaborated spatial plans for the riverine area, concentrating on the floodplains ${ }^{286}$. The Rhine itself was monitored by toxicologists and aquatic ecologists, but thought to be too polluted to be worthy of ecological study at the Nijmegen Laboratory ${ }^{287}$. In the latter half of the eighties, the tides were turning. The Sandoz disaster which brought the Rhine Action Plan with its ambitious ecological targets, created new opportunities for research. Shortly after the RAP had been signed, three research institutes, RIZA, RIVM and RIVO, associated with the Ministries of Public Works (V\&W), Housing, Spatial Planning and Environment (VROM), and Agriculture, Nature Management and Fisheries (LNV) respectively, had drawn up a joint research proposal288. The three Ministries provided funds for 20 fulltime researchers for a period of three years to start with. Ecological Rehabilitation of the Rhine (EHR), as the research programme was called, aimed at studying the Rhine as an ecosystem and closely monitoring its restoration. It referred to ecological concepts discussed in the proceedings of the first international symposium on regulated streams held in 1979, The ecology of regulated streams (see chapter 3).

\footnotetext{
284 But see Dave Huitema and Stefan Kuks, who note that water management and spatial planning are still dealt with relatively separately. Dave Huitema and Stefan Kuks 'Harboring Water in a Crowded European Delta', p. 64 in: Hans Bressers and Stefan Kuks (eds.) Integrated governance and water basin management. Conditions for regime change towards sustainability Dordrecht: Kluwer Academic Publishers, 2004

285 BION Jaarverslagen 1980 and later years

286 J. Kuiper, R.H.G. Jongman 'Inrichting van uiterwaarden' in: Landschap 2(3), 1985, pp. 183-192

287 Interview, Gerard van der Velde, 30 May 2005; G.van Urk 'Lower Rhine-Meuse' in: B.A. Whitton (ed.)

Ecology of European Rivers Oxford: Blackwell, 1984 illustrates that the ecology of the Rhine was monitored at the time by RIZA, Rijkswaterstaat's freshwater research institute.

288 DBW/RIZA, RIVM, RIVO Ecological rehabilitation of the river Rhine: a proposal for a Netherlands research programme EHR rapport 1 Lelystad: RIZA, 1988
} 
Biologist Eric Marteijn, the newly appointed head of the subdepartment of Field Biology at Rijkswaterstaat's freshwater research institute RIZA, saw in EHR an opportunity to make engineers and ecologists work together on river restoration ${ }^{289}$. Marteijn had relevant experience in this regard: he had cooperated with engineers on issues related to the Oosterschelde storm surge barrier, which was considered a highly innovative example of how ecology and engineering could be integrated ${ }^{290}$. Besides being motivated by the Oosterschelde experience, Marteijn was much inspired by the approach to river restoration presented in Ooievaar. Ooievaar had also been embraced in the higher echelons of Rijkswaterstaat, but Marteijn soon realized that river restoration would have to start small, to gradually convince the engineering community that an ecological approach to river management wasn't 'going to bring Rijkswaterstaat on the rocks' as one engineer put it. A considerable amount of resistance to experimenting with river restoration existed at Rijkswaterstaat's regional offices. But there were also engineers who were willing to work with ecologists, but had no interdisciplinary experience. Marteijn saw it as a challenge to get these engineers involved in EHR. The first restorative measures realised under his responsibility were fish passages, and experiments with willows as river bank protection, the latter being allowed under the condition that the willows would be removed after five years ${ }^{291}$.

The early nineties saw the rapid emergence of a network of river restoration researchers. Within the framework of EHR, research was being commissioned to ecotoxicologists, aquatic ecologists, landscape ecologists, geomorphologists and engineers affiliated to governmental research institutes, universities and specialised consultancy firms ${ }^{292}$. As river restoration in the Guelders Gate area was expected to take shape as one of the first large scale experiments, Rijkswaterstaat's regional office in Arnhem and provincial authorities started to commission research to elaborate the plans. The design of stable side channels and the rate of forest growth in the floodplains were to be looked into before river restoration could be allowed on a large scale. Thus, a whole network of organisations with expertise on river engineering, riverine ecology and nature management became involved in research projects geared to elaborate river restoration along the lines of Ooievaar and Living Rivers. What is more, in the early nineties restoration of the river Meuse came to be viewed as particularly feasible as it was suggested that nature restoration could be financed from gravel revenues ${ }^{293}$. A plan had been drawn up by a consultancy firm specialised in stream restoration and was well received in policy circles. In 1992, Rijkswaterstaat's research institute RIZA started a project Ecological Rehabilitation of the Meuse, as a twin project to EHR.

The emerging community of river restoration researchers formed more or less distinct subgroups with different ecological orientations, that were having a different weight in river restoration practice. Ecotoxicologists focused on toxic substances and their effects on riverine organisms, aquatic ecologists inventoried and modelled riverine communities in floodplain lakes and the main river channel, while landscape ecologists, geomorphologists and engineers elaborated river restoration scenarios and plans. The former two groups continued to do research in the context of EHR, meticulously monitoring the ecological state of the Rhine, without having

\footnotetext{
289 Interview, Eric Marteijn, 19 March 2004

290 See Cornelis Disco 'Remaking “nature”. The Ecological Turn in Dutch Water Management' in: Science, Technology \& Human Values, 27/2, 2002, pp. 206-235

291 Interview, Eric Marteijn, 19 March 2004

292 J.A. van de Kraats Rehabilitation of the River Rhine. Proceedings of the International Conference on the Rehabilitation of the River Rhine 15-19 March 1993, Arnhem, the Netherlands Pergamon, 1994

293 Jeroen F. Warner The politics of flood insecurity. Framing contested river management projects Doctoral dissertation University of Wageningen, 2008, pp. 145-172
} 
much influence on the practice of river restoration. The latter group gradually developed what could be called a symbiotic relationship with river management authorities ${ }^{294}$. This symbiotic relationship took shape in the course of the nineties, through distributed reconfigurations and a centre for river research, institutional developments that I will now look into.

In 1992, the important contribution of landscape ecology to river restoration research was acknowledged institutionally. The Staring Centre (SC-DLO) and the Institute for Forestry and Nature Management (IBN-DLO), two nature management research institutes of the Ministry of Agriculture, Nature Management and Fisheries, joined RIZA, RIVM and RIVO in the second phase of EHR ${ }^{295}$. Landscape ecologists at the two institutes had elaborated the so-called Ecological Main Infrastructure of which the large rivers formed part, and had built models with which river landscape scenarios could be developed. Research referred to as 'habitat restoration' now became a joint responsibility of RIZA, SC-DLO and IBN-DLO.

In 1993 a considerable sum of money became available for R\&D projects related to river management. The Ministry of Economic Affairs and the Ministry of Education and Science agreed to spend part of the national gas revenues on the Dutch 'knowledge infrastructure', 250 million guilders (113 million euro) in total. The injection was meant to stimulate the use and further development of information technologies in physical planning and the economy. The interdepartmental committee responsible for allocating the funds (ICES-KIS) approached the civil engineering community to draw up a programme. In 1992, a project group rivers was formed to contribute to a programme provisionally titled Land Water Impulse (LWI). In 1993, a 90 million guilders 4-year R\&D programme had been drawn up requesting ICES-KIS 45 million as the funds were allocated on the condition of $50 \%$ matching by the participating institutes themselves ${ }^{296}$. The programme, managed by the Ministry of Public Works with heavy involvement of Rijkswaterstaat, was meant to stimulate cooperation within the civil engineering sector, between 'developers' and 'users' of knowledge. However, the practice of elaborating research proposals in concertation with other parties was new to the civil engineers of Delft University, who were used to the commissioning of research by Rijkswaterstaat. A practicable procedure for the selection of academic research proposals was only developed when the LWI programme, retitled Land Water Environment Information Technology, was already half-completed 297 . Most river projects revolved around building Decision Support Systems: software applications based on hydraulic models, GIS and remote sensing techniques resulting from cooperation between Rijkswaterstaat, Delft Hydraulics and one of the major civil engineering firms ${ }^{298}$. The project group rivers had been allocated some 13 million guilders for the whole period, running from 1993 until 1997. Like the Universities of Delft, Twente and Utrecht, the nature management research institutes SC-DLO and IBN-DLO only became involved in the later stages of the programme. The civil engineering

\footnotetext{
${ }^{294}$ Ecotoxicology and aquatic ecology also interact with water management authorities, but through specific boundary arrangements. See Willem Halffman Boundaries of Regulatory Science. Eco/toxicology and aquatic hazards of chemicals in the US, England and the Netherlands, 1970-1995 Doctoral dissertation University of Amsterdam, 2003 on ecotoxicology and Henny J. van der Windt 'De amoebe als verbeelding der natuur' in: Kennis \& Methode, 19/3, 1995, pp. 251-276 on aquatic ecology.

295 W. Admiraal et al. Ecological Rehabilitation of the rivers Rhine and Meuse: Netherlands research program 1992-1995 EHR rapport 40, Lelystad: RIZA, 1992

296 Ministerie van Verkeer en Waterstaat Land Water Impulsprogramma. Investeringsplan ICES-project kennisinfrastructuur, 1993

297 Interview, Peter Holdert, 7 July 2004

298 LWI Alle projecten van LWI op CD, 2000
} 
community responsible for drawing up the programme had overlooked the river modelling activities taking place within these institutes 299 .

In 1994, aquatic ecologist Piet Nienhuis was appointed full professor at the department of Environmental Sciences at the University of Nijmegen. Nienhuis was well aquainted with the local situation as he held a chair in estuarine ecology in Nijmegen since 1988 (see chapter 4). He found that the environmental sciences department lacked in research focus, while it did well in acquiring contract research at a variety of governmental levels ${ }^{300}$. The department decided that its niche within the environmental sciences was to be 'river science'. Several strategic considerations lay at the basis of this decision. As river restoration figured prominently on policy agendas and could be combined with other politically hot issues like biodiversity and climate change, it seemed safe to count on a continuing stream of funds for river science. What is more, both the department itself and neighbouring departments like the aquatic ecology group had been involved in river research for years. Close contacts existed with RIZA, through EHR, and with the regional office of Rijkswaterstaat in Arnhem. Furthermore, river science had become a distinctive focus of interdisciplinary research at the international level (see chapter 3), to which the department could contribute. In 1995, the year that the government announced a Delta Plan for the large rivers in response to the river floods in January, the department organised a symposium on integrated management of large river catchments and presented its first research programme. In his contribution to the symposium Piet Nienhuis advocated international, catchment oriented river management based on insights that fifteen years of interdisciplinary river science had yielded ${ }^{301}$. A list of 'conclusions and recommendations for further research' made at the 1993 international conference on the rehabilitation of the Rhine organized by RIZA in the context of EHR, was pasted into the research programme ${ }^{302}$. The biggest challenge, according to the EHR conclusions, lay in habitat restoration, which required close cooperation between ecologists and engineers. The department of Environmental Sciences at the University of Nijmegen considered itself ideally suited to take on this challenge.

By the mid-nineties then, a variety of cooperative arrangements between river research groups existed without forming a fully connected network. Delft Hydraulics and Delft University cooperated with RIZA, the Wageningen based nature management research institutes SC-DLO and IBN-DLO and the Universities of Utrecht and Twente. The University of Nijmegen had a longstanding cooperation with RIZA, while it considered SC-DLO and IBN-DLO as competitors. On the whole, river research thrived after the second near-flood event in 1995, as the government made available ample funds for realizing its new policy to create room for rivers. In 1997, the European government followed by making available funds for a flood control programme drawn up by river management authorities in the countries that are part of the Rhine and Meuse river basins. Soon, it became clear that the Interreg Rhine Meuse Activities (IRMA) programme held opportunities for doing research. At around the same time, the Delft based civil engineering community was busy establishing a so-called Delft Cluster with the aim of jointly drawing up a long-term integrated research programme eligible for funds within the ICES-KIS scheme. In ICES-KIS II 465 million guilders were made available in total for a four year period again.

\footnotetext{
299 Interview, Peter Holdert, 7 July 2004

300 Interview, Piet Nienhuis, 28 April 2003

301 P.H. Nienhuis ‘ntegraal beheer van onze grote rivieren in een stroomversnelling’ in: Anon. Symposiumbundel Integraal beleid en beheer voor grote riviergebieden: een internationale uitdaging UCM/NIVAS KUN, 1995

302 P.H. Nienhuis Rivierkunde 1995-2000
} 
In this context of newly emerging funding opportunities, Delft Hydraulics took the initiative to establish a Netherlands Centre for River Studies (NCR), as a belated twin of the Netherlands Centre for Coastal Research (NCK). NCK had been established in 1992 as a cooperative arrangement between the Universities of Delft, Utrecht and Twente and Delft Hydraulics. NCK was considered a great success and served as a role model for NCR ${ }^{303}$. Coastal researchers had found cooperation beneficial, not the least in getting access to European funding. NCR was to have a somewhat different composition than NCK, reflecting the different cooperative arrangements that existed in river research. More explicitly than NCK, NCR aimed at responding to societal demands in river management ${ }^{304}$. The Centre listed hydrology, fluvial hydraulics, sedimentology, geomorphology, river ecology and social sciences as relevant fields.

By bringing together existing cooperative arrangements in a centre, new connections were established. The Environmental Sciences group at the University of Nijmegen, which had few contacts within the Delft based institutes, eagerly responded to the initiative. It considered river science as its 'core business' and saw 'added value' in integrating its knowledge of river ecology with other river research orientations ${ }^{305}$. October 1998, representatives of nine institutions signed the arrangement, involving a board, programme committee and a secretary at Delft Hydraulics. The University of Twente and the International Institute for Hydraulic Engineering (IHE) had by then joined the initial group, consisting of Delft Hydraulics, RIZA, SC-DLO, IBN-DLO and the Universities of Delft, Utrecht and Nijmegen.

Soon after its establishment, the NCR was asked to take on the responsibility of drawing up and managing a research programme as part of the Interreg Rhine-Meuse Activities (IRMA). Of the 114 million euro allocated to IRMA from Interregional EU funds, 15.7 million euro were available for 'improving knowledge and cooperation' ${ }^{306}$. By the end of 1999, a programme had been drawn up, listing 13 projects to be executed by NCR's members in cooperation with Belgian, German, French and Swiss research institutes and universities. IRMA-SPONGE (Scientific Programme on Generating Sustainable Flood Control) as the programme was called, was to develop a 'transnational, integrative, innovative and transferable' approach to flood risk management, and to make European scientists, water managers and spatial planners cooperate on this policy goal 307 .

The IRMA-SPONGE programme fulfilled the expectation that participating in NCR meant access to European funding sources. But access to European funding sources, however important, was not the mission of the centre. From the beginning, developing a joint research programme had been an important aim. Taken together, research undertaken by NCR's members was to answer 'the long-term needs of society' for river expertise as formulated by Rijkswaterstaat's research institute RIZA ${ }^{308}$. In a preliminary version of the programme, topics of interest were listed under one of three themes, according to scale: river basin, river and floodplain ${ }^{309}$. In a later version listing projects, the latter two themes were combined into one, and the theme of 'development of large systems' was added, reflecting the important role of computer modelling and data

\footnotetext{
303 Interview, Ad van Os (secretary NCK and NCR), 13 June 2003

${ }^{304}$ Anon. Achtergronden NCR. Document dating from 1998.

305 R.S.E.W Leuven \& P.H. Nienhuis 'River science at Nijmegen University: ecological rehabilitation of rivers', paper for the Fifth Convention day River Basin Management, May 28, 1998

${ }^{306}$ A. Hooijer, A.G. van Os Umbrella Programme IRMA-SPONGE. Background, Scope and Methodology. NCR Publicatie 04-2001, p. 11

307 idem, p. 2

${ }^{308}$ A.F. Wolters \& E.C.L. Marteijn (eds.) De weg van maatschappelijke vraag naar onderzoek NCR publicatie 02-2000

309 Anon. 1998 NCR Hoofdlijnen van het activiteitenprogramma
} 
management in river research ${ }^{310}$. As a rule, projects were listed in the programme if two or more of NCR's member institutes were involved in it. One of the consequences of this rule was a large overlap between the NCR programme and the Delft Cluster river engineering programme, in which the University of Delft and Delft Hydraulics were heavily involved. By 2000 then, the research programme of NCR had taken shape as an aggregation of two large programmes, Delft Cluster and IRMA-SPONGE, and a number of smaller projects sorted into three themes. Early 2001, a somewhat more refined subdivision of research themes was agreed upon. On the scale of the river basin, 'genesis of floods' referred to research on hydrological processes and flood control. The themes of 'multiple spatial planning' and 'cyclic rejuvenation of floodplains' were to cover research on the smaller scale, that of river and floodplain, characterized as 'research on the interface physics/morphology/ecology'311. For each of the themes, the board had appointed a coordinator, whose task it would be to identify 'knowledge gaps' after making an inventory of research relevant to the theme, and to stimulate NCR members to 'fill up' the gaps ${ }^{312}$. According to Hans Middelkoop, coordinator of the Cyclic Floodplain Rejuvenation theme, this procedure worked in characteristic bottom-up fashion leaving the much treasured academic freedom intact313.

The above sketch of emerging interdisciplinary river science in the Netherlands highlights institutional developments as strategic responses to changing contexts of river management, research funding and, more in the background, emerging river science as a field. In the late eighties and early nineties, ecologists, geomorphologists and engineers at governmental research institutes, universities and engineering firms were hired by Rijkwaterstaat's research institute RIZA, the regional office of Rijkswaterstaat in Arnhem, and by non-governmental nature organisations like the World Wildlife Fund, to elaborate river restoration principles and plans. Joint involvement of ecologists, geomorphologists and engineers in river restoration research started at RIZA in the late eighties. The frequent contacts between ecologists, geomorphologists and engineers at research institutes, universities and engineering firms, who were hired for their expertise then made something of a river research community emerge. In the mid-nineties, the formation of an academic river science niche at the University of Nijmegen and the reorientation of Delft river engineers to new sources of research funding brought with it new cooperative arrangements. The prospect of jointly applying for river research funds at national and European levels then culminated in a national centre for river studies with governmental research institutes and universities as participants. The formation of the centre brought with it joint research programming, with the identification of priority themes and new joint research projects.

\subsection{The shaping of a local research configuration}

When in the late eighties Rijkswaterstaat had embraced restoration of the Rhine along the lines of Ooievaar, a set of questions arose from its task to safely conduct a design flood. The central question was which impact river restoration might have on water levels during floods. This was crucial information in view of the so-called compensatory principle as formulated in the law

\footnotetext{
310 Anon. 2000 Samenvatting NCR programma, versie 1999-2000

311 A.G. van Os (ed.) Summary of NCR Programme, version 2001-2002 NCR publication 05-2001, p. 3

312 A.J.M. Smits \& H. Middelkoop 'Introduction to NCR-research theme Cyclic Floodplain Rejuvenation' in:

R.S.E.W Leuven, A.G. van Os \& P.H. Nienhuis (eds.) Proceedings NCR-days 2002. Current themes in Dutch

river research. NCR Publication 20-2003, pp. 88-91

313 Interview, Hans Middelkoop, 17 May 2005
} 
(Rivierenwet 1908): if floodplain forests would push up the water level in one place, this effect was to be compensated elsewhere to reduce the net effect in a section of the river to zero.

Rijkswaterstaat had at its disposal an hydraulic model built by Delft Hydraulics with which the net effects of different designs were calculated. In the model, called WAQUA, floodplain vegetation was represented in a roughness parameter. Experiments with physical scale models and measurements of water levels in vegetated floodplains during floods had yielded estimations of roughness values for different types of vegetation. To run the numerical hydraulic model, the river was spatially represented as a grid of cells, each cell having values for roughness and height of the river bed. For a given flood wave then, the model could calculate water levels in each cell of the grid. In 1990, Rijkswaterstaat's regional office in Arnhem presented the results of water level calculations for different acreages of floodplain forests and floodplain lowering, involving different scenarios for the Millingerwaard, which belongs to the Guelders Gate ${ }^{314}$.

Projecting acreages of forests in floodplains for hydraulic calculations was one thing, knowing how the growth of vegetation in floodplains would actually take place was another, no less crucial question. Once summer dikes would be breached, side channels dug and floodplains lowered, a sequence of riverine habitats was expected to develop spontaneously. But the picture sketched in Ooievaar was very general and also contested among ecologists. Rijkswaterstaat could do with some more detailed, floodplain specific information of how vegetation could be expected to develop after the digging had been done. In the context of the research programme Ecological Rehabilitation of the Rhine, research was commissioned to ecologists using different models to predict vegetation development.

At the Ecology and Policy section of the National Technological Institute (TNO), ecologist Harm Duel elaborated a model of potential climax vegetation in floodplains as determined by conditioning factors ${ }^{315}$. In the model, inundation duration and vegetation management were regarded the main manipulable conditions. The former depended on the level of the floodplain, which could be lowered, the latter involved grazing by large herbivores, or grassland production, or no intervention at all. The soil as deposited by the river, the geomorphology of the floodplain, also counted as a conditioning factor. From recent inventories of floodplain vegetation and conditioning factors, Duel composed a matrix consisting of 35 types of vegetation, each type corresponding with specific combinations of factors. Riparian woodland dominated by Salix alba (a willow species) for instance, could be expected in parts of the floodplain bordering the main channel, inundated between 50 and 150 days a year. In the parts inundated between 120 and 150 days a year, swamp vegetation with Carex acuta (a sedge species) would occur as well, while in the less frequently inundated parts, other swamp and grass species would accompany the willow woods. For each scenario of floodplain redesign, the model yielded a 'potential vegetation', the vegetation types to be expected at a specific location. The hydraulic model calculated water levels for grid cells of $50 \times 50$ metres, which was considered a scale fine enough to represent vegetation types as well. The results of modelling the potential vegetation for each of the Millingerwaard scenarios were fed into the hydraulic model to get an idea of the impact of different acreages of forest on water levels.

\footnotetext{
${ }^{314}$ Harm Duel \& Cees Kwakernaak 'Rivierdynamiek in uiterwaarden' in: Landschap 1992 9/4, pp. 255-271

315 Harm Duel Natuurontwikkeling in de uiterwaarden. Perspectieven voor het vergroten van de rivierdynamiek en het ontwikkelen van ooibossen in de uiterwaarden van de Rijn. Rapport Ecologisch Herstel Rijn, nr. 29, 1991
} 
In 1990, RIZA commissioned ecologist Han Runhaar at the Centre for Environmental Sciences $(\mathrm{CML})$ at the University of Leiden with a river ecosystems study316. The study was to yield a typology for making an inventory of ecosystems in the whole riverine region, and a model to predict the impact of interventions. In the eighties, ecologists at CML had drawn up a classification of vegetation types in which the main determining 'operational' factors were soil acidity, nutrients, humidity, and dynamics in the sense of natural disturbances. The basic units of the classification, areas homogeneous in vegetation type, were called ecotopes. For the Netherlands as a whole, 80 ecotopes had been distinguished, each with its characteristic plant species. Though more detailed in terms of plant species composition, Runhaar considered the ecotope classification compatible with the vegetation types as proposed by Duel. The ecotope model was, however, considered superior in how it represented the factors underlying the distribution of vegetation types.

Since a complete field inventory of vegetation types in the riverine area would be very expensive, Runhaar proposed to use aerial photographs instead. A vegetation structure map of scale 1:10.000 could be produced for 60,000 guilders, compared to more than 2 million guilders for a complete field inventory. Such a map would do for evaluating the impact of vegetation on water levels. The WAQUA hydraulic model required roughness values for grid cells of $50 \times 50$ metres. A vegetation structure map at scale 1:10.000 would be adequate in this respect, given the coarse information available on roughness values of vegetation. To make a more refined ecotope map with information about plant species composition, available field vegetation inventories could be used. An indication of plant species composition would also be required if the ecotope inventory was to be used in connection with existing ecological status indicators for aquatic environments like the AMOEBE ${ }^{317}$. A stochastic model, an alternative to the proposed deterministic model would not do, Runhaar concluded, since the hydraulic WAQUA model required spatially determined outcomes.

By the mid-nineties, ecotopes, conceived as spatial units homogeneous in vegetation that could be discerned by visually inspecting aerial photographs had become the standard for inventorying river nature and modelling its development. In 1994, RIZA had decided that a standard would have to be defined for planning and policy studies since the existing systems were all different and neither of these was completely satisfactory ${ }^{318}$. Roughly a dozen classification systems existed, including the vegetation types and the ecotope system as proposed in the TNO and CML studies. The standard would be based on existing classifications, and was to be meaningful from a policy perspective. Policy relevance was further specified as hydraulic and ecological criteria. The former entailed 'a typology which links up with aspects that can be manipulated in river management, such as hydraulic resistance, height and conveying capacity', the latter translated into 'ecotopes distinguished on the basis of specific ecological content (vegetation composition,

\footnotetext{
$316 \mathrm{~J}$. Runhaar Beschrijving en voorspelling van de vegetatie in het rivierengebied. Opzet van een Geografisch Informatiesysteem en een voorspellingsmodel voor de vegetatie in het gebied van de Grote Rivieren. CML report 72, 1991

317 AMOEBE (Abstract Method for Overall Examination of the Biological Ambience) had been developed during the eighties as an ecological indicator of water quality. It visualised species abundance (both plants and animals) as compared to an ecological reference (the year 1930). The AMOEBE mediated between science and policy, and was widely embraced as an ecological indicator. Henny J. van der Windt 'De amoebe als verbeelding der natuur' in: Kennis \& Methode, 19/3, 1995, pp. 251-276

318 J.G.M. Rademakers \& H.P. Wolfert Het Rivier-Ecotopen-Stelsel: een indeling van ecologisch relevante ruimtelijke eenheden ten behoeve van ontwerp- en beleidsstudies in het buitendijkse rivierengebied EHR rapport 61, RIZA Lelystad, 1994
} 
soil development and habitat quality)'319. The classification system should also be of a manageable size, counting between 15 and 25 ecotopes. Finally, drawing ecotope maps should be uncomplicated, and make use of available sources like soil maps and aerial photographs. Having these requirements in view and on the basis of earlier experience in river nature studies, landscape ecologists affiliated to the engineering firm Grontmij and SC-DLO devised a RiverEcotope-System. It counted 18 ecotopes, that could be subdivided further into eco-elements. The classification was based on three factors determining vegetation types: hydrological, morphological and land use dynamics, each factor being represented as a small number of classes.

The River Ecotope System soon became widely accepted as a standard in the policy oriented environment of SC-DLO, RIZA and Delft Hydraulics ${ }^{320}$. At SC-DLO, ecotopes had become the basic units of nature to work with since the elaboration of the Ecological Main Structure in the late eighties. Parallel to the studies at TNO and CML, nature development plans for the Guelders Gate area had been evaluated by ecologists from SC-DLO. Their studies had yielded a Landscape Ecological Decision Support Model (LEDESS), with which ecotope development could be simulated over time ${ }^{321}$. RIZA combined the LEDESS and WAQUA models to assess plans for redesigning the floodplains in the context of the new policy room for the rivers. At Delft Hydraulics, ecologists debated the pros and cons of ecotopes to formulate aims of nature policies and came to the conclusion that ecotope distributions were to be preferred over species numbers ${ }^{322}$. In their view, ecotopes could be quantified, steered and monitored much more easily than species abundance, while representing the habitat of species and thus a measure of their potential abundance. From a policy studies perspective then, ecotope distributions were considered an appropriate measure of the state of nature.

Assessing the impact of room for the river measures on vegetation development and water levels thus proceeded by coupling two models, a hydraulic model and a vegetation development model. In this modelling exercise it was assumed that the geometry of the river bed would not change after the floodplain lowering had been completed. But river engineers and geomorphologists were well aware that this assumption did not hold. Even the channel of highly regulated, canalized rivers was known to undergo erosion and sedimentation and these morphological dynamics were expected to increase with the 'room for the rivers' interventions. For this reason, morphological dynamics of the Rhine branches were receiving ample attention in the mid-nineties. Delft Hydraulics had built morphological models in which water flow and sediment transport were coupled processes, and the subject received attention at the University of Delft as well. At the University of Utrecht, geomorphologists were elaborating ways of measuring and estimating the speed at which floodplains were silting up ${ }^{323}$.

In the late nineties, it came to be considered feasible and desirable to model three interacting dynamics that had hitherto been dealt with in couples of two: water flow, river morphology and vegetation development. Two new university chairs, at Nijmegen and Delft, and the establishment of the Netherlands Centre for River Studies worked as catalysts for this problem of interacting

\footnotetext{
319 idem, p. 23

320 Interview, Henk Wolfert, 24 June 2003

321 W.B. Harms, W.C. Knol en J. Roos-Klein Lankhorst 'Het LEDESS-model. Een gebiedsgericht kennismodel bij scenario's voor natuurontwikkeling' in: Landschap 12/2, 1995, pp. 83-98

322 G.B.M. Pedroli, R. Postma, M.J.J. Kerkhofs en J.G.M. Rademakers 'Welke natuur hoort er bij de rivier?' in Landschap 13/2, 1996, pp. 97-113

323 Abstracts symposium Rivierdynamiek, verleden, heden en toekomst 30 October 1997
} 
river dynamics to emerge on the research agendas of Dutch river researchers and rank high on it in a few years time.

At the University of Delft, civil engineer Huib de Vriend was appointed to a part-time chair in river morphology and engineering (see chapter 4). The hydraulic engineering section of which the chair was part, closely cooperated with Delft Hydraulics and largely depended on Rijkswaterstaat for contract research. De Vriend knew this institutional environment well, as he had been working at Delft Hydraulics until he moved to Twente, and he supported the new paradigm of 'working with the natural river dynamics'. This new engineering paradigm opened up a whole set of research questions about river dynamics, De Vriend argued. One of these questions concerned the interaction between physical river dynamics and vegetation:

... the behaviour of natural rivers is co-determined, on all sorts of scales, by vegetation through a process of lively mutual interaction. This is a fascinating research area, hardly tread upon, in which morphologists trained in engineering have a role to play too ${ }^{324}$.

At the University of Nijmegen, ecologist Toine Smits was appointed to a special chair in nature conservation of stream corridors, funded by Rijkswaterstaat. Smits had been working on ecological studies at RIZA in the early nineties, had completed a PhD in aquatic ecology at the University of Nijmegen in 1995, and was now involved in the research project Room for the Rhine branches at the regional office of Rijkswaterstaat in Arnhem. The chair meant a further strengthening of the river science orientation of the Department of Environmental Sciences. What is more, Smits soon started bringing together river engineers and ecologists to stimulate further cooperation between them, which was a goal figuring prominently in the department's research programme. In September 1998, an international conference was held in Nijmegen, having sustainable river management as its topic ${ }^{325}$. Prince Willem-Alexander of the Netherlands held an opening address, promoting the 'room for rivers' policy by employing a metaphor of life:

Rivers are like living creatures. They are dynamic and need space. It is in the nature of rivers that they refuse to stay straight. If you try to cage a river by building dikes too close to the main stream and by excessive normalisation, it will struggle to break out like a wild beast 326 .

Meanwhile, the Netherlands Centre for River Studies (NCR) was taking shape and prospects for doing research in the context of the International Rhine-Meuse Activities (IRMA) arose. At Delft Hydraulics where the NCR was going to be based, the Delft Cluster research programme was in course of preparation. Ecologist Harm Duel, who had moved from TNO to Delft Hydraulics and was interested in interactive river dynamics, took on the first opportunity with Toine Smits, and the second with Huib de Vriend. To the IRMA-SPONGE management, which was the NCR, a research proposal entitled 'cyclic rejuvenation of floodplains' was submitted and granted funding327. Contractor of the research project was Rijkswaterstaat, with Delft Hydraulics, Nijmegen University, Delft University, the two nature management research institutes SC-DLO and

324 H.J. de Vriend Een kwestie van respect Inaugural address University of Delft, 24 January 1997, p. 5 325 A.J.M. Smits, P.H. Nienhuis \& R.S.E.W Leuven (eds.) New approaches to river management Leiden: Backhuys Publishers, 2000

326 Prince Willem-Alexander of Orange 'The value of sustainable river management' in: A.J.M. Smits et al. New Approaches to river management, p. 4

327 A.J.M. Smits, P.H. Nienhuis \& R.S.E.W Leuven 'New approaches to river management: general introduction' in: A.J.M. Smits et al. New approaches to river management Leiden: Backhuys Publishers, 2000, pp. 7-14 
IBN-DLO which had merged into Alterra, the German Department of Public Works, the World Wildlife Fund and Stuttgart University as subcontractors. When the IRMA-SPONGE projects were starting up, a complementary research proposal titled 'biogeomorphological development of floodplains' was drawn up for the Delft Cluster programme ${ }^{328}$. Participants in this research project were Delft Hydraulics, the University of Delft, Alterra and the International Institute for Hydraulic Engineering (IHE). Both research projects revolved around modelling interactions between hydrological, morphological and vegetation dynamics.

The notion of cyclic rejuvenation had been adopted from the river science literature ${ }^{329}$. In the mid-eighties, the French PIREN-Rhône team (see chapter 3) had described how during flooding events floodplain forests were 'set back' to the pioneer stage of succession. Different parts of the floodplain were 'rejuvenated' at each flooding event, as the river shifted its course. These dynamics were considered responsible for the high biodiversity of river floodplains. To enhance biodiversity in the Rhine floodplains then, the dynamics of cyclic rejuvenation were to be reintroduced. The highly regulated Rhine river could, however, not be turned into a freely meandering river again. Cyclic floodplain rejuvenation as proposed by Smits entailed an ingenious alternative: the natural dynamics could be mimicked by cutting down forests, lowering floodplains and digging side channels. This conception of cyclic rejuvenation in terms of river floodplain maintenance solved the problem of the decreasing conveyance capacity as well. If forests were cut down and floodplains lowered from time to time, then the conveyance capacity of the river could be maintained.

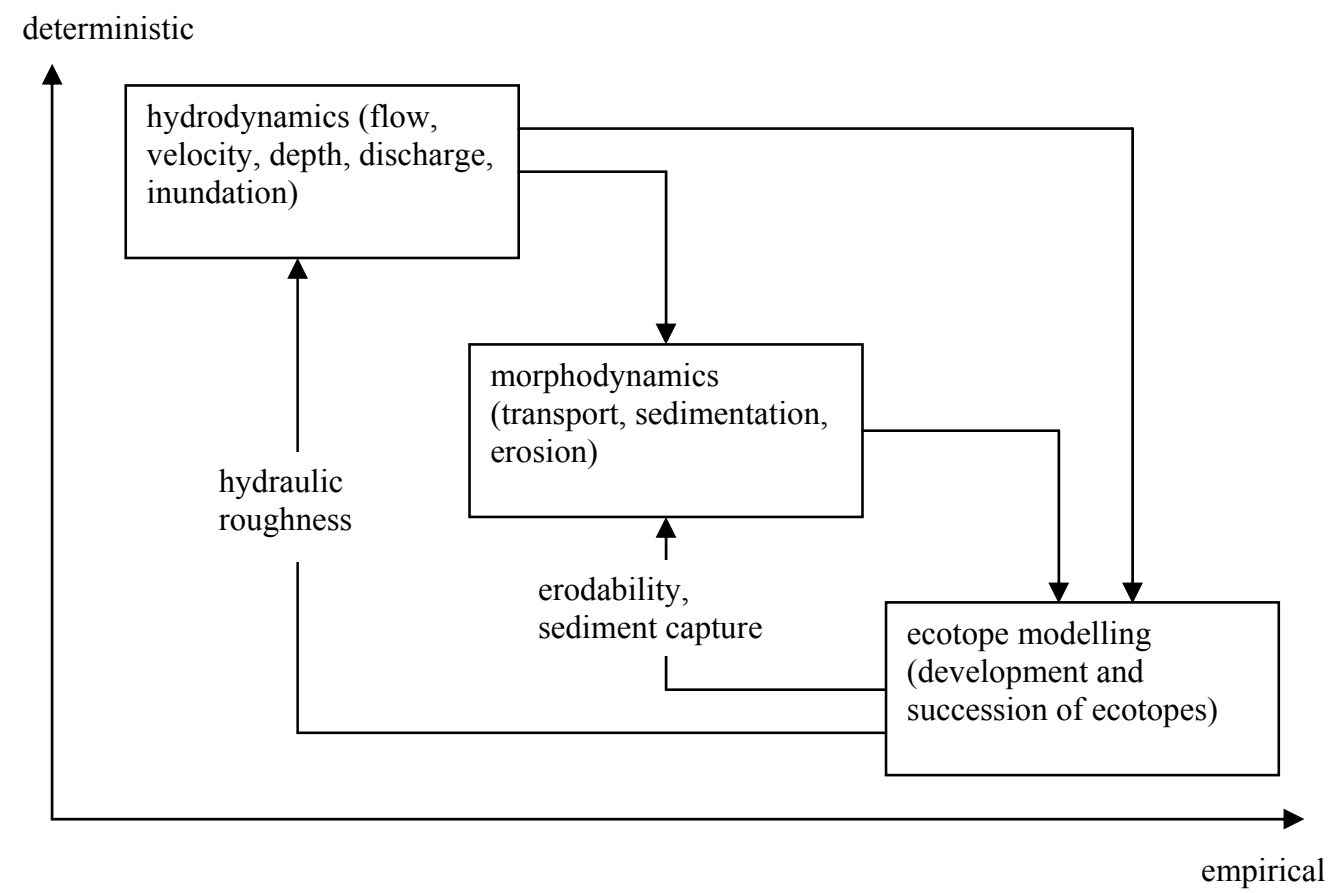

Fig.6 Model of interactive river dynamics in IRMA-SPONGE cyclic floodplain rejuvenation research (NCR publication 04-2001, p. 38). The model couples hydraulic, morphological and ecological modules.

\footnotetext{
328 Anon. Biogeomorphological development of floodplains, research proposal Delft Cluster Theme 3 Coast and River, 2000

329 Interview, Gertjan Geerling, 30 November 2005
} 
The main goal of the IRMA-SPONGE research project was to elaborate cyclic rejuvenation in terms of spontaneous ecological and morphological developments in river floodplains on the one hand, and the maintenance needed to mimick rejuvenation while keeping within the constraints of flood safety on the other ${ }^{330}$. Flood safety, translated as water levels that should not be exceeded, determined what was relevant to study about ecological and morphological dynamics. In this context, 'hydraulic roughness' of vegetation emerged as a topic of central importance. To show how riverine plant and animal communities would benefit, the availability of habitats and their suitability for specific species would be assessed ${ }^{331}$. This second line of study would build on the first as it worked with the same units of river nature: ecotopes.

The Delft Cluster research project titled biogeomorphological development of floodplains was going to deal with the same research problem of interactive dynamics, but with a different emphasis. The study, being oriented to 'the integrated discipline of biogeomorphology' had as its main objective:

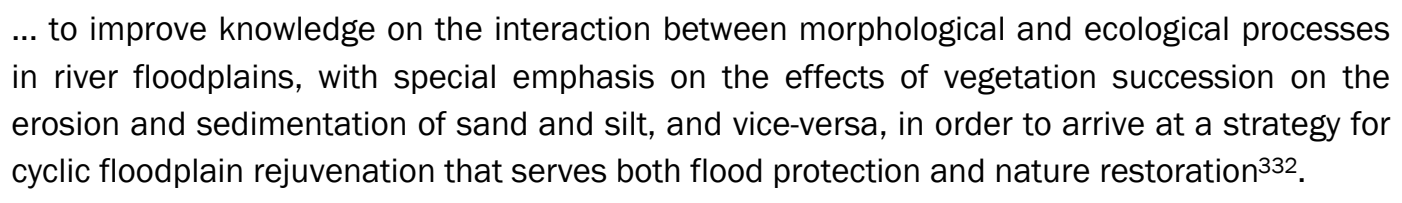

The Delft Cluster project thus focused on the interaction between morphological dynamics and vegetation succession, while the IRMA-SPONGE project dealt with the impact of hydrodynamics and morphodynamics on vegetation succession and the subsequent changes in flood water levels as caused by the changed geometry and hydraulic roughness. The IRMA-SPONGE research problem was formulated in such a way that results could be generated by running available hydraulic, morphological and vegetation succession models in sequence ${ }^{333}$ :

The modelling framework consists of three modules that will be run in sequence. First, the water movement is computed using DELFT3D-FLOW, next the morphological developments are computed using DELFT3D-MOR. Output from these modules will feed into a third module, the ecotope generator .... The hydrodynamic and morphological models deliver the abiotic conditions that denote the suitability for ecotopes and the succession of vegetation which affects hydraulic roughness that is subsequent input for the hydro-morphological models. 334

This modelling exercise, further sophistication of the modules and the Delft Cluster project together provided the basis for a PhD study on biogeomorphology335. Like in regular hydraulic research, the modelling was geared to solving a design problem. Being a research problem of representing natural river dynamics on the one hand and a design problem of how to maintain river floodplains in view of specific safety norms on the other, it translated a primacy of safety into a primacy of hydraulics. That is, the model was run with design water levels as the end-point of

\footnotetext{
330 H. Duel, M. Baptist \& W.E. Penning Cyclic Rejuvenation of Floodplains. CFR Project Main Report. NCR Publication 2001 p. 14

331 idem, p. 5

332 Anon. 'Biogeomorphological development of floodplains', research proposal Delft Cluster Theme 3 Coast and River, 2000.

333 H. Duel et al. 'Cylic Rejuvenation of Floodplains' p. 43

${ }^{334}$ A. Hooijer \& A.G. van Os Umbrella Program IRMA-SPONGE Background, Scope and Methodology NCR publication 04-2001, p. 37

335 Martin Baptist Modelling floodplain biogeomorphology Doctoral dissertation University of Delft, 2005
} 
iterations, floodplain sedimentation, forest growth and 'rejuvenation' measures being simulated until the design water levels were reached ${ }^{336}$.

By the time the IRMA-SPONGE project had ended, cyclic floodplain rejuvenation and biogeomorphology had been adopted by the NCR board members as labels for river research at the scale of the floodplain. Running floodplain scale research projects were rubricated under the label of cyclic floodplain rejuvenation and new projects were formulated, some following up the 'recommendations for further research' as formulated in the final report of the IRMA-SPONGE research project. In these recommendations, it was suggested that besides advancing modelling, giving more attention to the monitoring of river dynamics would be of central importance to elaborate cyclic floodplain rejuvenation as a strategy of dynamic river management. The monitoring was to focus on hydraulic roughness and ecotope types, for which remote sensing techniques were considered 'very promising'337.

The prioritisation of hydraulic roughness and ecotopes as topics for research and the characterisation of remote sensing, and more specifically Landsat images and laseraltimetry as promising techniques did not come out of the blue. Since 1998, Rijkswaterstaat had used ecotope maps that were based on the River Ecotope System. Ecotopes were converted into roughness values to feed the hydraulic models. Ecotopes had hitherto been mapped by visually inspecting aerial photographs, while remote sensing techniques held possibilities for automatised monitoring of ecotopes. Remote sensing could be used to produce more finely grained vegetation structure maps, and thus more finely grained hydraulic roughness maps. In the late nineties, Toine Smits' group at the University of Nijmegen and the Survey Department of Rijkswaterstaat had come to cooperate on the subject with an eye to the cyclic floodplain rejuvenation strategy. Developing a method to use remote sensing for monitoring floodplain vegetation now continued as a PhD project funded by the Survey Department, which also delivered the data ${ }^{338}$. Another project revolving around the use of remote sensing was granted funding from the Land Ocean Interactions in the Coastal Zone-International Geosphere-Biosphere Programme (LOICZ-IGBP) managed by the national research council NW0339. In this project, the department of Environmental Sciences at the University of Nijmegen cooperated with the department of Physical Geography at the University of Utrecht, to make it an interdisciplinary project fitting the requirements of the research council funding 340 .

Cyclic floodplain rejuvenation and biogeomorphology came to refer to hydraulic, geomorphological and ecological research considered relevant to the research problem of interactive river dynamics and dynamic river management. In a more narrow sense, these labels referred to the interdisciplinary research problem of interactive river dynamics as it had been

\footnotetext{
${ }^{336}$ Martin J. Baptist, W. Ellis Penning, Harm Duel, Antonius J.M. Smits, Gertjan W. Geerling, Guda E.M. Van der Lee, and Jos S.L. Van Alphen 'Assessment of Cyclic Floodplain Rejuvenation on Flood Levels and Biodiversity in the Rhine River' in: River Research and Applications 20/3, 2004, pp. 285-297. The localness of the CFR model, and its relation with Dutch river management policy and practice also comes out clearly when constrasted with a similar but different local research problem and modular modelling approach of interactive river dynamics without the safety constraints and with an emphasis on river channel pattern evolution and plant succession, not roughness: Keith Richards, James Brasington and Francine Hughes 'Geomorphic dynamics of floodplains: ecological implications and a potential modelling strategy' in: Freshwater Biology 47, 2002, pp. 559-579

${ }^{337} \mathrm{H}$. Duel et al. 'Cyclic Rejuvenation of Floodplains', p. 61

338 G.W. Geerling \& A.J.M. Smits 'Monitoring floodplain vegetation dynamics using remote sensing in the context of cylic floodplain rejuvenation' in: Proceedings NCR-days 2002, NCR publication 20-2003, pp. 9295

339 http://nwo.nl/projecten.nsf/pages/1700113894 accessed 17 April 2008

340 Interview, Piet Nienhuis, 28 April 2003
} 
taking shape since the late nineties. Here, hydraulic roughness emerged as a central concern and remote sensing came to be seen as the most promising technique to obtain values of this parameter at detailed spatial scales.

In sketching the emergence of a local research configuration revolving around a research problem of three interacting river dynamics, I aimed at discussing how Dutch river management has contributed to shaping it. In the emergence of the research problem of interacting hydrodynamics, morphodynamics and vegetation dynamics, two phases may be distinguished. From the late eighties until the late nineties, two pairs of research problems were dealt with separately. Firstly, there was the question of how vegetation in the floodplain would develop, depending on water levels, and how water levels in turn would be raised as vegetation developed. Ecologists at universities and governmental research institutes were commissioned to study the question of how floodplain vegetation would develop. To calculate water levels, a hydraulic model was available, as well as roughness parameter values for vegetation types. As my account shows, the ecological studies were accommodated to the hydraulic modelling that served to calculate safe floodplain designs. Ecotopes, as defined in the River Ecotope System, emerged as standard units of river nature. Ecology was thus narrowed down to vegetation structure. Secondly, there was the question of interacting hydrodynamics and morphodynamics. This was a long-standing engineering problem, for which Delft Hydraulics had elaborated computer models. The research problem of interacting hydrodynamics, morphodynamics and vegetation dynamics emerged from these existing lines of modelling. It emerged as a design problem: how to reconcile the policy aims of safety and biodiversity in the design of floodplains. In terms of a design problem, the primacy of safety remained uncontested. For the modelling of the three interacting dynamics this meant that the requirements of the hydraulic model determined what was relevant about morphology and ecology. This primacy of hydraulics has also left it mark on the further elaboration of the interacting dynamics: hydraulic roughness has become a central concern.

Institutionally, the first phase of the emergence of the local research configuration was centred in research institutes, notably RIZA, Delft Hydraulics, SC-DLO and IBN-DLO, and Rijkswaterstaat, notably its regional office in Arnhem. In the second phase, the Universities of Nijmegen and Delft, and again Delft Hydraulics came to play a pivotal role, Rijkswaterstaat being closely involved as well. Institutional heterogeneity is even more pronounced if the wider circle of participating research institutes, universities, governmental agencies, non-governmental nature organisations and engineering firms are taken into account.

\subsection{Conclusions}

How to characterise emerging interdisciplinary river science in the Netherlands? The first two parts of this chapters show how interdisciplinary river science has emerged in close interaction with the shift to a new river management regime. Institutional interdependencies, dual affiliations, and research programmes geared to deal with river management problems point to a symbiotic relationship between emerging interdisciplinary river science and transforming river management in the Netherlands. An apparent continuity is a primacy of safety in river management, which translates into a primacy of hydraulics in interdisciplinary configurations.

The Netherlands Centre for River Studies, while not being the exclusive locus of interdisciplinary river research, has become an important institutional arrangement as it helps in getting access to funding sources by fulfilling the requirements of interdisciplinary, inter- 
institutional river research. As noted, the Centre's initial research programme overlapped to a large extent with the programmes of Delft based institutes. The long-standing cooperation between Delft Hydraulics and the University of Delft translated into a strong position of these hydraulics oriented institutes in the new Centre. Subsequent programming and interdisciplinary modelling maintained the strong position of river engineering in interdisciplinary river research. Interdisciplinary river research in the Netherlands as it develops through the Centre's involvement is first and foremost hydraulics oriented. The Centre's listing of hydrology, fluvial hydraulics, sedimentology and geomorphology as individually relevant specialties and the lumping of ecological specialties into river ecology as well as social scientific specialties into social sciences furthermore expresses a primacy of engineering and earth sciences over ecology and social sciences.

All in all, interdisciplinary river science in the Netherlands is first and foremost hydraulics and natural sciences oriented. The above account however shows that the continuing primacy of hydraulics (and secondary primacies like just mentioned) is not to be understood as simply motivated and brought about by interests of powerful actors and institutions, but as 'sedimented' relations of power in knowledge configurations. The historically strong position of hydraulics in river research and management in the Netherlands is re-inscribed in newly emerging models and institutional arrangements, protected by the continuing concern about safety 341 .

Practitioners of different fields may follow their own perspective while embarking on interdisciplinary research cooperation, by flexibly interpreting a shared thing, concept, or story line. This is captured by the notion of boundary object. These often emerge in contexts in which hierarchies play a role ${ }^{342}$. What insights does my analysis of the local research configuration of interacting river dynamics yield in this respect? In the assembled research problem of interacting hydrodynamics, morphodynamics and ecological dynamics as it emerged in the late nineties the ecotope, a spatial unit, has functioned as a boundary object. The ecotope is a landscape ecological notion, which became accepted as a basic unit of river nature in the context of river management requirements, notably spatial information on hydraulic roughness of vegetation. From the perspective of hydraulics, an ecotope represents hydraulic roughness, in geomorphology it is a landscape element and from an ecological perspective it is the habitat of plant and animal species. As one river researcher phrased the difference between hydraulics and ecology, and the way they relate in research problems of interacting river dynamics:

A hydraulic engineer sees a stick that forms an obstacle and an ecologist sees a Poplar that is healthy or not and that lives in competition. But the fact that the Poplar is there follows from the laws of ecology, while it influences the river system according to the laws of hydraulics ${ }^{343}$.

\footnotetext{
${ }^{341}$ Cornelis Disco speaks of Dutch 'water culture' as multilevel technological systems, modes of organization and mentality. Cornelis Disco 'Delta Blues' in: Technology and Culture vol. 47, 2006, pp. 341348. Anne Wesselink views Dutch framings of and responses to flood risks as an expression of a vulnerable technological culture which finds itself in a hydraulic engineering control paradigm lock-in. A.J. Wesselink 'Flood safety in the Netherlands: The Dutch response to Hurricane Katrina' in: Technology in Society 29, 2007, pp. 239-247. Both discuss the central role of hydraulics in Dutch 'water-and-safety' culture. I show how the centrality of hydraulics affects the production of new knowledge of rivers.

342 Chunglin Kwa points at such hierarchies in the emergence of boundary objects in his study of ecology in the International Geosphere-Biosphere Programme. Chunglin Kwa 'Local Ecologies and Global Science: Discourses and Strategies of the International Geosphere-Biosphere Programme' in: Social Studies of Science 36/6, 2005, pp. 923-950

343 Interview, Hans Middelkoop, 17 May 2005
} 
In this quote, there is no notable primacy, but processes are framed as one-way. There is a suggestion of ontological incommensurability combined with a pragmatic commensurability of causal regularities. But there is a primacy as the dominance of safety considerations in river management has brought with it a primacy of hydraulics in the interdiscipinary modelling effort: ecology is relevant only in so far as it yields information on hydraulic roughness. In terms of data, this means that only vegetation structure, not its composition, matters and that aquatic life is irrelevant. A similar selection is at work in the representation of morphological dynamics: relevant are the changing geometry of the river bed and its roughness, not its history. Thus, ecological and morphological modelling is geared to provide information on hydraulic parameters. At the same time ecological and morphological modelling is not restricted to what is relevant to hydraulics. Ecological research on ecotope succession contributes to the interdisciplinary research problem of interactive river dynamics, but also to the ecological research problem of how habitats are spatially distributed. Aquatic ecology has adopted the notion of ecotope too, but studies aquatic ecotopes in ways very different from landscape ecology.

The research problem of interacting river dynamics discussed thus brings and ties together disparate fields and other institutions into a local research configuration which yields local knowledge, and which affects these fields. The binding involves more than a single boundary object, but less than a fully standardised package. As in a standardised package, there are several elements providing for common ground: the ecotope, remote sensing as a source of data, model coupling. There is also a shared research problem which puts the component research problems of hydrodynamics, morphodynamics and vegetation dynamics in a new, interdisciplinary perspective. But there is no standard for obtaining and exchanging the spatial information that forms the input and output of the coupled models, and in that sense no standardised package. A variety of remote sensing techniques, including satellite spectrometry, airborne spectrometry and airborne laseraltimetry, are currently experimented with ${ }^{344}$.

In this chapter I have discussed emerging river science in the Netherlands and a local research configuration, as shaped by evolving river management policies and practices on the one hand and research funding opportunities on the other. The accounts presented in earlier chapters invites at a discussion of the ways in which Dutch river science and the local research configuration of interacting river dynamics has been shaped by other contexts than those relevant in the light of the localised setting of research. The division of labour between specialties in the local research configuration, with input-output relations between specialty modules in the interdisciplinary model, and the use of remote sensing as an important source of data can be related to wider developments (discussed in chapters 3 and 4). The local research configuration, local knowledge of river dynamics, bears traces of both the localised setting and cosmopolitan river science, as well as other contexts. It is also clear that the local research configuration cannot be reduced to a local instance of cosmopolitan river science nor its component problems be reduced to local instances of the specialties that contribute to river science.

\footnotetext{
${ }^{344}$ For an account of the emergence of the 'digital ecotope' see: C.L. Kwa, M. van Hemert \& L. van der Weij 'Visualizing Landscapes: Gestalts, Models, Pictures' forthcoming in: Scholten, H.J., van de Velde, R.J., van Manen, N. (eds), The role of Geo-ICT and Spatial Approaches in Science, Springer, Dordrecht, 2008
} 


\section{Chapter 6 Conclusions}

This chapter first presents summaries of the three 'cross-sections' of river science, and draws some conclusions by adding them up. Next, it offers a contribution to the debate on features of contemporary technoscience as distilled from the three diagnoses, by specifying aspects of river science listed in chapter 2 and evaluating claims made in the diagnoses. Finally, I discuss contributions to the current debate on (river) nature and landscape in the Netherlands to explore how this study may contribute to this debate.

\subsection{Research findings}

In this study I have articulated three 'cross-sections' of river science in the sense that they are different historical accounts, with different units of analysis, at different 'levels', while covering the same period of twenty-five years. Together, they provide a layered, composite, unfolding picture of the emergence and development of river science between 1980 and 2005.

\section{Summaries}

The first 'cross-section' is an account of the emergence and development of river science as a cosmopolitan field. The central question is how interdisciplinarity took shape over the years, conceptually, instrumentationally and institutionally, and how these dimensions of river science were mutually adjusted.

It appeared that river science as an interdisciplinary field emerged around the environmental issue of degraded, dammed rivers. An important event for the emergence of interdisciplinary river science was an international meeting devoted to the ecology of regulated rivers. At the meeting, stream ecologists formulated a research agenda for the study of dammed rivers, with earth scientists and engineers participating as well. At the time, interdisciplinarity in river research was being experimented with in a variety of ways. Theoretical unification was still an ideal, visible in the River Continuum Concept. The RCC imported energy equilibrium theory from geomorphology to stream ecology. Energy equilibrium theory thus figured as a unifying theory to explain the physical and biological functioning of a river from source to mouth. Interdisciplinarity also assumed other forms at the time, including a spatial classification shared between ecologists and geomorphologists and the assessment of suitable fish habitat by simulating hydraulic conditions of river sections.

In the course of the eighties, complexity thinking came to pervade ecology and the earth sciences and the ideal of theoretical unfication withered. Computer modelling and the use of available remote sensing images, notably satellite images of increasing resolutions came to be seen as promising techniques to advance knowledge of rivers. Contacts between river researchers of ecological and earth scientific backgrounds intensified as international meetings on regulated rivers were held every four years, a journal was established, and river restoration became a goal of governments. With different strands of complexity thinking circulating, river scientists embraced a version of hierarchy theory that matched the emerging concern about spatial scales and the availability of spatial techniques to obtain and analyse spatial data. By the end of the eighties, widespread agreement had emerged around the conception of the river as a spatially nested hierarchy. To further articulate this conception empirically, satellite and airborne remote sensing techniques with their growing range of spatial resolutions and reflectances seemed a particularly suitable source of data. Gradually, remote sensing came to be seen as an 
indispensable source of data, given its range of spatial resolutions, its synoptic images and its possibilities for automated data gathering and analysis. Thus, the conception of the river as a spatially nested hierarchy and the use of remote sensing and spatial modelling techniques to articulate patterns and processes at different levels of resolution evolved interdependently. Related to these developments in turn were emerging views of interdisciplinary cooperation as the coupling of specialty modules.

Thus, I argue that in recent years views on interdisciplinary divisions of labour in river science are shaped by a discourse on modularity. Modularity is recognisable in widely embraced concepts and instruments. Hierarchical hydrological/geomorphological/ecological systems are viewed as composed of spatial units at different levels, nested into higher level spatial units. Processes of water flow, landscape formation and animal and plant life are generally dealt with as modules, to be coupled in an integrated modelling framework. In the first conception, modules are spatial units, in the second, modules represent separate processes modeled by different specialties. The two are aligned in various ways in proposals of how to do interdisciplinary river science building on a conception of rivers as spatially nested hierarchies. Information and spatial technologies have contributed to shaping this conception of the river as a spatially nested hierarchy and to institutionalising interdisciplinarity, in both concrete and discursive ways.

The second 'cross-section' takes a look at developments in five fields that contribute to river research in the Netherlands. It is an attempt to articulate how national science policies have contributed to shaping conceptual, instrumentational and institutional developments in five fields, that are institutionalised as specialties at the national level. Thus, in this cross-section the unit of analysis is comprised of five specialties: landscape ecology, freshwater ecology, geomorphology, hydrology and hydraulics. To discuss how science policies have contributed to developments in these specialties, I distinguish between conceptual and instrumentational dimensions or 'search strategies' on the one hand and institutional 'survival' strategies on the other. Science policies generally refrain from steering search strategies directly, while in the period of study notable pressure has been exerted on research groups to 'scale up' institutionally and to embark on interdisciplinary research cooperation.

To articulate the co-production of search strategies and institutional survival strategies as induced by science policies, I followed a three track approach. Firstly, I interviewed group leaders about their strategies vis-à-vis interdisciplinary and inter-institutional research cooperation. It appeared that the group leaders generally considered it necessary to embark on inter-institutional and interdisciplinary research cooperation. That is, they considered establishing or joining interinstitutional and interdisciplinary centres and programmes crucial to get access to important sources of funding at national and European levels. It appeared, furthermore, that in these centres and programmes some search strategies were favoured over others. Also, group leaders indicated how interdisciplinary research cooperation generally proceeded, not by probing into one another's theories and methods, but by connecting what had been developed within different specialties. To further investigate possible structural effects of science policies in this regard, I looked into science policies on the one hand and developments in the specialties on the other, both from roughly 1980 onwards. An analysis of policy documents yielded that the general thrust of science policies was towards increased cooperation and coordination, between research groups and societal actors, between research groups nationally, between research groups internationally, and, increasingly, between disciplines. Calls to cooperate, coordinate and programme at the national, disciplinary level were characteristic of the eighties, motivated by a 
striving for efficiency. Interdisciplinarity was associated with the solving of societal problems and with applied science. During the nineties, cooperation, coordination and programming at national and international levels came to be motivated more by competitiveness. Calls for interdisciplinary complementarity on the one hand, and disciplinary coordination on the other, existed side by side. In the course of the nineties, interdisciplinary research came to be appreciated for its production of novelty. I conclude that the different pressures and appreciations added up to a space of opportunities and requirements in which retaining a viable position within a discipline (specialty) was to be reconciled with participating in interdisciplinary research programmes. Then, the question is how all this had worked out, structurally, at the level of specialties. Sketches of developments in the five specialties serve to draw tentative conclusions. Besides the apparent contrasts between the specialties, which emerged under different historical circumstances, constructed very different objects of study and evolved in unique ways, I have noted commonalities and convergences. It appeared that in all of the specialties research programming and the setting of priorities has been introduced in the eighties. In the nineties, research schools and centres have been established either along specialty lines or as a combination of specialties. Regarding search strategies, the specialties have come to employ roughly the same repertoire of modelling strands, and the same spatial technologies: geographic information systems and remote sensing. A systems view was shared among the specialties around 1980 and still is, yet its meaning has shifted with the adoption of complexity thinking. Self-organisation has become a widely shared notion.

I conclude that the multiplication of institutional frameworks and instances of coordination among and between researchers and research groups oriented to different specialties has contributed to the widespread adoption of specific search strategies. Science policies geared to coordination and cooperation thus contribute to intellectual change.

The third 'cross-section' again takes river science as its unit of analysis. It discusses how interdisciplinary river science has been emerging in the Netherlands in symbiosis with a new regime of river management. I then analyse how a local river research configuration is shaped in part by river management policies and practices.

In the Netherlands, the engineering paradigm of river management started to crumble in the early eighties, following more than a decade of protests against dike raising. According to the protesters, the engineering approach destroyed the nature, culture and landscape of the riverine area. In 1986, Ooievaar, a plan to restore riverine nature while removing agriculture from the floodplains, was widely embraced as the new, integrated approach to river management. After the Sandoz accident, ecological monitoring and experimental restoration of the Rhine were taken up by a variety of research institutes and university groups, the freshwater research institute of Rijkswaterstaat playing a central role. In the mid-nineties, in the context of two near-flood events, flood safety became high on the political agenda. Room for the rivers, the widening and lowering of floodplains, was presented as a timely alternative to the unsustainable approach of raising the dikes ever further. In recent years, dynamic river management has been elaborated as a synthesis of floodplain maintenance with an eye to flood safety on the one hand and the mimicking of river dynamics deemed natural on the other.

With the emergence of integrated river management in the late eighties, ecologists and geomorphologists at research institutes and universities saw opportunities emerge for doing commissioned river research. In elaborating river management along the lines of Ooievaar, Rijkswaterstaat and its freshwater research institute called for expertise on the development of 
vegetation in the floodplain. Forests in the floodplain would raise the water level and thus compromise safety. With an eye to controlling this type of 'hydraulic roughness', landscape ecologists were asked to model the expansion of forests in the floodplain. Aquatic ecologists had no role to play but to continue the monitoring of river and floodplain lake ecology. To be able to deal with the question of roughness efficiently, the freshwater research institute decided upon standardisation. A standard, the river ecotope system, was devised by concentrating on vegetation structure rather than other aspects, like composition. The distribution of river ecotopes could be monitored relatively cheaply with aerial photographs.

Meanwhile, a network of river researchers was taking shape in the context of shifting research funding opportunities and the emergence of river science as a cosmopolitan field. The University of Delft and Delft Hydraulics had long-standing relations with the freshwater institute and Rijkswaterstaat. Ecologists at the University of Nijmegen formulated a river science research programme advocating cooperation with engineers. In 1998, river researchers established a national centre, to enhance cooperation and get access to research funding requiring interinstitutional, interdisciplinary river research. In the European research programme that followed soon, ecologists and engineers forged a new synthesis between flood safety and enhancement of river nature. Cyclic floodplain rejuvenation, as the synthesizing concept was called, entailed the modelling of three interacting river dynamics.

I discuss how this model was shaped in part by Dutch river management policy. In river management policy, flood safety holds primacy over other considerations, like biodiversity. As safety is framed in terms of water levels that should not be exceeded, hydraulics provides the relevant expertise. The contribution of ecology and geomorphology depends on what they can deliver for the parameters of the hydraulic model. Thus, for instance, the contribution of ecology to the interdisciplinary modelling practice is a model of ecotope dynamics, which feeds the hydraulic model with roughness values. In this way, a primacy of safety translates into a primacy of hydraulics in the model of interacting river dynamics.

\section{Adding up the cross-sections}

The three historical accounts together offer a 'composite picture' of the emergence and development of river science between 1980 and 2005. Each of the three cross-sections foregrounds specific contexts relevant to the emergence and development of river science. The first account, of cosmopolitan interdisciplinary river science, shows how river science emerged around an issue, then institutionalised and further transformed with information and remote sensing technologies becoming pervasive. The second account, which has five specialties which contribute to river science in the Netherlands as its focus, sheds light on the strategising of scientists vis-à-vis science policies and what this strategising adds up to. The third account, which focuses on river science in the Netherlands and the emergence of a local research configuration, foregrounds how river management policies and practices contribute to shaping a local river research configuration. The three cross-sections are interrelated: a local research configuration can be interpreted as being shaped by both national river management policies and practices, as well as by more extended institutional and technological contexts.

River science has emerged under different circumstances in different countries and geographical regions. The examples from the US, France and the Netherlands show differently configured specialty interactions. In the US and France, the issue of river degradation caused by large dams resulted in interactions most strongly between aquatic ecology (and fisheries research), hydrology (and hydraulics), and geomorphology. Later on, landscape ecology became a 
guiding ecological approach. In the Netherlands, river degradation caused by canalisation emerged as an issue somewhat later (with pollution as a prominent issue as well), and resulted in interactions between emerging landscape ecology, hydraulics and geomorphology. The prominent role of hydraulics in the Netherlands can be attributed to the specific history of dealing with flood safety, the 'hydraulic culture'.

Interdependencies between local and cosmopolitan practices have changed. Around 1980, river researchers published primarily with colleagues from their own institution or other institutions in their country. Cosmopolitan activities were international meetings and journal publishing. Currently, teams of researchers from different countries jointly publish articles. Cosmopolitan activities now include email lists and internet. While not a theme in this study as such, processes of Europeanisation and globalisation are clearly visible.

\subsection{Contribution to current debates}

The co-production approach as adopted in this study has yielded a historical and contextual account of 1. divisions of labour between specialties (how interdisciplinarity institutionalises), the subject of knowledge, 2. conceptions of rivers (the concepts and models), the object of knowledge, and 3. the technologies (instrumentation), that mediate between subject and object, which fits one of the central theses in science studies. This thesis entails that neither nature nor social relations explain the production of (scientific) knowledge.

This study of river science is meant as a contribution to two debates. The first debate has been introduced in chapter 1 and concerns diagnoses of contemporary science, aspects of which are to be evaluated with river science as a case. The second concerns the role of techno-science in our dealings with nature and landscape, a debate that I sketch to explore how this thesis may contribute. In what follows, I will deal with the two debates separately.

What sorts of insights do the three accounts yield in the light of the questions raised at the beginning? In chapter 2, I distilled five aspects from three diagnoses of recent science. I will now evaluate these aspects on the basis of the research findings as summarised above.

Primacy of technology

What are roles of technology in river science? In chapter 3 I have explored this question by distinguishing between concrete and discursive workings of technology. At a concrete level, the dynamic interplay between remote sensing techniques as a source of data and spatial modelling of riverine processes has come to play a central role in the production of new knowledge about rivers. Rivers have come to be conceived of as spatially nested hierarchies in the context of diversifying remote sensing techniques and remote sensing has subsequently been identified as an indispensable source of data to elaborate this conception empirically. Thus, a productive cycle is at work which thrives on the further elaboration of remote sensing techniques as a source of data and the further sophistication of spatial simulation models to deal with these data. One may speak of a primacy of technological development over conceptual development. But then, isn't this - filling up a paradigm with data - what Kuhn has called normal science? The question may be turned around: do river scientists (still) bother about conceptual development and how? Here, it appears that complexity thinking has brought about a remarkable shift. Around 1980, emerging interdisciplinary river science saw its last attempt at unified theory. The widespread adoption of complexity thinking in the eighties made theorizing a much more local affair, in the sense that the modelling of processes proceeded without an overarching theory. Complexity thinking does not 
provide an overarching theory, it rather made river scientists adopt a new ontology: the river is a spatially nested hierarchy. This has, in a certain sense, reversed the roles of technological and conceptual development: what is henceforth shared among local modelling efforts was not (the expectation of) a unifying theoretical framework, but technologies interacting with concepts. What is more, the prominence of data-driven modelling as noted in chapter 4 indicates that theorizing about processes is no longer considered necessary to advance the modelling of river behaviour and to come up with predictions. A primacy of technology as manifest in the concrete workings of technologies like remote sensing and modelling thus revolve around an overall predominance of data-technology in the production of new knowledge.

By suggesting discursive workings of technology in river science, I have added an extra layer which puts the question of a primacy of technology in a paradoxical light. Here, the insight that concepts emerge both in discourse and in a material, technological setting helps us to understand how hierarchy theory, the conception of rivers as spatially nested hierarchies and proposals for interdisciplinary cooperation revolving around modularity are shaped in part by information technology and by a discourse that expresses the pervasiveness of information technologies. As Rosalind Williams notes, technologies may be so pervasive that they come to shape cultural practices to an important extent: 'The rules that govern the technology start to govern everything else. Technological drift becomes technological momentum, which begins to feel very much like technological determinism'345. This is how in river science technology works through discourse.

Disciplines, interdisciplinarity, transdisciplinarity

How do disciplinary frameworks endure or dissolve from the perspective of river science and what has been shared across disciplines and specialties? It seems that the widespread approach to interdisciplinarity in which specialty modules are coupled makes disciplines both endure and dissolve. Emerging interdisciplinary river science is an example of how new, interdisciplinary combinations of specialties come to exist alongside older specialties. This is in itself nothing new, but the eagerness with which specialty combinations are currently proclaimed to be new fields and their proliferation seem unprecedented. By way of comparison, the seventies were a time when further specialisation within disciplines resulted in such (sub)specialties as stream ecology and fluvial geomorphology, interdisciplinary combinations such as landscape ecology being rarer.

When the perspective is shifted to older specialties that contribute to river science, as in chapter 4 , it turns out that these configurations do not disappear from the scene. In most of the specialties studied, concerns about being recognized in science policy circles as an autonomous, fully-fledged scientific field bring with it research programming and community building at the national level. In some cases, the balance shifts to interdisciplinary institutional configurations, but specialty affiliations continue to be meaningful ties, as apparent from the specialty accounts. That doesn't imply that researcher's identities are always clearcut - as one river scientist with an environmental sciences background told me: 'I don't really have a discipline. You see that with other river scientists as well.'

Chapters 3, 4 and 5 have given both broad and detailed accounts of what has been shared across specialties, including specialties of different disciplines, between 1980 and 2005. In chapter 3, it turned out that around 1980, interdisciplinarity was practised in at least three ways. The adoption of geomorphological energy equilibrium theory by stream ecologists involved the

${ }^{345}$ Rosalind Williams Retooling: a historian confronts technological change Cambridge (Mass.): MIT Press, 2002, p. 116 
sharing of theory, with an eye to theoretical unification. The Fluvial Hydrosystems framework entailed a spatial classification shared by geomorphologists and ecologists, with chaos theory as a non-equilibrium outlook in the background. In PHABSIM, a hydraulic module provided data for an ecological module, simulated hydraulic variables functioning as an indication of habitat suitability. With the emergence of the spatially nested hierarchy paradigm with remote sensing as a source of data, tasks are being assigned to specialties as specialty modules in a systems architecture. Chapter 4 revealed that the concept of self-organisation, the spatial technologies of GIS and remote sensing, and a repertoire of modelling strands are widely shared across bio/geoscience specialties and hydraulics. Practitioners of the specialties admit that interdisciplinarity generally doesn't involve the probing of one another's theories and methods. In chapter 5 , the local research configuration revolving around the research problem of interacting hydro-, morpho- and ecodynamics entails the coupling of hydraulic, morphological and ecotope development modules, through conversion of spatial attributes.

The above characterisation of cross-disciplinary traffic, coordination and cooperation confirm Forman's claim about the sharing of technology rather than theory. Furthermore, while older specialties endure, the proliferation of specialty combinations does indicate a backgrounding of disciplines as guiding institutions. The local research configuration discussed in chapter 5 has many of the characteristics of a transdisciplinary configuration as proposed by Gibbons and colleagues. The integration of specialty contributions as the coupling of specialty modules geared to solving a design problem fits their notion of transdisciplinarity, which does not differentiate between the sharing of theory or technology. The two claims together thus yield a fairly accurate picture of the character of cross-disciplinary traffic and cooperation in river science.

My analysis of what is shared across specialties that contribute to river science concurs with Chunglin Kwa's more general analysis of interdisciplinarity in the bio/geosciences ${ }^{346}$. He notes a waning of unifying deductive theory since the late seventies, which he interprets as science's version of the demise of grand narratives. Deductive theory has been substituted by 'low theories', medium-level theories and models living together eclectically. These 'low theories' are made commensurable through the data-technology of remote sensing. That is, conceptual incommensurability is ignored, and the sharing of remote sensing as a source of data allows for the building of interdisciplinary models. This is exactly what happens in river science as well. What my analysis adds to this is how interdisciplinary research as the coupling of specialty modules, complexity thinking, remote sensing and computer modelling evolve interdependently. Unlike in Kwa's examples interdisciplinary cooperation is actively pursued by river scientists, not only an opportunity in large research programmes. Divisions of labour between specialties are accommodated to concepts and technologies deemed promising.

Institutional heterogeneity

The sort of institutional heterogeneity concerning the involvement of different fields in the production of knowledge - interdisciplinarity - has been discussed above. But there is more to institutional heterogeneity in river science: a variety of societal institutions is involved alongside cosmopolitan institutions, scientific fields. What may be concluded about this sort of institutional heterogeneity? The account of emerging river science in the Netherlands has yielded relevant findings. It appeared that in the traditional engineering regime of river management, Rijkswaterstaat, assumed a central position. Rijkswaterstaat dealt with river channels and floodplains as

346 Chunglin Kwa 'Interdisciplinarity and Postmodernity in the Environmental Sciences' in: History and Technology, 21/4, 2005, pp. 331-344 
hydraulic structures and accommodated heterogeneous concerns if these could be brought in line with hydraulic requirements. Research was commissioned to individual research groups at research institutes and universities. For hydraulic expertise, Rijkswaterstaat relied on Delft Hydraulics and the University of Delft, and the governmental freshwater research institute RIZA. With the emergence of integrated river management, the 'room for the rivers' policy and interdisciplinary river science, a far more heterogeneous configuration of institutions became involved in the design of river channels and floodplains. Universities, research institutes focusing on nature management, governmental agencies on a variety of levels, non-governmental nature organisations and specialised firms have come to cooperate with Rijkswaterstaat and its traditional partners. Research is no longer commissioned to single groups, instead institutionally heterogeneous consortia are formed. The research programmes of the Netherlands Centre for River Studies and its research projects like those rubricated under the theme of cyclic floodplain rejuvenation reflect this sort of institutional heterogeneity.

Institutional heterogeneity in the sense of different institutions being involved, however, does not imply the co-existence and confrontation of heterogeneous perspectives and approaches. As institutionally heterogeneous configurations institutionalise, and different perspectives and approaches are brought in alignment, dominant sets of rules emerge. Mutual coordination within institutionally heterogeneous configurations may make different institutions converge in their practices. This sort of processes have been shown to be at work in river science and contributing specialties as converging search strategies in chapter 4 and standardisation of river nature as ecotopes in chapter 5 .

What may be said about the structure of institutionally heterogeneous knowledge producing configurations? Here, my analysis of cyclic floodplain rejuvenation as a local research configuration provides relevant details. It appears that hydraulics has primacy over other specialties: it constrains and enables the sort of contribution that other fields may make in the interdisciplinary configuration. The primacy of hydraulics is related to the primacy of flood safety in river management framed as water levels that should not be exceeded. It may be concluded that Rijkswaterstaat has retained its central position, since it continues to set hydraulic constraints to accommodating heterogeneous concerns. With institutional heterogeneity becoming the rule, relations have not simply changed from hierarchical into heterarchical, as suggested in the mode 2 diagnosis. The situation is more complex: an earlier dominant institution is confronted with more heterogeneity than before, but retains its primacy, while also accommodating to the changes.

Relevance, practical problems and binding

How has river science and its local research configurations been shaped by specific institutions and practical problems? The account of the emergence of river science as a field provides a first indication of river science's institutional orientations. Around 1980, interdisciplinary river science emerged around the issue of degraded, dammed rivers. Its proponents aimed at providing an ecologically sound alternative to the engineering paradigm of river management. They formed part of the environmental movement which protested against the damming of rivers. In the course of the eighties and nineties, river restoration became a goal of governments and river scientists were in a position to provide relevant expertise. Alongside orientations to ecology and earth science, and the social movement fighting large dams, river science became strongly oriented to river management authorities and their policies. 
Chapter 5 provides an analysis of how river scientists developed a close relationship with river management authorities in the Netherlands, and how interdisciplinary river science developed in symbiosis with the emerging regime of integrated river management. The way in which local knowledge of rivers, the modeling of interacting river dynamics, has been geared to designing safe and biodiverse rivers could be framed in terms of an 'inbuilt relevance' as the diagnosis of strategic science proposes. The 'inbuilt relevance' of interdisciplinary river science in the Netherlands seems largely continuous with the 'inbuilt relevance' of hydraulics in the engineering regime. In both cases, research is geared to solving design problems.

But there is more to the relationship between river science and the management of rivers. A conceptualisation of this relation in terms of co-production draws the attention to the ongoing mutual shaping of representations and interventions. In the engineering regime of river management, rivers were canalised and normalised on the basis of hydraulic principles. These interventions made rivers conform better to hydraulics, which was largely based on the behaviour of water in canals and other streams of controlled dimensions. This is an example of the 'selfvindication' of hydraulic knowledge, albeit not as drastic and stable as in a laboratory, where conditions are more controlled than in the field. In the current regime of integrated river management, and more specifically, dynamic river management, keeping the distribution of ecotopes stable is one of the principles that guides interventions. Even if this principle is not applied ruthlessly, rivers will conform better to the cyclic rejuvenation principle if ecotope distributions are being controlled. Hence, an extension of the (partial) self-vindication of hydraulics.

What may be concluded about the tying of river science to specific institutions? The account of emerging river science in the Netherlands shows how close river science's relationship is with river management authorities. This relationship involves funding of research that is expected to contribute to elaborating current river management policies. The symbiotic relationship has been aimed at explicitly by funders of research: close interaction between 'developers' and 'users' of research has been promoted by all sorts of research funding bodies and 'bridging gaps' between research and policy is a prominent concern. It is the Netherlands Centre for River Studies' raison d'être. However, the tying of river science to river management has its side effects. The tighter the relationship between river science and river management, the less likely it is that radically different conceptions of rivers and river management may be formulated and practised.

\section{Governance of science}

How have science policies contributed to emerging river science? The accounts of chapter 4 and 5 , dealing with science policies, specialties that contribute to river science, and river science's interdisciplinary configurations in the Netherlands, provide some indications. Conceiving of science policies, their discourse and funding arrangements, as one context among others and focusing on the strategising of scientists vis-à-vis these contexts has proven a valuable approach. It shows how science policies may impact on scientific practices without arrangements being forced upon scientists in a top-down manner. Scientists conceive of the science policy context as a space of opportunities and requirements that allows for strategising. Yet, ample as the room for strategising may be, the coping strategies of scientists do have structural effects, as Norma Morris showed in her study of life scientists in the UK ${ }^{347}$. Although the science policy context in the UK is very different from that in the Netherlands, there are commonalities in how scientists

\footnotetext{
347 Norma Morris Scientists responding to Science Policy. A multi-level analysis of the situation of life scientists in the UK Doctoral dissertation University of Twente, 2004
} 
adapt to science policy agendas and how this leads to structural effects on research agendas. Morris also notes commonalities across European countries. For the UK, she observes that life scientists have come to take interdisciplinary, collaborative and user-oriented research for granted, but are concerned about the pressures sponsors exert by setting priorities (in grant schemes) and requesting relevance to immediate needs (in contract research). An aggregated, structural effect of the - individually different - ways in which scientists respond to these pressures is an accommodation of research agendas to the needs of sponsors. Thus, research agendas subtly shift, while (new) researchers adapt to the pressures and come to view and value intellectual autonomy, collaboration and societal relevance differently. There is a structural effect of these adaptations, and the processes of adapting are influenced by structural features of the research system. That is, the accommodation is shaped through the development and strengthening of organisational structures at intermediate levels, where research management and sponsors meet. Apart from what Morris calls a 'scaffolding' of the research system, these intermediate levels contribute to an evolving synergy of agendas. As Morris puts it: 'Compatibility between the official policies and pressures from science is a result of the enabling and mediating role that Research Councils and similar meso-level bodies are often able to play'348.

The processes and structural effects that Morris describes have been shown to be at work in the ways specialties and practitioners contributing to river science strategise vis-à-vis science policies as well. In the Netherlands, the intermediate level of research programming (and a striving for consensus) is more pronounced than in the UK, which explains the impression of an overall synergy between science policies and research agendas. The co-production perspective adopted in this study, foregrounding interdependencies between institutional survival strategies and search strategies, also adds to Morris' analysis. Research agendas and research lines are not only adapted in response to direct pressures ensuing from funding schemes and contracts, but search strategies are also adapted in processes of scaling up institutionally and interdisciplinary research programming. As these are strategies actively pursued by many scientists, they work in ways more subtle than unwelcome pressures.

Furthermore, while Morris notes that fragmentation as a result of local deals, local 'compromise packages' potentially weakens the cohesion of the research system - the scaffolding may lead to a mosaic building - I interpret fragmentation differently. Researchers shift between multiple sponsors, research programmes and inter-institutional arrangements, and they may do so by making modules: recombinable research lines. This suggests cohesion through discourse, which has its side effects. I will come back to the side effects at the end of this chapter.

The emergence and development of river science in the Netherlands can furthermore be attributed to science policies in several respects. The retrenchments of the eighties made river researchers at universities and research institutes keen to diversify their sources of research funding. Acquiring contract research from Rijkswaterstaat and its freshwater research institute was one way of coping with retrenchments. The Rhine Action Plan and other funds related to the Sandoz accident brought river researchers from a variety of disciplinary backgrounds and institutional affiliations together. Thus, the need to diversify research funding and to develop relations with governmental agencies has played a role in the emergence of interdisciplinary river science rather than science policies directly. Working relations between river researchers at

348 idem, p. 14 in Analysis and Conclusions 
Rijkswaterstaat, its freshwater research institute, other research institutes and universities consolidated without forming a fully connected network.

In response to a second wave of funding for river research after the near-floods of the midnineties, Nijmegen environmental scientists identified interdisciplinary river science as a viable niche in ecology. Here, science policies played a role but again only indirectly. River science held the possibility to score high on interdisciplinarity and societal relevance and the group could also profit from links with more specialised ecologists. This indicates strategising in the context of a science policy discourse and funding arrangements in which combining interdisciplinarity, societal relevance and excellence appeared as particularly desirable.

For the emergence of the Netherlands Centre for River Studies (NCR) in 1998 science policies have again played a role indirectly. The Centre has not profited from funds meant to stimulate the establishment of interdisciplinary, inter-institutional research centres. Yet, expectations about research funding have played a role in the establishment of the Centre. An important motive for establishing the Centre was that it could provide access to research funding for which interdisciplinary, inter-institutional cooperation was required. In this sense, the Centre was a strategic response to opportunities and requirements created by science policies at national and European levels. The Centre played a catalytic role in the further development of interdisciplinary river science in the Netherlands.

Finally, the coordination of research agendas at a variety of levels and the formulation of joint research projects in inter-institutional, interdisciplinary centres like the NCR has had its effects. River scientists, like other bio/geoscientists, have considered it strategically sensible to embark on inter-institutional, interdisciplinary research cooperation. This happened in a broader context of converging search strategies among specialties contributing to river science, as discussed in chapter 4. This convergence, the extension of common ground, has been a context for embarking upon interdisciplinary river research, while interdisciplinary river research has also contributed to further convergence.

In conclusion

From the above discussion of aspects of the diagnoses of recent science, it appears that river science largely supports claims I distilled from the diagnoses (with the exception of heterarchical relations) and further specifies these aspects for river science. This study of river science's configurations draws the attention to a way of producing novelty that has been noticed in other recent configurations as well, but which does not figure in the diagnoses and thus was not part of the questions specified in chapter 2. A salient feature of emerging river science is that it is design oriented. River science aims to come up with ecologically and socially sustainable designs of river landscapes. In river science, these designs are supposed to be based on how river nature works. In this way, research on the workings of nature is inextricably bound up with an orientation towards design. This dual orientation of river science brings together fields that have a long tradition in design work (hydraulics) with fields that until recently had not (ecology and earth science). A further salient feature of river science as fields brought together in design oriented configurations is that tasks are being assigned to specialties in terms of the dominant conceptualisation of rivers. Thus, conceptions of nature, divisions of labour between specialties and designs are co-produced (with process theories being considered the domain of specialties). 
This sort of co-production is taking place in other emerging configurations and fields like nanotechnology 349 and nutrigenomics ${ }^{350}$ as well.

The primacies, hydraulic and technological, that were identified and the convergence of search strategies can be seen as unintended consequences because they were not shared goals worked towards, but an outcome of interactions and co-production more generally. This invites reflection on the shaping and working of river science. This reflection, I suggest, may benefit from explorations of how pluralism could be practised. The notion of pluralism is used in both science and politics, but the two uses are generally kept apart. Co-production entails that science and politics are interdependent practices in the shaping and working of knowledge in society. It suggests reflecting on pluralism in knowledge practices as they intervene in the world. In what follows, I will discuss interventions in river nature and landscape in the Netherlands with a focus on questions of pluralism.

\subsection{Rivers and pluralism: a debate on nature development}

In the Netherlands, in discussions following the introduction of nature development in the 1980s, questions of how to deal with nature and landscape have been articulated to some depth. I will briefly summarise controversial issues articulated in these debates and then discuss a recent contribution. Nature development was introduced as an offensive strategy to enhance the state of nature, and presented as radically different from what were seen as half-hearted attempts to conserve what was left of nature in the densely populated, thoroughly domesticated Dutch landscape. Traditional nature conservation was too much interwoven with agricultural practices to the taste of nature developers: the kind of nature aimed at by nature conservationists could hardly be called nature anymore. The proponents of nature development aimed at re-creating a landscape that they considered authentic. The landscape they had in view was a reconstruction of the delta of the Rhine and Meuse rivers as it had existed before human settlement. While considerable controversy arose over the reconstruction itself, it was largely adopted as an 'ecological reference' for nature development. When nature development became widely embraced in policy circles as a better alternative to the defensive strategy of nature protection, dissenters began to voice their concerns. The contestation of nature development as the one legitimate and timely successor to nature conservation revolved around issues concerning authenticity, a dichotomy between culture and nature and the hegemony of one image of nature. Nature developers have claimed to re-create authentic nature, while not problematising the notion of authenticity and their own interpretation of it. This notion and its interpretation then became controversial. Why would river nature as it existed before human settlement be more authentic than the historical river landscape that we have now? How would human interventions re-creating conditions of a past result in authentic nature? Why strive for authenticity? Then, it has been argued that nature development expresses a dichotomous view and separation of nature and culture. Nature development has aimed at re-creating wild nature, primeval nature, nature without people. But the Netherlands has a long history of domesticating nature. Nature development has aimed at strictly separating nature from cultural practices like farming, but interweaving, as in the earlier nature conservation practices, must be considered an option too, it

\footnotetext{
${ }^{349}$ A. Nordmann 'Philosophy of nanotechnology' In: Günter, Schmid (eds.) Nanotechnology Vol. 1 Principles and fundamentals Weinheim: Wiley VCH, 2008, pp. 217-243

350 Bart Penders From seeking health to finding healths. The politics of large-scale cooperation in nutrition science Doctoral dissertation University of Maastricht, 2008
} 
has been argued ${ }^{351}$. The 'separatist discourse' sets people apart from nature and does not acknowledge that nature and culture are not necessarily an opposition. Furthermore, nature development has been presented as objective and science-based which has been considered in policy circles as a legitimate basis for interventions. This claiming of scientific authority by nature developers suppressed two types of debate, it has been argued: debate over different scientific interpretations (for instance between systems ecology, which dominates conceptions of nature development, and evolutionary ecology) and debate over scientific and other interpretations ${ }^{352}$.

In a very insightful study, Martin Drenthen has come up with a critical evaluation of objectivist, subjectivist and constructivist approaches to dealing with nature and landscape ${ }^{353}$. Drenthen discusses, in line with earlier critical evaluations as sketched above, how an objectivist approach to nature shapes Dutch nature development practices to an important extent. In his account, systems ecology with its a-historical outlook is relied on to re-design river floodplains ${ }^{354}$. In recent years, subjectivist approaches have come to complement objectivist approaches, Drenthen notes. In subjectivist approaches, human experiencing of nature is deemed relevant to river restoration and nature development more generally. Policy documents referring to social scientific research on people's views of nature articulate this subjectivist approach. Then, there is the constructivist approach to nature and landscape, which is Drenthen's most prominent target of critique.

Drenthen presents the constructivist approach to nature and landscape as one that holds that none of the views may lay claim to ultimate authority. After all, any interpretation of nature is contingent and reflects particular preferences and interests. Rather, different views of nature should be confronted through deliberative, democratic procedure. Thus, the constructivists' ideal would be a 'democratic landscape'. But Drenthen's concern is nature, not democracy. He grants the constructivist approach that it precludes the making absolute of any one view, but reproaches constructivists that they stand empty-handed with regard to appreciating nature's complexity. Drenthen then comes up with a diagnosis of the paradoxicality of our moral relation to nature, which in his view may contribute to an engagement with nature while not standing in the way of democratising political struggles about nature and landscape. He contends that our relation to nature is paradoxical since on the one hand it consists, through interpretation, in a moral appropiation of nature, while on the other hand as post-moderns we long for nature in how it resists interpretation, its wildness. This paradox is the core of Drenthen's 'critical notion of wilderness', a reflexive notion as it reminds us of the problematic character of our interpretations of nature, our relation to nature. I would agree with Drenthen that this insight can enrich the debate on nature and landscape, even if I have problems accepting that contemplating nature brings with it violent moral appropriation. By stating that '[i]n a pluralistic struggle of interpretations nature emerges as a creative manifold of possibilities', Drenthen aims to add a reflexive notion of nature to the 'democratic landscape' debate. Yet, his discussion of ideas and practices of nature development at one point borders on plain contradiction rather than paradox.

\footnotetext{
351 Hein-Anton van der Heijden 'Ecological restoration, Environmentalism and the Dutch Politics of 'New Nature" in: Environmental Values 14, 2005, pp. 427-446

352 Jozef Keulartz 'Engineering the Environment: The Politics of 'Nature Development”' in: Frank Fischer and Maarten A. Hajer (eds.) Living With Nature. Environmental Politics as Cultural Discourse Oxford: Oxford University Press, 1999, pp. 83-102.

353 Martin Drenthen Grenzen aan wildheid. Wildernisverlangen en de betekenis van Nietzsches moraalkritiek voor de actuele milieu-ethiek Budel: Damon, 2003. Drenthen also discusses other than Dutch contributions to the wildness and wilderness debates in environmental ethics.

354 This study suggests that hydraulics plays a constraining and enabling role in an interdisciplinary configuration in which ecology participates, but this does not affect Drenthen's overall assessment that objectivist approaches guide river restoration to an important extent.
} 
First, he states that although the ideology behind nature development is one that preaches restraint, its practice is one of ongoing interventions ${ }^{355}$. Later on, he speaks approvingly of nature development as practised in the Millingerwaard (which figures in this study as well, see chapter 5), as it exemplifies a modest attitude towards nature, an attitude of restraint which allows river nature to express itself:

Nature development is an attempt not to create nature after our own image, but to be open again to the otherness of the spontaneous processes of self-organisation in nature ${ }^{356}$.

Here, my study of river science and its restoration practices adds elements to Drenthen's diagnosis. Firstly, the 'spontaneous processes of self-organisation in nature' appears to be a contemporary scientific image of nature, to be understood in the context of particular discourses and technologies. As an interpretation, 'self-organisation' is 'nature after our own image' and arguably after our own image more than ever ${ }^{357}$. Secondly, the Millingerwaard as an example of restraint causes surprise ${ }^{358}$. The Millingerwaard has been modelled and monitored extensively with an eye to designing 'safe river nature'. There is also a pilot project for 'cyclic floodplain rejuvenation' in the area. In both its conceptualisation as in how its is practised, cyclic management entails recurrent interventions: cutting trees and shoveling away river sediments, to keep the ecotope distribution stable and satisfy the safety norm. It could be granted to cyclic management that it preaches what it practices: intervening in river nature 359 .

I conclude then, that even when my account of river science may be seen as just confirming the insight that views of nature are contingent, it has something to offer in discussing more in detail contemporary, dominant views in their context. Thus, this study of river science may enrich the debate about nature and landscape. Views of nature as interpretations matter, but practices and contexts too. My analysis of conceptions as related to technologies and institutions suggest specific shapings of river nature.

In her plea for epistemological pluralism, Helen Longino draws a contrast between two contexts of knowledge production, one of which is river restoration:

For example, in a context, like industrial manufacture, in which the interest is in understanding the properties and processes of a system so as to construct a replica that functions in the same way, or has the same products (e.g. a cell system for producing human insulin), it may not be necessary to understand the unrepresentativeness of bacterial DNA. In a context, like riparian restoration or conservation, in which the interest is in understanding the properties and processes of a system so as to interact with it in its "natural" state,

\footnotetext{
355 Martin Drenthen Grenzen aan wildheid, p. 208

356 idem, p. 239

357 Our access to nature may always be mediated, but as the world of mediations extends, it shapes the expression and experiencing of phenomena. Yet, this argument can hardly be made in a consistent way if nature is not set apart from culture (and mediations are not an in-between world), a view that has many merits. It is an intuitive stance rather than one I am able to argue in a consistent way. 358 Drenthen probably refers to the part of the Millingerwaard that has been left to develop spontaneously, 14 hectares out of 700 hectares in total. I do not deny that an attitude of restraint prevails there, and that this is interesting as it may inform our relation to nature, and an expression of nature in ways that Drenthen discusses. But this little patch of river foreland is being monitored as part of the overall ecotope distribution and thus part of the practices of modelling, monitoring and intervention. Thus, what appears to be unrestrained from one perspective, appears to be subjected to attempts at control from another. 359 Koen Moons 'Dynamiek buiten oevers. Ingrijpen in riviernatuur mag weer' in: Boomblad nr. 3, 2006, pp. $12-15$
} 
acknowledging the partiality based on one or a few models and the consequent need for multiple approaches may be crucial to success. The monism or pluralism expressed in scientific judgements may be a function of the overall aims of research rather than a brute metaphysical commitment 360 .

In the light of this study of river science, and its relation with river management, Longino's plea and contrast raise a number of questions. Firstly, Longino seems to imply that river restoration is to be based on scientific practices, more specifically, a plurality of them. Yet, her outlook on local epistemologies is that they are not only partial but also contingent. Thus, what 'nature' is in particular local epistemologies, is to be understood in its (historical) context. Scientists do not have a privileged access to nature 'as it is', they construct natures in a specific context of inquiry. The conception of science adopted in this study and the account of emerging river science presented endorse this view. But it means that there is no particular reason why river restoration should be based on science more than on other cultural practices. A plurality of cultural practices, possibly embodying radically different conceptions of rivers and river landscapes, may contribute to shaping the river landscape ${ }^{361}$. The emergence of 'river restoration' as an ideal is also to be understood in particular contexts, and embodies conceptions of river nature that may clash with other conceptions.

The contrast that Longino draws between two contexts of knowledge production provokes thoughts about the nature development debate in yet another way. Longino puts "nature" between quotation marks, in line with her plea for pluralism: different local epistemologies embody different views of nature. The contrast that she draws is between a contingent, pluralistic view of "nature" and replicas. Apparently, the kind of nature she has in mind for river restoration is unique nature, not a replica. But there is an irony in that nature development has been diagnosed as the production of replicas. Critical analysts of nature development speak of nature development as the technical reproduction of nature ${ }^{362}$. Already in the mid-nineties, when nature development was still a rather new practice, writer Willem van Toorn noted that it tends to deny that landscapes have a history ${ }^{363}$. Drenthen too points at the a-historical outlook of nature development, noting its actualism and its use of a particular historical reference ${ }^{364}$. My account of recent developments in river restoration as practised in the Netherlands confirms that an ahistorical outlook prevails in 'dynamic river management'. This is not to deny that in planning interventions in the river bed historical traces may receive attention, e.g. by being labelled cultural heritage. But the overall outlook is one that denies that river landscapes have a history: both the

\footnotetext{
360 Helen E. Longino The fate of knowledge, pp. 200-201

${ }^{361}$ A similar outlook is expressed by Cordula Kropp: '... one "nature" as a point of reference will no longer serve. Among others things, this opens the way for a fundamental debate on the coexistence of rivers and humans. The shaping and management of river landscapes becomes a political issue, on which all sides, human and nonhuman, must be heard' in: Cordula Kropp 'River Landscaping in Second Modernity' in: Bruno Latour and Peter Weibel (eds.) Making Things Public: atmospheres of democracy Cambridge (Mass.): MIT Press, 2005, pp. 486-491

362 Hein-Anton van der Heijden 'Ecological restoration, Environmentalism and the Dutch Politics of 'New Nature" in: Environmental Values 14, 2005, p. 437, Henk van den Belt 'Networking Nature, or Serengeti Behind the Dikes' in: History and Technology, 20-3, 2004, p. 325

363 Willem van Toorn Leesbaar landschap Amsterdam: Querido, 1998

${ }^{364}$ Actualism is an interpretive approach to studying preserved geological traces based on the assumption that general process mechanisms in past geological times were the same as in actuality. In other words, it assumes that natural mechanisms are timeless.
} 
physics of water flow and morphological dynamics, and the ecology in terms of ecotope distributions are viewed as timeless mechanisms that serve as design principles ${ }^{365}$.

The 'pluralistic struggle for interpretations' that Drenthen advocates may include scientific interpretations. In contemporary society scientific practices shape our world, including its rivers, to an important extent. My analysis of how specific search strategies are becoming widely adopted in river science, and bio/geoscience and -engineering more generally, provides insights that are relevant to the problem of pluralism within science, which has consequences for pluralism in the wider sense.

In conclusion

The metaphor of 'making rivers modular' in the title draws attention to how scientific conceptions of rivers (the river as a spatially nested hierarchy), ways of integrating contributions from different specialties (the coupling of specialty modules) and designs of river landscapes (interchangeability of standard units of river nature, ecotopes) have been shaped to an important degree by technologies that have become pervasive over the last couple of decades (information technology and remote sensing).

There are tendencies toward uniformity. Too strong a reliance on the same spatial modelling techniques and sources of data across fields reduces space for pluralism. The tendency to make practices commensurable by means of information and remote sensing technologies may become the norm for communication across cultural practices with regard to nature and landscape more generally. This may threaten the co-existence of radically different conceptions of nature and landscape.

My study of river science allows for an assessment of pluralism in practices: scientific and other cultural practices, each particular practice offering different conceptions of rivers and suggesting different dealings with rivers. There is a tension with integration as a catchword in river science and management, and the fervent striving for it. The discourse on modularity shortcircuits questions of pluralism. Pluralism as a countervalue must be nurtured.

\footnotetext{
365 But see Rob Lenders, who includes a historical dimension in his approach to river rehabilitation. Rob Lenders Environmental rehabilitation of the river landscape in the Netherlands. A blend of five dimensions. Doctoral dissertation University of Nijmegen, 2003.
} 


\section{Bibliography}

Aart, P.J.M. van der 'Landschapsecologie binnen NWO' in: Biovisie Magazine 2/Juli 1988

Aart, P.J.M. van der, J. van Andel, J.W. Woldendorp Programma voor oecologisch onderzoek Den Haag: BION, 1988

Abbott, M.B. Computational hydraulics London: Pitman, 1979

Abbott, M.B. Hydroinformatics Aldershot: Ashgate, 1991

Abbott, M.B., Babovic, V.M., and Cunge, J.A. 'Towards the hydraulics of the hydroinformatics era' Journal of Hydraulic Research, 39 (4), 2001, pp. 339-349

Admiraal, W. et al. Ecological Rehabilitation of the rivers Rhine and Meuse: Netherlands research program 1992-1995 EHR rapport 40, Lelystad: RIZA, 1992

Allen, T.F.H. and Thomas B. Starr Hierarchy. Perspectives for Ecological Complexity Chicago, The University of Chicago Press, 1982

Amoros, C. , M. Richardot-Coulet, J.-L. Reygrobellet Cartographie polythématique appliquée à la gestion écologique des eaux. Publication PIREN, 1982

Amoros, Claude, Jean-Claude Rostan, Guy Pautou, Jean-Paul Bravard 'The Reversible Process Concept Applied to the Environmental Management of Large River Systems' in: Environmental management vol. 11, no. 5, 1987

Amoros, C., A.L. Roux, J.L. Reygrobellet, J.P. Bravard and G. Pautou 'A method for applied ecological studies of fluvial hydrosystems' in: Regulated Rivers 1, 1987, pp. 17-36

d'Angremond, K., Flexibiliteit in de waterbouwkunde Inaugural speech University of Delft 1990

Aubin, David, and Amy Dahan Dalmedico 'Writing the History of Dynamical Systems and Chaos: Longue Durée and Revolution, Disciplines and Cultures' in: Historia Mathematica 29, 2002, pp. 1-67

Bailey, Robert G. 'The factor of scale in ecosystem mapping' in: Environmental Management, 9/4, 1985, pp. 271-275

Baptist, Martin J., W. Ellis Penning, Harm Duel, Antonius J.M. Smits, Gertjan W. Geerling, Guda E.M. Van der Lee, and Jos S.L. Van Alphen 'Assessment of Cyclic Floodplain Rejuvenation on Flood Levels and Biodiversity in the Rhine River' in: River Research and Applications 20/3, 2004, pp. 285-297

Baptist, Martin Modelling floodplain biogeomorphology Doctoral dissertation University of Delft, 2005

Belt, Henk van den, 'Networking Nature, or Serengeti Behind the Dikes' in: History and Technology, 20/3, 2004, pp. 271-275

Bestuur van de WLO 'De rol van de WLO in het onderzoeksbeleid op het gebied van de landschapsecologie' in WLO Mededelingen 7 (1980) 1

Bierkens, Marc F.P. Het Water en de Leer Inaugural speech University of Utrecht 2003

Blume, Stuart 'The development of Dutch science policy in international perspective 1965-1985. A report to the Raad van Advies voor het Wetenschapsbeleid' Zoetermeer: Ministerie van Onderwijs en Wetenschappen, 1985

Böhme, Gernot 'Autonomization and finalization: a comparison of fermentation research and fluid dynamics' in: W. Schäfer et al. Finalization in Science: The Social Orientation of Scientific Progress Dordrecht: Reidel, 1983, pp. 53-91

Bourcier, A., I. Poudevigne, R.M. Teeuw 'The use of SPOT imagery as a tool for ecological analysis of river floodplains: a case study in the Seine valley', p. 64 in: R.S.E.W. Leuven et al. Application of Geographic Information Systems and Remote Sensing in River Studies Leiden: Backhuys Publishers, 2002

Bravard, J.P., C. Amoros, G. Pautou 'Impact of civil engineering works on the successions of communities in a fluvial system' in: OIKOS 47, 1986, pp. 92-111

Bruin, D. de Rivierbeheer op de Nederlandse Rijntakken Rijkswaterstaat Directie Bovenrivieren Arnhem, 1982

Bruin, Dick de et al. Ooievaar. De toekomst van het rivierengebied Arnhem: Stichting Gelderse Milieufederatie, 1987

Burrough, P.A. 'Geografische informatiesystemen: gereedschappen voor landschaps- en milieuanalyse' in: Landschap, 1985, no. 4, pp. 269-277

Clarke, Stewart J., Lydia Bruce-Burgess and Geraldene Wharton 'Linking form and function: towards an ecohydromorphic approach to sustainable river restoration' in: Aquatic Conserv: Mar. Freshw. Ecosyst. 13, 2003, pp. 439-450

Committee on River Science at the US Geological Survey River Science at the US Geological Survey Washington: The National Academies Press, 2007

Cramer, J., M. Kuiper, J. Vos 'Landschapsecologie: een nieuwe onderzoeksrichting?' in: Landschap 1984, 1/3, pp. 176-183

Cramer, Jacqueline Mission-orientation in ecology: the case of Dutch fresh-water ecology Doctoral dissertation University of Amsterdam, 1987

Cramer, J.M. \& W. van der Wulp 'De ontwikkeling van de Nederlandse landschapsecologie als 
interdisciplinair wetenschapsgebied in internationaal verband' in Landschap 6/1, 1989, pp. 47-64

Dahan, Amy 'Models, anti-reductionnism and complexity in Climate Change' in: P. Cerrai (ed.) The Science of Complexity: Chimera or Reality, Proceedings of Arcidosso International Workshop September 2003, Esculapio Editions, coll. Miriam pp. 115-131

Dam, J.C. van Hydrologie, grondslag voor water- en milieubeheer Inaugural speech University of Delft

DBW/RIZA, RIVM, RIVO Ecological rehabilitation of the river Rhine: a proposal for a Netherlands research programme EHR rapport 1 Lelystad: RIZA, 1988

Décamps, Henri ‘Towards a landscape ecology of river valleys' in: T.H. Cooley and F.B. Golley (eds.) Trends in ecological research for the 1980s New York: Plenum Press, 1984, pp. 163-178

Deuten, J.J. Cosmopolitanising technologies. A study of four emerging technological regimes Doctoral dissertation University of Twente, 2003

Dietz, Ton \& Frans Kwaad Dutch geography 1996-2000 Utrecht, International Geographical Union, the Netherlands, 2000

Disco, Cornelis, Arie Rip and Barend van der Meulen 'Technical innovation and the universities: divisions of labour in cosmopolitan technical regimes' in: Social Science Information, 31/3, 1992, pp. 465-507

Disco, Cornelis 'Remaking “nature”. The Ecological Turn in Dutch Water Management' in: Science, Technology \& Human Values, 27/2, 2002, pp. 206-235

Disco, Cornelis 'Delta Blues' in: Technology and Culture vol. 47, 2006, pp. 341-348

Dollar, E.S.J., C.S. James, K.S. Rogers and M.C. Thoms 'A framework for interdisciplinary understanding of rivers as ecosystems' in: Geomorphology 89/1-2, 2007, pp. 147-162

Dolman, A.J. Blauw en Groen in Broeikas Aarde Inaugural address Free University of Amsterdam, 2003

Donk, Ellen van Netwerken in het water Inaugural speech University of Nijmegen 2002

Douben, N., H.E.J. Simons en M. ten Harkel Dynamisch rivierbeheer. Inventarisatie informatiebehoefte, resultaten eerste fase RIZA rapport 2002.004, Arnhem, RIZA, 2002

Drenthen, Martin Grenzen aan wildheid. Wildernisverlangen en de betekenis van Nietzsches moraalkritiek voor de actuele milieu-ethiek Budel: Damon, 2003

Dreyfus, Hubert L. and Paul Rabinow Michel Foucault. Beyond Structuralism and Hermeneutics Chicago: The University of Chicago Press, 1983

Duel, Harm \& Cees Kwakernaak ‘Rivierdynamiek in uiterwaarden’ in: Landschap 1992 9/4, pp. $255-271$

Duel, Harm Natuurontwikkeling in de uiterwaarden. Perspectieven voor het vergroten van de rivierdynamiek en het ontwikkelen van ooibossen in de uiterwaarden van de Rijn. Rapport Ecologisch Herstel Rijn, nr. 29, 1991

Duel, H., M. Baptist \& W.E. Penning Cyclic Rejuvenation of Floodplains. CFR Project Main Report. NCR Publication 2001

Dijksma, Roel 'Het Nederlands Hydrologisch Platform, een zeer nuttige bundeling van krachten' in: Stromingen 7, 2, 2001, pp. 47-52

Elias, Norbert 'Scientific establishments' in: Norbert Elias, Herminio Martins and Richard Whitley (eds.) Scientific Establishments and Hierarchies, Sociology of the Sciences Yearbook, volume VI, Dordrecht: Reidel, 1982, pp. 3-69

Elzinga, Aant 'The science-society contract in historical transformation: with special reference to "epistemic drift" in: Social Science Information, 1997, pp. 411-445

Ende, J.C.M. van den The turn of the tide: computerization in Dutch society 1900-1965 Doctoral dissertation University of Delft, 1994

Engelen, G.B. Rentmeesters van water Inaugural speech Free University of Amsterdam, 1974

Fanta, J. Landschapsecologie in de nieuwe tijden Farewell speech, University of Amsterdam, 1996

Feddes, R.A. Waar blijft het water ... Inaugural speech, University of Wageningen, 1990

Fish, Hugh 'Guest editorial' in: Regulated Rivers vol. 1, 1, 1987

Forman, R.T. and M. Godron 'Patches and structural components for a landscape ecology' in: BioScience 31/10, 1981, pp. 733-740

Forman, Richard T.T. 'The beginnings of landscape ecology in America' in: I.S. Zonneveld and R.T.T. Forman Changing landscapes. An ecological perspective New York: Springer-Verlag, 1990

Forman, Paul 'Recent Science. Late modern and post-modern' reprinted in: Philip Mirowski and EstherMirjam Sent (eds.) Science bought and sold. Essays in the Economics of Science Chicago: The University of Chicago Press, 2002, pp. 109-148

Frissell, Christopher A., William J. Liss, Charles E. Warren, Michael D. Hurley 'A hierarchical framework for stream habitat classification: viewing streams in a watershed context' in: Environmental Management vol. 10, no. 2, 1986, pp. 199-214

Fujimura, Joan H. 'Constructing ‘Do-Able’ Problems in Cancer Research: Articulating Alignment' in: Social Studies of Science, 17/2, 1987, pp. 257-293

Fujimura, Joan H. 'Crafting Science: Standardized Packages, Boundary Objects, and “Translation"' in: Pickering, Andrew (ed.) Science as practice and culture Chicago: The University of Chicago Press, 1992, 
pp. $168-211$

Geerling, G.W. \& A.J.M. Smits 'Monitoring floodplain vegetation dynamics using remote sensing in the context of cylic floodplain rejuvenation' in: Proceedings NCR-days 2002, NCR publication 20-2003, pp. 92-95

Gibbons, Michael, Camille Limoges, Helga Nowotny, Simon Schwartzman, Peter Scott, Martin Trow The New Production of Knowledge: the Dynamics of Science and Research in Contemporary Societies London, Sage, 1994

Gore, J.A. (ed.) The restoration of streams and rivers. Theories and experience Butterworth: Ann Arbor, 1985

Groenendael, J.M. van Tussen gen en Gaia: oecologie in dilemma Inaugural speech University of Nijmegen 1995

Guston, David Between Politics and Science: assuring the integrity and productivity of research Cambridge: Cambridge University Press, 2000

Hacking, lan 'The Self-Vindication of the Laboratory Sciences' in: Andrew Pickering (ed.) Science as practice and culture Chicago: The University of Chicago Press, 1992, pp. 29-64

Hackmann, Heide National Priority-setting and the Governance of Science Doctoral Dissertation University of Twente, 2003

Haggerty, J.J. Spinoff 1983, NASA Office of external relations, 1983

Halffman, Willem Boundaries of Regulatory Science. Eco/toxicology and aquatic hazards of chemicals in the US, England and the Netherlands, 1970-1995 Doctoral dissertation University of Amsterdam, 2003

Hall, Stephen S. 'Ground truth: Landsat Maps and the Remote Sensing revolution' in: Stephen S. Hall Mapping the next millennium, the discovery of new geographies New York: Random House, 1992, pp. $52-70$

Hannah, David M., Paul J. Wood and Jonathan P. Sadler 'Ecohydrology and hydroecology: a 'new paradigm'?' in: Hydrological Processes, 18, 2004, pp. 3439-3445

Haraway, Donna Simians, Cyborgs and Women: The Reinvention of Nature New York, Routledge, 1991

Harms, W.B., W.C. Knol en J. Roos-Klein Lankhorst 'Het LEDESS-model. Een gebiedsgericht kennismodel bij scenario's voor natuurontwikkeling' in: Landschap 12/2, 1995, pp. 83-98

Hartog, C. den Grootschalige veranderingen in aquatische systemen. (On)voorspelbaarheid en implicaties Farewell Speech University of Nijmegen 1996

Hassanizadeh, S. Beyond Darcy's law Inaugural speech University of Utrecht, 2002

Hayles, N. Katherine Chaos Bound. Orderly disorder in contemporary literature and science Ithaca: Cornell University Press, 1990, pp. 211-218

Heidelberger, Michael 'Applying models in fluid dynamics' in: International Studies in the Philosophy of Science vol. 20, no. 1, 2006, pp. 49-67

Hemert, Mieke van 'Ruimte voor de ingenieur. Rivierbeheer in Nederland eind jaren negentig' in: Kennis \& Methode 23/4, 1999, pp. 361-378

Hessels, Laurens K., Harro van Lente 'Re-thinking new knowledge production: A literature review and a research agenda' in: Research Policy 37, 2008, pp. 740-760

Heijden, Hein-Anton van der 'Ecological restoration, Environmentalism and the Dutch Politics of 'New Nature" in: Environmental Values 14, 2005, pp. 427-446

Hoekstra, Piet 'Recent innovations in coastal research in the Netherlands' in: Ton Dietz, Piet Hoekstra, Frans Thissen (red.) The Netherlands and the North Sea. Dutch Geography 2000-2004 Netherlands Geographical Studies 325 Utrecht: KNAG/IGU, 2004, pp. 19-25

Hooijer, A., A.G. van Os Umbrella Programme IRMA-SPONGE. Background, Scope and Methodology. NCRPublicatie 04-2001

Houten, H.J. van Aarde, Wetenschap en Samenleving. Verslag van een Delphi-onderzoek, uitgevoerd in opdracht van de Commissie ad hoc Bestudering positie Aardwetenschappen in Nederland. Zoetermeer: Min. O\&W, 1983

Huisman, Pieter 'Rijnoeverstaten en Europese Unie ondernemen acties na vergiftingings- en overstromingsrampen' in: Tijdschrift voor Waterstaatsgeschiedenis 16/1, 2007, pp. 46-55

Huitema, Dave and Stefan Kuks 'Harboring Water in a Crowded European Delta', in: Hans Bressers and Stefan Kuks (eds.) Integrated governance and water basin management. Conditions for regime change towards sustainability Dordrecht: Kluwer Academic Publishers, 2004, pp. 59-94

Hulscher, Suzanne J.M.H. Ruwweg natuurlijk waterbeheer? Natuurlijk! Inaugural address University of Twente, 2003

ICG Research programme of the Netherlands Centre for Geo-ecological Research, October 1997

$\mathrm{IOH}$ Interinstitutionele Onderzoekschool 'Hydrologie voor water- en milieubeheer'. Aanvrage KNAWerkenning Delft: Onderzoekschool Hydrologie, 1995

Jasanoff, Sheila 'Beyond Epistemology: Relativism and Engagement in the Politics of Science' in: Social Studies of Science vol. 26, no. 2, 1996, pp. 393-418 
Jasanoff, Sheila ‘The idiom of co-production' in: Sheila Jasanoff (ed.) States of knowledge: the coproduction of science and social order London: Routledge, 2000, pp. 1-12

Jasanoff, Sheila ‘Ordering knowledge, ordering society' in: Sheila Jasanoff (ed.) States of knowledge: the coproduction of science and social order London: Routledge, 2000 pp. 13-45

Jong, Mechtild D.Th.M. de Scheidslijnen in het denken over Natuurbeheer in Nederland Doctoral dissertation University of Amsterdam, 2003

Jongman, R.H.G. 'En wie betaalt het landschapsecologisch en milieukundig onderzoek?' in: WLO Mededelingen 10 (1983) 4

Jongman, R.H.G. 'Voordat de ooievaar komt ...' in: Landschap 4/1, 1987, pp. 41-48

Jongman, Rob Landscape ecology at the university in Europe Inventory by the IALE, 2002

Jorde, Klaus 'River restoration - Potential, Constraints, and the Role of Ecohydraulics', in Proc. $4^{\text {th }}$ Ecohydraulics Conference, March 4-8, 2002, Cape Town, South Africa

Kalkhoven, Jan 'Landschapsecologie als zelfstandig vakgebied' in: D. van Dorp et al. (eds) Landschapsecologie. Natuur en Landschap in een veranderende samenleving Amsterdam: Boom, 1999, pp. 15-46

KNAW Turning the Water Wheel Inside Out. Foresight Study on Hydrological Science in the Netherlands Amsterdam, KNAW, 2005

Keulartz, Jozef 'Engineering the Environment: The Politics of 'Nature Development" in: Frank Fischer and Maarten A. Hajer (eds.) Living With Nature. Environmental Politics as Cultural Discourse Oxford: Oxford University Press, 1999, pp. 83-102

Koningsveld, Mark van Matching Specialist Knowledge with End User Needs Doctoral dissertation University of Twente, 2003

Koster, E.A. Zand erover. Een positiebepaling van de (actuele) paleogeomorfologie Inaugural speech Utrecht University 1982

Koster, E.A. 'Drieëenheid in de fysische geografie?' In: KNAG Geografisch Tijdschrift XVIII Nr. 5, 1984, pp. 324-329

Koster, E.A. and F.J.P.M. Kwaad 'Geomorphology in the Netherlands' in: H.J. Walker and W.E. Grabau (eds.) The Evolution of Geomorphology Chichester: John Wiley \& Sons, 1993

Koster, Eduard A. 'Preface' in: ICG Research at the Netherlands Centre for Geo-ecological Research ICG Publications 3, 1995

Kraats, J.A. van de Rehabilitation of the River Rhine. Proceedings of the International Conference on the Rehabilitation of the River Rhine 15-19 March 1993, Arnhem, the Netherlands Pergamon, 1994

Kropp, Cordula 'River Landscaping in Second Modernity' in: Bruno Latour and Peter Weibel (eds.) Making Things Public: atmospheres of democracy Cambridge (Mass.): MIT Press, 2005, pp. 486-491

Kuiper, J., R.H.G. Jongman 'Inrichting van uiterwaarden' in: Landschap 2(3), 1985, pp. 183-192

Kuks, Stefan 'The Sustainability Performance of National Resource Regimes' in: Ingrid Kissling-Näf and Stefan Kuks The Evolution of National Water Regimes in Europe Dordrecht: Kluwer Academic Publishers, 2004, pp. 87-142

Kundzewicz, Zbigniew W. 'Special Section on Ecohydrology-Editorial' in: Hydrological Sciences, 47/5, 2002, pp. 797-798

Kwa, Chunglin 'Representations of Nature Mediating between Ecology and Science Policy: the Case of the International Biological Programme' in: Social Studies of Science 17, 1987, pp. 413-442

Kwa, Chunglin 'Local Ecologies and Global Science: Discourses and Strategies of the International Geosphere-Biosphere Programme' in: Social Studies of Science 36/6, 2005, pp. 923-950

Kwa, Chunglin 'Interdisciplinarity and Postmodernity in the Environmental Sciences' in: History and Technology, 21/4, 2005, pp. 331-344

Kwa, Chunglin 'Speaking to science. The programming of interdisciplinary research through informal science-policy interactions' in: Science and Public Policy 33/6, 2006, pp. 457-467

Kwa, C.L., M. van Hemert \& L. van der Weij 'Visualizing Landscapes: Gestalts, Models, Pictures' forthcoming in: Scholten, H.J., van de Velde, R.J., van Manen, N. (eds), The role of Geo-ICT and Spatial Approaches in Science, Springer, Dordrecht, 2008

Kwakernaak, C. 'Informatie als begrip in de landschapsecologie' in: Landschap 1986, no. 3, pp. $182-189$

Lenders, Rob Environmental rehabilitation of the river landscape in the Netherlands. A blend of five dimensions. Doctoral dissertation University of Nijmegen, 2003

Lengwiler, Martin \& Dagmar Simon (eds.) New Governance Arrangements in Science Policy, Social Science Research Center Berlin, August 2005

LeRoy Poff, N., J. David Allan, Margaret A. Palmer, David D. Hart, Brian D. Richter, Angela H. Arthington, Kevin H. Rogers, Judy L. Meyer, and Jack A. Stanford 'River flows and water wars: emerging science for environmental decision making' in: Front. Ecol. Environ. 1, 6, 2003, pp. 298-306

Leuven, R.S.E.W \& P.H. Nienhuis 'River science at Nijmegen University: ecological rehabilitation of rivers', paper for the Fifth Convention day River Basin Management, May 28, 1998 
Leuven, R.S.E.W, I. Poudevigne \& R.M. Teeuw 'Remote sensing and Geographic Information Systems as emerging tools for riverine habitat and landscape evaluation: from concepts to models' in: R.S.E.W. Leuven, I. Poudevigne \& R.M. Teeuw (eds.) Application of Geographic Information Systems and Remote Sensing in River Studies Leiden: Backhuys Publishers, 2002, pp. 217-239

Leydesdorff, L. and Susan E. Cozzens 'The delineation of specialties in terms of journals using the dynamic journal set of the SCl' in: Scientometrics vol. 26, no. 1, 1993, pp. 135-156

Linsen, Lex ‘Banenverlies onvermijdelijk bij NIOO’ in: Bionieuws 10, 22 mei 1993

Longino, Helen E. The fate of knowledge Princeton: Princeton University Press, 2002

LWI Alle projecten van LWI op CD, 2000

Marres, Noortje No Issue, No Public. Democratic Deficits after the Displacement of Politics Doctoral dissertation University of Amsterdam, 2005

McCully, Patrick Silenced rivers: the ecology and politics of large dams London: Zed, 1996

Milhous, Robert T. 'The PHABSIM system for Instream Flow Studies' in: Proceedings for the 1979 Summer Computer Simulation Conference 1979, pp. 440-446

Ministerie van Economische Zaken Kennis in Beweging: over kennis en kunde in de Nederlandse economie Den Haag:Ministerie van Economische Zaken, 1995

Ministerie van Onderwijs en Wetenschappen Wetenschapsbudget 1979, Den Haag: SDU, 1978

Ministerie van Onderwijs en Wetenschappen Wetenschapsbudget 1982 Den Haag: Staatsuitgeverij, 1981

Ministerie van Onderwijs en Wetenschappen Naar een wetenschapsbeleid voor de jaren negentig. Discussienota Den Haag: DOP, 1988

Ministerie van Onderwijs en Wetenschappen Wetenschapsbeleid in de jaren tachtig. Uitwerking van het model van gezamenlijke actie, Zotermeer: Ministerie van Onderwijs en Weetenschappen, 1989

Ministerie van Onderwijs en Wetenschappen Wetenschapsbudget 1990 Den Haag: SDU Uitgeverij, 1989

Ministerie van Onderwijs en Wetenschappen Wetenschapsbudget 1993 Den Haag: SDU Uitgeverij, 1992

Ministerie van Onderwijs, Cultuur en Wetenschappen Wetenschapsbudget 1997 (summary) Den Haag: SDU Uitgeverij, 1996

Ministerie van Onderwijs, Cultuur en Wetenschappen Wetenschapsbudget 2000, Den Haag: Sdu Servicecentrum, 1999

Ministerie van Onderwijs, Cultuur en Wetenschappen Wetenschapsbudget 2004, Den Haag: Sdu Servicecentrum, 2004

Ministerie van Verkeer en Waterstaat Land Water Impulsprogramma. Investeringsplan ICES-project kennisinfrastructuur, 1993

Minshall, G.W., K.W. Cummins, R.C. Petersen, C.E. Cushing, D.A. Bruns, J.R. Sedell, and R.L. Vannote 'Developments in Stream Ecosystem Theory' in: Can. J. Fish. Aquat. Sci. Vol 42, 1985, pp. 1045-1055

Moons, Koen 'Dynamiek buiten oevers. Ingrijpen in riviernatuur mag weer' in: Boomblad nr. 3, 2006, pp. 12-15

Moore, Gerald K. 'What is a picture worth? A history of remote sensing' in: Hydrological Sciences Bulletin 24, 4, 12, 1979, pp. 477-485

Muller, Etienne, Henri Décamps and Michael K. Dobson 'Contribution of space remote sensing to river studies' in: Freshwater Biology, 29/2, 1993, pp. 301-312

Morris, Norma Scientists responding to Science Policy. A multi-level analysis of the situation of life scientists in the UK Doctoral dissertation University of Twente, 2004

Morris, Norma and Arie Rip 'Proactive adaptation. Scientists' coping strategies in an evolving research system: the case of life scientists in the UK' in: Science and Public Policy 33/4, 2006, pp. 253-263

Naylor, L.A., H.A. Viles, N.E.A Carter 'Biogeomorphology revisited: looking towards the future' in: Geomorphology 47, 2002, pp. 3-14

Nienhuis, P.H. Rivierkunde 1995-2000. Onderzoek vakgroep Milieukunde KUN Verslagen Milieukunde nr. 100, 1995

Nienhuis, P.H. 'Integraal beheer van onze grote rivieren in een stroomversnelling' in: Anon. Symposiumbundel Integraal beleid en beheer voor grote riviergebieden: een internationale uitdaging UCM/NIVAS KUN, 1995, pp. 11-19

Nienhuis, P.H. Water en waarden. Ecologisch onderzoek als basis voor waterbeheer en natuurbeheer Farewell Speech University of Nijmegen 2003

Nordmann, A. ‘Philosophy of nanotechnology' In: Günter, Schmid (eds.) Nanotechnology Vol. 1 Principles and fundamentals Weinheim: Wiley VCH, 2008, pp. 217-243

NWO Meerjarenplan 1991-1994, Nederlandse Organisatie voor Wetenschappelijk Onderzoek, Den Haag, 1990

Opdam, P.F.M. ‘De metapopulatie: model van een populatie in een versnipperd landschap' in: Landschap 4/4, 1987, pp. 288-306

Orange, Prince Willem-Alexander of 'The value of sustainable river management' in: A.J.M. Smits et al. New Approaches to river management Leiden: Backhuys Publishers, 2000, pp. 3-6 
Os, A.G. van (ed.) Summary of NCR Programme, version 2001-2002 NCR publication 05-2001

Overlegcommissie Verkenningen Ruimte voor Aardwetenschappen. Toekomstverkenning aardwetenschappelijk onderzoek OCV, Amsterdam, 1997

Palmer, Tim Endangered Rivers and the Conservation Movement Berkeley: University of California Press, 1986

Palmer, Margaret A. and Emily S. Bernhardt 'Hydroecology and river restoration: ripe for research and synthesis' in: Water Resources Research, vol. 42, 2006, pp. W03S07

Pedroli, G.B.M., R. Postma, M.J.J. Kerkhofs en J.G.M. Rademakers 'Welke natuur hoort er bij de rivier?' in Landschap 13/2, 1996, pp. 97-113

Penders, Bart From seeking health to finding healths. The politics of large-scale cooperation in nutrition science Doctoral dissertation University of Maastricht, 2008

Pestre, Dominique 'Pour une histoire sociale et culturelle des sciences. Nouvelles définitions, nouveaux objets, nouvelles pratiques' in: Annales. Histoire, Sciences Sociales, 50/3, 1995, pp. 487-522

Petts, Geoffrey Impounded rivers. Perspectives for Ecological Management Chichester: John Wiley, 1984

Petts, G.E., H. Moller and A.L. Roux (eds.) Historical change of large alluvial rivers: Western Europe Chichester: John Wiley, 1989

Petts, Geoffrey E. 'Editorial' in: River Research and Applications, 20, 2004, pp. 1-2

Petts, Geoff and Robert Kennedy (eds.) Emerging Concepts for Integrating Human and Environmental Water Needs in River Basin Management, US Army Corps of Engineers. Engineer Research and Development Center, September 2005

Poole, Geoffrey C. 'Fluvial landscape ecology: addressing uniqueness within the river discontinuum' in: Freshwater Biology, 47, 2002, pp. 641-660

Rademakers, J.G.M. \& H.P. Wolfert Het Rivier-Ecotopen-Stelsel: een indeling van ecologisch relevante ruimtelijke eenheden ten behoeve van ontwerp-en beleidsstudies in het buitendijkse rivierengebied EHR rapport 61, RIZA Lelystad, 1994

Richards, Keith, James Brasington and Francine Hughes 'Geomorphic dynamics of floodplains: ecological implications and a potential modelling strategy' in: Freshwater Biology 47, 2002, pp. 559-579

Rip, Arie and Barend J.R. van der Meulen 'The post-modern research system' in: Science and Public Policy 23/6, 1996, pp. 343-352

Rip, Arie 'A cognitive approach to relevance of science' in: Social Science Information 36/4, 1997, pp. 615640

Rouse, Joseph Knowledge and power: Toward a Political Philosophy of Science Ithaca: Cornell University Press, 1987

Rouse, Joseph 'Foucault and the natural sciences' in: J. Caputo and M. Yount Foucault and the critique of institutions University Park: The Pennsylvania State University Press, 1993, pp. 137-164

Rouse, Joseph 'Understanding Scientific Practices. Cultural Studies of Science as a Philosophical Program' in: M. Biagioli The Science Studies Reader New York: Routledge, 1999, pp. 442-456

Runhaar, J. Beschrijving en voorspelling van de vegetatie in het rivierengebied. Opzet van een Geografisch Informatiesysteem en een voorspellingsmodel voor de vegetatie in het gebied van de Grote Rivieren CML report 72, 1991

Rijkswaterstaat Maatregelen voor de verlaging van de maatgevende hoogwaterstanden van de Waal Arnhem: RIZA nota 91.022, 1985

Rijn, L.C. van Zee en zand in Holland. Over hydrodynamika en morfodynamika. Inaugural speech University of Utrecht 1995

Savenije, H.H.G. Het meeste valt ernaast Inaugural speech University of Delft 2005

Scheffer, Marten Het meer als microkosmos Inaugural speech University of Wageningen 1999

Schroevers, P.J. (ed.) Landschapstaal. Een stelsel van basisbegrippen voor de landschapsecologie Wageningen: Pudoc, 1982

Segers, Martine 'Onderzoekscholen sterven langzame dood' in: TUDelta jrg. 32 nr. 36, 2000

Shackley, Simon and Brian Wynne 'Global climate change: the mutual construction of an emergent sciencepolicy domain' in: Science and Public Policy, 1995, pp. 218-230

Shove, Elisabeth 'Principals, agents and research programmes' in: Science and Public Policy 30/5, 2003, pp. 371-381

Siebelink, Bart 'UvA wil vakgroep schrappen’ in: Bionieuws 10, 22 mei 1993

Smaal, Aad 'Perspectieven voor de aquatische ecologie en de aquatisch ecologen' in: E.J.A. Zevenhuizen et al. Een historische schets van de aquatische ecologie in Nederland en Vlaanderen. Publicatie no. 7 van de Nederlandse Vereniging voor Aquatische Ecologie, Amsterdam 1996, pp. 51-54

Smits, A.J.M., P.H. Nienhuis \& R.S.E.W Leuven (eds.) New approaches to river management Leiden: Backhuys Publishers, 2000

Smits, A.J.M., P.H. Nienhuis \& R.S.E.W Leuven 'New approaches to river management: general introduction' in: A.J.M. Smits et al. New approaches to river management Leiden: Backhuys Publishers, 2000, pp. 7- 
14

Smits, A.J.M. \& H. Middelkoop 'Introduction to NCR-research theme Cyclic Floodplain Rejuvenation' in: R.S.E.W Leuven, A.G. van Os \& P.H. Nienhuis (eds.) Proceedings NCR-days 2002. Current themes in Dutch river research. NCR publication 20-2003, pp. 88-91

Solomatine, D.P. 'Data-driven modelling: paradigm, methods, experiences' in: Proc. $5^{\text {th }}$ Int. Conf. On Hydroinformatics, Cardiff, UK, July1-5, 2002

Stanford, Jack A. and J.V. Ward 'Revisiting the serial discontinuity concept' in: Regul. Rivers: Res. Mgmt. 17, 4/5, 2001, pp. 303-310

Star, Susan L. and James R. Griesemer 'Institutional ecology, "Translations”, and Boundary Objects: Amateurs and Professionals in Berkeley's Museum of Vertebrate Zoology, 1907-39' in: Social Studies of Science 19, 1989, pp. 387-420

Stichting Hydrologisch Centrum Onderwijs en onderzoek in de hydrologie en het waterbeheer. Aqua: Quo Vadis, Den Haag: SHC, 1988

Stive, M.J.F. De kust is vrij: pleidooi voor een dynamische omgang met het raakvlak land-zee Inaugural address University of Delft 1995

Terwindt, J.H.J. Landschap en proces in de fysische geografie Inaugural speech University of Utrecht 1977

Thoms, Martin C. \& Melissa Parsons 'Eco-geomorphology: an interdisciplinary approach to river science' in: Fiona J. Dyer, Martin C. Thoms \& John M. Olley (eds.) The Structure, Function and Management Implications of Fluvial Sedimentary Systems IAHS Publication no. 276, Wallingford, IAHS Press, 2002, pp. 113-119

Thorp, James A., Jack A. Stanford, Martin C. Thoms, Geoffrey E. Petts 'Global partnerships and the new international society for river science (ISRS)' in: River Research and Applications, 23/1, 2007, pp. 1-5

Tockner, Klement, Christopher Robinson 'James Vernon Ward - eine Nachbetrachtung' in: EAWAG Jahresbericht 2002

Toorn, Willem van Leesbaar landschap Amsterdam: Querido, 1998

Troch, P.A. Laten we de (water)balans opmaken. Inaugural speech University of Wageningen, 2001

Turnbull, David Masons, Tricksters and Cartographers. Comparative Studies in the Sociology of Scientific and Indigenous Knowledge London: Routledge, 2000

Urk, G. van 'Lower Rhine-Meuse’ in: B.A. Whitton (ed.) Ecology of European Rivers Oxford: Blackwell, 1984, pp. 438-468

Valk, Michael R. van der 'Hydrologic Sciences. Taking Stock and Looking Ahead' in: Stromingen, 5/4, 1999

Vannote, R.L. G.W. Minshall, K.W. Cummins, J.R. Sedell and C.E. Cushing 'The River Continuum Concept' in: Canadian Journal of Fisheries and Aquatic Sciences, 37, 1980, pp. 130-137

Verhoeff, K. (ed.) Biologie: van levensbelang Den Haag: Staatsuitgeverij 1983

Verkenningcommissie Biologie Biologie: het leven centraal Amsterdam: KNAW, 1983

Versleijen, Anouschka (ed.) Dertig jaar publieke onderzoeksfinanciering in Nederland 1975-2005. Historische trends, actuele discusses Den Haag: Rathenau Instituut, 2007

Vreugdenhil, C.B. Water, onberekenbaar? Inaugural speech University of Delft, 1979

Vriend, H.J. de Een kwestie van respect Inaugural address University of Delft, 1997

Vriend, Huib de Onzeker? Zeker weten! Farewell speech University of Twente, 2002

Vries, J. J. de Anderhalve eeuw hydrologisch onderzoek in Nederland Amsterdam: Rodopi, 1982

Vries, J.J. de Tussen waterschap en wetenschap Inaugural speech Free University of Amsterdam, 1990

Vrijling, J.K. Kansen in de waterbouw Inaugural speech University of Delft 1990

VSNU, Discipline Overlegorgaan Geografie, Planologie, Pre- en Protohistorie Profielschets Fysische Geografie, Sociale Geografie, Planologie Utrecht: VSNU, 1989

Ward, James V. and Jack A. Stanford The ecology of regulated streams New York \& London: Plenum Press, 1979

Warner, Jeroen F. The politics of flood insecurity. Framing contested river management projects Doctoral dissertation University of Wageningen, 2008

Watson-Verran, Helen and David Turnbull 'Science and Other Indigeneous Knowledge Systems' in: S. Jasanoff (ed.) Handbook of science and technology studies Thousand Oaks, CA.: Sage 1995, pp. 115139

Weingart, Peter 'Interdisciplinarity: The Paradoxical Discourse' in: Peter Weingart \& Nico Stehr Practising interdisciplinarity Toronto: University of Toronto Press, 2000, pp. 25-41

Wereld Natuur Fonds Levende Rivieren Zeist, WNF, 1992

Werkgroep ‘Theorie' van de WLO ‘Methoden en begrippen in de landschapsecologie' in: Landschap 1986, no. 3, pp. 172-181

Wesselink, A.J. 'Flood safety in the Netherlands: The Dutch response to Hurrican Katrina' in: Technology in Society 29, 2007, pp. 239-247

Whitley, Richard The intellectual and social organization of the sciences Oxford: Clarendon Press, 1984

Wieriks, Koos and Anne Schulte-Wülwer-Leidig 'Integrated water management for the Rhine river basin, 
from pollution prevention to ecosystem improvement' in: Natural Resources Forum, vol. 21, no. 2, 1997, pp. 147-156

Williams, Rosalind Retooling: a historian confronts technological change Cambridge (Mass.): MIT Press, 2002

Wind, H.G. Civieltechnisch management Inaugural address University of Twente 1988

Windt, Henny J. van der En dan: wat is natuur nog in dit land?: natuurbescherming in Nederland 18801990 Amsterdam: Boom, 1995

Windt, Henny J. van der 'De amoebe als verbeelding der natuur' in: Kennis \& Methode, 19/3, 1995, pp. 251-276

WLO werkgroep universiteiten De positie van de landschapsecologie aan de Nederlandse universiteiten November 1994

Wolff, Wim J. 'The development of aquatic ecology in the Netherlands' in: Netherlands Journal of Aquatic Ecology 30 (4) 1996, pp. 241-253

Wolman, M. Gordon 'The Nation's Rivers' in: Science 26 November 1971, vol. 174, no. 4012, pp. 905-918

Wolman, M. Gordon 'Interdisciplinary education: a continuing experiment' in: Science New Series, Vol. 198, No. 4319. (Nov. 25, 1977), pp. 800-804

Wolters, A.F. \& E.C.L. Marteijn (eds.) De weg van maatschappelijke vraag naar onderzoek NCR-publicatie $02-2000$

Zevenhuizen, E.J.A. et al. Een historische schets van de aquatische ecologie in Nederland en Vlaanderen. Publicatie no. 7 van de Nederlandse Vereniging voor Aquatische Ecologie, Amsterdam 1996

Zonneveld, J.I.S. 'Fysische geografie in Nederland' in: KNAG Geografisch Tijdschrift XI 1977, nr. 3

Zonneveld, I.S. Een eigen weg tot wetenschap Inaugural speech Wageningen University 1982

Zonneveld, I.S. 'Theorieën en concepten: een tussentijdse balans' in: Landschap 1989, no. 1, pp. 65-76

Zonneveld, Isaak 'How I became a landscape ecologist' in IALE bulletin vol. 16 no. 16, November 1998

Zonneveld, I.S. 'Count your blessings? Twenty-five years of landscape ecology' in: J.A. Klijn \& W. Vos (eds.) From landscape ecology to landscape science. Proceedings of the European congress on landscape ecology Dordrecht: Kluwer, 2000, pp. 30-42

\section{Additional sources:}

Archief KNAW Voorwaardelijke Financiering

Annual Reports Functional Ecology

ICG Research Programmes

Jaarverslagen AWON

Jaarverslagen BION

Jaarverslagen Delft Hydraulics, Hydrodelft

\section{Appendix 1: interviews (relevant affiliations indicated)}

Piet Nienhuis, professor, Environmental Sciences, University of Nijmegen, 28 April 2003

Ad van Os, programming secretary, Netherlands Centre for River Studies, 13 June 2003

Henk Wolfert, researcher, Landscape Systems, Alterra, 24 June 2003

Rob Leuven, associate professor, Environmental Sciences, University of Nijmegen, 1 July 2003

Eric Marteijn, researcher, Ecological Rehabilitation of the Rhine, RIZA, 19 March 2004

Peter Holdert, consultant, LWI Impulse Programme, 7 July 2004

Huib de Vriend, professor, River Morphology and Engineering University of Delft; director, Delft Hydraulics, 4 May 2005

Hans Middelkoop, associate professor, Physical Geography, University of Utrecht, 17 May 2005

Peter Troch, professor, Hydrology and Quantitative Water Management, University of Wageningen,

24 May 2005

Gerard van der Velde, professor, Aquatic Animal Ecology, University of Nijmegen, 30 May 2005

Gertjan Geerling, PhD candidate, Environmental Sciences, University of Nijmegen, 30 November 2005

Menno Straatsma, PhD candidate, Physical Geography, University of Utrecht, 1 December 2005 


\section{Nederlandse samenvatting}

Deze studie behandelt hoe opvattingen van rivieren in interdisciplinaire rivierkundige praktijken zijn veranderd tussen 1980 en 2005366. Hierbij worden nieuwe wetenschappelijke opvattingen van rivieren in verband gebracht met veranderende institutionele en technologische contexten. Een benadering van wetenschap als culturele praktijk, het inzicht dat kennis, sociale en materiële ordening samen vorm krijgen ('co-productie') en contextuele geschiedschrijving zijn richtinggevend voor de interpretatie van veranderende rivierkundige praktijken.

Interdisciplinaire rivierkunde dient als een casus om diagnoses van recente wetenschap tegen het licht te houden. Uit drie diagnoses (mode 2 science, strategic science, post-modern science) destilleer ik vijf aspecten die ik nader ga onderzoeken: een primaat van technologie in wetenschappelijke praktijken, het vervagen van disciplinaire grenzen en de opkomst van inter- en transdisciplinariteit, institutionele heterogeniteit, een oriëntatie op praktische problemen en specifieke instituties, en (zelf)sturing van wetenschap.

Opkomende interdisciplinaire rivierkunde wordt besproken in drie geschiedenissen die hetzelfde tijdvak bestrijken (1980-2005). In opeenvolgende hoofdstukken worden rivierkundige configuraties ontvouwd van cosmopoliet wetenschappelijk veld, via nationaal geïnstitutionaliseerde specialisaties die bijdragen aan interdisciplinaire rivierkunde in Nederland, naar opkomende interdisciplinaire rivierkunde en een lokale onderzoeksconfiguratie in Nederland. De drie 'dwarsdoorsnedes' zijn daarbij niet op te vatten als niveaus in een multi-level systeem, noch als delen uit een gegeven geheel van interdisciplinaire rivierkunde, maar als onderling gerelateerde, niet-reduceerbare configuraties.

De eerste 'dwarsdoorsnede' behandelt de opkomst van interdisciplinaire rivierkunde als wetenschappelijk veld. De centrale vraag is hoe interdisciplinariteit vorm kreeg in concepten, instrumenten en instituties, en hoe deze dimensies van rivierkundige praktijken op elkaar afgestemd raakten.

Interdisciplinaire rivierkunde begon eind jaren zeventig vorm te krijgen, met als belangrijke aanleiding rivierdegradatie als gevolg van de aanleg van grote dammen. Een belangrijke gebeurtenis voor het ontstaan van interdisciplinaire rivierkunde als wetenschappelijk veld was een internationale bijeenkomst tijdens een limnologencongres in 1979 (Erie, VS) gewijd aan 'gereguleerde rivieren'. Op de bijeenkomst, waaraan ook ingenieurs en aardwetenschappers deelnamen presenteerden rivierecologen James Ward en Jack Stanford een onderzoeksagenda voor de studie van gedegradeerde, afgedamde rivieren.

Met interdisciplinair rivieronderzoek werd in die tijd op verschillende manieren geëxperimenteerd. Ik bespreek drie invloedrijke conceptuele innovaties in het interdisciplinaire rivieronderzoek van rond 1980. Het River Continuum Concept, ontwikkeld door rivierecologen in de VS behelsde het importeren van energie-evenwichtstheorie vanuit geomorfologie naar ecologie, als een analogie. Energie-evenwichtstheorie had de rol van een unificerende theorie om het fysische en biologische functioneren van een rivier te verklaren, van bron tot monding. In Frankrijk kwamen geomofologen en ecologen een hiërarchische ruimtelijke classificatie van de bovenloop van de Rhône overeen en muntten het concept Fluvial Hydrosystems. In de VS werd

\footnotetext{
366 Ik vertaal 'river science' als 'interdisciplinaire rivierkunde' omdat 'rivierwetenschap' geen gangbare term is en 'rivierkunde' wordt geassocieerd met de civieltechnische benadering.
} 
door ecologen en ingenieurs het simulatiemodel PHABSIM ontwikkeld. Op basis van hydraulische simulaties gaf het model arealen aan geschikt habitat voor specifieke vissoorten aan.

In de loop van de jaren tachtig ging complexiteitsdenken een belangrijke rol spelen in ecologie en aardwetenschappen en werd het ideaal van theoretische unificatie losgelaten. Computermodellering en gebruik van beschikbare remote sensing beelden, met name de geleidelijk in resolutie toenemende satellietbeelden, werden gezien als veelbelovende technieken om rivierkunde verder te brengen. De samenwerking tussen ecologen en aardwetenschappers werd intensiever met de voortzetting van internationale bijeenkomsten gewijd aan gereguleerde rivieren, de uitgave van een internationaal wetenschappelijk tijdschrift, en overheden die rivierherstel tot beleid maakten. Terwijl diverse vormen van complexiteitsdenken circuleerden, omarmden rivierecologen een versie van hiërarchietheorie die goed aansloot bij de aandacht voor ruimtelijke schalen en de beschikbare technieken om ruimtelijke data te verkrijgen en analyseren. Aan het eind van de jaren tachtig werd de opvatting dat de rivier een ruimtelijk geneste hiërarchie is breed gedeeld onder rivierkundigen. Om deze conceptualisering empirisch in te vullen werden remote sensing technieken, satellietbeelden en beelden vanuit vliegtuigen waarvan een groeiende range aan resoluties en reflecties beschikbaar kwam, bijzonder geschikt geacht. Geleidelijk werd remote sensing beschouwd als een onmisbare bron van data, gezien de range aan ruimtelijke resoluties, de synoptische beelden en de mogelijkheid om dataverzameling en -analyse te automatiseren. De conceptie van de rivier als een ruimtelijk geneste hiërarchie en het gebruik van remote sensing beelden en ruimtelijke modellen om patronen en processen op verschillende schaalniveaus te articuleren kregen dus in wisselwerking vorm. Vervolgens ging in wisselwerking met deze conceptuele en instrumentationele dimensies ook een visie op interdisciplinaire samenwerking als het koppelen van specialisatie specifieke modellen opgeld doen. Ik stel dat recentelijk visies op interdisciplinaire arbeidsdeling vorm hebben gekregen binnen een discours van modulariteit. Modulariteit is herkenbaar in de breed omarmde rivierkundige concepten en instrumenten. Hiërarchische hydrologisch/geomorfologisch/ ecologische systemen worden opgevat als bestaand uit ruimtelijke eenheden die genest zijn in ruimtelijke eenheden op hogere schaalniveaus. De processen van waterstroming, landschapsvorming en dier- en plantenleven worden behandeld als modules, te koppelen tot een geïntegreerd model. In de eerste opvatting zijn modules ruimtelijke eenheden, in de tweede representeren modules de processen die worden gemodelleerd binnen de verschillende specialisaties. De twee concepties worden op verschillende manieren samengebracht in voorstellen hoe interdisciplinariteit in rivierkunde vorm te geven. Informatie- en ruimtelijke technologieën hebben bijgedragen aan de verbreiding van de opvatting van de rivier als een ruimtelijk geneste hiërarchie en institutionalisering van interdisciplinariteit, zowel door concrete wisselwerking als via het discours van modulariteit.

De tweede 'dwarsdoorsnede' bespreekt ontwikkelingen binnen vijf specialisaties die bijdragen aan rivieronderzoek in Nederland: landschapsecologie, aquatische ecologie, geomorfologie, hydrologie en hydraulica. De centrale vraag is hoe nationaal wetenschapsbeleid heeft bijgedragen aan conceptuele, instrumentationele en institutionele ontwikkelingen in deze vijf specialisaties. Ik maak onderscheid tussen 'institutionele overlevingsstrategieën' en 'zoekstrategieën' om te laten zien hoe deze strategieën verweven zijn. In het wetenschapsbeleid wordt in het algemeen afgezien van een directe sturing van concepten en instrumenten die wetenschappers hanteren: dit wordt als intern wetenschappelijk beschouwd. Sturing op institutionele dimensies door het stimuleren van bijvoorbeeld samenwerkingsverbanden is wel gebruikelijk. In de bestudeerde 
periode is in het wetenschapsbeleid druk uitgeoefend op onderzoeksgroepen om interinstitutionele en interdisciplinaire samenwerkingsverbanden aan te gaan.

Om te onderzoeken hoe wetenschapsbeleid heeft bijgedragen aan ontwikkelingen binnen de specialisaties, volg ik drie sporen. Interviews met leiders van onderzoeksgroepen dienen om zicht te krijgen op strategieën van wetenschappers vis-à-vis mogelijkheden en vereisten van interinstitutionele en interdisciplinaire samenwerking. Het blijkt dat onderzoeksgroepen zich genoodzaakt zien om inter-institutionele en interdisciplinaire samenwerkingsverbanden aan te gaan om toegang te krijgen tot belangrijke bronnen van onderzoeksfinanciering. Tevens blijkt dat bepaalde zoekstrategieën meer kans maken binnnen de inter-institutionele en interdisciplinaire samenwerkingsverbanden dan andere. Ook geven groepsleiders aan dat interdisciplinaire onderzoekssamenwerking in het algemeen niet gepaard gaat met het delen van theorieën en methoden, maar neerkomt op het samenbrengen van binnen specialisaties ontwikkelde bijdragen. Om na te gaan in hoeverre er mogelijk sprake is van structurele effecten van wetenschapsbeleid in dit opzicht, bespreek ik enerzijds het Nederlandse wetenschapsbeleid van ruwweg 1980 tot 2005 en anderzijds ontwikkelingen binnen specialisaties in deze periode.

Een analyse van beleidsdocumenten heeft opgeleverd dat in het wetenschapsbeleid in het algemeen is gestreefd naar meer samenwerking en afstemming: tussen onderzoeksgroepen en maatschappelijke actoren, tussen onderzoeksgroepen op nationaal niveau, tussen onderzoeksgroepen op internationaal niveau, en in toenemende mate, tussen disciplines. Een roep om samenwerking, afstemming en programmering binnen disciplines, op nationaal niveau, met doelmatigheid als drijfveer kenmerkte de jaren tachtig. In de loop van de jaren negentig werd competitiviteit een belangrijk argument voor samenwerking, afstemming en programmering op nationaal en internationaal niveau. $\mathrm{Er}$ werd geroepen om zowel interdisciplinaire complementariteit als disciplinaire afstemming. Daarbij ging interdisciplinair onderzoek in de loop van de jaren negentig geapprecieerd worden om wat het aan vernieuwing opleverde. Ik concludeer dat een ruimte van mogelijkheden en vereisten ging ontstaan waarin het behouden van een levensvatbare positie binnen een specialisatie moest worden verzoend met het deelnemen aan interdisciplinaire onderzoeksprogramma's.

De vraag was vervolgens hoe het wetenschapsbeleid structureel had uitgewerkt op het niveau van specialisaties. Hiertoe heb ik ontwikkelingen binnen de landschapsecologie, zoetwaterecologie, geomorfologie, hydrologie en hydraulica in Nederland in kaart gebracht. Naast duidelijke contrasten tussen de specialisaties die onder verschillende historische omstandigheden zijn ontstaan, heel verschillende onderzoeksobjecten hebben geconstrueerd en elk een unieke ontwikkeling te zien geven, zijn er ook overeenkomsten en convergenties. In elk van de specialisaties zijn in de jaren tachtig onderzoeksprogrammering en prioriteitsstelling geïntroduceerd. In de jaren negentig zijn onderzoekscholen en -centra opgericht, sommigen voor een enkele specialisatie, anderen als een combinatie van specialisaties. Wat betreft zoekstrategieën zijn binnen de vijf specialisaties dezelfde modellerings- en ruimtelijke technieken op grote schaal in gebruik genomen: computermodellering, Geografische Informatie Systemen (GIS) en remote sensing. Rond 1980 werd een systeemopvatting gedeeld door de specialisaties. Dat is nog steeds het geval, maar de betekenis van het systeemconcept is veranderd met het omarmen van complexiteitsdenken. De notie van zelf-organisatie wordt breed gedeeld.

Ik concludeer dat de verveelvoudiging van institutionele kaders en afstemmingsmomenten binnen en tussen onderzoeksgroepen die op verschillende specialisaties georiënteerd zijn, heeft bijgedragen aan het op grote schaal overnemen van zoekstrategieën. Wetenschapsbeleid gericht 
op afstemming en samenwerking draagt daarmee bij aan inhoudelijke ontwikkelingen in de wetenschap.

In de derde 'dwarsdoorsnede' is, net als in de eerste, interdisciplinaire rivierkunde eenheid van analyse. Besproken wordt hoe in Nederland interdisciplinaire rivierkunde opkwam in symbiose met een nieuw regime van rivierbeheer en hoe een lokale onderzoeksconfiguratie vorm kreeg.

In Nederland begon het ingenieursparadigma van rivierbeheer af te brokkelen aan het begin van de jaren tachtig na meer dan een decennium van protesten tegen dijkversterking. De tegenstanders van dijkversterking betoogden dat de ingenieursbenadering natuur, cultuur en landschap van het rivierengebied zwaar aantastte. In 1986 werd Ooievaar, een plan om riviernatuur te herstellen en de landbouw uit de uiterwaarden te weren, breed omarmd als een nieuwe, integrale benadering van rivierbeheer. $\mathrm{Na}$ de Sandoz-ramp gingen onderzoeksinstituten en universitiare onderzoeksgroepen zich bezighouden met monitoring en experimenten die ecologisch herstel van de Rijn beoogden, waarbij het zoetwater-onderzoeksinstituut van Rijkswaterstaat (RIZA) een centrale rol speelde. Midden jaren negentig kwam veiligheid tegen overstroming weer hoog op de politieke agenda te staan in de context van twee bijnaoverstromingen in opeenvolgende winters. 'Ruimte voor de rivier', het verbreden en verdiepen van uiterwaarden werd, in de context van een opkomend klimaatveranderingsdiscours, gepresenteerd als een tijdig alternatief voor de niet-duurzame benadering van het almaar verder verhogen van de dijken. Recentelijk is 'dynamisch rivierbeheer' opgekomen als een synthese van enerzijds het onderhouden van de uiterwaarden met het oog op veiligheid tegen overstroming en anderzijds het nabootsen van rivierdynamiek die natuurlijk wordt geacht.

Met de opkomst van integraal rivierbeheer eind jaren tachtig zagen ecologen en geomorfologen van onderzoeksinstituten en universiteiten mogelijkheden ontstaan voor het doen van onderzoek in opdracht. Bij het uitwerken van rivierbeheer in de lijn van plan Ooievaar deden Rijkswaterstaat en zijn zoetwateronderzoeksinstituut RIZA een beroep op ecologische expertise om de ontwikkeling van vegetatie in de uiterwaarden beter in te kunnen schatten. Bossen in de uiterwaarden zouden het water opstuwen en daarmee de veiligheid in gevaar kunnen brengen. Om deze vorm van 'hydraulische ruwheid' in de hand te houden werd aan landschapsecologen gevraagd om de verbreiding van bossen in de uiterwaarden te modelleren. Aquatisch ecologen hadden geen andere rol dan het continueren van de monitoring van de ecologie van rivieren en uiterwaardplassen. Om op een efficiënte manier met de ruwheidskwestie om te gaan besloot het RIZA tot standaardisering. Bij het ontwikkelen van een standaard, het Rivier-Ecotopen-Systeem, lag de focus op vegetatiestructuur, en waren andere aspecten zoals vegetatiesamenstelling van ondergeschikt belang. De verdeling van rivierecotopen kon relatief goedkoop worden gemonitord met behulp van luchtfoto's.

Intussen begon een netwerk van rivieronderzoekers vorm te krijgen in een context van veranderende onderzoeksfinanciering en de opkomst van interdisciplinaire rivierkunde als wetenschappelijk veld. De Universiteit Delft en het Waterloopkundig Laboratorium werkten al sinds lang samen met het RIZA en Rijkswaterstaat. Ecologen van de Universiteit Nijmegen stelden een onderzoeksprogramma op dat opriep tot samenwerking met ingenieurs. In 1998 werd een nationaal centrum voor rivierkunde opgericht, om samenwerking te bevorderen en toegang te krijgen tot onderzoeksfinanciering waarvoor inter-interinstitutionele, interdisciplinaire samenwerking vereist werd. In het Europese onderzoeksprogramma dat snel volgde kwamen ecologen en ingenieurs tot een nieuwe synthese van veiligheid tegen overstroming en riviernatuurherstel. 
Het synthetiserende concept, 'cyclische uiterwaardverjonging', behelsde de modellering van drie rivierdynamieken in onderlinge wisselwerking.

Ik bespreek hoe dit model is ontstaan in de context van het Nederlandse rivierbeheer. In het rivierbeheer ligt het primaat bij veiligheid tegen overstroming en zijn andere overwegingen, zoals biodiversiteit, ondergeschikt. Het handhaven van veiligheid tegen overstroming wordt opgevat als waterhoogten die niet mogen worden overschreden. De hydraulica levert hiervoor de relevante expertise. De bijdragen van ecologie en geomorfologie zijn beperkt tot wat deze specialisaties aan relevante informatie kunnen leveren voor de parameters van het hydraulische model. De bijdrage van ecologie aan de interdisciplinaire modelleringspraktijk is een model van ecotopendynamiek dat ruwheidswaarden levert aan het hydraulische model. Op deze manier vertaalt een primaat van veiligheid tegen overstroming in het rivierbeheer zich in een primaat van de hydraulica in de modellering van interacterende rivierdynamieken.

In een concluderend hoofdstuk bespreek ik hoe de vijf aspecten die ik heb gedestilleerd uit diagnoses van recente wetenschap zich manifesteren in interdisciplinaire rivierkunde. Is er sprake van een primaat van technologie? Er blijkt sprake te zijn van een productieve wisselwerking tussen het gebruik van remote sensing technieken als een bron van data en de verdere ontwikkeling van ruimtelijke modellen binnen de conceptualisering van rivieren als ruimtelijk geneste hiërarchieën. De centrale rol die deze data- en modelleringstechnologie is gaan spelen in de ontwikkeling van kennis over rivieren suggereert een primaat van technologie. Daarbij heeft de omarming van complexiteitsdenken, het ermee gepaard gaande afscheid van unificerende theorie en de prominente rol van data-gedreven modellering theoretischconceptuele ontwikkeling relatief naar de achtergrond gedrongen. Verder blijkt een discours van modulariteit werkzaam te zijn in de afstemming tussen concepten, instrumenten en interdisciplinaire arbeidsdeling. In dit discours uit zich de alomtegenwoordigheid van informatietechnologie.

Vervagen disciplinaire grenzen, hoe krijgt interdisciplinariteit vorm en kan er gesproken worden van transdisciplinariteit? Interdisciplinaire samenwerking waarbij binnen specialisaties ontwikkelde modules worden gekoppeld lijkt met zich mee te brengen dat disciplines zowel voortbestaan als oplossen. Er komen nieuwe interdisciplinaire combinaties van specialisaties op, terwijl oudere specialisaties zich handhaven. Hiermee komen disciplines als richtinggevende institutionele kaders meer op de achtergrond. Verder blijkt dat Geografische Informatiesystemen, remote sensing, een repertoire van modelleringstechnieken en de notie van zelf-organisatie worden gedeeld door de specialisaties. Procestheorieën worden binnen de specialisaties ontwikkeld. De onderzochte lokale onderzoeksconfiguratie kan worden gekarakteriseerd als een transdisciplinaire: integratie van specialisatiebijdragen krijgt vorm met het oog op een praktisch probleem. Het delen van data en het negeren van incommensurabiliteit in theorie/ontologie past binnen een meer algemene tendens in de bio/geowetenschappen.

Hoe uit institutionele heterogeniteit zich in interdisciplinaire rivierkunde? Naast institutionele heterogeniteit door een oriëntatie op verschillende specialisaties ('interdisciplinariteit'), is er ook sprake van institutionele heterogeniteit door betrokkenheid van andere maatschappelijke instituties. In vergelijking met begin jaren tachtig toen individuele onderzoeksgroepen van universiteiten en onderzoeksinstituten in opdracht onderzoek deden is er nu sprake van een grotere institutionele heterogeniteit. In recent interdisciplinair onderzoek vormen universiteiten, onderzoeksinstituten, NGO's, overheidsinstanties en gespecialiseerde adviesbureau's consortia. Institutionele heterogeniteit als een betrokkenheid van verschillende maatschappelijke 
organisaties impliceert echter geen heterogeniteit aan gezichtspunten en benaderingen en evenmin afwezigheid van hiërarchie. Onderlinge afstemming kan leiden tot convergentie, zoals zichtbaar in zoekstrategieën en standaardisering. In de onderzochte lokale onderzoeksconfiguratie ligt het primaat bij de hydraulica, en worden andere bijdragen geaccommodeerd.

Hoe krijgt maatschappelijke relevantie gestalte, en is er sprake van een oriëntatie op praktische problemen en specifieke instituties? Ik heb beschreven hoe interdisciplinaire rivierkunde onstond rondom het issue van rivierdegradatie en bijdroeg aan de beweging die protesteerde tegen de aanleg van grote dammen. In de loop van de jaren 80 en 90 raakte het opkomende veld meer georiënteerd op overheden die rivierherstel tot beleid maakten. In Nederland kreeg interdisciplinaire rivierkunde vorm in symbiose met een opkomend regime van integraal rivierbeheer. Lokale kennis van rivieren is ontwikkeld met het oog op het ontwerp van veilige en biodiverse rivieren. Dit kan worden opgevat als een 'ingebouwde relevantie' van rivierkunde, maar daarmee blijft onbesproken hoe rivieren worden gevormd in wisselwerking met de kennis die wordt ontwikkeld en hoe deze kennis ernaar neigt zichzelf te bevestigen. In Nederland is de symbiotische relatie tussen rivierkunde en rivierbeheer doelbewust tot stand gekomen: onderzoeksfinanciering wordt toegekend met het doel onderzoek en beleid beter te laten aansluiten. Dit heeft echter neveneffecten: hoe nauwer de relatie, hoe minder waarschijnlijk het is dat radicaal andere opvattingen van rivieren zich aandienen.

Hoe kan (zelf)sturing van interdisciplinaire rivierkunde worden begrepen? Een benadering van wetenschapsbeleid als een van de relevante contexten waarin wetenschappers strategisch handelen is vruchtbaar gebleken om te bespreken hoe discoursen en arrangementen van wetenschapsbeleid invloed hebben op wetenschapspraktijken zonder wetenschappers top-down aan te sturen. De ruimte voor strategisch handelen mag groot zijn, overlevingsstrategieën van wetenschappers in de context van wetenschapsbeleid hebben wel degelijk structurele effecten. Dat gebeurt niet alleen door een directe druk die wordt uitgeoefend door prioriteitstelling en relevantie-eisen in onderzoeksfinanciering, zoals ander onderzoek laat zien. Zoekstrategieën worden ook aangepast door onderlinge afstemming bij institutionele opschaling en interdisciplinaire onderzoeksprogrammering, zoals deze studie laat zien. Het discours van modulariteit dat daarbij werkzaam is, brengt een vorm van cohesie met zich mee die neveneffecten heeft.

Wetenschapsbeleid heeft ook anderszins de opkomst van interdisciplinaire rivierkunde in Nederland mede bepaald. Onderzoekers zijn in de jaren tachtig op zoek gegaan naar alternatieven voor eerste geldstroomfinanciering, die ze vonden in contractonderzoek. Interdisciplinaire rivierkunde gaf mogelijkheden om interdisciplinariteit, maatschappelijke relevantie en excellentie te combineren en zo te hoog te scoren op criteria die doorwerken vanuit het wetenschapsbeleid. Ook het Nederlands Centrum voor Rivierstudies is een antwoord op mogelijkheden en verwachtingen rond nationale en Europese onderzoeksfinanciering. Verder heeft interdisciplinaire rivierkunde vorm gekregen in een context van convergerende zoekstrategieën meer algemeen in de bio/geowetenschappen en draagt het bij aan een verdere convergentie.

De analyse van interdisciplinaire rivierkunde als een casus van recente wetenschap onderschrijft de diagnoses grotendeels op de onderzochte aspecten. Een aspect dat niet in de diagnoses naar voren komt maar dat opvalt in interdisciplinaire rivierkunde, en dat ook in andere recente configuraties speelt, is een gerichtheid op ontwerp.

Het primaat van technologie in interdisciplinaire rivierkundige praktijken, het primaat van hydraulica in een lokale onderzoeksconfiguratie en convergentie van zoekstrategieën zijn op te vatten als onbedoelde gevolgen: ze zijn een niet-beoogde uitkomst van interacties. 
Ik stel dat een focus op pluralisme waardevol kan zijn bij een reflectie op de vorming en werking van kennis in de maatschappij. In onze omgang met rivieren is pluralisme een belangrijke waarde. Het convergeren van zoekstrategieën en een eenzijdig streven naar integratie van kennis vormen een bedreiging van pluralisme. Het behouden en creëren van ruimte voor het naast elkaar bestaan van radicaal verschillende opvattingen van en manieren van omgaan met natuur en landschap vergt aandacht voor pluralisme in wetenschappelijke en andere praktijken. 


\section{Curriculum Vitae}

Mieke van Hemert studied physical geography (MSc. University of Utrecht 1989) and science \& technology dynamics (MSc. University of Amsterdam 1999). She worked for the NGO Both Ends (Environment and Development Service for NGOs), the physical planning department of Amsterdam and as a freelance editor/copywriter. In 2002, she contributed to an evaluation study of the Veluwe Border Lakes integrated planning process at the University of Amsterdam. Later in 2002, she started a PhD study at the University of Twente, resulting in this thesis. Her ongoing research interests are in cultural practices dealing with nature and landscape, and co-existence of radically different knowledges. 